\title{
ESTUDO DA ESTRUTURA TURBULENTA EM ESCOAMENTOS GERADOS POR GRADES OSCILANTES
}

LEONARDO BARRA SANTANA DE SOUZA

Dissertação apresentada à Escola de Engenharia de São Carlos, da Universidade de São Paulo, como parte dos requisitos para obtenção do título de Mestre em Hidráulica e Saneamento.

ORIENTADOR: Prof. Tit. Harry Edmar Schulz 
Ficha catalográfica preparada pela Seção de Tratamento da Informação do Serviço de Biblioteca - EESC/USP

S729e

Souza, Leonardo Barra Santana de

Estudo da estrutura turbulenta em escoamentos gerados por grades oscilantes / Leonardo Barra Santana de Souza. -- São Carlos, 2002.

Dissertação (Mestrado) -- Escola de Engenharia de São Carlos-Universidade de São Paulo, 2002.

Área: Hidráulica e Saneamento.

Orientador: Prof. Tit. Harry Edmar Schulz.

1. Grades oscilantes. 2. Turbulência. 3. Velocimetria à laser. I. Título. 
FOLHA DE JULGAMENTO

Candidato: Engenheiro LEONARDO BARRA SANTANA DE SOUZA

Dissertação defendida e julgada em 29-05-2002 perante a Comissão Julgadora:
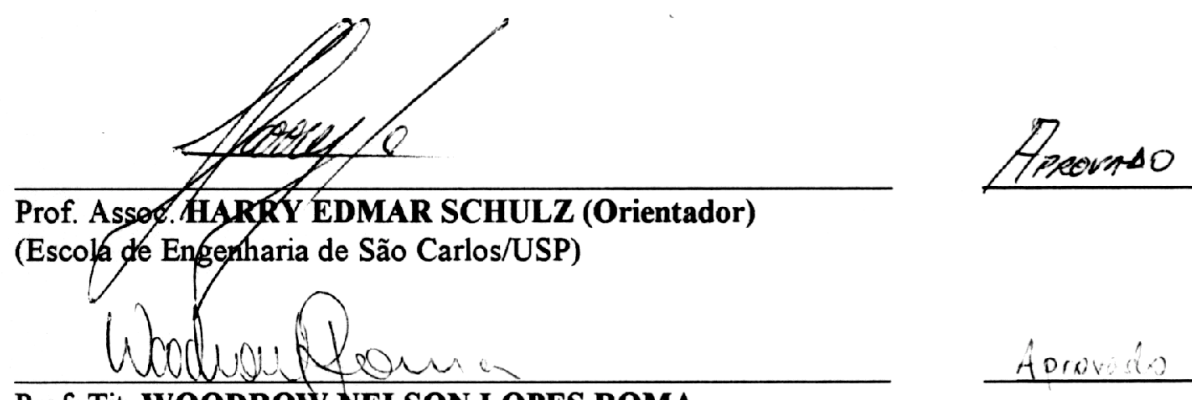

Prof. Tit. WOODROW NELSON LOPES ROMA

(Escola de Engenharia de São Carlos/USP)

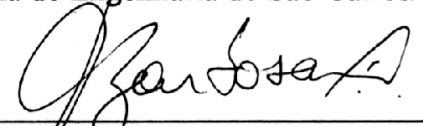

Prof. Dr. ANTENOR RODRIGUES BARBOSA JUNIOR

(Universidade Federal de Ouro Preto/UFOP)

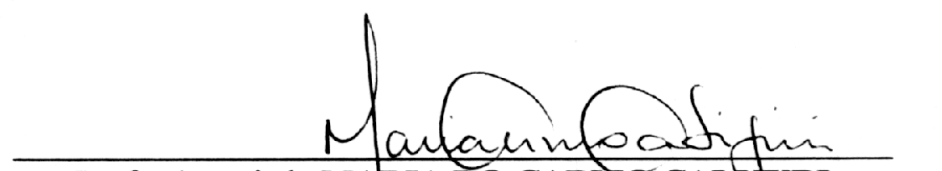

Profa. Associada MARIA DO CARMo CALIJURI

Coordenadora do Programa de Pós-Graduação

em Engenharia (Hidráulica e Saneamento) e

Vice-Presidente da Comissão de Pós-Graduação da EESC em

exercício 
Dedico este trabalho aos meus pais, João e Honorina, e ao meu irmão Leandro. 


\section{AGRADECIMENTOS}

À Coordenadoria de Aperfeiçoamento de Pessoal de Nível Superior - CAPES, mantenedora da bolsa de estudos.

À Fundação de Amparo à Pesquisa do Estado de São Paulo - FAPESP, pelo auxíliopesquisa 2000/13953-6.

Ao professor titular Harry Edmar Schulz, por sua orientação e principalmente pela confiança no meu trabalho.

Ao professor titular Woodrow Nelson Lopes Roma, pela colaboração constante e pelo incentivo.

Ao professor Dr. Antenor Rodrigues Barbosa Junior, pela contribuição quando da participação na banca.

Aos professores Swami Marcondes Villela e Ruth Gouvêa Duarte, por toda ajuda, incentivo e acima de tudo, carinho e amizade.

À Jaqueline, pelo amor, companheirismo, paciência ...

Ao amigo Johannes, pela colaboração na execução dos experimentos.

Ao meu irmão Leandro Barra Santana de Souza, pela colaboração no desenvolvimento do programa computacional, criado para a obtenção dos resultados finais desta pesquisa.

À Elena L. Palloni Gonçalves, bibliotecária da EESC, pela correção das referências bibliográficas.

A todos da Oficina Mecânica da Escola de Engenharia de São Carlos - Universidade de São Paulo (EESC - USP), em especial ao técnico Adolfo, pelas sugestões e construção do tanque em acrílico.

Ao técnico Osni, pela colaboração no projeto inicial do equipamento.

À Coordenação, aos professores, funcionários e colegas do Programa de PósGraduação em Hidráulica e Saneamento da EESC, pelos ensinamentos, pelo incentivo e, principalmente, pela amizade.

Ao FINEP e ao CNPq, que incentivaram a execução desta pesquisa através do convênio FINEP / PRONEX "Desenvolvimento e Otimização de Sistemas nãoConvencionais de Tratamento de Águas Residuárias Constituídos de Reatores Biológicos e Físico-Químicos Dispostos em Série". 


\section{SUMÁRIO}

LISTA DE FIGURAS ................................................................................

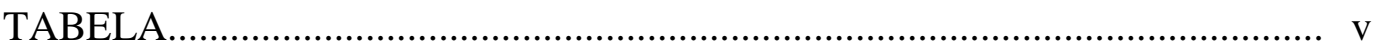

LISTA DE SÍMBOLOS _...................................................................... vi

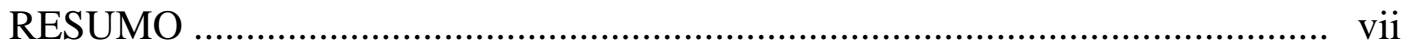

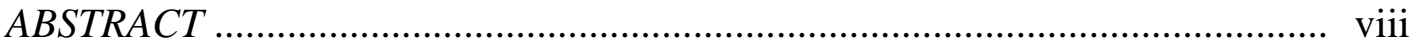

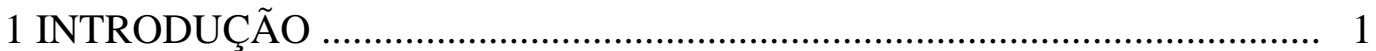

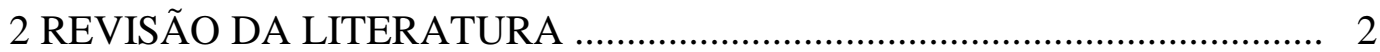

2.1 Estudo da turbulência.......................................................................... 2

2.2 Turbulência isotrópica.............................................................................. 4

2.3 Características da turbulência isotrópica...................................................... 5

2.4 Busca da turbulência isotrópica em laboratório................................................ 8

2.5 Túneis de ar e água............................................................................. 9

2.6 Tanque de grade oscilante........................................................................... 11

2.7 Dimensões do tanque e parâmetros de forma da grade.................................. 12

2.8 Amplitude e frequência de oscilação da grade............................................. 13

2.9 Turbulência quase-isotrópica no tanque....................................................... 14

2.10 Medição da turbulência................................................................................ 15

2.11 Tanques encontrados na literatura.......................................................... 18

2.12 Tanque de grade oscilante do SHS-EESC-USP......................................... 23

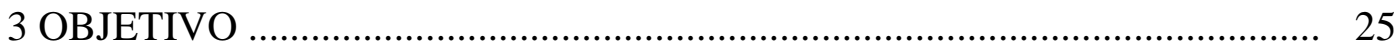

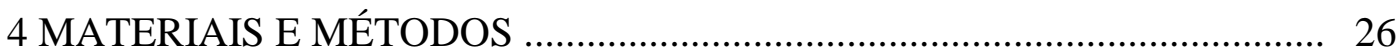

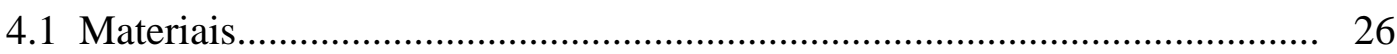

4.1.1 Construção do tanque de grade oscilante................................................... 26

4.1.1.1 Tanque em acrílico............................................................................. 29

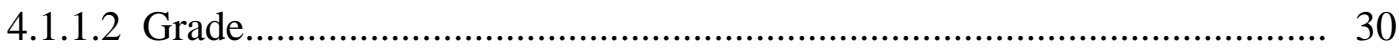

4.1.1.3 Mecanismo de oscilação da grade.......................................................... 32

4.1.1.4 Vedação entre tanque e compartimentos................................................. 36

4.1.2 Instalação do equipamento....................................................................... 38

4.1.3 Equipamento de medição de velocidade turbulenta..................................... 40

4.2 Metodologia experimental...................................................................... 45

4.2.1 Localização das regiões de estudo no tanque............................................. 45 
4.2.2 Definição de freqüência e amplitude de oscilação da grade. 46

4.2.3 Obtenção dos campos de velocidade turbulenta............................................ 48

4.2.4 Tensões médias de Reynolds............................................................... 50

4.2.5 Caracterização da turbulência gerada..................................................... 50

5 RESULTADOS E DISCUSSÕES ....................................................... 51

5.1 Campos instantâneos de velocidade........................................................ 51

5.2 Campos médios de velocidade .............................................................. 53

5.3 Campos de velocidade turbulenta....................................................... 55

5.3.1 Distribuição horizontal de $\mathbf{u}, \mathbf{w}$ e $\mathbf{i}$........................................................ 55

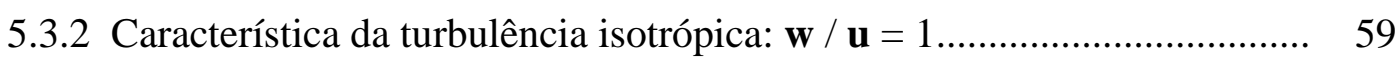

5.3.3 Tensões de Reynolds...................................................................... 60

5.3.4 Decaimento espacial da turbulência........................................................ 61

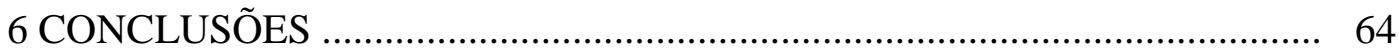

7 SUGESTÕES PARA TRABALHOS FUTUROS......................................... 65

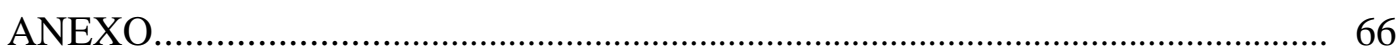

REFERÊNCIAS BIBLIOGRÁFICAS _................................................... 99

APÊNDICE 


\section{LISTA DE FIGURAS}

FIGURA 01 - Franjas de interferência na intersecção dos feixes de laser.......... 17

FIGURA 02 - Tanque gerador de turbulência do trabalho de ROMA (1988)... 23

FIGURA 03 - Mecanismo biela-manivela de oscilação da grade, no trabalho de ROMA (1988)

FIGURA 04 - Ligação da grade pela parte superior do tanque, comumente apresentada na literatura

FIGURA 05 - Esquema básico de um mecanismo (sistema) de oscilação com haste inferior movimentando a grade

FIGURA 06 - Vista geral do tanque em seu desenho de projeto, em AutoCad.. 28

FIGURA 07 - Tanque em acrílico, parafusado e vedado com silicone............. 29

FIGURA 08 - Cortes nas barras para montagem da grade............................... 30

FIGURA 09 - Projeto da grade...................................................................... 31

FIGURA 10 - Montagem da grade............................................................ 32

FIGURA 11 - Placas oscilantes montadas no interior dos compartimentos...... 33

FIGURA 12 - Vista superior da instalação de uma placa oscilante em um compartimento

FIGURA 13 - Projeto do sistema biela-manivela, para movimentação vertical das placas oscilantes

FIGURA 14 - Motor elétrico de 4 hp.......................................................... 35

FIGURA 15 - Painel de controle de rotação do motor....................................... 35

FIGURA 16 - Conjunto de redução em funcionamento................................... 36

FIGURA 17 - Sistema de vedação entre os compartimentos laterais e o tanque com a grade.

FIGURA 18 - Projeto do isolamento entre o tanque e os compartimentos laterais.

FIGURA 19 - Equipamento instalado.

FIGURA 20 - Registros de esfera de 3/4" para esvaziamento do tanque e dos compartimentos laterais.

FIGURA 21 - Apoio na parte superior do tanque, com madeira e borracha para se evitar vibrações consideráveis 
FIGURA 22 - Produção de luz pelo equipamento laser.

FIGURA 23 - Plano de luz iluminando as partículas no interior do tanque......

FIGURA 24 - Câmera instalada para obtenção das imagens do movimento do fluido.

FIGURA 25 - Calibração da câmera feita com uma régua graduada

FIGURA 26 - Realização de um experimento, com a câmera conectada ao microcomputador com o programa Visiflow.

FIGURA 27 - Tacômetro digital sendo usado para a medição da rotação do eixo que movimenta a grade.

FIGURA 28 - Plano 1: região sobre a barra central da grade.

FIGURA 29 - Plano 2: região entre barras da grade.

FIGURA 30 - Regiões de estudo

FIGURA 31 - Procedimento para obtenção dos campos de velocidade turbulenta, $\mathbf{u}$ e w.

FIGURA 32 - Campo instantâneo de velocidade, para a POS 1 e frequência de $1 \mathrm{~Hz}$

FIGURA 33 - Campo instantâneo de velocidade, para a POS 1 e frequência de $2 \mathrm{~Hz}$.

FIGURA 34 - Campo médio de velocidade para frequência de $1 \mathrm{~Hz}$. 54

FIGURA 35 - Campo médio de velocidade para frequência de $2 \mathrm{~Hz}$.

FIGURA 36 - Localização dos vetores usados na representação da distribuição horizontal da velocidade turbulenta.

FIGURA 37 - Distribuição horizontal de $\mathbf{u}, \mathbf{w}$ e i, para frequência de 1Hz...... 57

FIGURA 38 - Distribuição horizontal de $\mathbf{u}, \mathbf{w}$ e i, para frequência de $2 \mathrm{~Hz}$....... 58

FIGURA 39 - Relação w / u para frequências de $1 \mathrm{~Hz}$ e 2 Hz......................... 60

FIGURA 40 - Tensões de Reynolds para frequências de $1 \mathrm{~Hz}$ e $2 \mathrm{~Hz}$.............. 61

FIGURA 41 - Decaimento espacial da turbulência na região do Plano 1.......... 62

FIGURA 42 - Decaimento espacial da turbulência na região do Plano 2.......... 62

FIGURA 43 - Campo instantâneo de velocidade, para Pos 1 e frequência $3 \mathrm{~Hz} \quad 66$

FIGURA 44 - Campo instantâneo de velocidade, para Pos 1 e frequência 4 Hz 66

FIGURA 45 - Campo instantâneo de velocidade, para Pos 2 e frequência $1 \mathrm{~Hz} \quad 67$ 
FIGURA 46 - Campo instantâneo de velocidade, para Pos 2 e frequência $2 \mathrm{~Hz} \quad 67$

FIGURA 47 - Campo instantâneo de velocidade, para Pos 2 e frequência $3 \mathrm{~Hz} \quad 68$

FIGURA 48 - Campo instantâneo de velocidade, para Pos 2 e frequência $4 \mathrm{~Hz} \quad 68$

FIGURA 49 - Campo instantâneo de velocidade, para Pos 3 e frequência $1 \mathrm{~Hz} \quad 69$

FIGURA 50 - Campo instantâneo de velocidade, para Pos 3 e frequência $2 \mathrm{~Hz} \quad 69$

FIGURA 51 - Campo instantâneo de velocidade, para Pos 3 e frequência $3 \mathrm{~Hz} \quad 70$

FIGURA 52 - Campo instantâneo de velocidade, para Pos 3 e frequência $4 \mathrm{~Hz} \quad 70$

FIGURA 53 - Campo instantâneo de velocidade, para Pos 4 e frequência $1 \mathrm{~Hz} \quad 71$

FIGURA 54 - Campo instantâneo de velocidade, para Pos 4 e frequência $2 \mathrm{~Hz} 71$

FIGURA 55 - Campo instantâneo de velocidade, para Pos 4 e frequência $3 \mathrm{~Hz} \quad 72$

FIGURA 56 - Campo instantâneo de velocidade, para Pos 4 e frequência $4 \mathrm{~Hz} \quad 72$

FIGURA 57 - Campo instantâneo de velocidade, para Pos 5 e frequência $1 \mathrm{~Hz} \quad 73$

FIGURA 58 - Campo instantâneo de velocidade, para Pos 5 e frequência $2 \mathrm{~Hz} 73$

FIGURA 59 - Campo instantâneo de velocidade, para Pos 5 e frequência $3 \mathrm{~Hz} \quad 74$

FIGURA 60 - Campo instantâneo de velocidade, para Pos 5 e frequência $4 \mathrm{~Hz} \quad 74$

FIGURA 61 - Campo instantâneo de velocidade, para Pos 6 e frequência $1 \mathrm{~Hz} \quad 75$

FIGURA 62 - Campo instantâneo de velocidade, para Pos 6 e frequência 2 Hz 75

FIGURA 63 - Campo instantâneo de velocidade, para Pos 6 e frequência 3 Hz 76

FIGURA 64 - Campo instantâneo de velocidade, para Pos 6 e frequência 4 Hz 76

FIGURA 65 - Campo médio de velocidade para Pos 1 e freqüência 3 Hz........ 77

FIGURA 66 - Campo médio de velocidade para Pos 1 e freqüência 4 Hz........ 77

FIGURA 67 - Campo médio de velocidade para Pos 2 e freqüência $1 \mathrm{~Hz}$........ 78

FIGURA 68 - Campo médio de velocidade para Pos 2 e freqüência 2 Hz........ 78

FIGURA 69 - Campo médio de velocidade para Pos 2 e freqüência 3 Hz........ 79

FIGURA 70 - Campo médio de velocidade para Pos 2 e freqüência 4 Hz........ 79

FIGURA 71 - Campo médio de velocidade para Pos 3 e freqüência $1 \mathrm{~Hz}$......... 80

FIGURA 72 - Campo médio de velocidade para Pos 3 e freqüência 2 Hz........ 80

FIGURA 73 - Campo médio de velocidade para Pos 3 e freqüência 3 Hz........ 81

FIGURA 74 - Campo médio de velocidade para Pos 3 e freqüência 4 Hz........ 81

FIGURA 75 - Campo médio de velocidade para Pos 4 e freqüência $1 \mathrm{~Hz}$........ 82

FIGURA 76 - Campo médio de velocidade para Pos 4 e freqüência 2 Hz........ 82 
FIGURA 77 - Campo médio de velocidade para Pos 4 e freqüência 3 Hz........ 83

FIGURA 78 - Campo médio de velocidade para Pos 4 e freqüência 4 Hz........ 83

FIGURA 79 - Campo médio de velocidade para Pos 5 e freqüência 1 Hz........ 84

FIGURA 80 - Campo médio de velocidade para Pos 5 e freqüência 2 Hz........ 84

FIGURA 81 - Campo médio de velocidade para Pos 5 e freqüência 3 Hz........ 85

FIGURA 82 - Campo médio de velocidade para Pos 5 e freqüência 4 Hz........ 85

FIGURA 83 - Campo médio de velocidade para Pos 6 e freqüência $1 \mathrm{~Hz}$........ 86

FIGURA 84 - Campo médio de velocidade para Pos 6 e freqüência 2 Hz........ 86

FIGURA 85 - Campo médio de velocidade para Pos 6 e frequiência 3 Hz........ 87

FIGURA 86 - Campo médio de velocidade para Pos 6 e freqüência 4 Hz........ 87

FIGURA 87 - Distribuição horizontal de $\mathbf{u}, \mathbf{w}$ e i, para o Plano 1 e freqüência 3 Hz.... 88

FIGURA 88 - Distribuição horizontal de $\mathbf{u}, \mathbf{w}$ e i, para o Plano 1 e freqüência 4 Hz.... 89

FIGURA 89 - Distribuição horizontal de $\mathbf{u}, \mathbf{w}$ e i, para o Plano 2 e frequiência $1 \mathrm{~Hz} . . . .90$

FIGURA 90 - Distribuição horizontal de u, w e i, para o Plano 2 e freqüência 2 Hz.... 91

FIGURA 91 - Distribuição horizontal de u, w e i, para o Plano 2 e freqüência 3 Hz.... 92

FIGURA 92 - Distribuição horizontal de u, w e i, para o Plano 2 e freqüência 4 Hz.... 93

FIGURA 93 - Relação w / u para o Plano 1 e frequiências de 3 Hz e 4 Hz................... 94

FIGURA 94 - Relação w / u para o Plano 2 e freqüências de 1, 2, 3 e 4 Hz................ 95

FIGURA 95 - Tensões de Reynolds para o Plano 1 e freqüências 3 Hz e 4 Hz........... 96

FIGURA 96 - Tensões de Reynolds para o Plano 2 e freqüências de 1, 2, 3 e 4 Hz..... 97 
TABELA

TABELA 01 - Parâmetros de tanques de grades oscilantes encontrados na literatura. 


\section{LISTA DE SÍMBOLOS}

$v \quad$ - velocidade turbulenta, $\mathrm{cm} / \mathrm{s}$

$\mathrm{u}^{\prime}, \mathrm{v}^{\prime} \mathrm{e} \mathrm{w}^{\prime}$ - componentes da velocidade turbulenta nos eixos $\mathrm{x}, \mathrm{y} \mathrm{e} \mathrm{z}, \mathrm{cm} / \mathrm{s}$

V - velocidade instantânea, $\mathrm{cm} / \mathrm{s}$

$\mathrm{U}, \mathrm{V}$ e W - componentes da velocidade instantânea nos eixos x, y e z, cm/s

$\bar{V} \quad$ - velocidade média, $\mathrm{cm} / \mathrm{s}$

$\overline{\mathrm{U}}, \overline{\mathrm{V}}$ e $\overline{\mathrm{W}}$ - componentes da velocidade média nos eixos $\mathrm{x}, \mathrm{y}$ e $\mathrm{z}, \mathrm{cm} / \mathrm{s}$

i - intensidade turbulenta ou velocidade turbulenta média, $\mathrm{cm} / \mathrm{s}$

u, v e w - componentes da intensidade turbulenta nos eixos $\mathrm{x}, \mathrm{y} \mathrm{e} \mathrm{z}, \mathrm{cm} / \mathrm{s}$

M - espaçamento entre as barras da grade, $\mathrm{cm}$

f - freqüência de oscilação da grade, $\mathrm{Hz}$

S - amplitude de oscilação da grade, $\mathrm{cm}$

z - distância do ponto até o centro de oscilação da grade, cm

C - constante que depende da geometria da grade

d - dimensão da seção transversal da grade (lado ou diâmetro), cm 


\section{RESUMO}

Este trabalho representa o início de uma série de pesquisas que visam o estudo da turbulência e de sua relação com processos de mistura e trocas gasosas entre ar e água, através de experimentos com grades oscilantes. Seu objetivo foi o projeto e a construção de um tanque de grade oscilante, equipamento que gera turbulência com intensidade controlável. Após a construção do tanque, experimentos para medições de velocidade turbulenta foram feitos, com uso de uma técnica de velocimetria a laser. Uma grade de 9x9 barras foi usada na agitação do fluido, com uma amplitude de oscilação de $3 \mathrm{~cm}$, para 4 diferentes freqüências de oscilação. Adquiriu-se 9600 imagens do movimento do fluido, em 6 regiões do tanque, para a obtenção dos campos de velocidade turbulenta, calculados através do software Visiflow e de um programa computacional desenvolvido neste trabalho. Os gráficos criados a partir dos campos possibilitaram a observação do decaimento espacial da turbulência e da região de sua produção. Os campos médios de velocidade mostraram-se bem inferiores aos campos instantâneos, indicando a existência de baixo escoamento médio do fluido. As condições de isotropia e a homogeneidade espacial da turbulência são mais aproximadas à medida que se afasta da grade. A intensidade turbulenta produzida é diretamente relacionada com a freqüência de oscilação. O número de imagens para a obtenção de uma média representativa da velocidade turbulenta neste equipamento parece ser dependente da frequência de oscilação da grade. Isto aponta para a necessidade de estabelecer corretamente as condições para os cálculos estatísticos em escoamentos turbulentos.

Palavras-chave: grades oscilantes, turbulência, velocimetria a laser. 


\section{ABSTRACT}

This work presents the project and construction of a tank with an oscillating grid, equipment which provides for the experimental studies of turbulence and its relation to mixing processes and gas transfer across fluid interface. Experiments were carried out with the use of digital particle image velocimetry technique, to investigate the properties of the produced turbulence. A grid made of 9x9 square bars was used to stir the water, with a stroke of $3 \mathrm{~cm}$ and 4 different oscillation frequencies. A number of 9600 images were acquired, in 6 regions of the tank, for the generation of the turbulent velocity fields through the software Visiflow and a computational program developed in this work. The results showed that the current equipment, with a new concept for the grid oscillation system, can be conveniently useful for studies in this research field. Average velocity fields appeared to be considerably smaller than the instantaneous velocity fields, which leads to the existence of nearly-stationary turbulence in the water volume. Nearly-isotropic turbulence and spatial homogeneity were approximate as the measurements distanced from the grid. The turbulent intensity was directly dependent on the oscillation frequency. The spatial decay of the turbulence and the region near the grid where it is produced could also be observed. The number of images necessary for the calculus of reliable root-mean-square turbulent velocities seems to be dependent on the oscillation frequency of the grid. It results in the necessity of establishing correct statistical analysis of turbulent flows.

Keywords: oscillating grids, turbulence, digital particle image velocimetry 


\section{INTRODUÇÃO}

Grande quantidade de processos importantes em águas paradas e correntes, que influem em sua qualidade, dependem diretamente das trocas gasosas entre ar e água. Devido ao importante papel desempenhado pelos gases solúveis nos corpos de água, são necessárias avaliações da transferência de gases tóxicos, orgânicos e inorgânicos, entre os meios aéreo e aquático. Para a qualidade da água, por exemplo, o oxigênio representa importante papel, uma vez que o mesmo supre necessidades bioquímicas de processos que nela ocorrem. Já para questões climáticas, o gás carbônico, entre outros compostos, desempenha papel central, pois as trocas existentes deste gás entre o ar e os oceanos (cerca de 3/4 da superfície terrestre) representam importante fator na definição do clima no planeta. De acordo com o artigo O PERIGO vem do Ártico (2001), 14\% de todo o gás carbônico existente na Terra está armazenado nas geleiras do solo Ártico, que vêm se derretendo devido ao calor anormal dos últimos anos. Isto representa centenas de gigatons deste gás, contra cerca de 6 gigatons de poluentes anualmente produzidos pela atividade industrial humana. $\mathrm{O}$ desconhecimento da troca destes gases na interface ar-água gera incertezas quanto a previsões de qualidade da água e condições climáticas do planeta.

Em Hidráulica Ambiental, as transferências de gases entre ar e água tornam-se cada vez mais importantes, motivo da proposta deste trabalho. Para simular condições de escoamento turbulento, regime no qual acontece a maioria das situações encontradas no ambiente, construiu-se um tanque de grade oscilante, equipamento cada vez mais presente em pesquisas que estudam turbulência e seu papel na transferência de gases entre fluidos. 


\section{REVISÃO DA LITERATURA}

\subsection{Estudo da turbulência}

"A compreensão e a modelagem dos fenômenos turbulentos têm desafiado a imaginação e a criatividade dos cientistas e engenheiros por muito tempo. A própria definição de turbulência é um assunto em aberto, sendo-lhe usualmente atribuída uma série de características próprias para sua identificação.” (SCHULZ, 2001, p.XV)

Turbulência, palavra originada do latim turbulentia, entre outras tem as conotações de agitação, desordem, motim (FERREIRA, 1999). Para HOUAISS \& VILLAR (2001), turbulência é "movimento de um fluido em que há flutuação irregular, aleatória, da velocidade e pressão locais." Menos geral que a primeira, também esta segunda definição não tem rigor científico.

TAYLOR \& KARMAN (1937) definiram turbulência como sendo um movimento irregular que geralmente acontece em fluidos, gases ou líquidos, quando estes escoam próximos a superfícies sólidas ou mesmo quando camadas adjacentes de um mesmo fluido escoam umas sobre as outras. Para a ocorrência deste fenômeno, diferentes partes do fluido precisam ter movimentos também diferentes, com necessidade de o escoamento apresentar condições de irregularidade. Estas características de irregularidade impedem a descrição, em detalhes, do movimento de um escoamento turbulento como função do tempo e do espaço. Contudo, parece possível a descrição de variáveis do movimento do fluido, como por exemplo, velocidade, pressão e temperatura, em função de valores médios obtidos de suas flutuações. Turbulência então parece ser não um fenômeno totalmente irregular, pois pode ser tratada de forma estatística. Desta forma, surge nova definição para turbulência: $o$ movimento turbulento de um fluido é condição irregular do escoamento no qual várias quantidades apresentam variação aleatória em tempo e espaço, mas das quais valores médios podem ser obtidos estatisticamente. HINZE (1959) 
A grande causa desta busca em desvendar os mistérios da turbulência, a começar por sua própria definição, vem do valor prático desse desafio: estudos de muitos problemas técnicos, industriais e ambientais que envolvem turbulência a cada vez requerem melhores e mais precisas soluções, que incluam características detalhadas do movimento turbulento em questão. Existe, então, a necessidade de avanço no entendimento da turbulência, para que esses problemas reais que a envolvem possam ser modelados com melhor representação. Como usualmente é comentado em trabalhos de investigação nessa linha de pesquisa, o aprimoramento da simulação em laboratório desses problemas é função do avanço no entendimento da turbulência e do progresso da computação, que disponibiliza processadores capazes de simular um fluido em movimento turbulento e calcular suas variáveis, em níveis consideráveis de velocidade e precisão.

HUNT et al. (2001) apresentam uma revisão do desenvolvimento das pesquisas em turbulência nas últimas décadas, principalmente nos anos 90 , baseada em trabalhos realizados no Isaac Newton Institute, Cambridge - UK, entre janeiro e junho de 1999. A partir dessa revisão, esse trabalho busca resposta para a questão: existem vários ou apenas um problema de turbulência? A pergunta resume a possibilidade de haver ou não características comuns da turbulência em suas diferentes manifestações, de ser possível universalizar esse fenômeno e suas propriedades (estatisticamente analisadas) para todos os tipos de escoamento turbulento plenamente desenvolvido. Os autores mostraram que, por um lado, pesquisas apresentam evidências e melhores explicações dinâmicas - embora sem teorias completas - para a ocorrência em todos os escoamentos turbulentos de aspectos qualitativos similares, referentes à micro-escala. Por outro lado, além de aspectos qualitativos referentes à macro-escala (grandes turbilhões) divergirem entre um tipo de escoamento e outro, aspectos quantitativos da micro-escala de alguma forma dependem da grande-escala do escoamento. Assim, com evidências favoráveis à não-universalidade, as conclusões obtidas são que o progresso conseguido nos últimos anos para melhor 
entendimento da turbulência é indiscutível, porém, ainda estão distantes respostas completas para o fenômeno. Devido à atual ênfase em estudos específicos para os diferentes tipos de escoamento, tem havido diversidade de conceitos e modelos para representação da turbulência.

Esta diversidade esclarece a tendência dos pesquisadores em criar especialidades para estudo das diversas formas de ocorrência do fenômeno físico da turbulência. As diferenças entre um escoamento e outro - como as propriedades do fluido e sua velocidade, a superfície sobre a qual ele escoa, as condições de contorno e a forma com que a turbulência é gerada (escoamento sobre superfície rugosa, mudança de direção do escoamento, sólido imerso no escoamento, etc) - têm separado pesquisas e formulado teorias, modelos e métodos computacionais de simulação, cada qual apresentado com suas restrições de uso e validado para determinados tipos de escoamento ou formas de produção de turbulência.

Dentro deste universo de problemas, o estudo da turbulência isotrópica, uma de suas formas relativamente fácil de ser analisada matematicamente se comparada às demais (DAVIES, 1972), compreende uma linha de pesquisa que iniciou-se há mais de meio século e tem apresentado grande número de trabalhos dedicados ao entendimento das propriedades da turbulência.

\subsection{Turbulência isotrópica}

O estudo de turbulência isotrópica teve início com TAYLOR (1935b) que a definiu como condição em que todos os valores médios das funções de variáveis de escoamento deveriam ser independentes de translação, rotação e reflexão dos eixos de referência. Desde então, por ser a classe mais simples de turbulência, onde é necessário o menor número de parâmetros e relações para descrevê-la, a turbulência isotrópica tem sido largamente estudada para melhor entendimento de suas características e de sua relação com processos 
de misturas de fluidos, misturas entre fluidos e sólidos, dispersão em meio turbulento e trocas gasosas entre ar e água. Além disso, a existência de características comuns a todos os escoamentos turbulentos permite que a compreensão da turbulência isotrópica esclareça questões referentes às formas mais complexas de turbulência. (TOWNSEND, 1976)

\subsection{Características da turbulência isotrópica}

A relativa simplicidade do equacionamento da turbulência isotrópica pode ser explicada a partir de alguns conceitos gerais de turbulência, com a velocidade como variável em estudo. A velocidade é a variável comumente trabalhada no estudo das propriedades da turbulência. Sua determinação vetorial (magnitude, direção e sentido) em vários pontos, combinada com ou mesmo obtida a partir de algum método de visualização do escoamento, permite uma boa descrição do movimento do fluido.

Parte-se então do conceito fundamental de velocidade turbulenta, como sendo a flutuação da velocidade em torno de seu valor médio. O valor da velocidade turbulenta é obtido de:

$$
v^{\prime}=V-\bar{V}
$$

onde $v^{\prime}$ é a velocidade turbulenta, $V$ é a velocidade instantânea, e $\bar{V}$ é a velocidade média, em algum ponto do escoamento.

Adotando-se como referência o sistema cartesiano de coordenadas e trabalhando com três componentes da velocidade no espaço tem-se, para os eixos $\mathrm{x}, \mathrm{y}$ e $\mathrm{z}$, respectivamente:

$$
\begin{aligned}
& \mathrm{u}^{\prime}=\mathrm{U}-\overline{\mathrm{U}} \\
& \mathrm{v}^{\prime}=\mathrm{V}-\overline{\mathrm{V}} \\
& \mathrm{w}^{\prime}=\mathrm{W}-\overline{\mathrm{W}}
\end{aligned}
$$


Mas a velocidade turbulenta não é estudada em sua forma instantânea. A análise de um escoamento turbulento não pode ser feita a partir de apenas uma flutuação da velocidade que ocorre em determinado instante. Por ser um movimento caótico (irregular), a turbulência requer tratamento estatístico, a partir de valores médios de suas variáveis em estudo. Assim, da mesma forma que é importante a obtenção da velocidade média a partir de valores instantâneos de velocidade, da forma

$$
\begin{aligned}
& \bar{U}=\frac{\sum_{i=1}^{n} U_{i}}{n} \\
& \bar{V}=\frac{\sum_{i=1}^{n} V_{i}}{n} \\
& \bar{W}=\frac{\sum_{i=1}^{n} W_{i}}{n}
\end{aligned}
$$

(onde n é o número de medidas obtidas para a velocidade instantânea), também é necessário tratar a velocidade turbulenta a partir de seu valor médio. Porém, a média simples das flutuações instantâneas, calculada como para a velocidade, seria igual a zero. Isto é, usandose o eixo x como referência, as flutuações positivas (quando $U\rangle \bar{U}$ ) e as negativas (quando $\mathrm{U}\langle\overline{\mathrm{U}}$ ) seriam adicionadas e se anulariam (o mesmo acontecendo nos eixos y e z). Para solução deste problema, DRYDEN \& KUETHE (1930) apud HINZE (1959) introduziram para a média das flutuações instantâneas um conceito que desde então se tornou convenção. A velocidade turbulenta média passou a ser obtida a partir da raiz quadrada da média quadrática das flutuações, ou seja:

$$
\begin{gathered}
\mathrm{u}=\sqrt{\overline{\mathrm{u}^{\prime 2}}} \\
\mathrm{v}=\sqrt{\overline{\overline{\mathrm{v}^{\prime 2}}}} \\
\mathrm{w}=\sqrt{\overline{\overline{\mathrm{w}^{\prime 2}}}}
\end{gathered}
$$


sendo:

$$
\begin{aligned}
& \overline{\mathrm{u}^{\prime 2}}=\frac{\sum_{\mathrm{i}=1}^{\mathrm{n}} \mathrm{u}^{\prime 2}}{\mathrm{n}} \\
& \overline{\mathrm{v}^{\prime 2}}=\frac{\sum_{\mathrm{i}=1}^{\mathrm{n}} \mathrm{v}^{\prime 2}}{\mathrm{n}} \\
& \overline{\mathrm{w}^{\prime 2}}=\frac{\sum_{\mathrm{i}=1}^{\mathrm{n}} \mathrm{w}^{\prime 2}}{\mathrm{n}}
\end{aligned}
$$

A velocidade turbulenta média geralmente é apresentada como $\mathbf{u}_{\text {RMS }}, \mathbf{v}_{\mathbf{R M S}}$ e $\mathbf{w}_{\text {RMS }}$, do inglês Root Mean Square. Observa-se que as notações $\mathbf{u}, \mathbf{u}^{\prime}, \mathbf{U}$ e $\overline{\mathbf{U}}$, não seguem uma convenção única, sendo diferentes para cada trabalho. HINZE (1959), por exemplo, utiliza u' não para a flutuação instantânea, mas para a média das flutuações. O mesmo acontece para as componentes da velocidade nos eixos y e z.

Baseando-se nestes conceitos, apresenta-se duas características importantes da turbulência isotrópica:

- Todas as componentes da velocidade turbulenta média em um ponto são iguais. Isto significa que

$$
\mathrm{u}=\mathrm{v}=\mathrm{w}
$$

A simplificação apresentada acima no sistema cartesiano pode também ser feita em qualquer sistema de eixos adotado. Esta vantagem para o equacionamento da turbulência foi recentemente comentada por SCHULZ $(2001$, p.5) “... o fato de considerar principalmente a turbulência isotrópica permite que as questões evidentes de tridimensionalidade possam ser elegantemente desviadas utilizando o ponto de vista da simetria esférica. Então, por exemplo, uma escala de comprimento tem o mesmo valor em qualquer direção e operações de cálculo passam a ser simplificadas considerando apensas um elemento diferencial (em vez de três)." 
- Como as flutuações são aleatórias no espaço, não existe relação entre suas componentes em diferentes eixos de coordenadas. Portanto, a média das tensões de cisalhamento, também conhecidas como tensões de Reynolds, é igual a zero. O equacionamento é dado por.

$$
\begin{aligned}
& \overline{u^{\prime} \cdot v^{\prime}}=0 \\
& \overline{u^{\prime} \cdot w^{\prime}}=0 \\
& \overline{v^{\prime} \cdot w^{\prime}}=0
\end{aligned}
$$

É importante salientar que o cálculo da média da velocidade turbulenta pode ser feito de diferentes maneiras. Sua média pode ser temporal ou espacial. No caso da turbulência isotrópica (interesse deste trabalho), as médias são temporais, obtidas com uma descrição Euleriana do escoamento, onde as velocidades medidas referem-se a pontos fixos, cujas posições no espaço não variam com o tempo.

\subsection{Busca da turbulência isotrópica em laboratório}

Com os objetivos de se entender turbulência e relacioná-la aos diferentes processos de transporte de calor e massa que ocorrem em fluidos, ao longo dos anos, pesquisadores têm construído diferentes equipamentos na busca da produção de turbulência isotrópica. Porém, apesar de todo o esforço, esta turbulência só pode ser aproximada, e segundo SRDIC et al. (1996), sua perfeita isotropia é apenas hipotética e nunca atingida em escoamentos reais ou experimentos. Desta forma, a turbulência gerada em pesquisas é chamada quaseisotrópica

A produção de turbulência quase-isotrópica em laboratório é conseguida com diferentes equipamentos que têm características particulares e apresentam vantagens e desvantagens entre si. Provavelmente, os equipamentos mais explorados ao longo da história 
do estudo da turbulência isotrópica têm sido os túneis de ar e água, utilizados por pesquisadores por mais de meio século. Por outro lado, tanques de grades oscilantes, também chamados tanques de grelhas oscilantes, têm sido a cada vez mais empregados em pesquisas atuais sobre turbulência isotrópica.

\subsection{Túneis de ar e água}

Ao longo de décadas, a aproximação experimental de turbulência isotrópica usualmente tem sido feita através de escoamento em túneis de água e, especialmente, de vento, fluido este preferido em relação à água, segundo TOWNSEND (1976), por permitir a obtenção de escoamento turbulento com maior facilidade. Nesses túneis, é colocada, em posição perpendicular ao escoamento, uma grade formada por uma malha de barras sólidas. Segundo COMTE-BELLOT \& CORRSIN (1966), o uso de grade imersa em um escoamento para obtenção de turbulência relativamente simples teve início mesmo antes dos estudos de TAYLOR (1935b) sobre turbulência isotrópica, com o trabalho de SIMMONS \& SALTER (1934), seguido pelo de TAYLOR (1935b) e os trabalhos de medição de turbulência de DRYDEN et al. (1937), CORRSIN (1942), BATCHELOR \& TOWNSEND $(1947,1948)$, BAINES \& PETERSON (1951), TSUJI \& HAMA (1953), GRANT \& NISBET (1957) e WYATT (1955), entre outros.

Nesse tipo de equipamento, a geração da turbulência e suas características são assim explicadas por DE SILVA \& FERNANDO (1994): a turbulência é gerada atrás da grade pelo desenvolvimento de jatos (parte do escoamento que passa entre as barras) e de esteiras (parte do escoamento que se depara com elas), que são, ainda, fortalecidos pela presença das tensões de cisalhamento. Se a grade obedece a certos parâmetros de forma, estes jatos e esteiras se fundem uns aos outros a uma certa distância à jusante de onde foram originados (grade). Nessa região, as tensões de cisalhamento se tornam desprezíveis e tem início o

\footnotetext{
${ }^{1}$ Turbulência quase-isotrópica: do inglês nearly-isotropic turbulence.
} 
decaimento da turbulência. A região de transição entre o desenvolvimento do escoamento turbulento e o decaimento da turbulência não é bem definida, mas se localiza, segundo HINZE (1959), aproximadamente 20M à jusante da origem da turbulência, sendo M (Mesh) o espaçamento entre as barras da grade. Seguindo-se adiante, no sentido do escoamento, chega-se à região onde a turbulência é considerada praticamente homogênea em planos perpendiculares ao escoamento, com a razão entre as velocidades turbulentas axial (no sentido do escoamento) e transversal (em qualquer eixo perpendicular ao escoamento) variando entre 1,05 e 1,35. Forçosamente, esta turbulência é dita isotrópica, para fins de pesquisa.

Porém, COMTE-BELLOT \& CORRSIN (1966) mostraram que essa razão entre as velocidades turbulentas axial e transversal, ocorrida provavelmente a 40M ou 50M à jusante da grade, poderia estar mais próxima da unidade se o escoamento passasse por contração de 1,27 vezes na área da seção transversal do túnel. Isso implicaria em melhor validade de comparação entre experimentos de túneis com grades e teorias de turbulência isotrópica. Contudo, mesmo após esse trabalho, experimentos seguintes foram feitos com produção de turbulência isotrópica em túneis sem contração. Segundo TOWNSEND (1976), os erros apresentados em experimentos sem a contração não afetam significantemente as conclusões dos trabalhos.

Durante décadas, experimentos com túneis de ar e água têm sido úteis ao estudo e ao equacionamento da turbulência, em particular da turbulência isotrópica. Todavia, esses equipamentos possuem certas características físicas que interferem de forma negativa no estudo da turbulência por eles próprios gerada. Uma dessas características diz respeito às dimensões desses equipamentos. Por se tratar de túneis ou canais, um considerável espaço do laboratório é ocupado por esses equipamentos. Como exemplo, tem-se os equipamentos dos trabalhos de COMTE-BELLOT \& CORRSIN (1966) com mais de $12 \mathrm{~m}$ de comprimento, de BUDWIG et al. (1985) com 4,2 m, de ITSWEIRE et al. (1986) com 5 m, e 
de MOHAMED \& LA RUE (1990) com 6,71 m. Uma outra característica dos túneis e canais é a impossibilidade da geração de turbulência pura no equipamento, isto é, não é possível gerar turbulência sem que haja escoamento do fluido. Isto significa que o estudo isolado da turbulência e de sua influência em outros fenômenos estudados em Mecânica dos Fluidos e Fenômenos de Transportes - tais como dispersão em meio turbulento, transferência gasosa na interface ar-água, mistura de fluidos, etc. - fica comprometido pela existência de outras variáveis, indesejáveis, pertencentes ao escoamento. SRDIC et al. (1996) comentam que devido ao rápido decaimento da turbulência, o uso de túneis no estudo de certos aspectos da turbulência isotrópica, como a dispersão, se torna impraticável sem o comprometimento de sua precisão e versatilidade.

Paralelamente aos vários trabalhos de geração e medição de turbulência quaseisotrópica utilizando túneis de ar e de água, pesquisadores têm recorrido a outro equipamento na busca dessa forma de turbulência em laboratório. Representando uma boa alternativa para eliminar as características indesejáveis apresentadas pelos túneis, o tanque de grade oscilante é um equipamento mais compacto, que gera turbulência de intensidade controlável, com velocidade média do fluido praticamente nula (sem existência de escoamento médio) e apresenta um volume bem definido de controle do fluido (geralmente água). O tanque de grade oscilante tem sido a cada vez mais utilizado em pesquisas que envolvem geração, estudo e aplicação de turbulência.

\subsection{Tanque de grade oscilante}

Embora o trabalho de ROUSE (1939) seja, segundo CHENG \& LAW (2001), o primeiro a utilizar um tanque de grade oscilante para geração de turbulência em laboratório, encontram-se na maior parte da literatura os trabalhos das décadas de 60 e 70 como pioneiros na utilização deste equipamento. BOUVARD \& DUMAS (1967), THOMPSON \& 
TURNER (1975), e HOPFINGER \& TOLY (1976) geralmente são os primeiros trabalhos citados nos estudos mais recentes envolvendo tanques de grade oscilante.

Este equipamento consiste em um tanque usualmente construído com material transparente (vidro ou acrílico) para melhor visualização do experimento. Dentro desse tanque, imersa no fluido que se deseja estudar, existe uma malha de barras, de seção retangular ou circular, formando uma grade (ou mais de uma, e neste caso é denominado tanque de grades oscilantes). Essa grade, posicionada normalmente em um plano horizontal a uma certa distância abaixo da superfície do líquido, é oscilada verticalmente por um equipamento externo ao tanque. Parâmetros como frequiência e amplitude de oscilação, bem como seção transversal das barras da grade, espaçamento entre elas e seu comprimento, devem obedecer a certos valores limites para que seja atingida a produção da turbulência quase-isotrópica no tanque.

\subsection{Dimensões do tanque e parâmetros de forma da grade}

$\mathrm{Na}$ literatura, as dimensões do tanque e os parâmetros de forma da grade não têm sido padronizados, apesar de também não divergirem consideravelmente. Pesquisas mais recentes têm mantido formas do tanque e dimensões da grade, e mesmo reutilizado equipamentos de outros trabalhos (tanques, grades, e o mecanismo de oscilação das grades). O uso de grades semelhantes às do trabalho de THOMPSON \& TURNER (1975) é preferido pelos pesquisadores, o que permite comparações de resultados, formulações para turbulência e conclusões de diferentes trabalhos. Embora ainda existam trabalhos que em seus experimentos façam uso de grades consideravelmente diferentes destas, chega-se à conclusão que essas diferenças afastam a isotropia da turbulência gerada no tanque. A falta de isotropia é devido ao fato de certos parâmetros de forma da grade terem influência direta nas características da turbulência gerada no tanque. 
Em seu trabalho com escoamento através de uma grade fixa, CORRSIN (1963) concluiu que somente quando a solidez da grade é suficientemente baixa, os jatos formados atrás das grades se fundem sem mudar sua direção. Quando a solidez é alta, os jatos se juntam e se tornam instáveis. Segundo HOPFINGER \& TOLY (1976), a solidez acima da qual essa instabilidade é observada é aproximadamente de $40 \%$. Entende-se como solidez a relação entre a área horizontal ocupada pelas barras da grade e a área total da superfície do tanque.

Talvez devido às limitações de espaço ou de material, ou mesmo devido à busca de dimensionamento ótimo que venha a padronizar este equipamento, diferentes medidas para os tanques são encontradas. Apesar de existirem referências a tanques de seção circular na literatura, como o de VOROPAYEV \& FERNANDO (1996), com $16 \mathrm{~cm}$ de diâmetro e 25 cm de altura, e de seção retangular (ATKINSON \& WOLCOTT, 1990), os tanques de seção quadrada são, sem dúvida, os mais utilizados.

\subsection{Amplitude e freqüência de oscilação da grade}

$\mathrm{Na}$ obtenção da turbulência quase-isotrópica no fluido do equipamento, amplitude e freqüência de oscilação da grade no tanque são duas variáveis importantes, tanto quanto as medidas do tanque e da grade,. THOMPSON \& TURNER (1975) em seu trabalho concluíram que a variação espacial da velocidade turbulenta, também conhecida como decaimento espacial da turbulência, é função de certas variáveis do equipamento. Nesta pesquisa, não se levando em consideração a forma da grade, $50 \%$ de seus dados se ajustaram bem à equação:

$$
\mathrm{u}=1,4 \cdot \mathrm{f} \cdot \mathrm{S}^{2,5} \cdot \mathrm{z}^{-1,5}
$$

onde:

u - velocidade RMS no plano horizontal;

f - freqüência de oscilação d grade em Hz; 
S - amplitude de oscilação da grade;

z - distância do ponto de medição da velocidade à origem virtual da turbulência (centro de oscilação da grade).

Posteriormente, HOPFINGER \& TOLY (1976) introduziram a distância entre barras, M (Mesh), como variável importante neste equacionamento, da forma:

$$
\mathrm{u}=\mathrm{C} \cdot \mathrm{S}^{3 / 2} \cdot \mathrm{M}^{1 / 2} \cdot \mathrm{f} \cdot \mathrm{z}^{-1}
$$

onde $\mathbf{C}$ é uma constante que depende da geometria da grade, igual a 0,25 para $\frac{\mathbf{M}}{\mathbf{d}}=5$, como foi o caso do seu trabalho. A variável d corresponde à espessura das barras (de seção quadrada) que formam a grade.

Comparando-se as equações (18) e (19), nota-se que há divergências em relação ao expoente de z, com o trabalho de HOPFINGER \& TOLY (1976) apresentando um decaimento mais lento para a componente horizontal da velocidade turbulenta. Um grande número de trabalhos com tanques de grades oscilantes estudam a definição desse expoente. Explora-se também a possibilidade desse expoente não ser constante e de não haver, então, apenas uma lei de decaimento da turbulência.

\subsection{Turbulência quase-isotrópica no tanque}

As equações (18) e (19) expressam a busca de pesquisadores ao entendimento da turbulência no tanque de grade oscilante. Estes equacionamentos relacionam a velocidade turbulenta horizontal u e a distância, expressa por $\mathbf{z}$, entre o ponto de medição desta velocidade e a origem da turbulência (assumida como o centro de oscilação da grade), e mostram o decaimento da velocidade turbulenta à medida que suas medições se afastam da grade, obviamente se mantidos constantes os demais parâmetros, S, M e f. Esta 
característica, conhecida como decaimento da turbulência, é importante para localização e quantificação da turbulência no interior do volume de controle desse equipamento.

A turbulência gerada próxima à grade não é considerada quase-isotrópica. Nessa região, o alto grau de agitação do fluido, induzido pela oscilação da grade em apenas uma direção, é formado por jatos e vórtices que preferencialmente seguem a direção vertical. À medida que se distanciam da grade, os efeitos da viscosidade da água resultam na conversão da energia cinética do escoamento em calor, o que faz do movimento turbulento um dissipador de energia. Se não existir uma fonte contínua de energia em todo o volume de água do tanque, agindo como gerador de turbulência, esta energia decairá com o aumento de z. Juntamente com este decaimento e resultante também dos efeitos viscosos do fluido, há transferência de quantidade de movimento das partículas de uma direção para outra. Então o movimento turbulento se assemelha nas diferentes direções, e as características estatísticas da turbulência praticamente não têm preferência de direção. Gera-se assim turbulência quase-isotrópica, a uma certa distância da grade oscilante. Esta forma de turbulência, admitida como isotrópica, facilita seu equacionamento e o estudo de sua relação com os fenômenos de transporte que ocorrem no fluido.

\subsection{Medição da turbulência}

O estudo teórico do movimento turbulento em um fluido é tarefa complexa. A verificação de modelos, novos conceitos e idéias, relacionados a algum movimento turbulento, é facilitada quando se inclui no estudo alguma técnica de medição e visualização da velocidade turbulenta.

A região de medição da velocidade no interior do tanque geralmente está compreendida em algum local entre a grade (caso esteja posicionada em plano horizontal) e a superfície do fluido. Uma vez definida a região de interesse do estudo, podem ser empregadas diferentes técnicas de medição de velocidade, cada qual com seu respectivo 
equipamento. Por representar a flutuação da velocidade em torno de seu valor médio, a velocidade turbulenta requer apuradas técnicas de medição, que utilizem equipamentos com precisão compatível com a escala de velocidade turbulenta no tanque de grade oscilante. Ao longo da história deste equipamento, três técnicas de medição se destacaram e foram largamente utilizadas. A apresentação destas técnicas segue a ordem cronológica de seu surgimento e, atualmente, todas elas são usadas.

- Anemometria de filme quente (Hot-film Anemometry)

Esta técnica utiliza um elemento diminuto (filme ou película), aquecido eletricamente. Um circuito eletrônico é usado para manter constante a temperatura deste elemento e sentir a taxa de aquecimento. Esta taxa pode ser relacionada, através de calibração à velocidade de escoamento, que por outro lado resfria o filme. Como a massa térmica do filme é muito pequena, a sua resposta às flutuações de velocidade do escoamento é muito rápida. Por esse motivo, o anemômetro de filme quente é utilizado para medições de quantidades turbulentas.

\section{- Laser Doppler Velocimetry - LDV}

O surgimento desta técnica representou grande avanço na área de medições em escoamento. Medidas de velocidade turbulenta feitas com este equipamento são diretas e não requerem calibração. $\mathrm{O}$ volume de água necessário para medição em um ponto é muito pequeno (algo em torno de um cubo com 0,2 $\mathrm{mm}$ de lado), e sua maior vantagem em relação à anemometria de filme quente está no fato de nenhum instrumento precisar ser inserido no escoamento (técnica não-intrusiva). A necessidade de transparência no canal do escoamento, para passagem do feixe de luz do laser, o custo e a complexidade do equipamento são inconvenientes dessa técnica. (DOEBELIN, 1990)

Em resumo, esta técnica consiste em focalizar dois feixes de laser, com mesmo comprimento de onda, em um ponto onde se deseja medir a velocidade, formando franjas de 
interferência (faixas de alta e baixa intensidade de luz) no volume de intersecção dos feixes, como é mostrado na FIGURA 01.

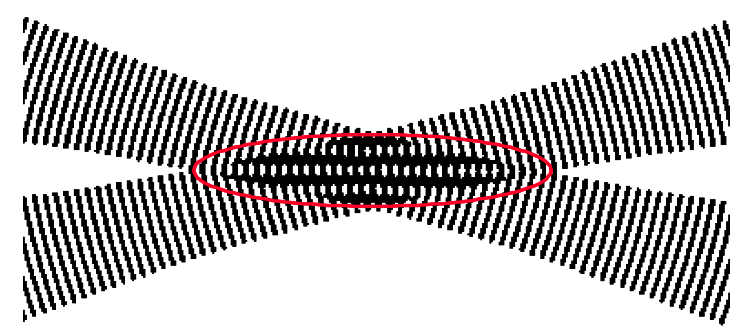

FIGURA 01 - Franjas de interferência na intersecção dos feixes de laser.

Quando uma partícula carregada pelo fluido passa através desta franja, ela reflete a luz do laser. Um fotodetector capta essa luz refletida, cuja intensidade varia com freqüência igual à velocidade da partícula dividida pelo espaçamento da franja. Admitindo-se que a velocidade da partícula seja igual à do fluido, e fazendo-se uma série de medições em vários pontos, obtém-se uma boa descrição do escoamento e da variação de sua velocidade turbulenta.

- Particle Image Velocimetry - PIV

Esta técnica ótica também não-intrusiva mede velocidade em uma seção bidimensional de escoamentos, e não apenas em um ponto, como na técnica LDV. Na técnica PIV, um equipamento laser emite um feixe de luz que, expandido na forma de um plano, é introduzido no escoamento. Uma câmera fotográfica, localizada perpendicularmente ao plano de luz, é utilizada na aquisição de fotos das partículas presentes no fluido, que estão se movendo e sendo iluminadas no interior desta folha. Se o intervalo de tempo entre as fotos é conhecido e se em cada foto uma partícula está em uma posição, a velocidade dessa partícula pode ser calculada. Através de duas fotos consecutivas, divide-se o espaço percorrido pela partícula pelo intervalo de tempo entre as fotos. Como 
existe um grande número de partículas presentes no fluido (partículas naturais ou traçadores inseridos no fluido), uma análise de correlação faz o reconhecimento das mesmas partículas nas diferentes fotos. Com a obtenção dos vetores velocidade em diversos pontos em um plano do fluido, um campo de velocidades é obtido.

A análise de correlação, o cálculo das velocidades e a obtenção do campo são efetuados por um software. No caso da aquisição de fotos ser feita por câmera fotográfica digital, essa técnica é chamada Digital Particle Image Velocimetry (DPIV), e o tempo para obtenção dos campos de velocidade é consideravelmente reduzido (as fotos são diretamente transferidas da câmera para o computador e analisadas pelo software).

\subsection{Tanques encontrados na literatura}

Devido à inexistência de padronização para tanque de grade oscilante, com definição de sua forma, dimensões, geometria e movimento da grade, foi feita uma revisão neste sentido, resumida na TABELA 1. Esta trás, também, a técnica de medição de velocidade turbulenta empregada. 
TABELA 01 - Parâmetros de tanques de grades oscilantes encontrados na literatura

\begin{tabular}{|c|c|c|c|c|c|c|c|}
\hline \multirow[t]{2}{*}{ TRABALHO } & \multicolumn{2}{|c|}{ DIMENSÕES DO TANQUE } & \multicolumn{2}{|c|}{ GRADE } & \multicolumn{2}{|c|}{ OSCILAÇÃOO } & \multirow{2}{*}{$\begin{array}{c}\text { TÉCNICA DE } \\
\text { MEDIÇÃO }\end{array}$} \\
\hline & Área $\left(\mathrm{cm}^{2}\right)$ & Altura $(\mathrm{cm})$ & Barras $\left(\mathrm{cm}^{2}\right)$ & $\operatorname{Mesh}(\mathrm{cm})$ & Amplitude (cm) & Frequência $(\mathrm{Hz})$ & \\
\hline BOUVARD \& DUMAS (1967) & $67,5 \times 67,5$ & 100 & \multicolumn{2}{|c|}{$\begin{array}{c}\text { placa perfurada } \\
4,55 \text { (diâm. furos) }\end{array}$} & $0-8$ & - & $\begin{array}{l}\text { Anemometria } \\
\text { de filme quente }\end{array}$ \\
\hline THOMPSON \& TURNER (1975) & $25,4 \times 25,4$ & 46 & $\begin{array}{c}1,0 \text { x 1,0 } \\
0,952 \text { (diâm.) }\end{array}$ & 5 & $\begin{array}{c}1 \\
1,4 ; 1,45\end{array}$ & $\begin{array}{c}3,33 \\
2,78 ; 5\end{array}$ & $\begin{array}{l}\text { Anemometria } \\
\text { de filme quente }\end{array}$ \\
\hline HOPFINGER \& TOLY (1976) & $\begin{array}{c}67,5 \times 67,5 \\
80 \times 80\end{array}$ & 100 & $\begin{array}{l}1,0 \times 1,0 \\
2,0 \times 2,0 \\
\end{array}$ & $\begin{array}{c}5 \\
10 \\
\end{array}$ & $\begin{array}{l}4 \\
9 \\
\end{array}$ & $2-6$ & $\begin{array}{l}\text { Anemometria } \\
\text { de filme quente }\end{array}$ \\
\hline McDOUGAL (1979) & $25,4 \times 25,4$ & 46 & $1,0 \times 1,0$ & 5 & 1 & $1-10$ & LDV \\
\hline BRUMLEY \& JIRKA (1987) & $50 \times 50$ & 40 & $1,3 \times 1,3$ & 6,35 & $1,3-15$ & $0,5-5$ & Anem. filme quente \\
\hline NOKES (1988) & $25,4 \times 25,4$ & 60 & $1,0 \times 1,0$ & 5 & $0,77-4,9$ & 4 & - \\
\hline ATKINSON \& WOLCOTT (1990) & $120 \times 30$ & 40 & $1,0 \times 1,0$ & 5 & 1 & $3 ; 4 ; 5$ & $*$ LDA \\
\hline MATSUNAGA et al. (1991) & $100 \times 25$ & 40 & $1,0 \times 1,0$ & 5 & $4 ; 8$ & $2-6$ & Anem. filme quente \\
\hline DE SILVA \& FERNANDO (1992) & $26 \times 26$ & 60 & $0,9 \times 0,9$ & $\begin{array}{c}2,93 ; 4,76 ; \\
6,2 \\
\end{array}$ & 0,$85 ; 2,1$ & $1-5$ & LDV \\
\hline DE SILVA \& FERNANDO (1994) & $\begin{array}{l}25,4 \times 25,4 \\
45,7 \times 45,7\end{array}$ & $\begin{array}{c}47 \\
45,7\end{array}$ & $\begin{array}{l}0,9 \times 0,9 \\
1,2 \times 1,9\end{array}$ & $\begin{array}{l}4,76 \\
7,97\end{array}$ & 0,$85 ; 2,1$ & $0-7$ & LDV \\
\hline CASSON et al. (1994) & - & - & $0,635 \times 0,635$ & 3,18 & $\begin{array}{l}1,91 \\
0,64\end{array}$ & $\begin{array}{l}0,25 \\
0,75\end{array}$ & LDV \\
\hline SRDIC et al. (1996) & $36 \times 36$ & 58 & $1,0 \times 1,0$ & 5 & $0-5,5$ & $0-5$ & LDV \\
\hline
\end{tabular}


TABELA 01 - Parâmetros de tanques de grades oscilantes encontrados na literatura

\begin{tabular}{|c|c|c|c|c|c|c|c|}
\hline \multirow[t]{2}{*}{ TRABALHO } & \multicolumn{2}{|c|}{ DIMENSÕES DO TANQUE } & \multicolumn{2}{|c|}{ GRADE } & \multicolumn{2}{|c|}{ OSCILAÇÃO } & \multirow{2}{*}{$\begin{array}{c}\text { TÉCNICA DE } \\
\text { MEDIÇÃO }\end{array}$} \\
\hline & Área $\left(\mathrm{cm}^{2}\right)$ & Altura $(\mathrm{cm})$ & $\operatorname{Barras}\left(\mathrm{cm}^{2}\right)$ & $\operatorname{Mesh}(\mathrm{cm})$ & Amplitude $(\mathrm{cm})$ & Frequência $(\mathrm{Hz})$ & \\
\hline VOROPAIEV \& FERNANDO (1996) & 16 (diâm.) & 25 & $\begin{array}{l}0,071 \\
0,071 \\
0,051\end{array}$ & $\begin{array}{c}0,318 \\
0,0,635 \\
0,18\end{array}$ & $0,045-0,45$ & $2-40$ & Câmera filmadora \\
\hline BRUNK et al. (1996) & $20 \times 40$ & 100 & 0,267 (diâm.) & 1,27 & $0,5-4$ & $1-8,5$ & **ADV \\
\hline $\begin{array}{l}\text { LYN (1997) apud } \\
\text { CHENG \& LAW (2001) }\end{array}$ & $25,4 \times 25,4$ & 48 & $0,95 \times 0,95$ & 4,8 & 5 & 4,6 & PIV \\
\hline KIT et al. (1997) & $47 \times 47$ & 45 & $1,93 \times 1,93$ & 8 & 3,2 & 2,$15 ; 2,9 ; 4,3$ & Anem. filme quente \\
\hline SHY et al. (1997) & $\begin{array}{l}15 \times 15 \\
30 \times 30\end{array}$ & $\begin{array}{l}30 \\
60\end{array}$ & $0,6 \times 0,6$ & 3 & 2 & $1-10$ & LDV \\
\hline BRUNK, B. K. et al (1998) & $20 \times 40$ & 25 & 0,267 (diâm.) & 1,27 & $0,5-4$ & $0-8$ & ADV \\
\hline LIEM et al. (1999) & $11,5 \times 11,5$ & 15 & $\begin{array}{l}0,32 ; 0,48 ; \\
0,64 \text { (diâm) }\end{array}$ & $\begin{array}{l}0,92 ; 1,1 ; \\
1,38 ; 18,3\end{array}$ & 13,5 & $\begin{array}{c}0,037 ; 0,48 ; \\
0,26 ; 0,37 ; 0,48\end{array}$ & LDA \\
\hline HIBBS \& GULLIVER (1999) & $50 \times 50$ & 50 & $1,77 \quad 1,77$ & 6,4 & 4 & $2-6$ & - \\
\hline BARRY et al. (2001) & $52 \times 48$ & 60 & $1 \times 1$ & 5 & 52 & - & - \\
\hline CHENG \& LAW (2001) & $50 \times 50$ & 100 & $1,0 \times 1,0$ & 5 & 4 & $1-4$ & DPIV \\
\hline
\end{tabular}

*LDA = Laser Doppler Anemometry

$* \mathrm{ADV}=$ Acoustic Doppler Velocimetry 
Apresenta-se comentários de algumas particularidades referentes aos trabalhos citados:

THOMPSON \& TURNER (1975) e NOKES (1988), usaram tanques de mesma seção transversal e grades idênticas às de TURNER (1968), parâmetros que proporcionaram geração de turbulência com características desejadas.

HOPFINGER \& TOLY (1976) utilizaram a mesma grade de TURNER (1968), porém em tanque construído por BOUVARD \& DUMAS (1967), que utilizaram uma placa perfurada, e não uma grade, como tornou-se comum nos trabalhos seguintes. Sua grade distava $45 \mathrm{~cm}$ do fundo do tanque, para reduzir os movimentos secundários gerados junto às paredes. Foram realizados experimentos preliminares com a grade instalada a uma distância de $20 \mathrm{~cm}$ do fundo, e seus resultados de velocidade turbulenta mostraram que movimentos secundários formados junto aos cantos modificaram a lei de decaimento.

McDOUGAL (1979) apud CHENG \& LAW (2001) concluíram que a turbulência gerada com amplitude de oscilação igual a $1 \mathrm{~cm}$ não tinha homogeneidade no plano horizontal e que frequiência superior a $7 \mathrm{~Hz}$ perdia sua relação com a velocidade turbulenta horizontal $\mathbf{u}$, causando um movimento de circulação do fluido no tanque.

BRUMLEY \& JIRKA (1987) projetaram seu tanque para ser isolado o máximo possível de fontes de vibração, para que medições de velocidade turbulenta pudessem ser feitas próximas à superfície do fluido, sem a presença de ondas. A solidez da grade deste trabalho obedeceu ao limite de 40\% apresentado por HOPFINGER \& TOLY (1976), e teve sua parte sólida ocupando $36 \%$ de toda a seção transversal do tanque.

ATKINSON \& WOLCOTT (1990) usaram um tanque para estudo de processos de mistura entre fluidos estratificados. Estes processos são importantes para desenvolvimento de modelos de misturas na superfície de corpos de água. Processos de mistura também foram estudados com uso de tanques de grades oscilantes em DE SILVA \& FERNANDO (1992) e CASSON et al. (1994). 
MATSUNAGA et al. (1991) compararam as propriedades da turbulência gerada por grades oscilantes através de análise numérica com as obtidas em seus experimentos. Os resultados experimentais corroboraram a proposta da solução analítica.

DE SILVA \& FERNANDO (1994) utilizaram dois tanques de diferentes tamanhos, com solidez de $36 \%$ para a grade do tanque de maiores dimensões e de $27 \%$ para a grade do menor tanque. Ambas as grades apresentavam distância de $3 \mathrm{~mm}$ de suas extremidades às paredes e distância de $25 \mathrm{~cm}$ em relação ao fundo do tanque. Os movimentos secundários apresentados foram muito fracos.

SRDIC et al. (1996) apresentaram nova concepção de montagem da grade em seu tanque de vidro, como alternativa de aproximação da turbulência isotrópica. Duas grades foram imersas verticalmente em um fluido homogêneo (água). As grades, paralelas entre si, não oscilavam em sincronia, e a região central entre as grades apresentou certas propriedades similares àquelas da turbulência isotrópica. SHY et al. (1997) também realizaram trabalho com duas grades oscilantes.

VOROPAYEV \& FERNANDO (1996), como equipamento de oscilação da grade, utilizaram um alto-falante a ela ligado. As distâncias entre as extremidades da grade e as paredes eram menores que $1 \mathrm{~mm}$ e, através de diferentes freqüências emitidas ao altofalante, eram obtidas amplitudes muito baixas e altas frequiências de oscilação da grade.

BRUNK et al. (1996) projetaram um tanque (reator) com cinco grades oscilantes dispostas em plano vertical para estudo de processos químicos e hidrodinâmicos relacionados à ação de poluentes em ambientes aquáticos naturais. 
CHENG \& LAW (2001), utilizando a técnica de medição DPIV para o estudo das propriedades da turbulência gerada neste equipamento, apresentaram grande quantidade de medidas de velocidade turbulenta através das componentes horizontal e vertical.

\subsection{Tanque de grade oscilante do SHS-EESC-USP}

Na literatura brasileira, ROMA (1988) foi o primeiro autor que construiu e utilizou um tanque de grade oscilante. Aliás, seu equipamento é também o único até o presente. Esse autor concentrou sua pesquisa no desenvolvimento de um sensor de turbulência para a camada da superfície de um meio líquido, embasado nos fenômenos de refração ótica na interface de dois meios refringentes. Esse sensor tem como finalidade avaliar o coeficiente de reaeração em montagem de laboratório.

Como as medidas de turbulência no trabalho de ROMA (1988) encontravam-se na superfície do fluido (água), não houve necessidade de construir seu tanque com material transparente, como vidro ou acrílico. O tanque foi construído com chapas de aço pintadas com tinta epóxi para minimizar os efeitos de oxidação. Sua área superficial é $0,50 \mathrm{~m}$ x $0,50 \mathrm{~m}$ e, sua profundidade, $0,80 \mathrm{~m}$. Na FIGURA 02 é mostrado esse equipamento.

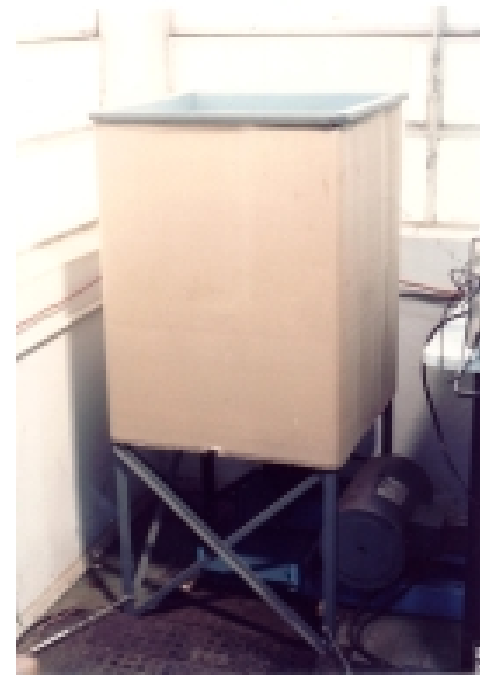

FIGURA 02 - Tanque gerador de turbulência do trabalho de ROMA (1988).

Foto retirada de seu trabalho original. 
Nesse trabalho foram utilizadas três diferentes grades, de acordo com a quantidade de malhas por unidade de área: 100 malhas $/ \mathrm{m}^{2}, 256$ malhas $/ \mathrm{m}^{2}$ e 400 malhas $/ \mathrm{m}^{2}$. Elas foram construídas com barras quadradas de seção $1 \mathrm{~cm}$ x $1 \mathrm{~cm}$, em madeira, coladas com araldite e pintadas com tinta esmalte. Durante os experimentos, a grade oscilava próxima ao fundo do tanque, mantendo uma distância de 0,70 m entre seu centro de oscilação e a superfície do fluido, com amplitude de oscilação de $10 \mathrm{~cm}$.

O sistema de oscilação da grade é composto por um motor de corrente contínua, através do qual várias frequiências de oscilação da grade puderam ser testadas, e por um mecanismo biela-manivela, localizado abaixo do tanque, que liga o motor à grade. Esse mecanismo, apresentado na FIGURA 03, permitiu a execução de experimentos com diferentes amplitudes de oscilação da grade, até a decisão por $10 \mathrm{~cm}$. Essa amplitude proporcionou, visualmente na superfície do fluido, turbulência adequada ao desenvolvimento da sonda ótica, objetivo do trabalho.

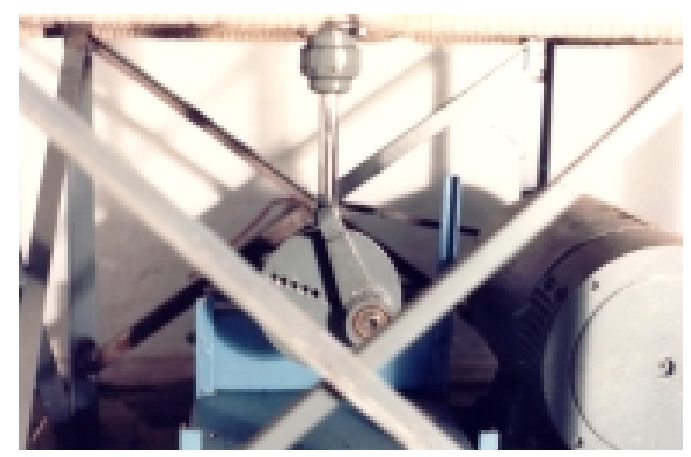

FIGURA 03 - Mecanismo biela-manivela de oscilação da grade, no trabalho de ROMA.(1988). Foto retirada de seu trabalho original.

O trabalho de ROMA (1988), realizado no Departamento de Hidráulica e Saneamento da Escola de Engenharia de São Carlos - USP, deu início a uma linha de pesquisa que visa a aplicação de um método de medida de turbulência, através do uso de sonda ótica para o estudo da reaeração de corpos d'água. Novos trabalhos nessa linha, desde então, para seus experimentos têm utilizado o mesmo tanque de grade oscilante. 


\section{OBJETIVO}

Este trabalho inicia-se com o projeto e a construção de um de um tanque de grade oscilante, de dimensões e geometria tais que possibilitem a geração, em seu volume de água, de turbulência com intensidade controlável. Esse tanque, de soluções inovadoras para a o sistema de movimentação da grade, deve permitir visualização do movimento do fluido no interior de um volume de controle bem definido, uso de grades de diferentes malhas em diferentes freqüências e amplitudes de oscilação. Os experimentos realizados no tanque compreenderam medições de velocidade turbulenta com uso de técnica DPIV, ao longo de planos verticais localizados acima da grade oscilante. O objetivo foi avaliar, nesse equipamento, a ocorrência de certas propriedades comuns aos escoamentos turbulentos produzidos por grades oscilantes. Tais características turbulentas referem-se à aproximação de condições de isotropia em determinadas regiões do tanque, à homogeneidade horizontal da turbulência, à ausência de escoamento médio, ao decaimento espacial da turbulência e à relação direta entre a intensidade turbulenta produzida e a frequiência de oscilação da grade. 


\section{MATERIAIS E MÉTODOS}

Os materiais usados para construção do tanque, os equipamentos e procedimentos experimentais utilizados neste trabalho serão descritos a seguir.

\subsection{Materiais}

\subsubsection{Construção do tanque de grade oscilante}

O projeto de construção do tanque de grade oscilante teve início com uma análise crítica dos trabalhos da literatura que usaram equipamentos similares. Os tanques de grades oscilantes (há tanques com uma, duas ou mais grades) pesquisados possuem certas características, referentes à ligação da grade com seu sistema de oscilação, que de alguma forma podem perturbar a busca do movimento turbulento desejado e que não são apresentadas nas publicações dos seus respectivos trabalhos. São dois os tipos de ligação comumente encontrados na literatura. O primeiro consiste em hastes verticais que descem ao tanque e se prendem à grade, mantendo-a suspensa (FIGURA 04). Nessa ligação, buscou-se evitar a quebra da superfície do líquido e a alteração de seu volume devido à entrada e saída das hastes no interior do tanque. Essas características, mesmo minimamente, interferem nos resultados dos experimentos.

O segundo tipo de ligação, ilustrado na FIGURA 05, é composto por apenas uma haste central que atravessa a base do tanque e se liga à grade. Segundo ROMA (2001) ${ }^{2}$, após longo período de funcionamento do seu equipamento com esse sistema de oscilação, ocorreram problemas de vedação no orifício da base do tanque, por onde passa a haste. Por estar suportada apenas por uma haste central, a rigidez das barras deve ser observada, para que não haja considerável flexão das extremidades da grade durante seu movimento.

\footnotetext{
${ }^{2}$ ROMA, W. N. L. (2001). (USP. Escola de Engenharia de São Carlos). Comunicação pessoal.
} 


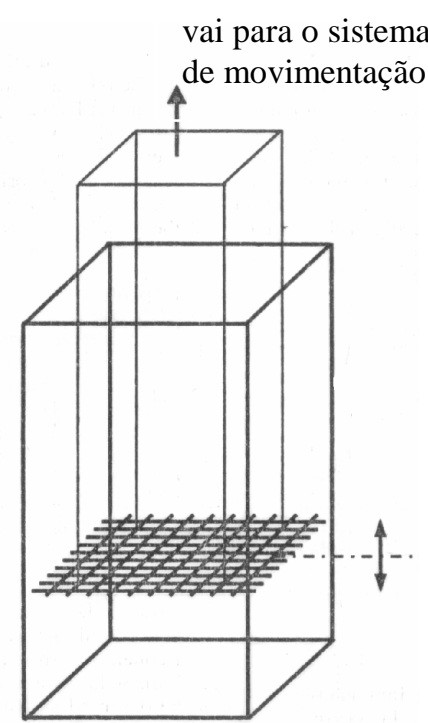

FIGURA 04 - Ligação da grade pela parte superior do tanque, comumente apresentada na literatura. Fonte: CHENG \& LAW (2001).

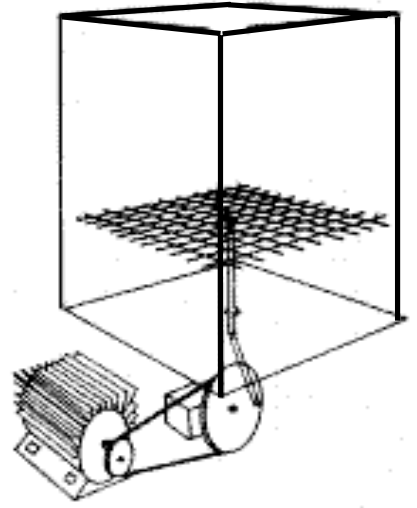

FIGURA 05 - Esquema básico de um mecanismo (sistema) de oscilação com haste inferior movimentando a grade.

O novo conceito para a construção do tanque de grade oscilante do presente trabalho, com novo sistema de oscilação, começou a ser concretizado com seu projeto em AutoCad3D. Quando da apresentação do projeto à Oficina Mecânica da Escola de Engenharia de São Carlos - USP, onde o equipamento seria construído, avaliou-se a viabilidade de sua execução e fez-se previsão do seu funcionamento e possíveis problemas que poderiam ocorrer. $\mathrm{O}$ projeto aos poucos tomou forma definitiva, após várias modificações e melhorias. Uma visão geral do desenho do equipamento em sua versão final 
é apresentada na FIGURA 06. Os detalhes do equipamento serão ilustrados e comentados separadamente.

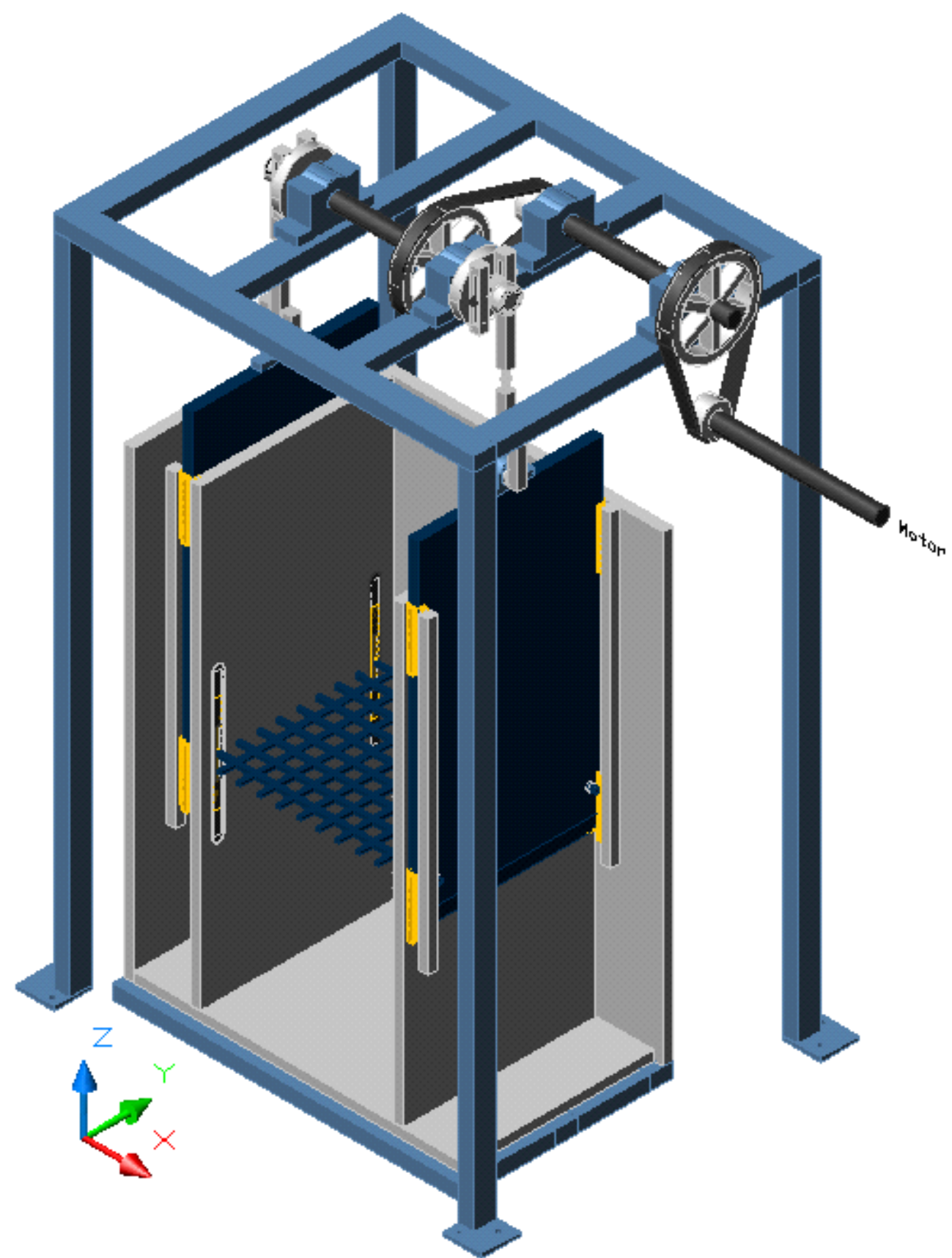

FIGURA 06 - Vista geral do tanque em seu desenho de projeto, em AutoCad. Duas placas de acrílico externas foram removidas, para visualização da grade no interior do tanque. 


\subsubsection{Tanque em acrílico}

Construiu-se um tanque com paredes em acrílico para permitir visualização de seu volume de controle e utilização do equipamento laser para medições de velocidade turbulenta com técnica DPIV. Sua área superficial de $0,5 \mathrm{~m}$ x $0,5 \mathrm{~m}$ é a mesma encontrada em BRUMLEY \& JIRKA (1987), HIBBS \& GULLIVER (1999) e CHENG \& LAW (2001), e próxima à dos trabalhos de DE SILVA \& FERNANDO (1994), KIT et al. (1997) e BARRY et al. (2001). Sua altura de 1,15 m (interna), superior à dos tanques pesquisados, possibilita boa variação da altura de água e estudo de sua influência sobre a turbulência gerada. Ainda não existe padronização desse equipamento.

Para que houvesse boa rigidez do tanque e ele não vibrasse sob o efeito da turbulência gerada, suas paredes foram montadas com placas de acrílico de $2,5 \mathrm{~cm}$ de espessura, parafusadas e coladas com silicone para se evitar vazamentos (FIGURA 07). Para alojar a ligação entre a grade e o sistema de oscilação, foram projetados compartimentos laterais ao tanque (dois 'tanques' menores).

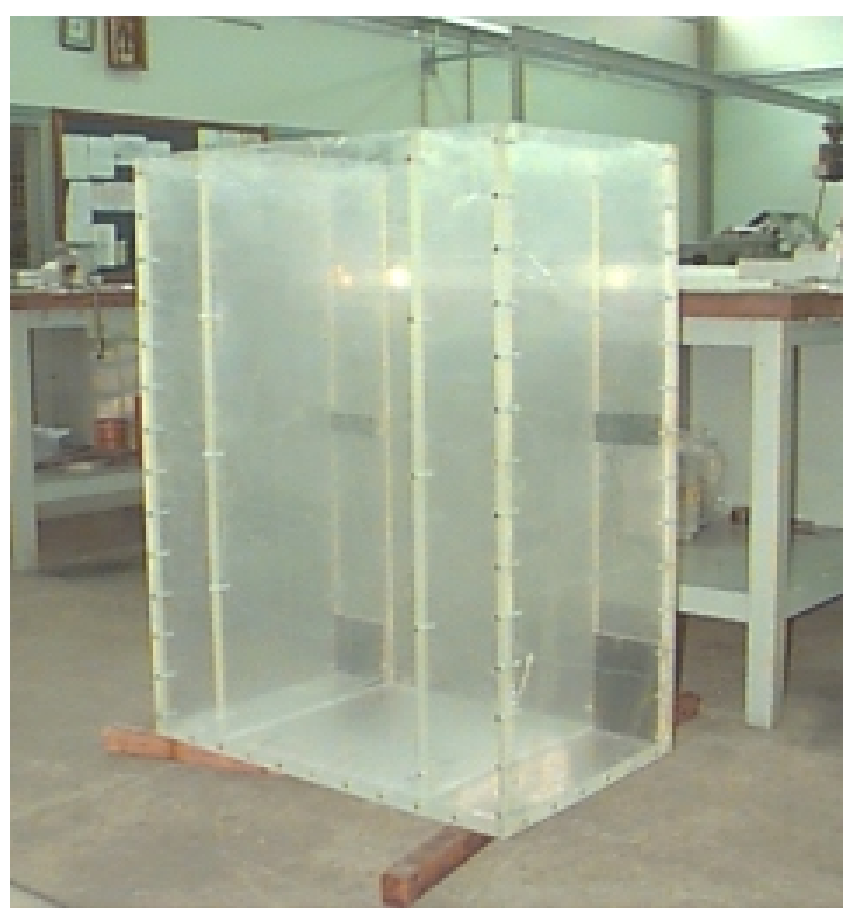

FIGURA 07 - Tanque em acrílico, parafusado e vedado com silicone. 


\subsubsection{Grade}

Para agitação do fluido e geração do movimento turbulento foi construída uma grade em aço inoxidável, com espaçamento entre os eixos das barras (Mesh) de $5,1 \mathrm{~cm}$ e área sólida, chamada solidez da grade, de $32 \%$ em relação à área superficial do tanque. As barras utilizadas neste trabalho tiveram as mesmas dimensões das barras dos trabalhos de THOMPSON \& TURNER (1975), HOPFINGER \& TOLY (1976), McDOUGAL (1979), NOKES (1988), SRDIC et al. (1996), VOROPAYEV \& FERNANDO (1996) e CHENG \& LAW (2001). O espaçamento entre elas foi determinado de forma a se obter solidez inferior a 40\% para a grade, necessária à geração da turbulência quase-isotrópica, sem escoamento no tanque (HOPFINGER \& TOLY, 1976 apud DE SILVA \& FERNANDO, 1994). Para que todas as barras ocupassem um mesmo plano horizontal, foram feitos cortes na forma de 'dentes', para formação e soldagem da grade (FIGURA 08). Projeto e montagem estão mostrados nas FIGURAS 09 e 10, respectivamente.

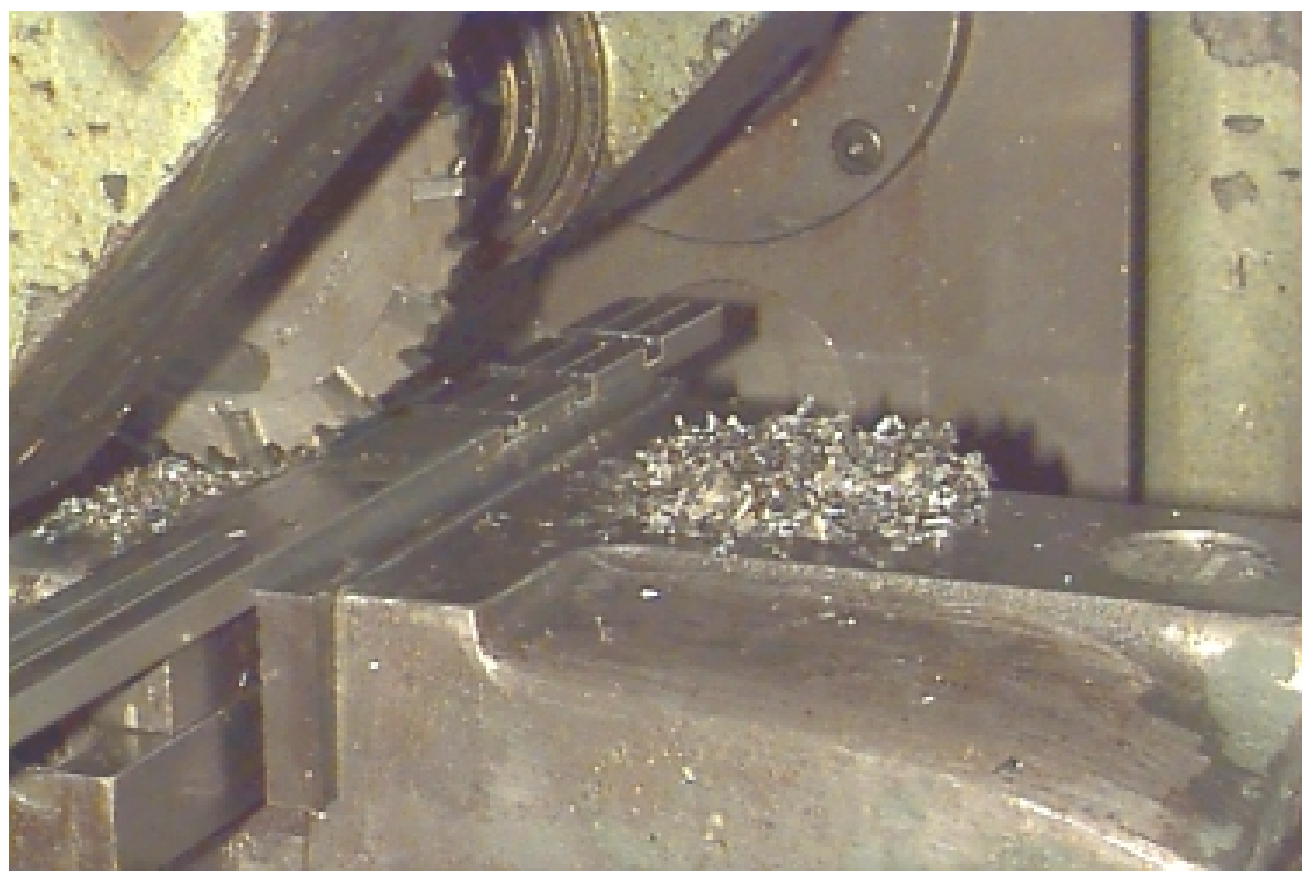

FIGURA 08 - Cortes nas barras para montagem da grade. 


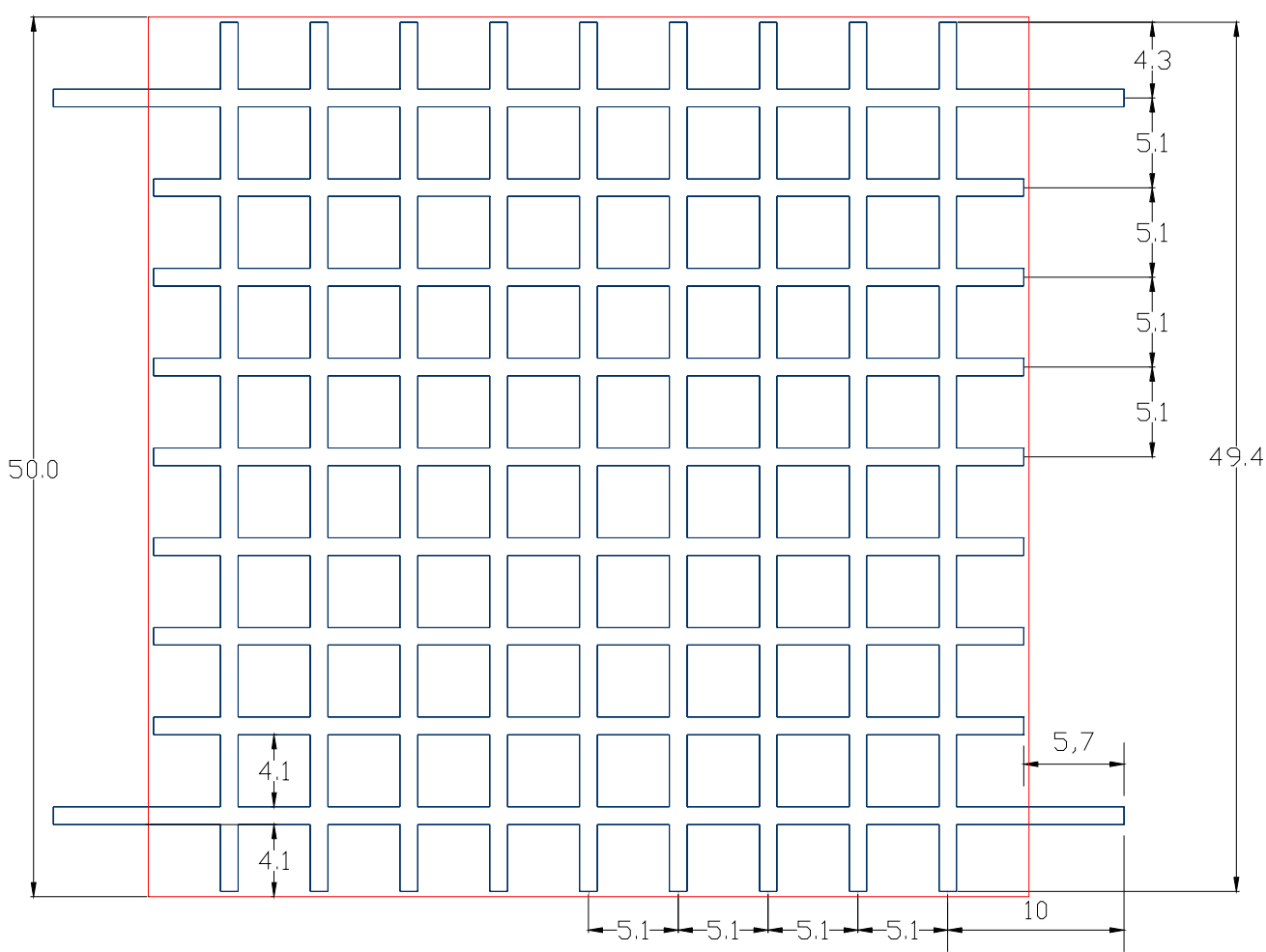

FIGURA 09 - Projeto da grade. Barras de comprimento 49,4 cm no interior do tanque (em vermelho) de $50 \mathrm{~cm} \times 50 \mathrm{~cm}$.

Nota-se, no projeto, que a abertura de 4,1 cm entre as barras é igual à distância existente entre as barras das extremidades e as paredes. Este dimensionamento foi baseado na idéia de se usar as paredes como se fossem outras barras. Essa idéia não segue a afirmação de E \& HOPFINGER (1986) apud BRUMLEY \& JIRKA (1987), que as paredes devem formar planos de simetria, com abertura entre as barras das extremidades e as paredes igual à metade da abertura entre duas barras paralelas. Para se evitar influências negativas das pontas das barras (CHENG \& LAW, 2001), sua distância às paredes do tanque foi mantida entre 0,2 e $0,3 \mathrm{~cm}$, variação explicada pela não-uniformidade da espessura das placas de acrílico.

A grade foi instalada no interior do tanque a uma distância de $55 \mathrm{~cm}$ do fundo, para que, experimentos de futuros trabalhos possam ser feitos com 'fundo falso' para estudos da influência dessa distância sobre a turbulência. 


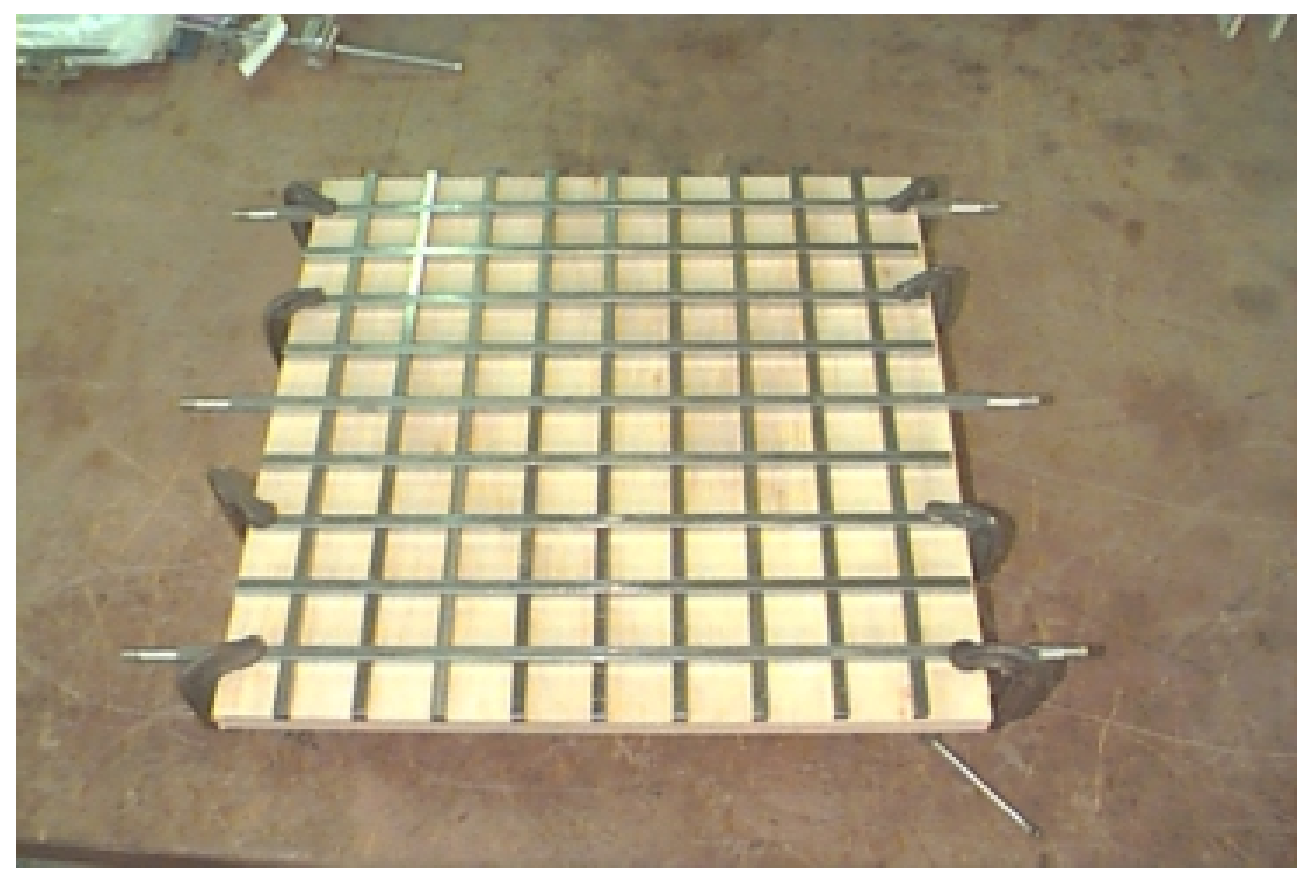

FIGURA 10 - Montagem da grade, com 9 x 9 barras de seção 1 x $1 \mathrm{~cm}$, e espaços de $5,1 \mathrm{~cm}$ (entre eixos).

\subsubsection{Mecanismo de oscilação da grade}

O estudo de novo sistema de oscilação da grade buscou evitar a colocação de qualquer parte de sua estrutura no interior do volume de controle. O objetivo foi ter apenas a grade no interior do tanque. Para isso, foram feitos recortes (fendas) em suas paredes, por onde passaram duas barras da grade, mais longas que as demais. Foi cortada uma terceira barra, central, que também atravessa a parede (FIGURA 10), pois após a primeira montagem dessa estrutura, previu-se rigidez suficiente da grade, caso durante sua movimentação, ela fosse sustentada apenas por duas barras laterais. As fendas tiveram comprimento vertical suficiente para permitir a movimentação da grade. Conectados às laterais do tanque dois compartimentos, também em acrílico, abrigaram as extremidades dessas barras e sua ligação com o sistema de oscilação. As barras foram encaixadas e presas às duas 'placas oscilantes' em acrílico. Essas placas, que tiveram sua parte inferior chanfrada para menor impacto com a água, ligaram o sistema de oscilação à grade, no interior dos compartimentos. Seu 
movimento foi guiado por tiras de teflon, parafusadas a elas e às paredes fixas do tanque. Sua montagem está ilustrada nas FIGURAS 11 e 12.

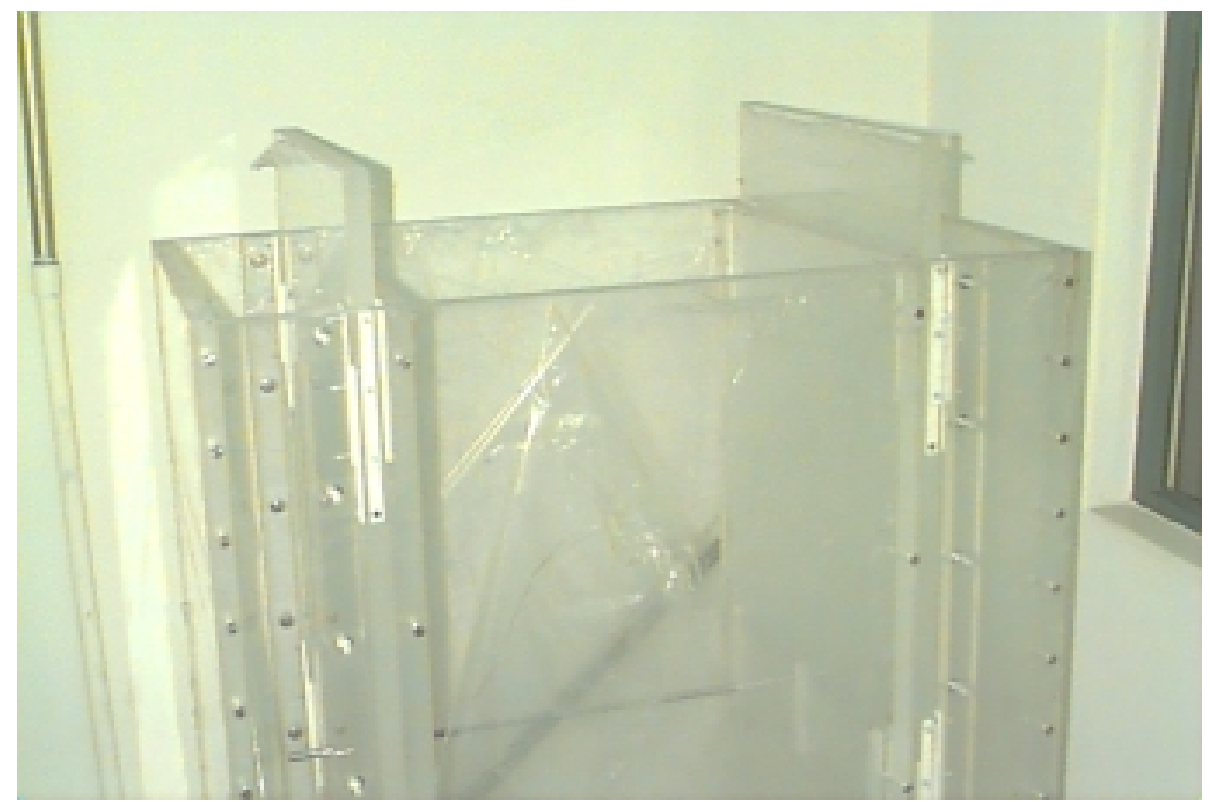

FIGURA 11 - Placas oscilantes (em acrílico) montadas no interior dos compartimentos. Os detalhes em cor branca são tiras de teflon que guiaram as placas em seu movimento vertical.

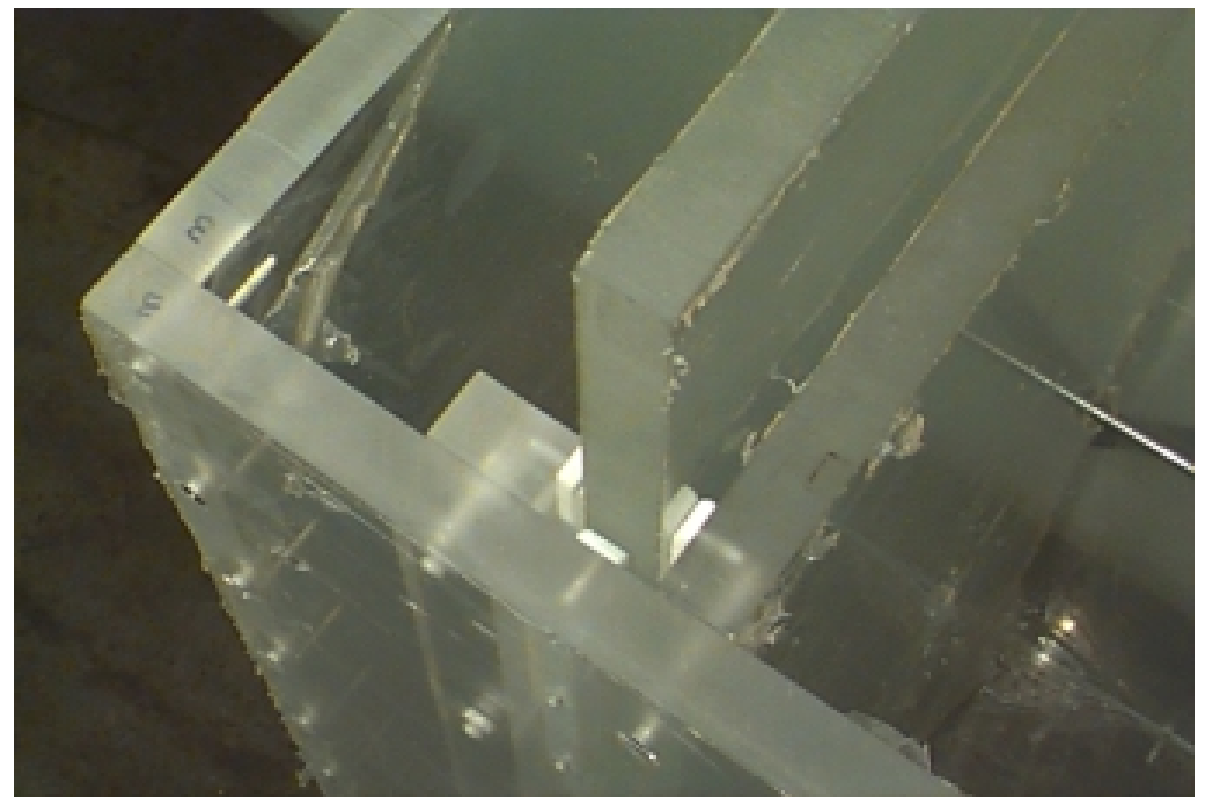

FIGURA 12 - Vista superior da instalação de uma placa oscilante em um compartimento.

Uma régua em acrílico, parafusada ao tanque, ajudava o direcionamento do movimento da placa. 
Pode-se observar na FIGURA 06 que o projeto de uma estrutura exterior ao tanque, responsável pela movimentação da grade e das placas, foi composta por um motor e um conjunto de rolamentos, mancais, eixos, polias e correias, detalhados a seguir:

Sistema biela-manivela: este mecanismo possibilitou a variação da amplitude de oscilação da grade. O movimento vertical permitido à grade, por este sistema, tem variação de velocidade senoidal, comum nos tanques da maioria dos trabalhos pesquisados. Para se ter uma biela de comprimento regulável, foram adaptadas duas barras de direção de automóvel. Este sistema foi projetado para se obter amplitudes de oscilação da grade entre zero e $10 \mathrm{~cm}$, variação essa determinada pela excentricidade da biela em relação ao eixo de rotação. O projeto deste sistema está ilustrado na FIGURA 13, sem as cotas, para sua simplificação.

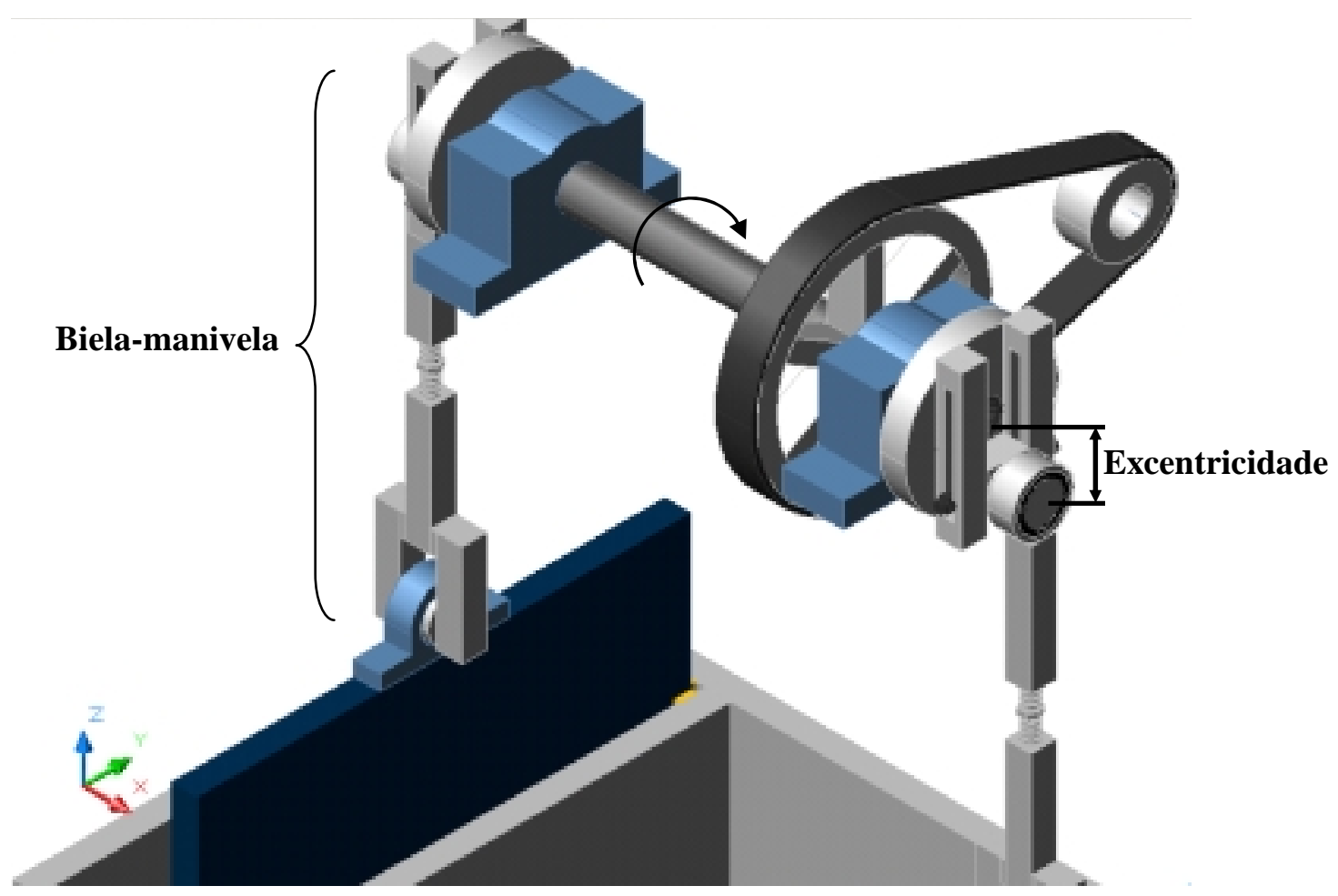

FIGURA 13 - Projeto do sistema biela-manivela, para movimentação vertical das placas oscilantes. 
Motor e conjunto de redução: um motor elétrico de $4 \mathrm{hp}$ e corrente contínua (FIGURA 14) tinha sua rotação variada, manualmente, através de um painel de controle (FIGURA 15). Através de um conjunto redutor, na razão 5:1, sua rotação máxima de 1700 rpm foi transferida à grade como $340 \mathrm{rpm}$, suficiente para a maior rotação utilizada nos experimentos (240 rpm). Essa redução, ilustrada na FIGURA 16, foi necessária para evitarse superaquecimento do motor quando utilizado em baixas rotações.

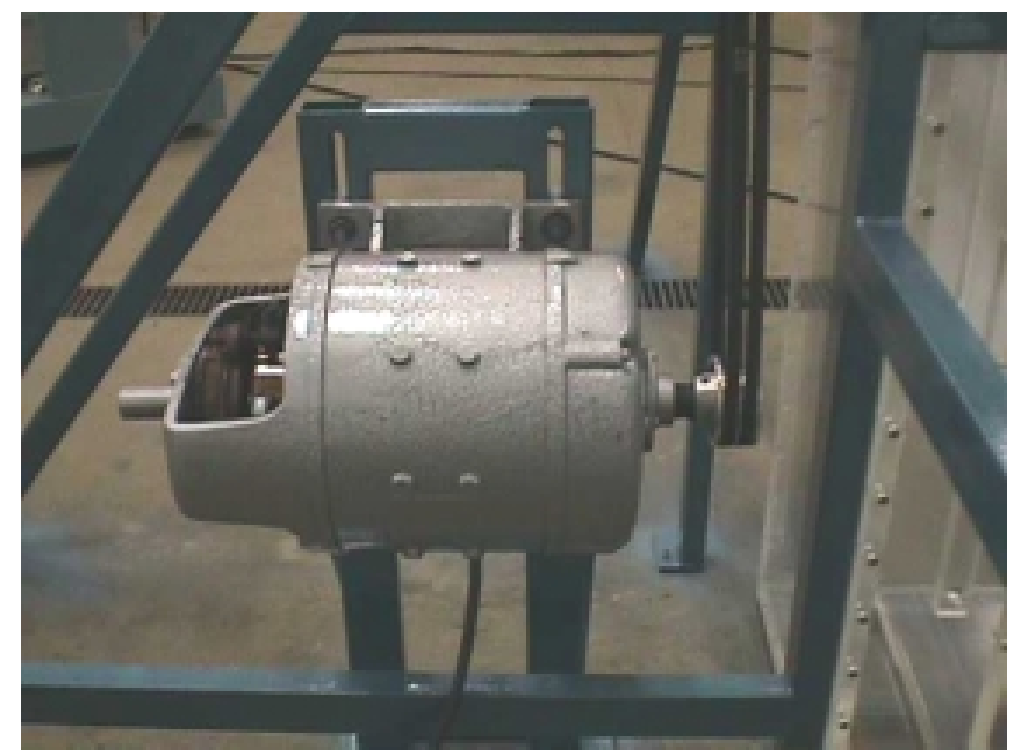

FIGURA 14 - Motor elétrico de 4 hp.

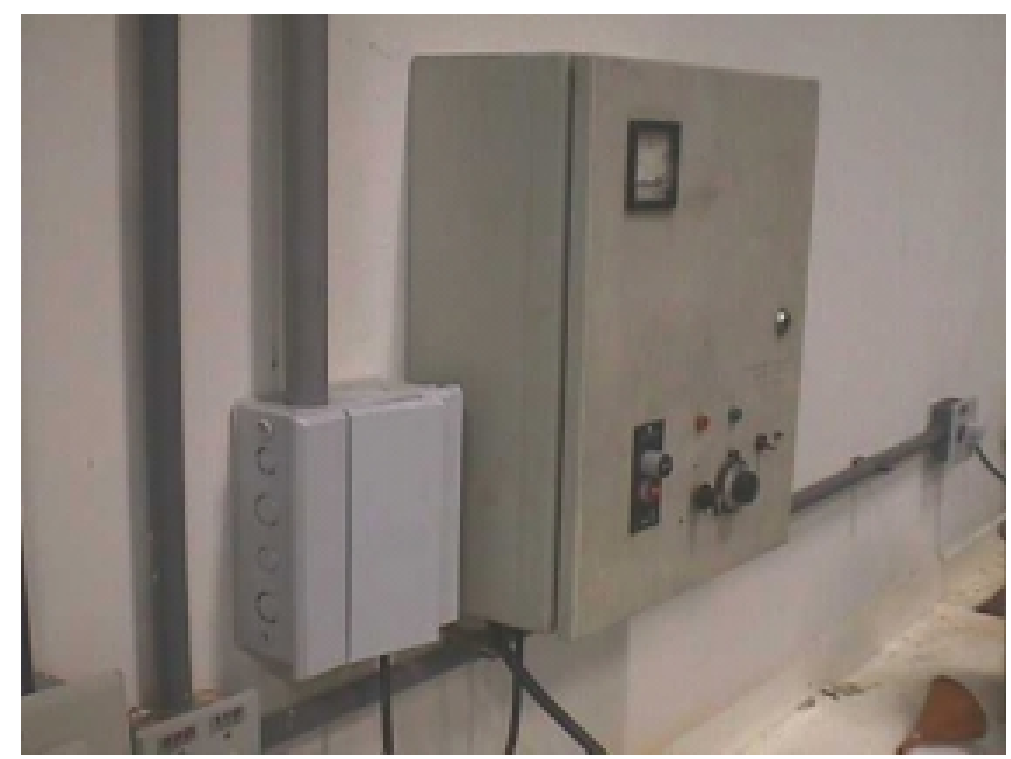

FIGURA 15 - Painel de controle de rotação do motor. 


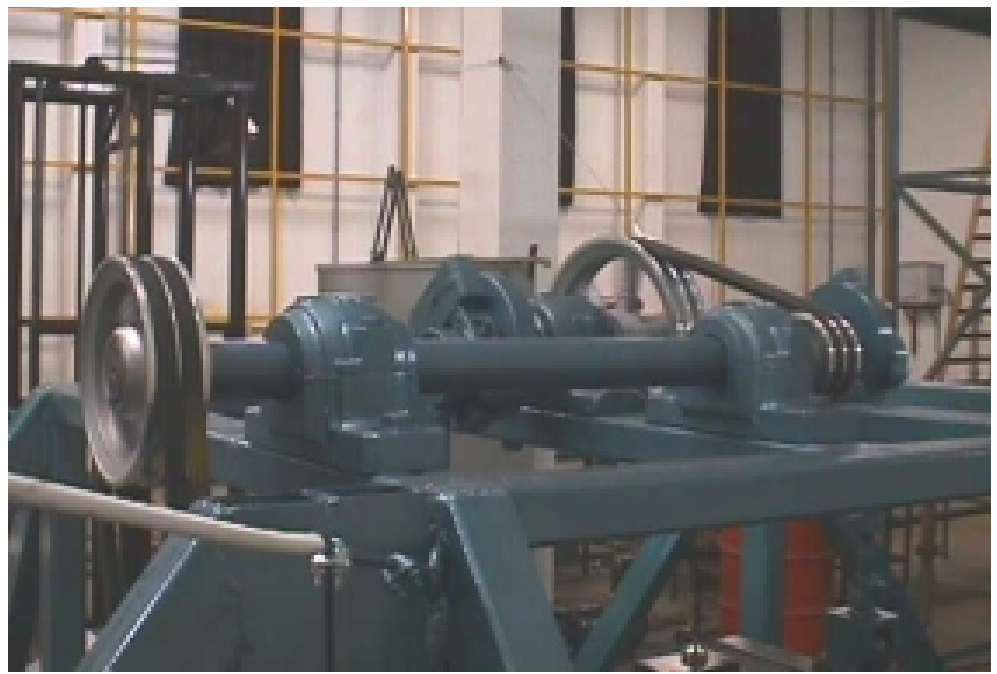

FIGURA 16 - Conjunto de redução em funcionamento.

\subsubsection{Vedação entre tanque e compartimentos}

A água dos compartimentos foi isolada do interior do tanque através de uma vedação com teflon (FIGURA 17), para que, durante os experimentos, a agitação da água dos compartimentos, causada pelo sistema de oscilação em movimento, não interferisse no volume de controle. Uma tira de teflon, com $0,5 \mathrm{~cm}$ de espessura, que ocupou todo o espaço da fenda na parede do tanque, oscilava juntamente com a grade. Uma chapa de aço inoxidável, parafusada na parede de acrílico, alojou o teflon na fenda.

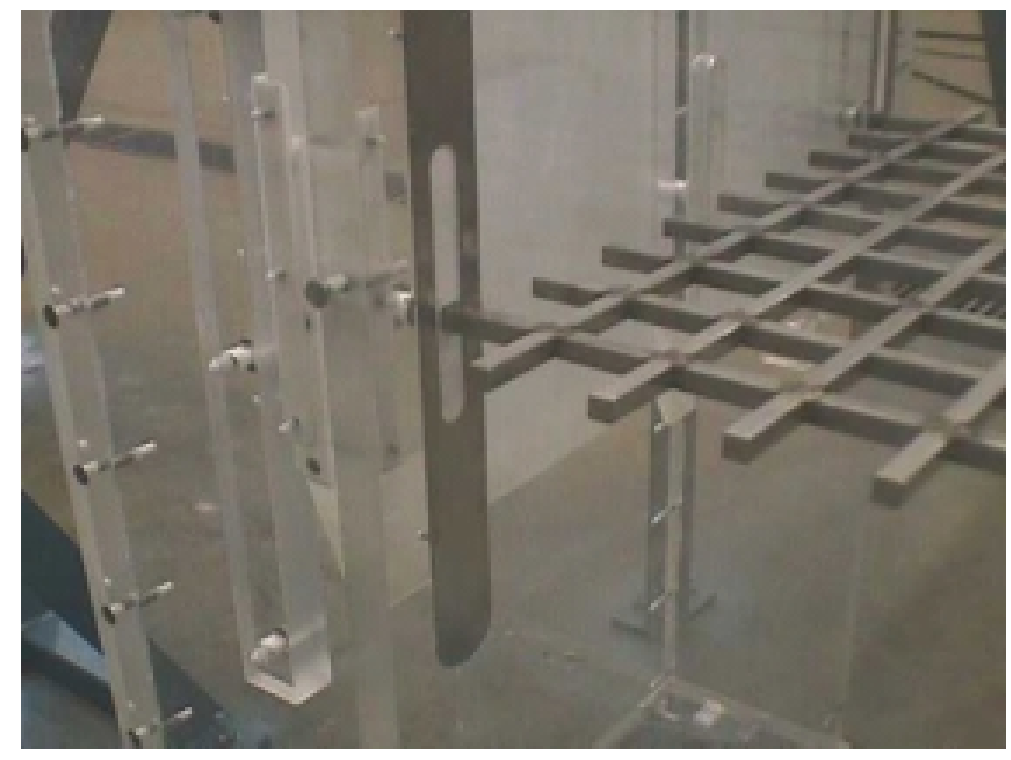

FIGURA 17 - Sistema de vedação entre os compartimentos laterais e o tanque com a grade. 
Na FIGURA 18, esse isolamento é apresentado em seu projeto, em partes separadas, para seu melhor entendimento. Observa-se que existe uma pequena fenda vertical, de $0,5 \mathrm{~cm}$ de profundidade, localizada atrás do alojamento do teflon. Sua função é permitir o fluxo vertical da água que é comprimida pela tira quando esta se movimenta para cima e para baixo. Na ausência desse compartimento, jatos de água poderiam ser direcionados para dentro do tanque e influenciar os experimentos.

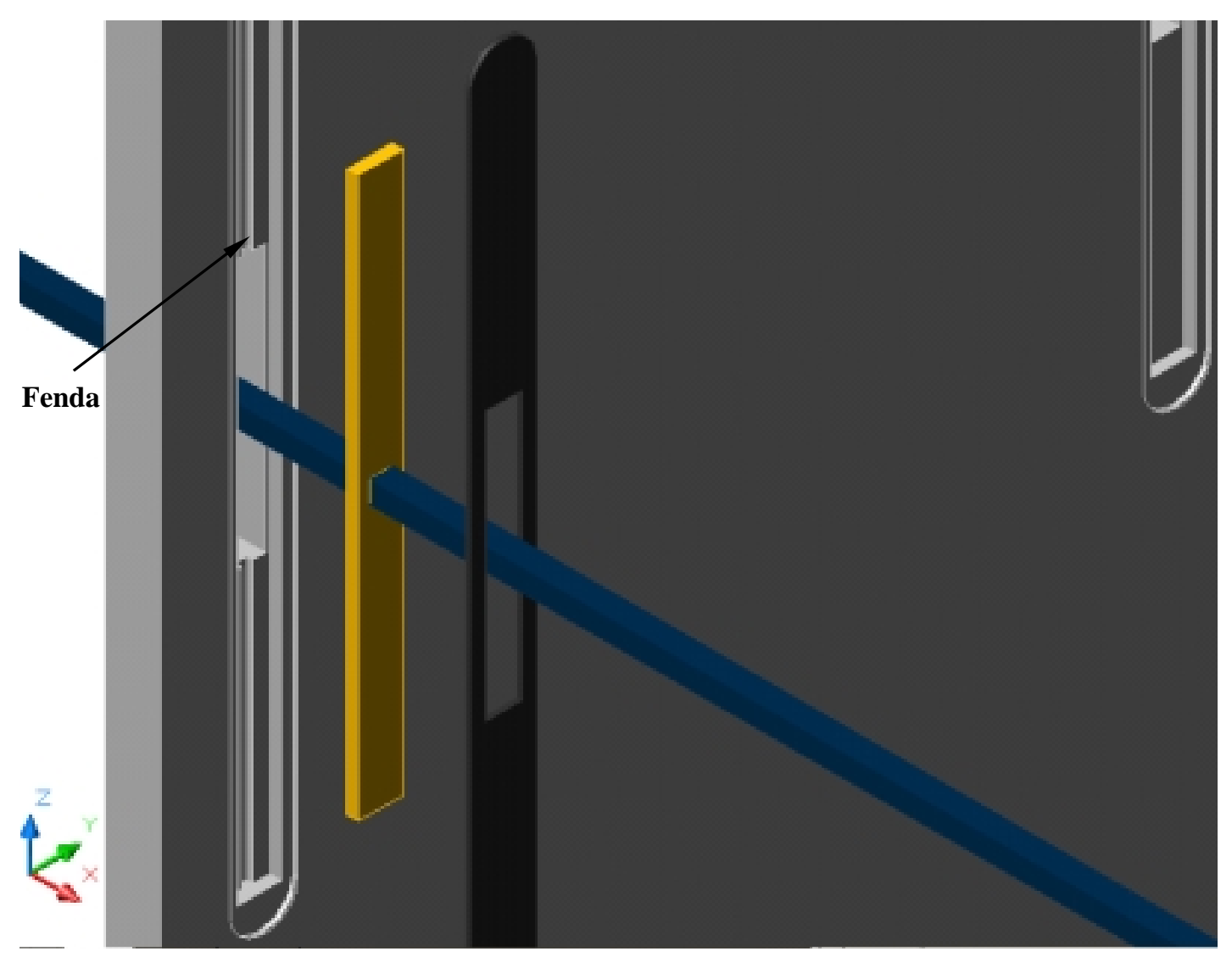

FIGURA 18 - Projeto do isolamento entre o tanque e os compartimentos laterais com a tira de teflon (em amarelo) que se move juntamente com a grade e a chapa de aço inoxidável (em cinza escuro) que a mantém rente à placa de acrílico (em cinza claro). A fenda na placa permite o fluxo da água comprimida durante o movimento do teflon. 


\subsubsection{Instalação do equipamento}

Concluída a construção do equipamento ele foi transportado para o Laboratório de Hidráulica Ambiental do Departamento de Hidráulica e Saneamento da EESC - USP, onde foi feito todo o trabalho experimental. Após pintura e fixação do equipamento, através de testes preliminares constatou-se que a estrutura que sustentava o conjunto redutor de rotação vibrava consideravelmente para frequiências de oscilação da grade superiores a $3 \mathrm{~Hz}$. Essa estrutura foi então reforçada e a influência de sua vibração nos experimentos pôde ser desprezada. O trabalho final da construção do equipamento está mostrado na FIGURA 19.

Detalhes do projeto do equipamento, completados após a fixação do tanque, devem ser comentados. Registros de esfera foram instalados nas laterais do tanque e dos compartimentos, para seu esvaziamento (FIGURA 20). O tanque de acrílico também recebeu reforço estrutural, para combate à vibração (FIGURA 21).

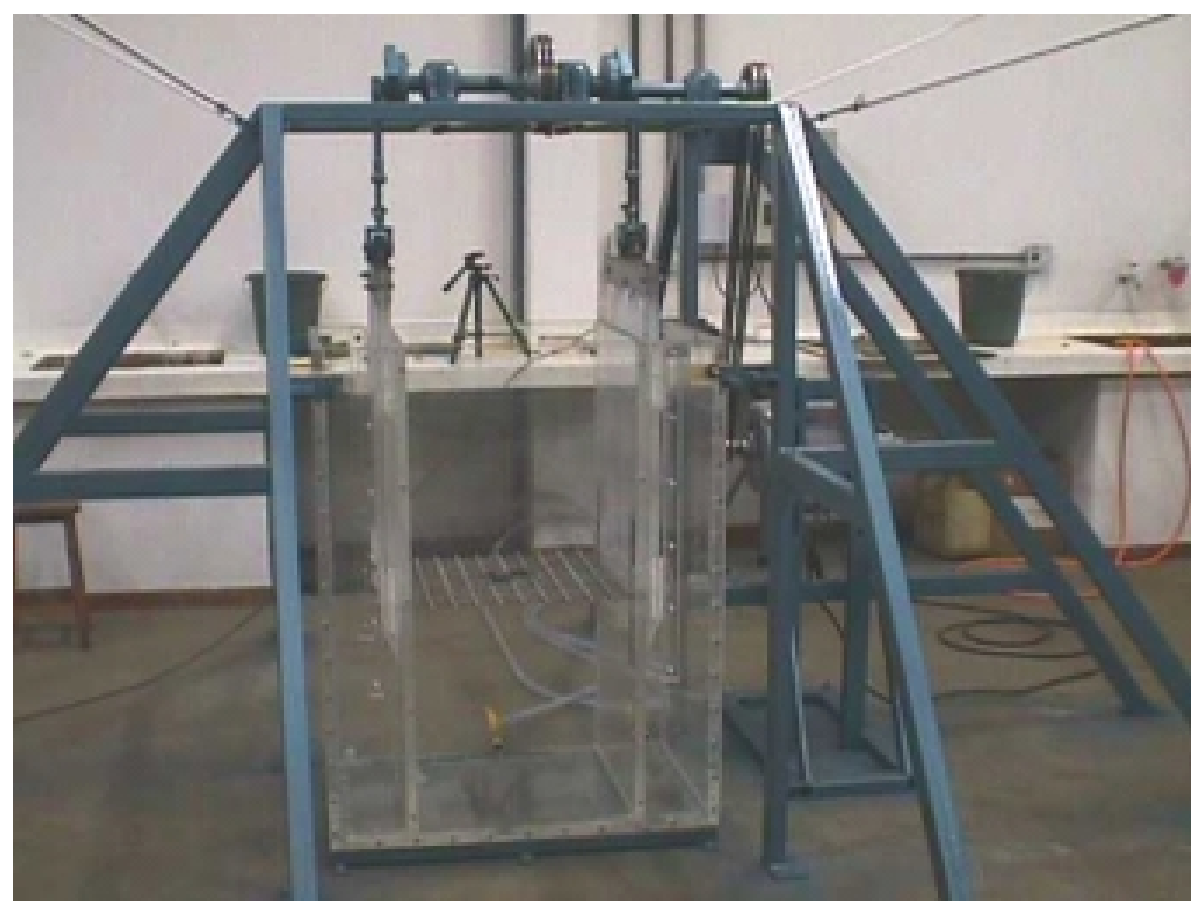

FIGURA 19 - Equipamento instalado, com a estrutura reforçada para se evitar grandes vibrações durante os experimentos com alta freqüência de oscilação da grade. 


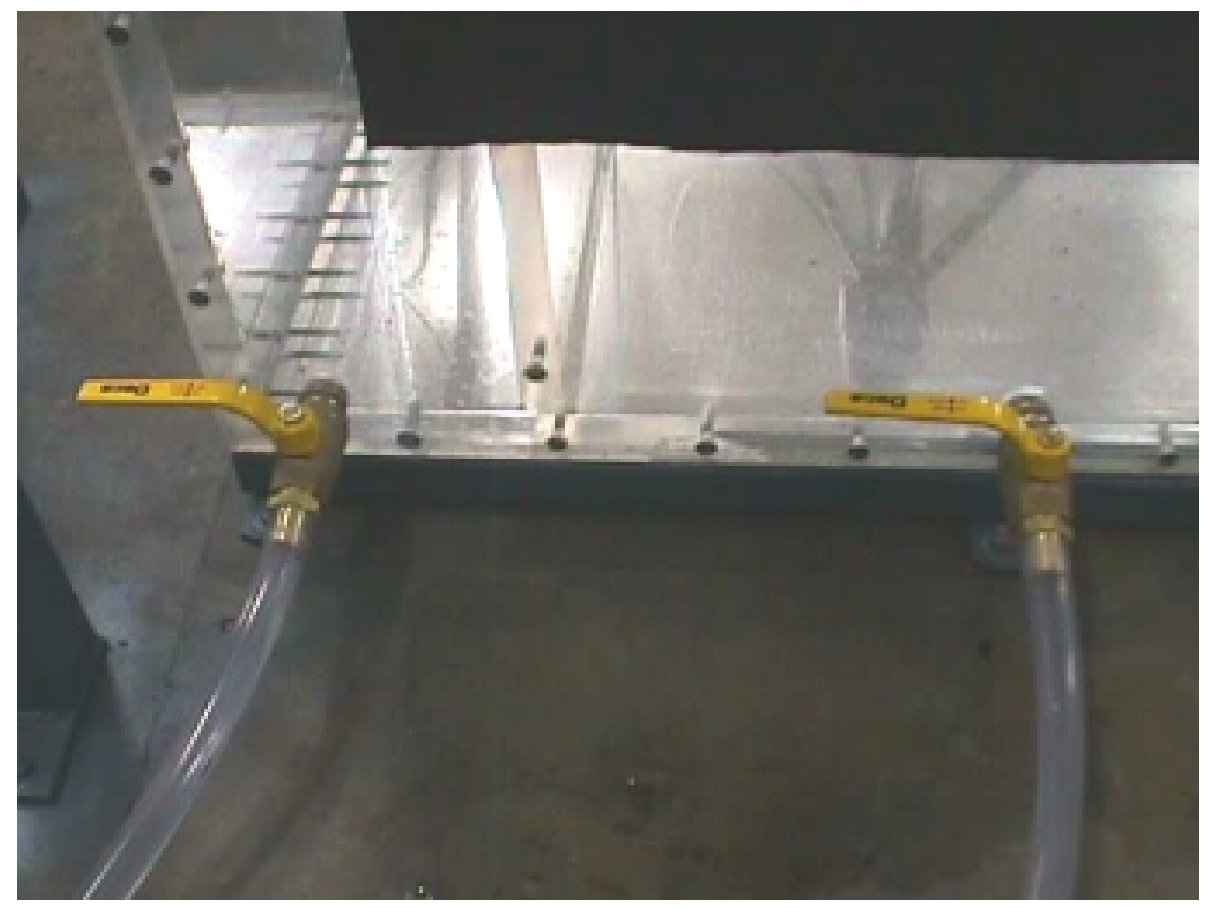

FIGURA 20 - Registros de esfera de 3/4" para esvaziamento do tanque e dos compartimentos laterais.

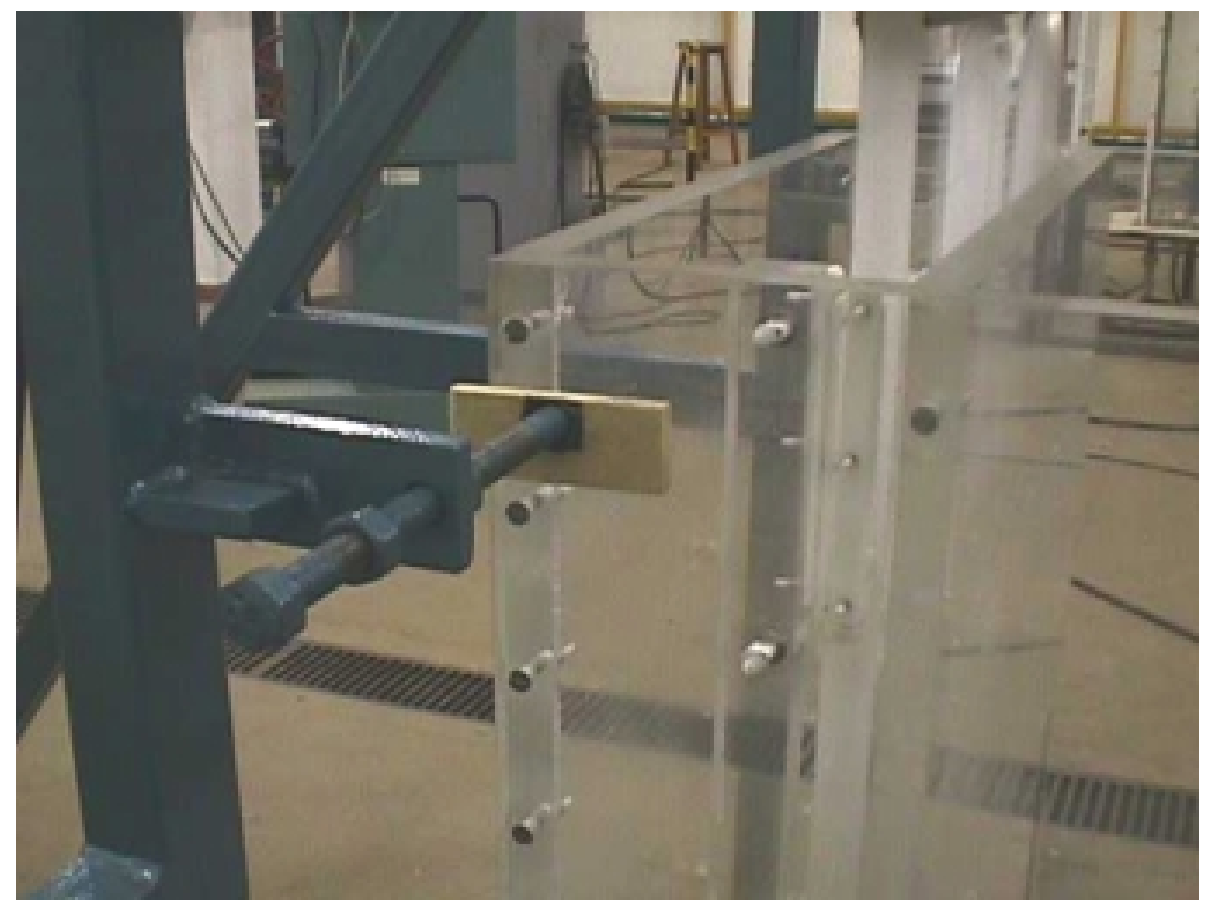

FIGURA 21 - Apoio de madeira e borracha na parte superior do tanque, para se evitar vibrações consideráveis. 


\subsubsection{Equipamento de medição de velocidade turbulenta}

Para realização dos ensaios de obtenção de campos de velocidade turbulenta no interior do tanque foram utilizados os seguintes equipamentos:

Laser Oxford, modelo LS20: laser a vapor de cobre, responsável pela produção do plano de luz, inserido no volume de água do tanque para obtenção dos campos. Esse equipamento tinha potência média de 20 Watts a $10 \mathrm{kHz}$, superior à dos lasers usados em trabalhos similares da literatura. Essa potência era suficiente para dispensar a adição de partículas traçadoras. As partículas 'naturais' da água, iluminadas pela luz do laser, já apresentavam boa visualização do movimento do fluido. Os comprimentos de onda de emissão de luz são de 510,6 nm (verde) e 578,2 nm (amarelo), com 1/3 emitido em amarelo e 2/3 em verde. O equipamento levava em média 2 horas para iniciar seu funcionamento e 1 hora para o processo de desligamento. A luz produzida é concentrada em fibra ótica e levada ao ponto de utilização (tanque), onde é convertida em folha de luz de espessura média de 0,3 cm através de um conjunto de lentes esféricas, côncavas e convexas (equipamento Fiber Sheet). O laser em funcionamento está ilustrado na FIGURA 22, e o plano de luz iluminando as partículas da água, na FIGURA 23. 


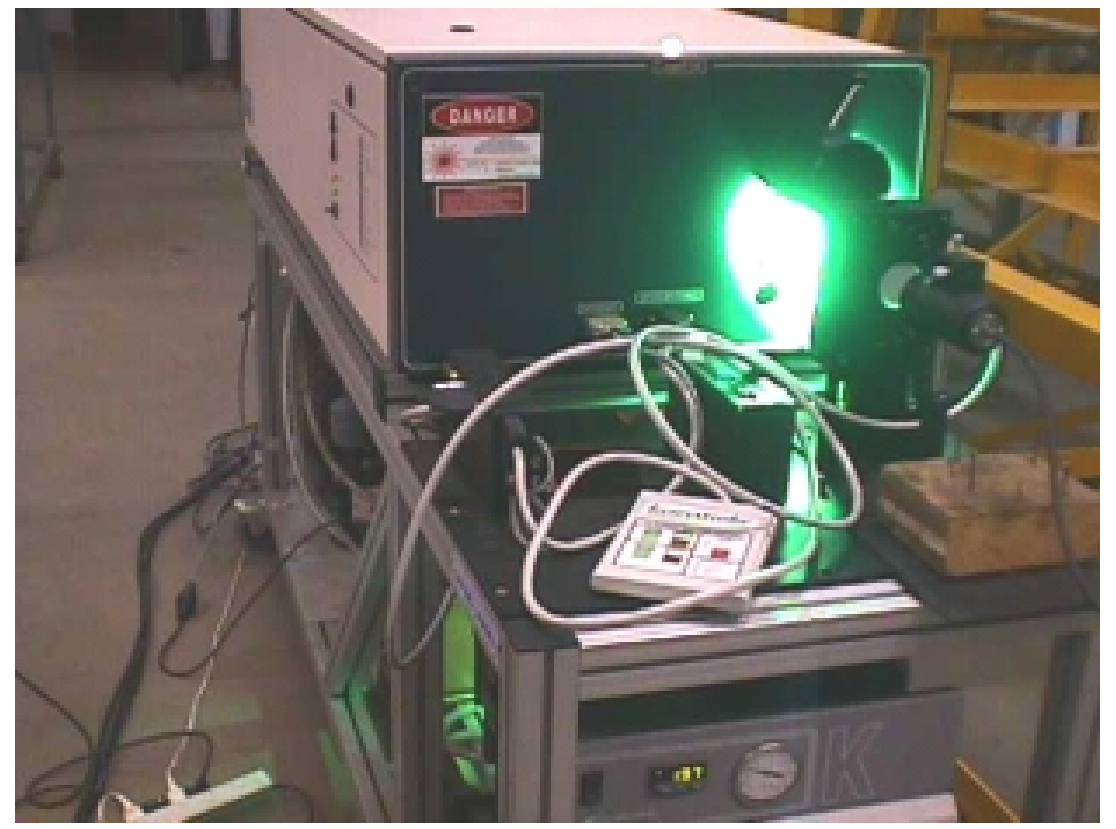

FIGURA 22 - Produção de luz pelo equipamento laser.

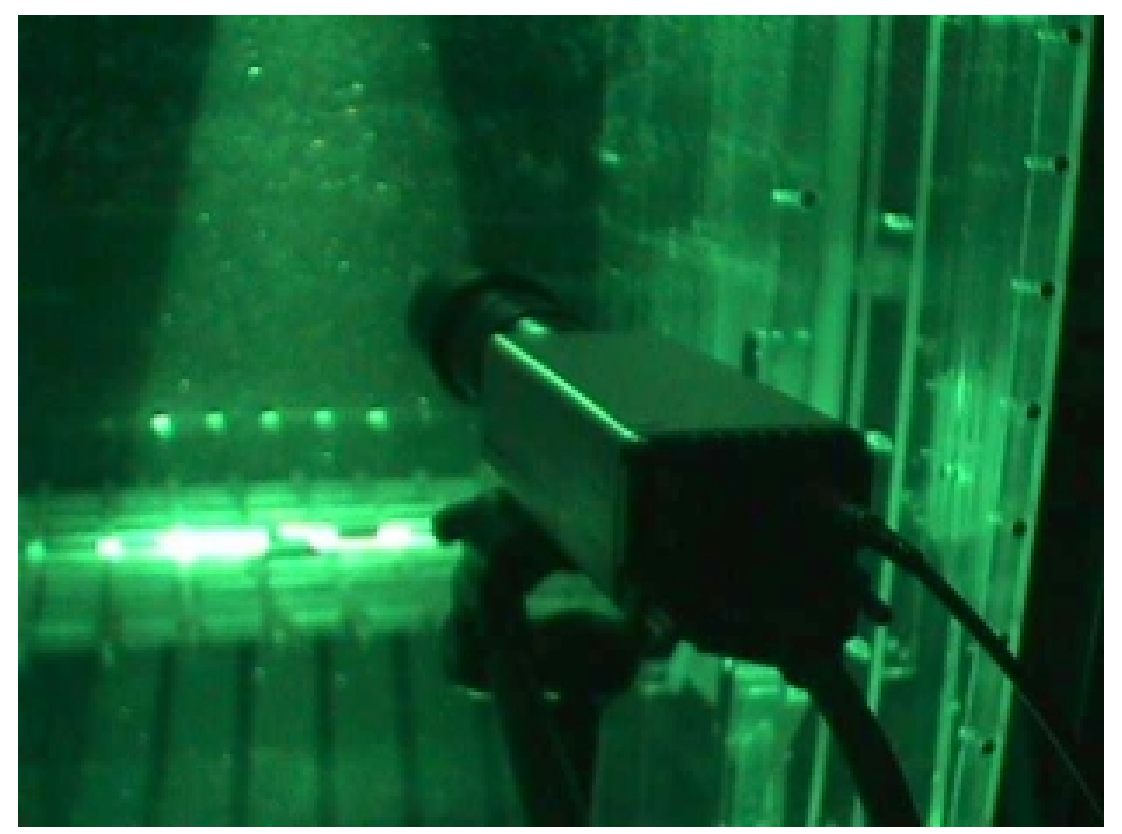

FIGURA 23 - Plano de luz iluminando as partículas no interior do tanque.

Câmera CCD Kodak Megaplus, modelo ES 1.0: esta câmera fotográfica digital captava as imagens do plano de fluido iluminado pelo laser, em escala de cinza. O controle 
de obtenção de imagens era feito via comunicação serial com um computador. Apesar de ter uma velocidade de captação de imagens de 30 exposições (fotos) por segundo, a memória desta câmera permitia uma armazenagem de apenas 16, o que comprometeu a metodologia experimental empregada. A FIGURA 24 mostra a câmera instalada perpendicularmente ao plano de luz do laser, imerso na água.

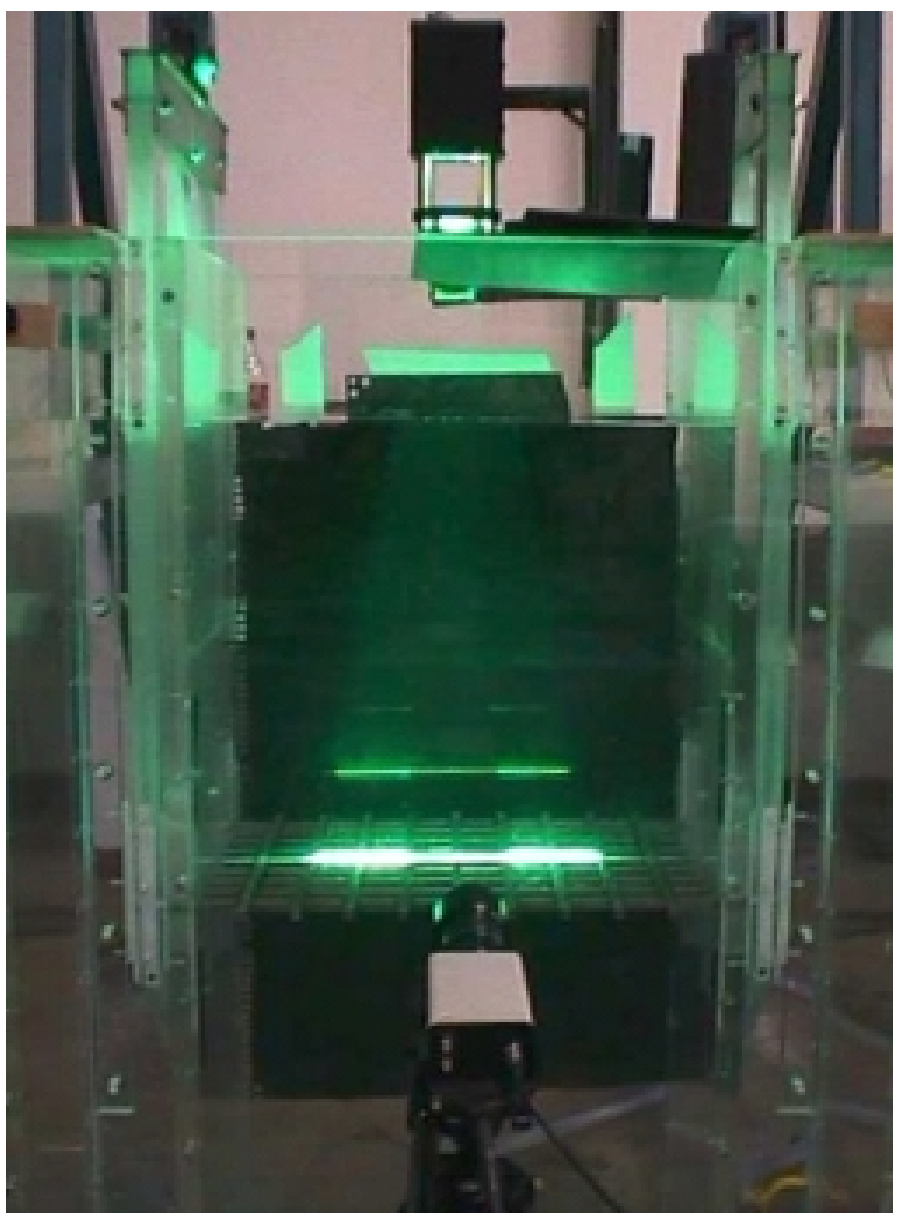

FIGURA 24 - Câmera instalada próxima a uma lateral do tanque, perpendicularmente ao plano de luz, para obtenção das imagens do movimento do fluido.

Após a instalação da câmera, fazia-se a focalização do plano de luz através do ajuste de seu conjunto de lentes. A calibração deste equipamento foi feita com régua de $10 \mathrm{~cm}$, colocada no interior do tanque, na região de obtenção dos campos de velocidade (FIGURA 
25). Com a imagem ao vivo na tela do microcomputador, visualizava-se 0 s $10 \mathrm{~cm}$ na régua e calibrava-se a câmera.

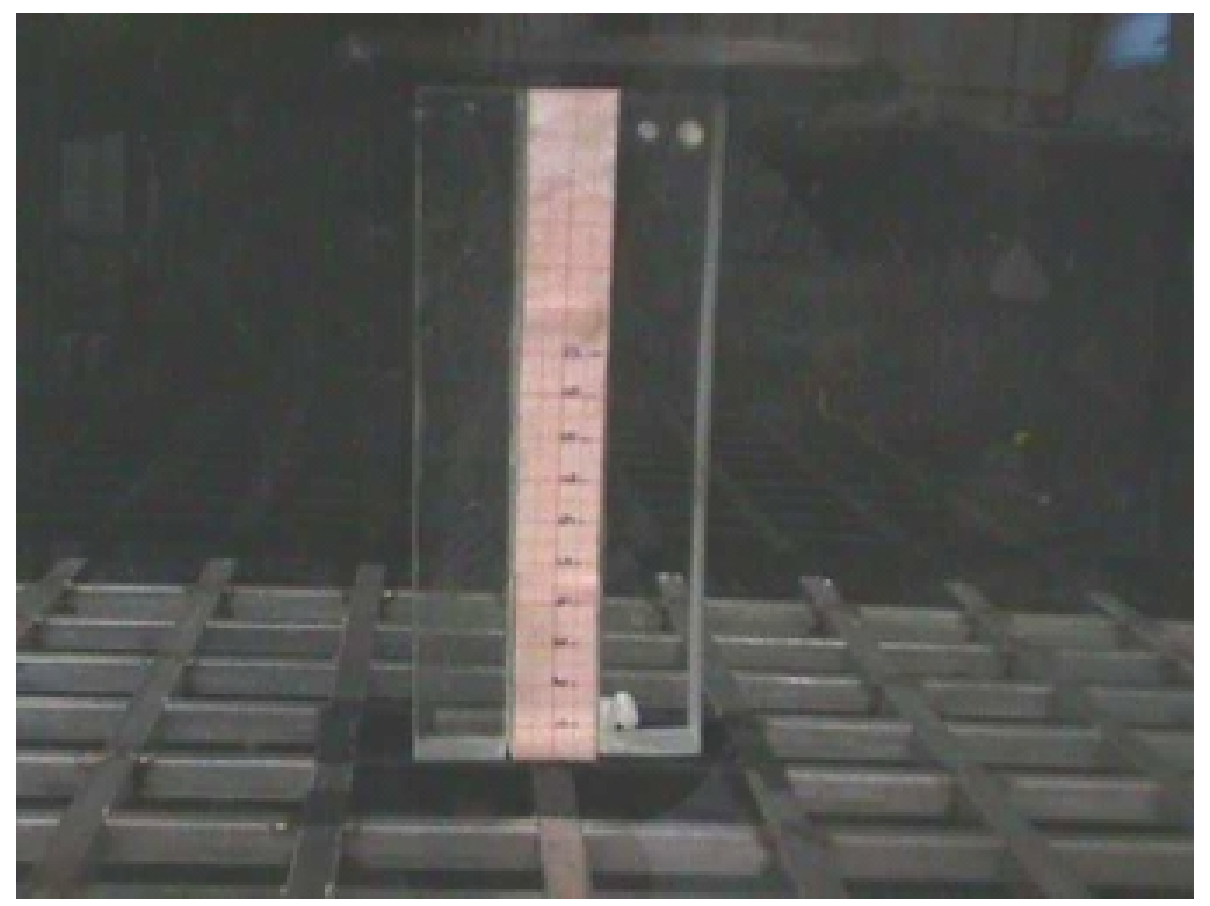

FIGURA 25 - Calibração da câmera feita com régua graduada.

Sistema computacional: as fotos capturadas pela câmera eram armazenadas em sua memória e enviadas para o disco rígido do microcomputador com processador Pentium 200 MHz. Este procedimento era gerenciado pela versão atualizada 6.14 do software Visiflow, da AEA Technology, adquirido para este trabalho de Mestrado. O programa Visiflow, através de técnica DPIV, fazia o tratamento das imagens, para obtenção dos campos de velocidade. O sistema computacional, conectado à câmera fotográfica durante um experimento, é mostrado na FIGURA 26. 


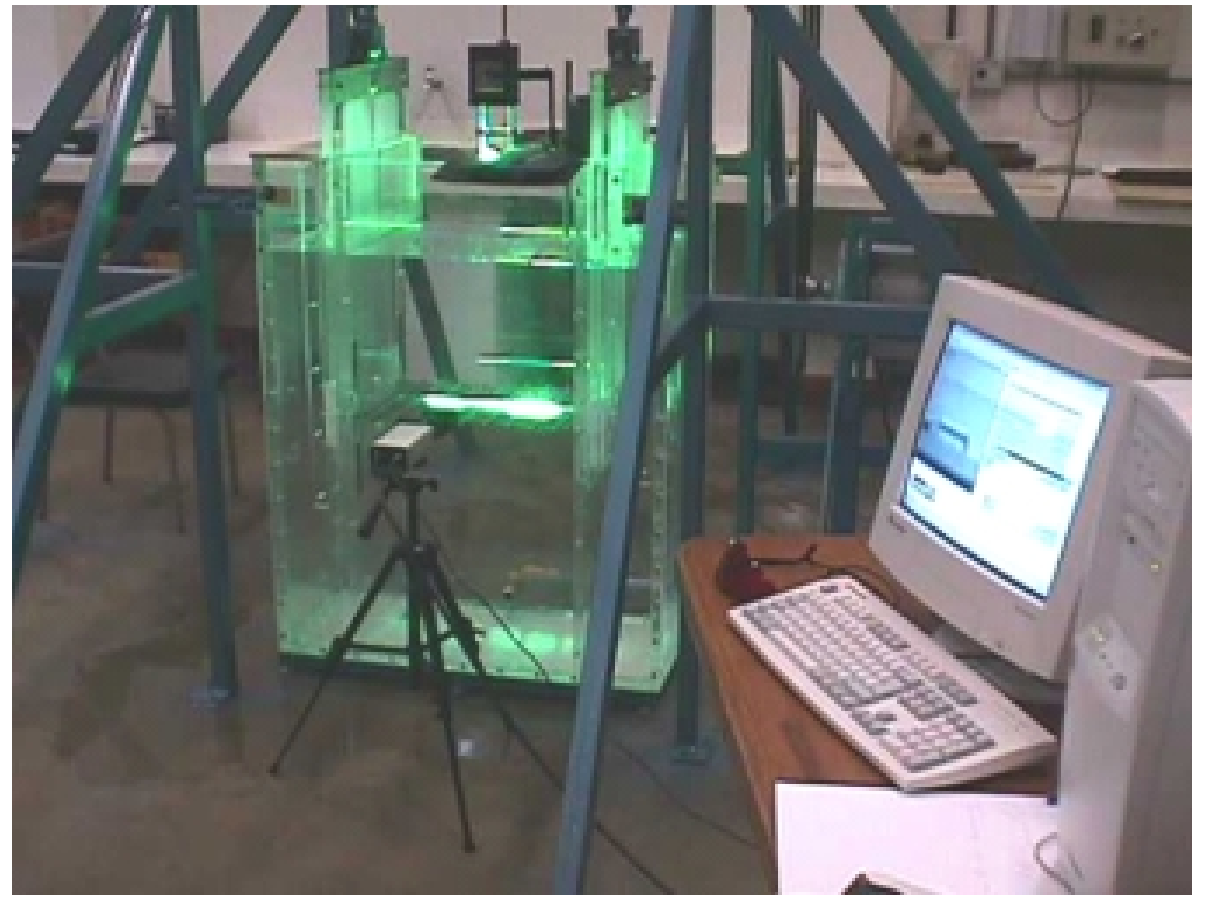

FIGURA 26 - Realização de um experimento, com a câmera conectada ao microcomputador com o programa Visiflow.

Tacômetro digital: o tacômetro era usado para regulagem da freqüência de oscilação da grade em cada experimento, com precisão de 0,1:1000 para rotações inferiores a 1000 rpm. Este equipamento também foi adquirido para este trabalho (Figura 27).

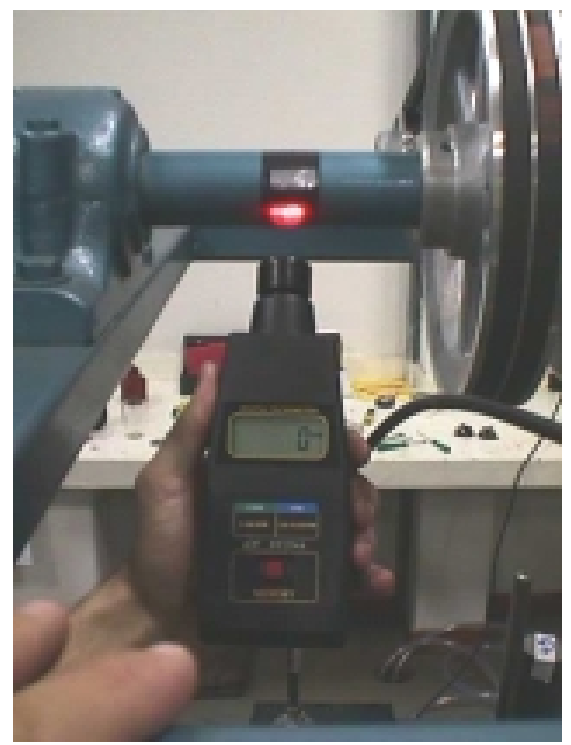

FIGURA 27 - Tacômetro digital em uso para medição da rotação do eixo que movimenta a grade 


\subsection{Metodologia experimental}

O procedimento experimental constituiu-se das seguintes etapas:

- localização das regiões de estudo no tanque;

- definição de freqüência e amplitude de oscilação da grade;

- obtenção dos campos de velocidade turbulenta;

- cálculo das tensões médias de Reynolds;

- caracterização da turbulência gerada.

\subsubsection{Localização das regiões de estudo no tanque}

Um dos objetivos deste trabalho foi obter campos de velocidade turbulenta em uma região do tanque. Porém, não era intenção desta pesquisa fazer análise de movimentos secundários que pudessem ter sido gerados pela influência das paredes laterais ou do fundo do tanque. Desta forma, foi escolhida para estudo, a região central do tanque, acima da grade.

Dois planos verticais e paralelos, cada um com $10 \mathrm{~cm}$ de base e $30 \mathrm{~cm}$ de altura, compreendiam as duas regiões a serem estudadas. O primeiro plano, chamado Plano 1, foi localizado sobre uma barra da grade. O segundo, denominado Plano 2, tinha sua base situada entre duas barras da grade. Como as fotos obtidas com a câmera correspondiam a imagens de $10 \mathrm{~cm}$ x $10 \mathrm{~cm}$ (dimensionamento determinado para se ter boa resolução das imagens), $\mathrm{o}$ Plano 1 foi dividido em três posições: Pos 1, Pos 2 e Pos 3, como ilustrado na FIGURA 28. Da mesma forma, o Plano 2 foi dividido em Pos 4, Pos 5 e Pos 6 (FIGURA 29). 


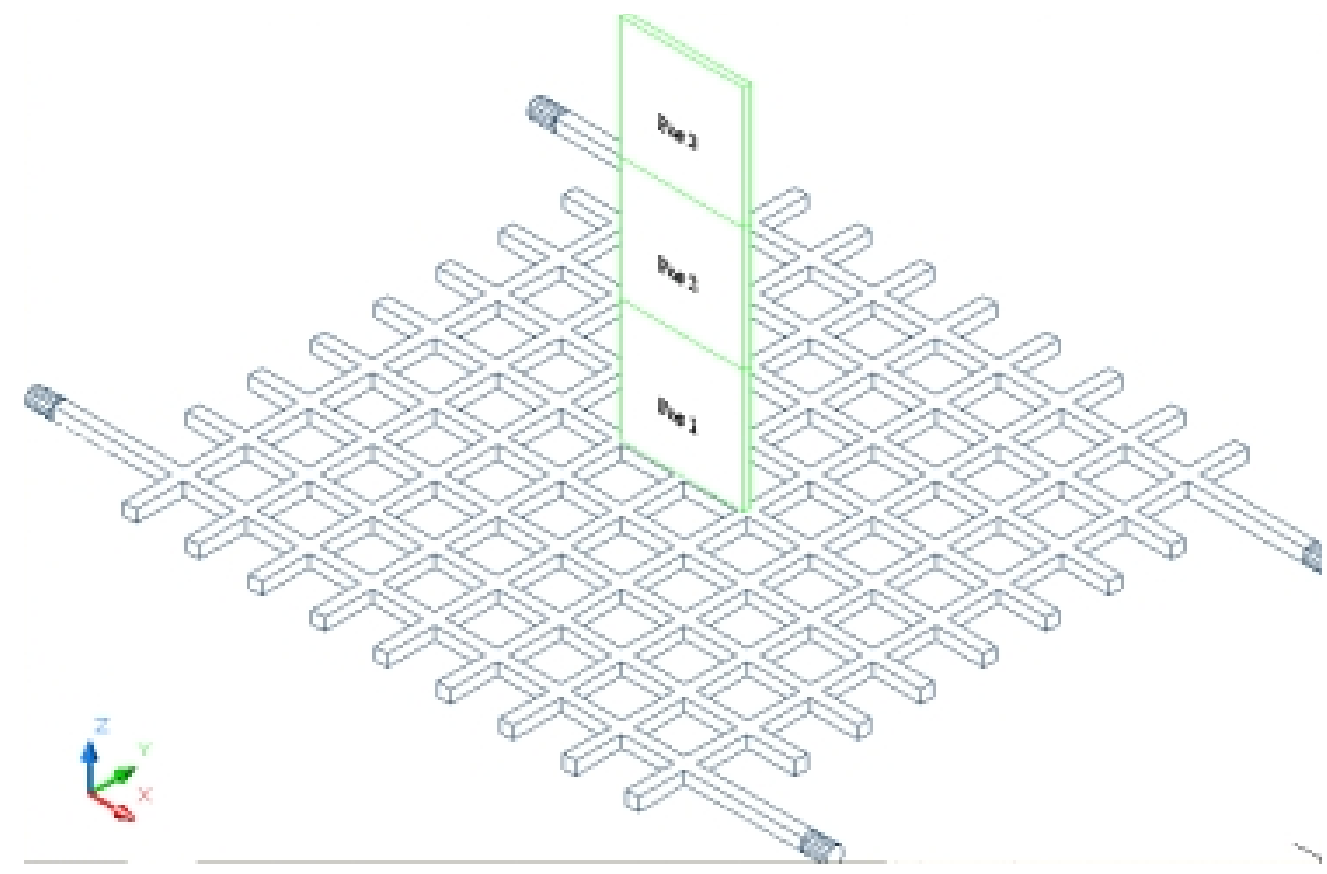

FIGURA 28 - Plano 1: região sobre a barra central da grade.

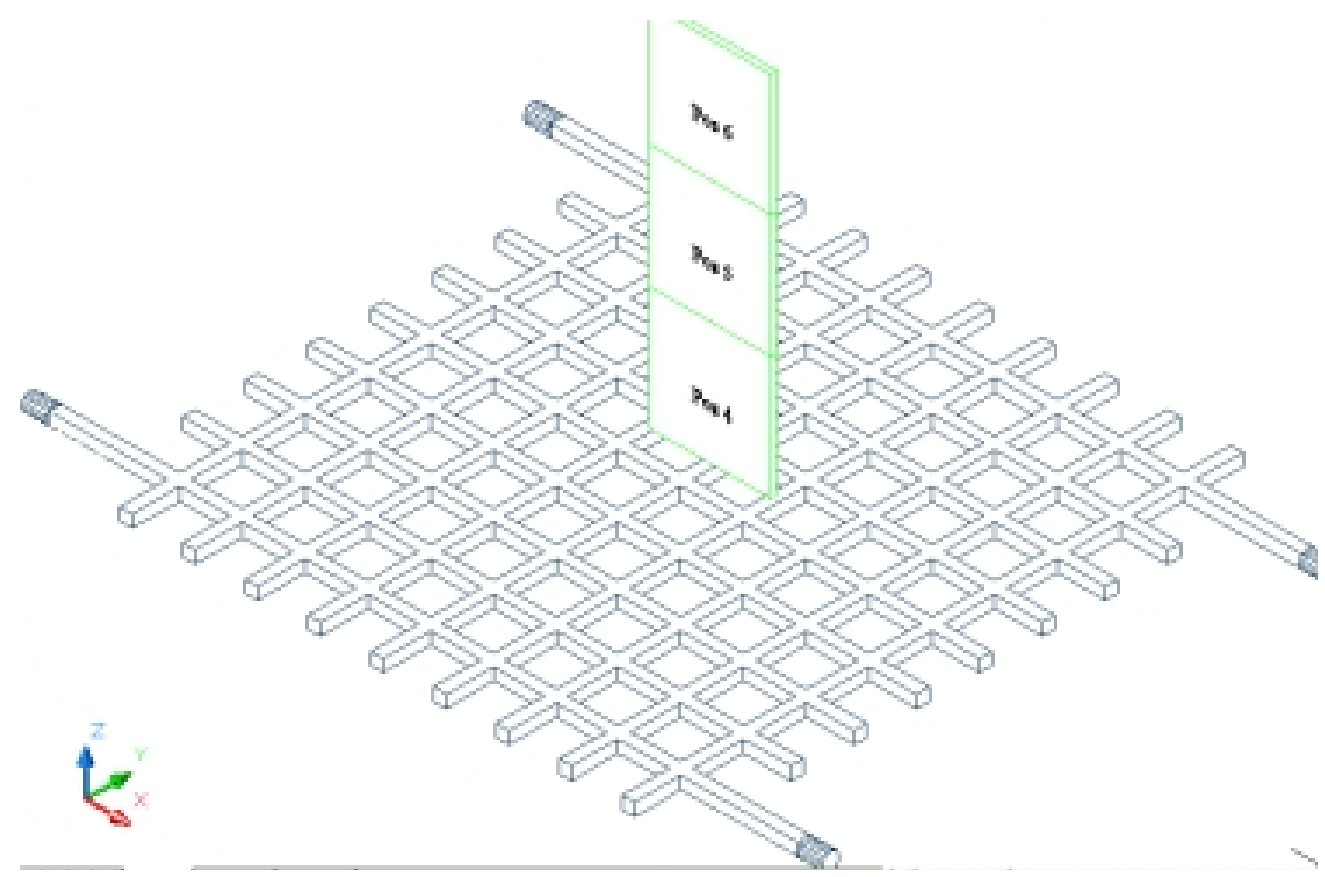

FIGURA 29 - Plano 2: região entre barras da grade.

\subsubsection{Definição de freqüência e amplitude de oscilação da grade}

Todos os experimentos foram realizados com amplitude de oscilação de $3 \mathrm{~cm}$, e as frequiências de oscilação da grade experimentadas foram 1, 2, 3 e $4 \mathrm{~Hz}$. Para que houvesse um estabelecimento da turbulência no interior do tanque, a grade era movimentada durante 
10 minutos na freqüência do experimento a ser realizado, antes de obter as imagens. $\mathrm{O}$ mesmo tempo de 10 min foi empregado no trabalho de DE SILVA \& FERNANDO (1994), e as freqüências de oscilação foram as mesmas recentemente estudadas por CHENG \& LAW (2001), porém com amplitude de $4 \mathrm{~cm}$.

Devido à amplitude de oscilação, as regiões de estudo localizavam-se logo acima da posição mais alta do movimento da grade (FIGURA 30). Isso impedia que a grade fosse capturada nas imagens e seu movimento confundido com o movimento das partículas, durante a geração dos campos de velocidade.

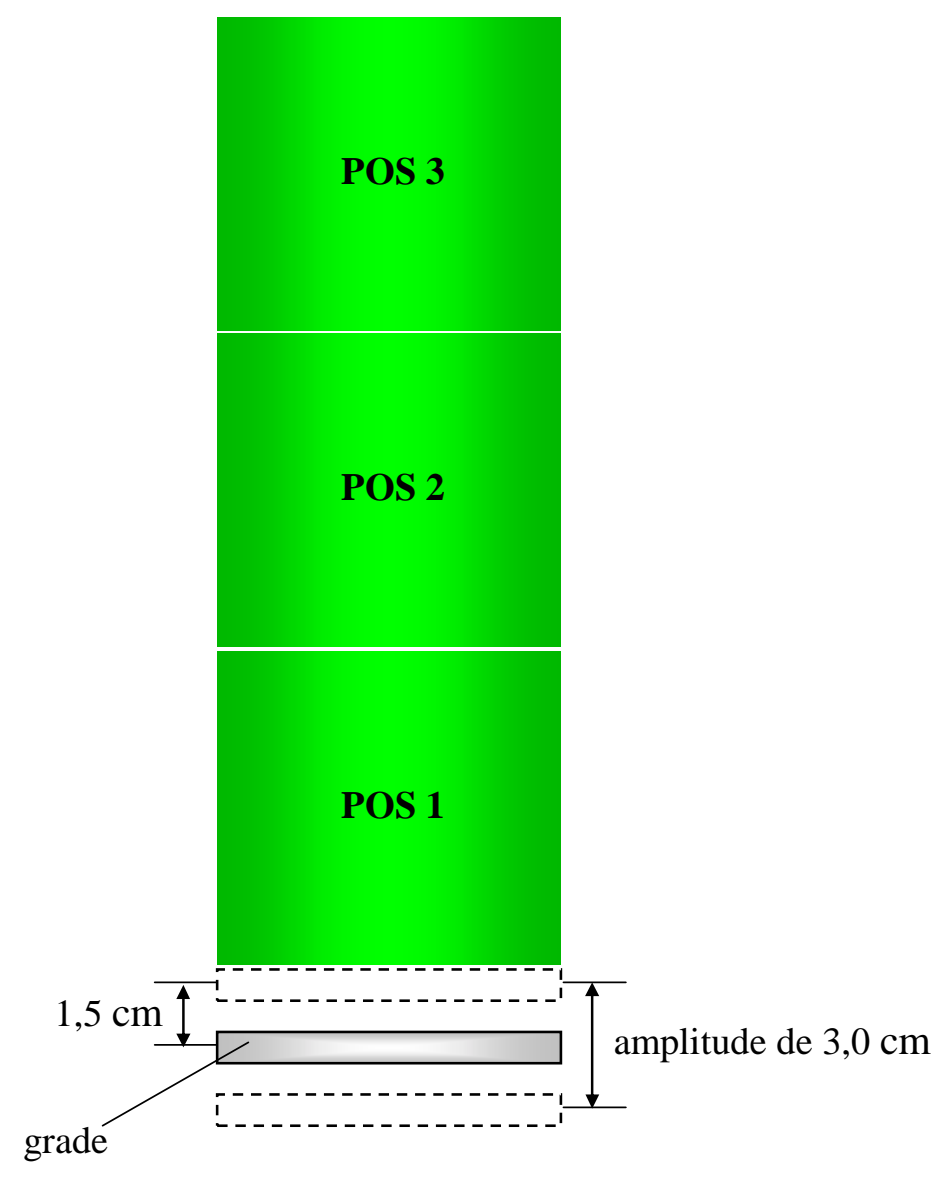

FIGURA 30 - Regiões de estudo logo acima da posição mais alta do movimento da grade. O mesmo posicionamento existiu para o plano das posições POS 4, POS 5 e POS 6. 


\subsubsection{Obtenção dos campos de velocidade turbulenta}

Nesta etapa, uma sequiência de passos foi seguida e empregada para as 24 diferentes situações de freqüência e posição da câmera fotográfica, experimentadas neste trabalho. Assim, faz-se a descrição desta seqüência utilizando apenas uma das situações: posição 1 da câmera (POS 1) e frequiência de 1 Hz. A FIGURA 31, auxilia essa descrição.
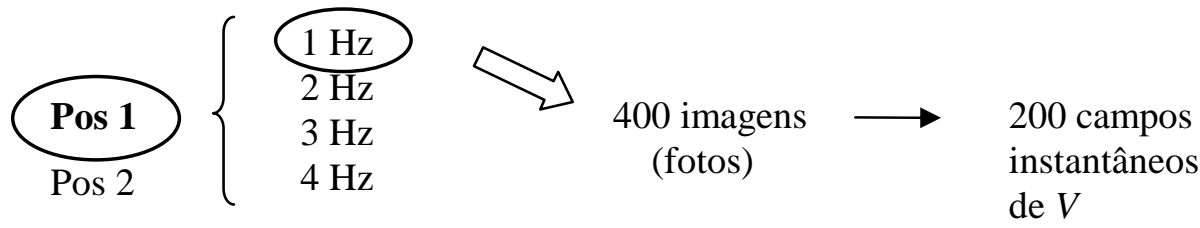

Pos 3

Pos 4

Pos 5

Pos 6
$\longrightarrow$ decomposição em U e W
$\longrightarrow \overline{\mathrm{U}} \mathrm{e} \overline{\mathrm{W}}$ dos 200 campos $\longrightarrow$ (média temporal)
u' e w' para cada um dos 200 campos

$\longrightarrow \mathbf{u}=\sqrt{\overline{\mathrm{u}^{\prime 2}}} ; \mathbf{w}=\sqrt{\overline{\mathrm{w}^{\prime 2}}}$

FIGURA 31 - Procedimento para obtenção dos campos de velocidade turbulenta, u e w.

- Para cada situação, foram tiradas 400 fotos, em grupos de 16 , devido à pequena memória de armazenamento da câmera digital. O intervalo de tempo entre duas fotos consecutivas de um mesmo grupo era de 0,033 segundos. Porém, após a obtenção de cada grupo de 16 fotos, eram necessários alguns segundos para que as fotos fossem transferidas para o disco rígido 
do computador e a memória da câmera fosse esvaziada para obtenção de novas fotos. Levouse, em média, 6 minutos para obtenção das 400 fotos de cada situação.

- Através de análise de correlação o programa Visiflow, fornecia um campo vetorial instantâneo para cada par de fotos consecutivas. Cada campo era formado por uma malha de 29 x 29 vetores velocidade. Esse campo era disponibilizado em duas formas: gráfica e em planilha do software Excel, com posição, magnitude e ângulo de inclinação de cada vetor. Do total de 4800 obtidos, a planilha gerada para um campo vetorial instantâneo é apresentada como exemplo no APÊNDICE deste trabalho.

- Cada vetor instantâneo era decomposto em suas componentes nos eixos x e z (eixos ilustrados na FIGURA 28).

A partir deste passo do procedimento, incluindo-o, os dados não puderam mais ser analisados através do Visiflow, que não oferecia operações de cálculo necessárias. Criou-se então, para este trabalho, um programa computacional capaz de decompor todos os 4.036.800 vetores (dos 4800 campos gerados a partir das 9600 fotos obtidas) gerados no software Visiflow, e prosseguir com a seqüência de cálculos necessária. O programa desenvolvido também auxiliou a otimização da obtenção dos campos de velocidade. As 400 fotos obtidas em cada experimento foram renomeadas pelo programa, para que o Visiflow em cada seqüência de 16 fotos, pudesse gerar todos os 200 campos de uma só vez, e não apenas 8 .

- Tirada a média das componentes instantâneas dos 200 campos, observou-se que a média era temporal, isto é, cada vetor pertencente à malha de 29 x 29 vetores de um campo foi somado apenas aos vetores dos outros campos, pertencentes à mesma posição na malha.

- Subtraiu-se de cada vetor instantâneo, o valor da média obtida para sua posição na malha. Desta forma, para cada situação, foram obtidos 200 campos de $\mathbf{u}^{\prime}$ e 200 campos de w'. 
- Extraiu-se a raiz quadrada da média dos quadrados de $\mathbf{u}^{\prime}$ e $\mathbf{w}^{\prime}$, isto é, $\sqrt{\overline{\mathbf{u}^{\prime 2}}}$ e $\sqrt{\overline{\mathbf{w}^{\prime 2}}}$.

- Foram obtidos 1 campo de $\mathbf{u}$ e um campo de $\mathbf{w}$ para cada situação de posição e frequiência ensaiadas.

Toda seqüência de cálculos envolvida nesta pesquisa requereu grande esforço de processamento do computador Pentium $200 \mathrm{MHz}$, pertencente ao Laboratório de Hidráulica Ambiental. Assim, apesar das imagens obtidas nos experimentos terem sido nele armazenadas, a geração dos campos instantâneos pelo programa Visiflow e dos campos de velocidade turbulenta através do programa desenvolvido, foi executada em um grupo de computadores Pentium 4, de processamento compartilhado.

\subsubsection{Tensões médias de Reynolds}

Foram calculadas para cada situação. Seu procedimento de cálculo assemelhou-se àquele ilustrado na FIGURA 31, até obtenção das flutuações instantâneas u' e w'. A partir de então, foi feita a média do produto destas flutuações, obtendo-se as Tensões de Reynolds - eq. (16).

\subsubsection{Caracterização da turbulência gerada}

Os dados de $\mathbf{u}, \mathbf{w}, \mathrm{e} \overline{\mathbf{u}^{\prime} \cdot \mathbf{w}^{\mathbf{1}}}$, obtidos através dos experimentos com o tanque de grade oscilante construído, para este trabalho, são apresentados graficamente no capítulo 5. Com base nesses gráficos, analisou-se a ocorrência, no interior do tanque, de duas propriedades da turbulência isotrópica mencionadas no item 2.3, eq. (14) e eq (16). Avaliou-se, também, o procedimento experimental seguido para obtenção dos dados. 


\section{RESULTADOS E DISCUSSÕES}

Os dados obtidos neste trabalho são resumidamente apresentados neste capítulo, através de gráficos. Dentre as 24 situações experimentadas, de posição da câmera e frequiência de oscilação da grade, são mostrados apenas os resultados de algumas delas. As discussões e conclusões desses resultados são comuns a todas as demais situações (gráficos no ANEXO). As duas situações exibidas referem-se aos experimentos com freqüências de oscilação de $1 \mathrm{~Hz}$ e $2 \mathrm{~Hz}$, realizados no Plano 1 (sobre a barra central).

\subsection{Campos instantâneos de velocidade}

Primeiramente, são apresentados os campos instantâneos de velocidade (campos de $\sqrt{\mathrm{U}^{2}+\mathrm{W}^{2}}$ ), obtidos na POS 1. A visualização desses campos permite comparação entre magnitude dos vetores calculados a partir dos experimentos com $1 \mathrm{~Hz}$ e $2 \mathrm{~Hz}$. Ambos os campos, os vetores foram normalizados com base em um vetor de $5 \mathrm{~mm} / \mathrm{s}$. Em todos os vetores dos campos a cor verde indica que vetores reais foram gerados pelo programa Visiflow. Isso significa que, em cada célula do campo, a densidade de partículas iluminadas pelo laser foi suficiente para geração de todos os seus vetores velocidade. Caso houvesse poucas partículas em uma célula, o vetor correspondente seria gerado por interpolação, e apresentado na cor vermelha.

As FIGURAS 32 e 33 mostram, respectivamente para $1 \mathrm{~Hz}$ e $2 \mathrm{~Hz}$, os campos instantâneos de velocidade. Comparando-os, pode-se observar aumento da magnitude dos vetores com o aumento da frequiência. A maior freqüência proporcionava maior agitação do fluido. Este aumento também foi observado quando se elevou a frequiência para $3 \mathrm{~Hz}$, e depois para $4 \mathrm{~Hz}$. Nas figuras a seguir, os campos estão apresentados no ambiente do Visiflow, programa em que foram gerados. 


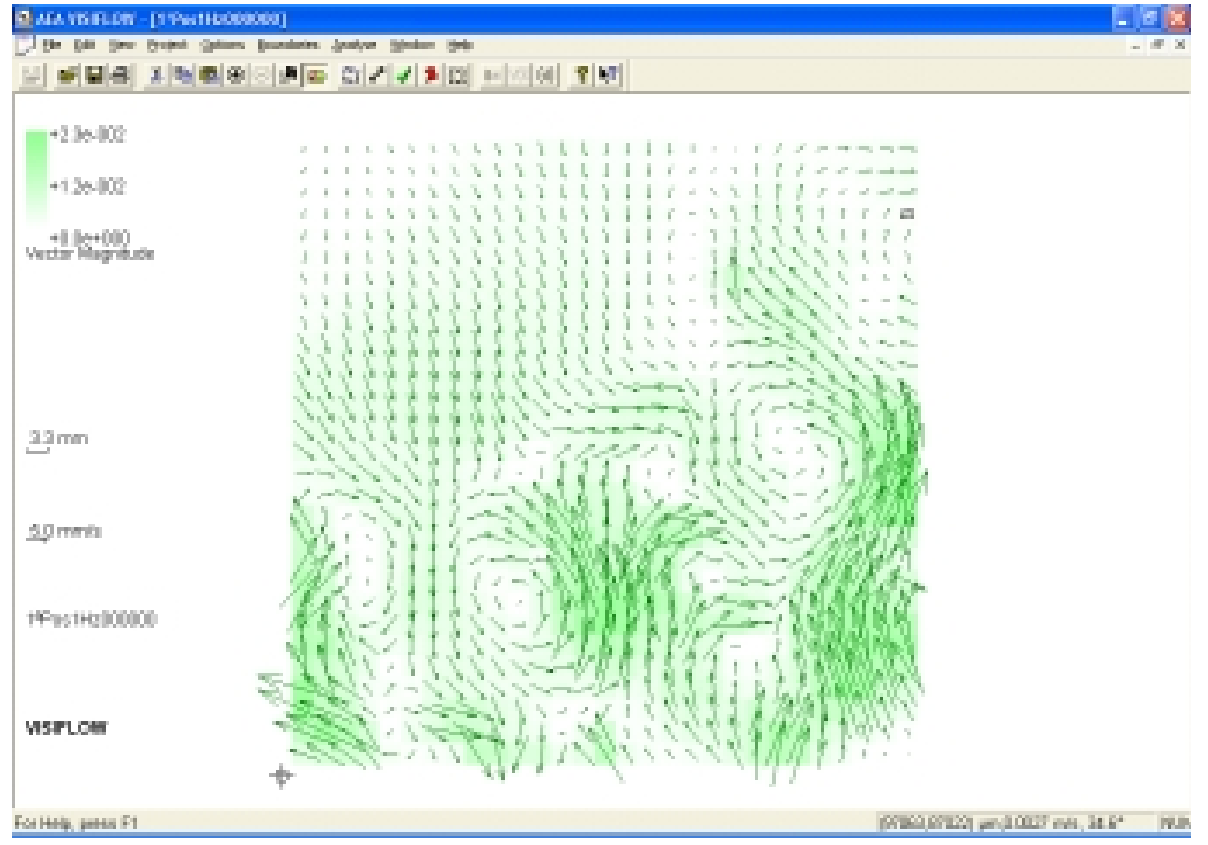

FIGURA 32 - Campo instantâneo de velocidade, para a POS 1 e freqüência de $1 \mathrm{~Hz}$.

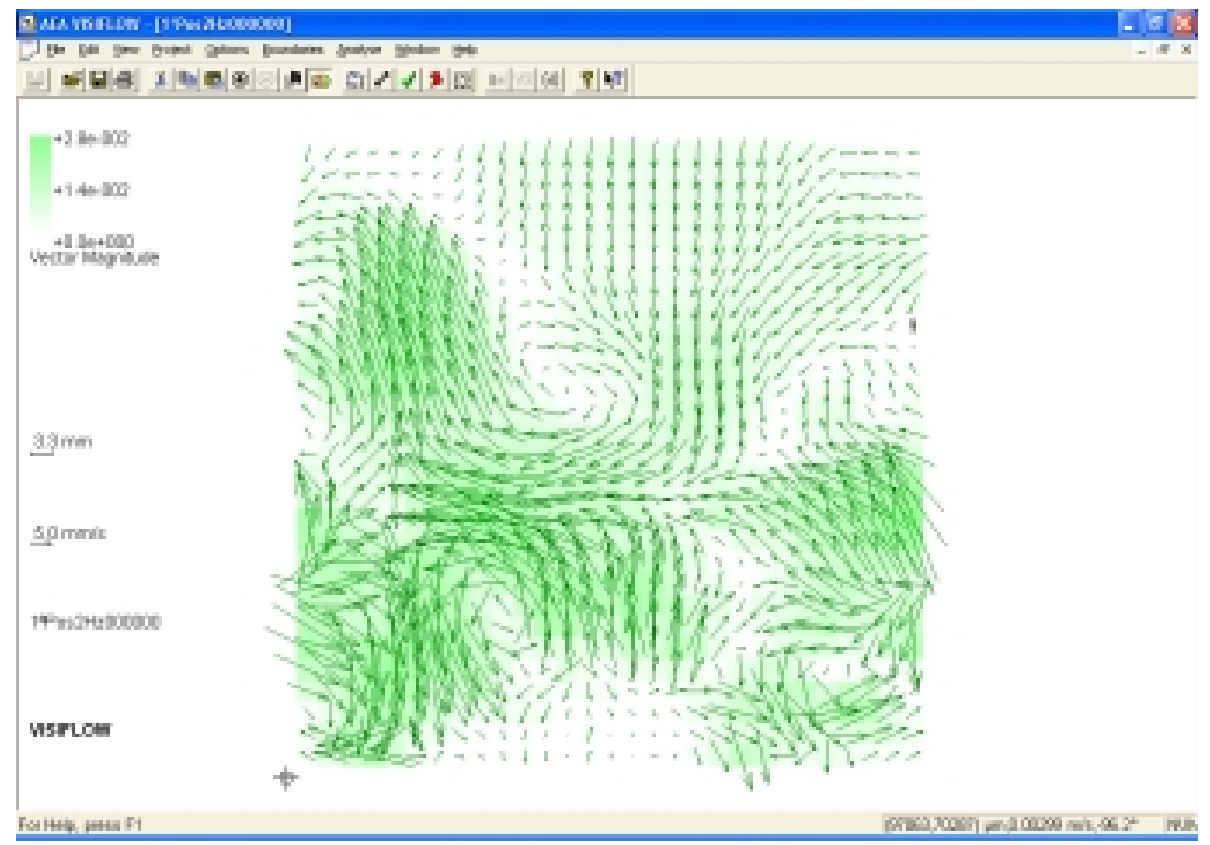

FIGURA 33 - Campo instantâneo de velocidade, para a POS 1 e frequiência de $2 \mathrm{~Hz}$.

A maior magnitude dos vetores na parte inferior das figuras significa maior intensidade turbulenta nesta região, que está mais próxima da grade geradora da turbulência. 
As diferentes direções dos vetores das duas figuras para a mesma posição do Plano 1, mostram as diferentes trajetórias percorridas pelas partículas do fluido, evidenciando ocorrência do movimento turbulento. Apesar de estar apresentada juntamente com apenas dois campos de velocidade de diferentes freqüências, baseada na aleatoriedade do movimento das partículas, a conclusão da ocorrência da turbulência pode ser observada em qualquer seqüência de 200 campos instantâneos, de qualquer das 24 situações estudadas. Todos os 4800 campos instantâneos de velocidade estão gravados e disponíveis no computador do Laboratório de Hidráulica Ambiental.

\subsection{Campos médios de velocidade}

O tanque de grade oscilante é conhecido como um equipamento que gera turbulência sem que haja escoamento médio do fluido. Assim, a magnitude dos vetores dos campos

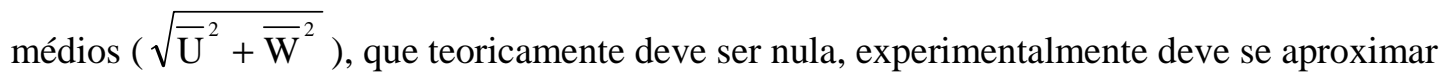
ao máximo de zero. Neste trabalho, os campos médios obtidos mostraram vetores com magnitude consideravelmente inferior à dos vetores dos campos instantâneos. Contudo, baseado na intensidade da cor verde nos campos médios para freqüências de $1 \mathrm{~Hz}$ e $2 \mathrm{~Hz}$ (FIGURAS 34 e 35, respectivamente), relacionada à magnitude dos vetores, observa-se que em certas regiões dos campos, a velocidade média se distanciou de zero. Isto leva à conclusão que um maior número de campos instantâneos deve ser obtido nos experimentos, para que o campo médio seja mais homogêneo e mais próximo de zero.

Da mesma forma, nota-se maior magnitude dos vetores do campo médio à medida que se aumenta a freqüência de oscilação da grade de $1 \mathrm{~Hz}$ para $2 \mathrm{~Hz}$. O mesmo acontece quando se aumenta a freqüência para $3 \mathrm{~Hz}$ e para $4 \mathrm{~Hz}$, como pode ser visto no ANEXO. Este fato mostra que o número de campos instantâneos, necessários para a obtenção de média representativa do fenômeno, pode ser dependente da freqüência adotada no experimento, o que aponta para a necessidade de se estabelecer, corretamente, as condições 
ideais para cálculos estatísticos em escoamentos turbulentos, nem sempre presentes em estudos da literatura.

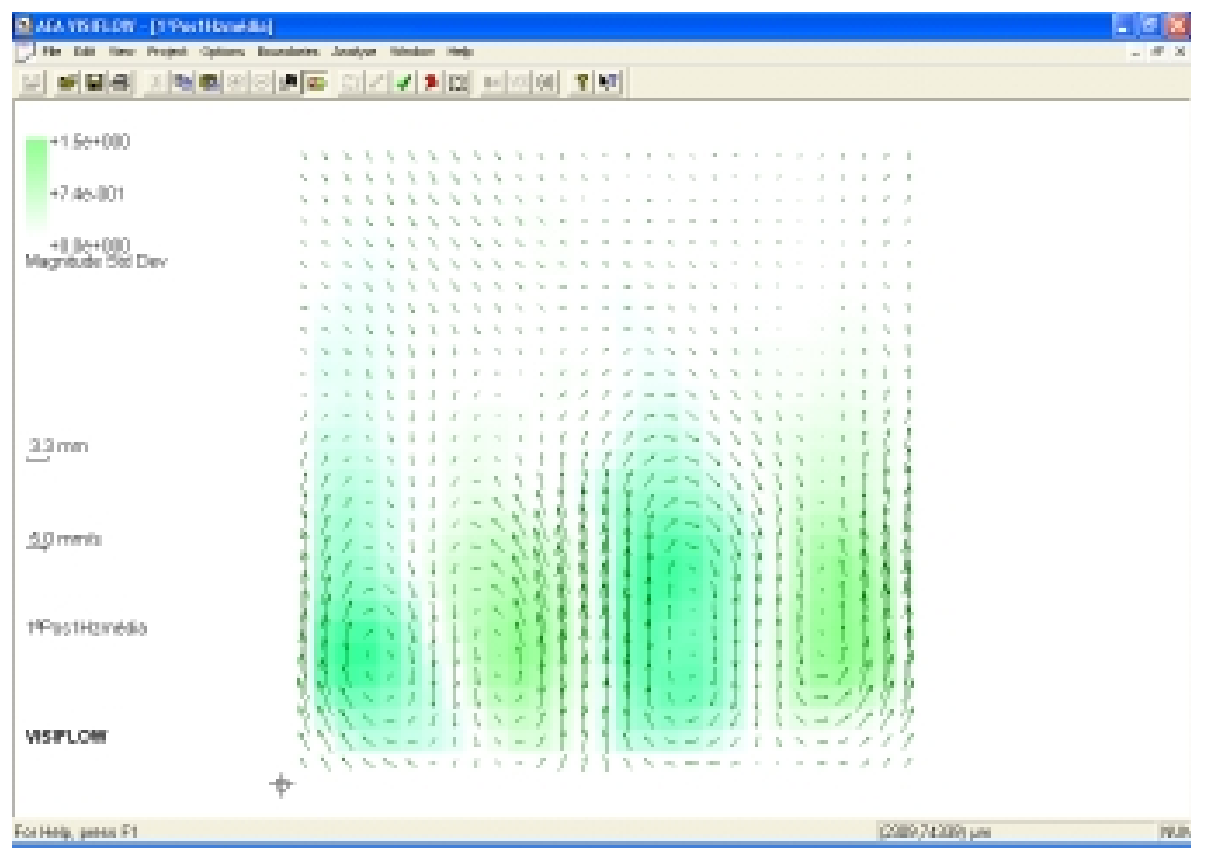

FIGURA 34 - Campo médio de velocidade para freqüência de $1 \mathrm{~Hz}$.

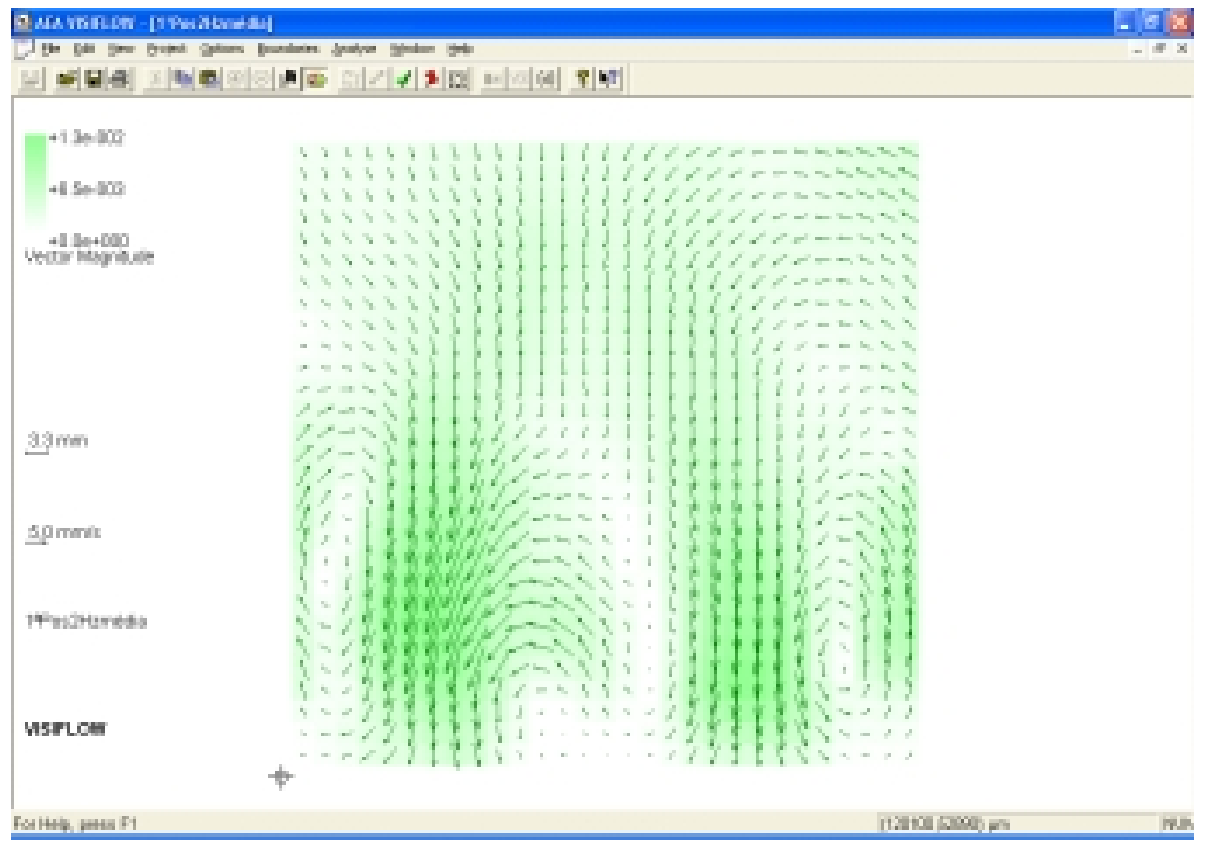

FIGURA 35 - Campo médio de velocidade para freqüência de $2 \mathrm{~Hz}$. 


\subsection{Campos médios de velocidade turbulenta}

Também chamados de campos de intensidade turbulenta, foram calculados com o programa desenvolvido para este trabalho e não podem ser visualizados. Seus dados são apresentados através dos gráficos a seguir.

\subsubsection{Distribuição horizontal de u, w e i}

Com o objetivo de analisar a homogeneidade da turbulência gerada, neste item é apresentada a distribuição horizontal das componentes $\mathbf{u}$ e $\mathbf{w}$ (respectivamente relativas aos eixos x e z da FIGURA 28) e da intensidade turbulenta $i=\sqrt{2 \cdot u^{2}+w^{2}}$. A consideração repetida da componente no eixo x da velocidade média turbulenta é usada para se compensar a falta da componente no eixo y (componente v), não registrada através do método DPIV. Esta consideração baseou-se nas semelhanças de geometria e de movimentação da grade, relativas a estes dois eixos.

Apesar de terem sido calculados todos os vetores das posições POS 1, POS 2 e POS 3 (Plano 1), a distribuição horizontal de u e w foi feita apenas para 7 'linhas' de vetores, com diferentes distâncias em relação ao centro de oscilação da grade (FIGURA 36). A distribuição horizontal de $\mathbf{u}, \mathbf{w}$ e $\mathbf{i}$, para as demais posições da câmera e freqüência de oscilação, também fazem parte do ANEXO deste trabalho.

Na FIGURA 37 são apresentados os gráficos da distribuição horizontal de $\mathbf{u}, \mathbf{w}$, e i, para a freqüência de $1 \mathrm{~Hz}$. Referentes à frequiência de $2 \mathrm{~Hz}$ os mesmos gráficos são mostrados na FIGURA 38.

Para comparação dos resultados mostrados nas figuras a seguir com os obtidos para frequiências maiores (apresentados no ANEXO), o limite máximo da escala vertical é o mesmo para todas as frequiências. Por isto, este limite pode parecer excessivo para os resultados apresentados neste capítulo. 


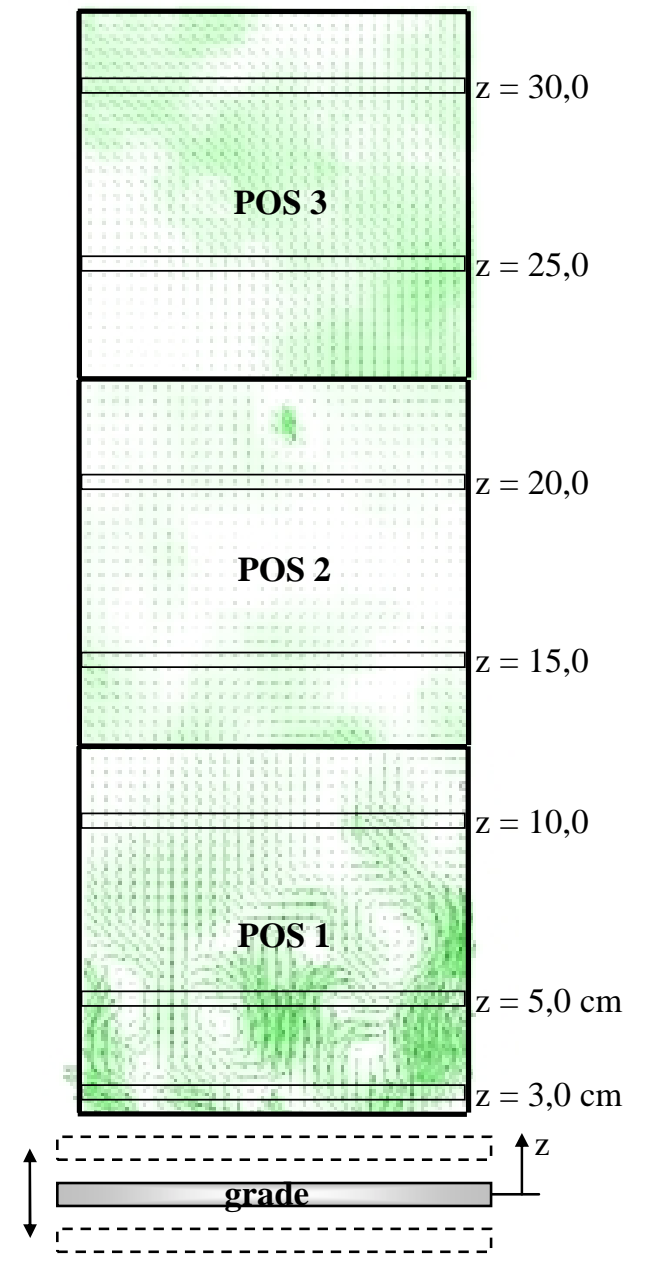

FIGURA 36 - Localização dos vetores usados na representação da distribuição horizontal da velocidade turbulenta. Os campos da figura servem apenas para ilustrar esta localização. 
Sobre a barra - $1 \mathrm{~Hz}$
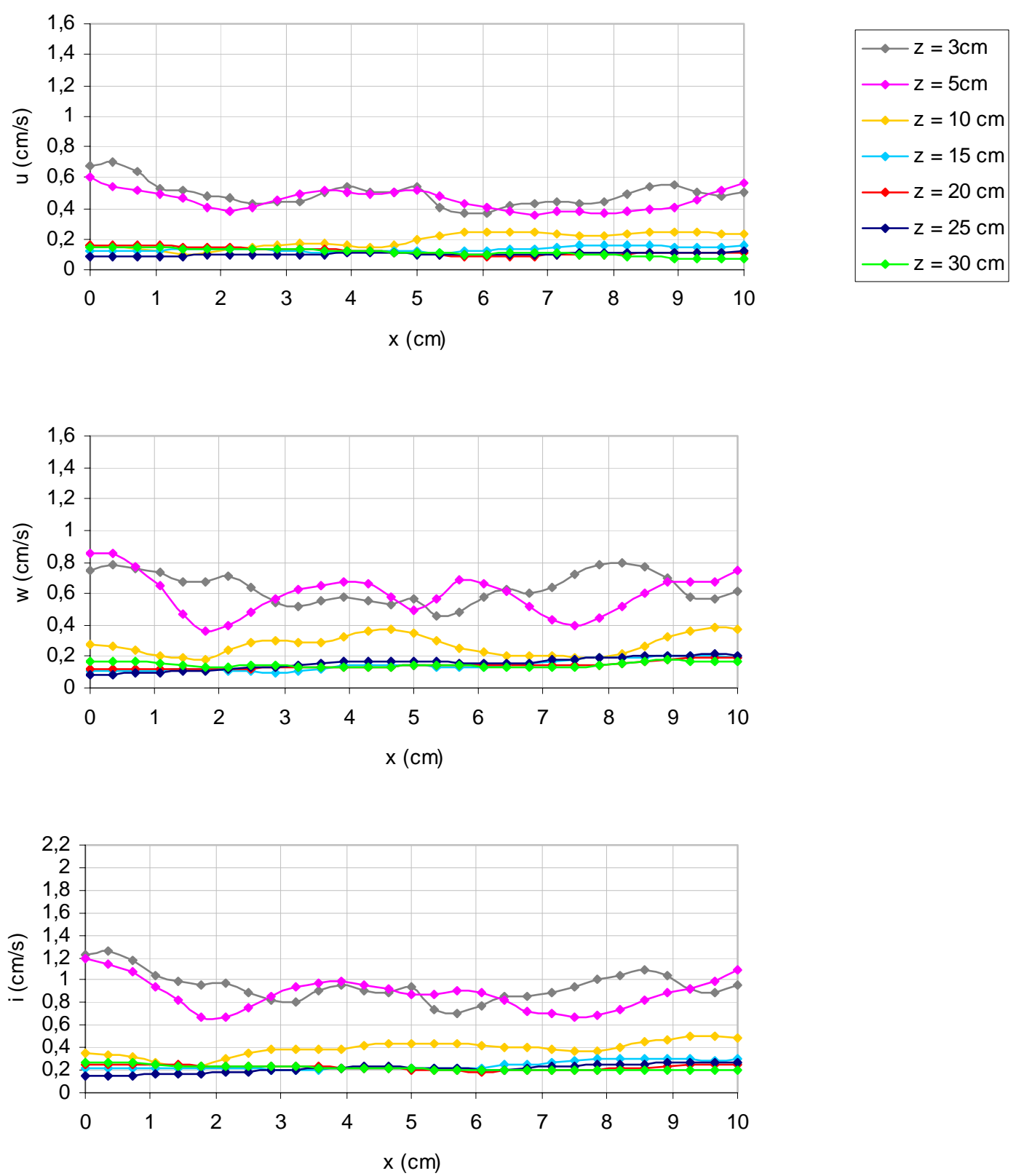

FIGURA 37 - Distribuição horizontal de u, w e i, para o Plano 1 e freqüência de $1 \mathrm{~Hz}$. 
Sobre a barra - $2 \mathrm{~Hz}$
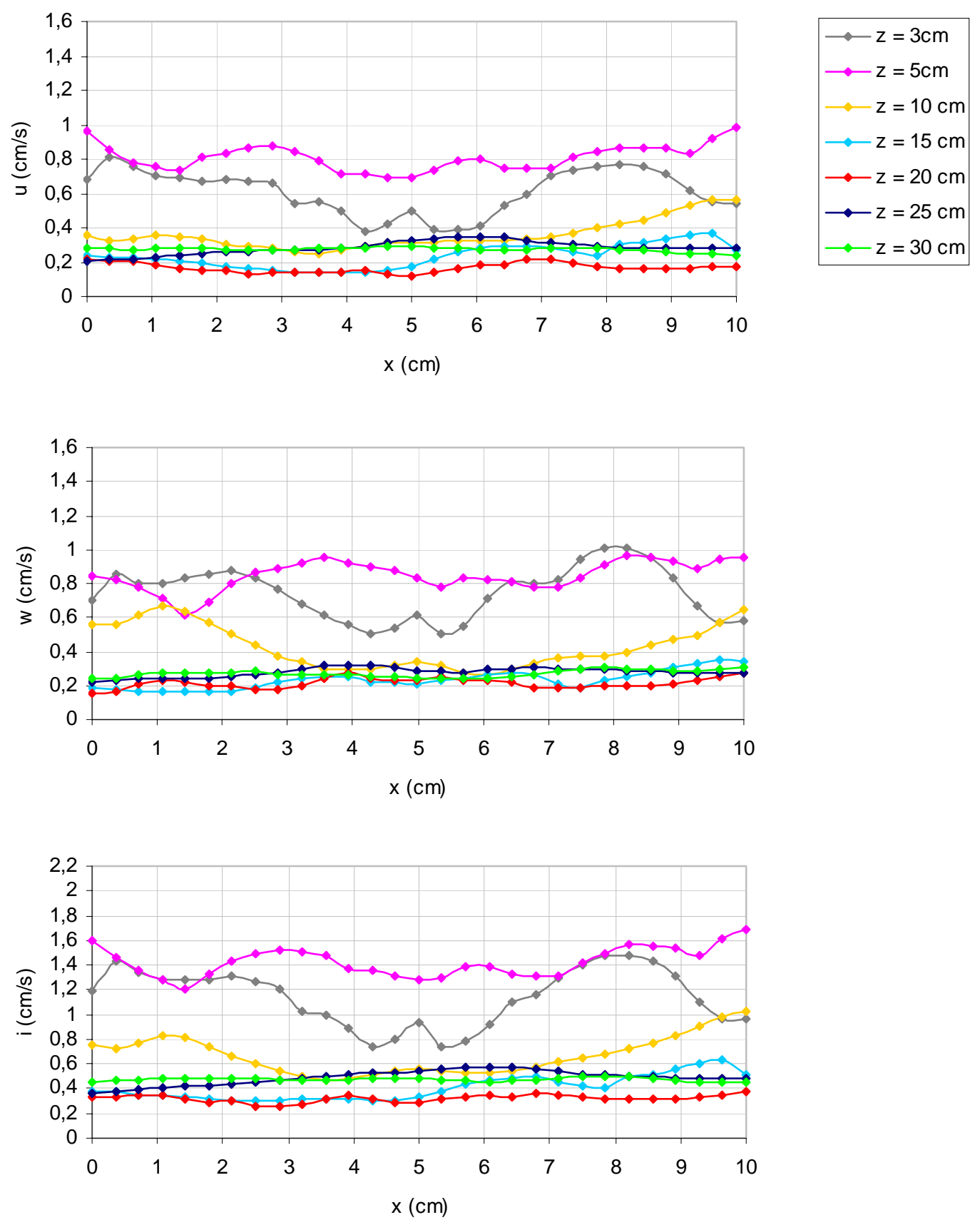

FIGURA 38 - Distribuição horizontal de u, w e i, para o Plano 1 e frequiência de $2 \mathrm{~Hz}$. 
Nos seis gráficos acima, apresentam-se distintas apenas as distribuições para $\mathrm{z}=3$ $\mathrm{cm} \mathrm{e} \mathrm{z}=5 \mathrm{~cm}$. Para as demais distribuições $(\mathrm{z}=10,15,20,25$ e $30 \mathrm{~cm})$ as linhas que teoricamente seriam separadas, com maior velocidade para as menores distâncias z, misturam-se em todos os gráficos. Apesar das incertezas acerca das médias obtidas, estes gráficos mostram tendência maior à homogeneidade, à medida que se distanciam da grade. Essa tendência, observada neste trabalho, concorda com os resultados experimentais de CHENG \& LAW (2001) e com a afirmação de DE SILVA \& FERNANDO (1994), sobre a ocorrência de turbulência aproximadamente homogênea a partir de (2-3) M da grade (entre 10 e $15 \mathrm{~cm}$ no presente trabalho).

\subsubsection{Característica da turbulência isotrópica: $\mathrm{w} / \mathrm{u}=1$}

Esta relação de w / u, baseada na eq. (14), varia experimentalmente entre 1,1 e 1,2, segundo DE SILVA \& FERNANDO (1994). Ilustrados na FIGURA 39, os gráficos mostram que, apesar dos dados obtidos neste trabalho apresentarem valores para esta relação superiores ao limite comentado, eles oscilam em torno da unidade $(\mathrm{w} / \mathrm{u}=1)$. Novamente, atribui-se à esta irregularidade a falta de campos médios melhores (mais reais), seja para a velocidade, seja para a flutuação (velocidade turbulenta). Os gráficos para as frequiências de $3 \mathrm{~Hz}$ e $4 \mathrm{~Hz}$ no Plano 1 e para todas as freqüências no Plano 2 são apresentados no ANEXO. 
Sobre a barra - $1 \mathrm{~Hz}$

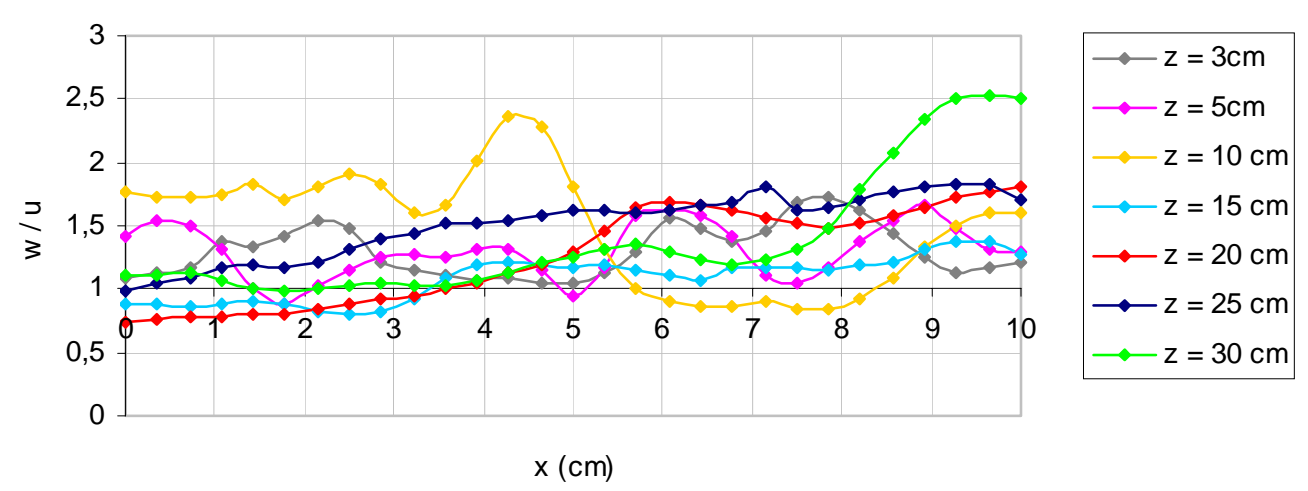

Sobre a barra - $2 \mathrm{~Hz}$

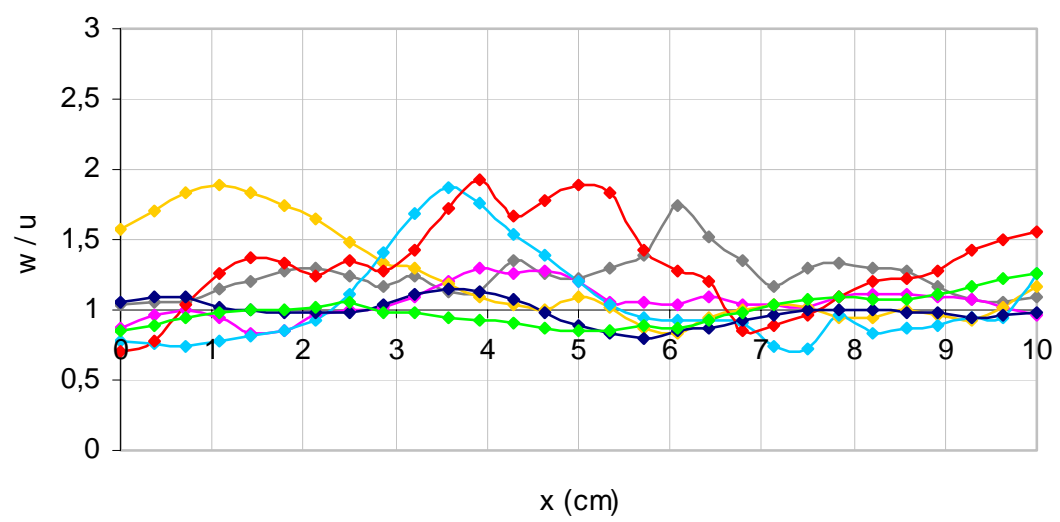

FIGURA 39 - Relação w / u para o Plano 1 e frequiências 1 Hz e 2 Hz.

\subsubsection{Tensões de Reynolds}

Como já foi comentado no Capítulo 2, as tensões de Reynolds são nulas para turbulência em condições de perfeita isotropia. Na FIGURA 40, os gráficos mostram que a turbulência gerada se torna mais isotrópica à medida que se distancia da grade. Comparando os dois gráficos, observa-se que são maiores as tensões obtidas com frequiência de $2 \mathrm{~Hz}$, principalmente as geradas próximas a grade, para $\mathrm{z}=3 \mathrm{~cm} \mathrm{e} \mathrm{z}=5 \mathrm{~cm}$. Esta diferença pode ser resultado da hipótese que a maior frequiência de oscilação da grade requer maior número de campos instantâneos para obtenção de média real. Pode-se também incluir como causa desta diferença a necessidade de maior distância $\mathbf{z}$ para que estas tensões se aproximem de 
zero, para maiores freqüências. Em outros termos, quanto maior a freqüência de oscilação, mais distantes da grade estarão as regiões com condições quase-isotrópicas.

Sobre a barra $-1 \mathrm{~Hz}$
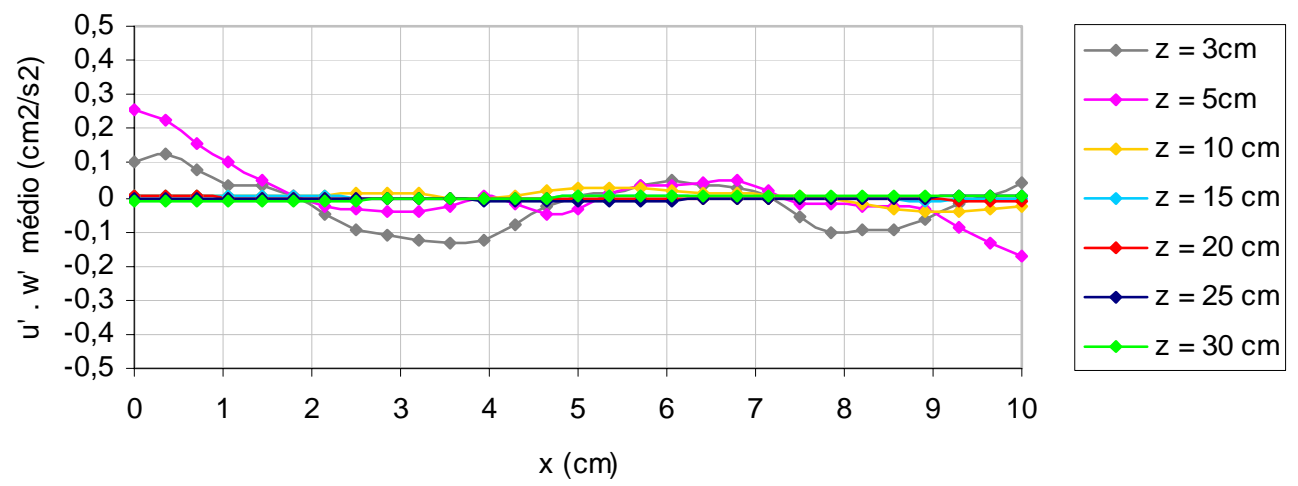

Sobre a barra - $2 \mathrm{~Hz}$

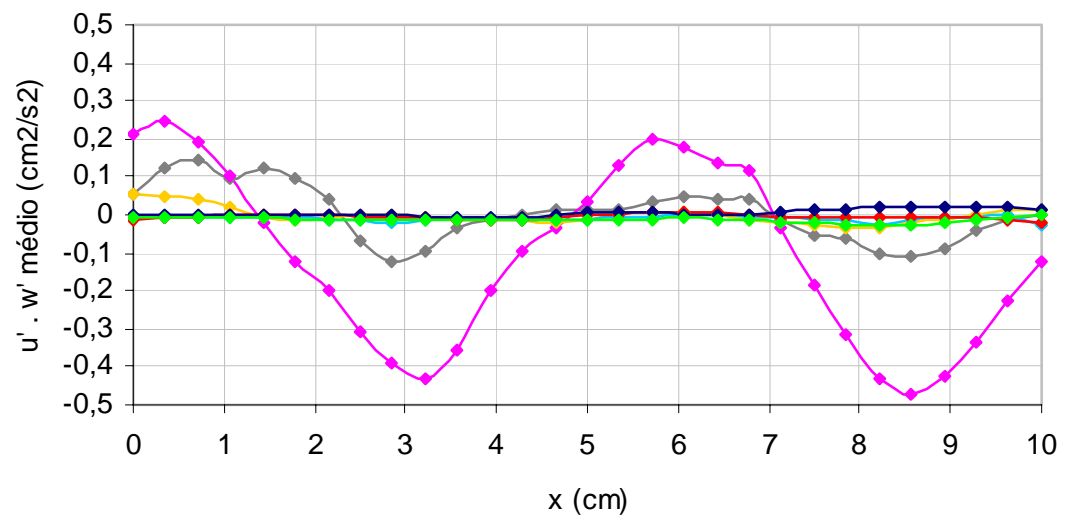

FIGURA 40 - Tensões de Reynolds para o Plano 1 e frequiências $1 \mathrm{~Hz}$ e $2 \mathrm{~Hz}$.

\subsubsection{Decaimento espacial da turbulência}

Os gráficos apresentados nas FIGURAS 41 e 42 mostram a evolução da intensidade turbulenta i, ao longo de z. Diferentemente dos gráficos já apresentados neste capítulo, estes representam as 24 situações de posição da câmera e freqüência de oscilação da grade. A intensidade turbulenta representada na FIGURA 41 corresponde àquela gerada no Plano 1 de obtenção de imagens, compreendendo as posições POS 1, POS 2 e POS 3 e todas as 
frequiências estudadas (1, 2, 3 e 4 Hz). A FIGURA 42 refere-se ao Plano 2 (mostrado na FIGURA 29) e às mesmas freqüências.

Nestes gráficos, a intensidade turbulenta apresentada é uma média espacial das intensidades para uma mesma altura z. Usando como exemplo o gráfico da FIGURA 37, da distribuição de $\mathbf{i}$ ao longo do eixo x, significa que cada conjunto de 29 pontos pertencentes a uma mesma altura $\mathrm{z}$ gera apenas um ponto no gráfico abaixo: sua média.

Sobre a barra

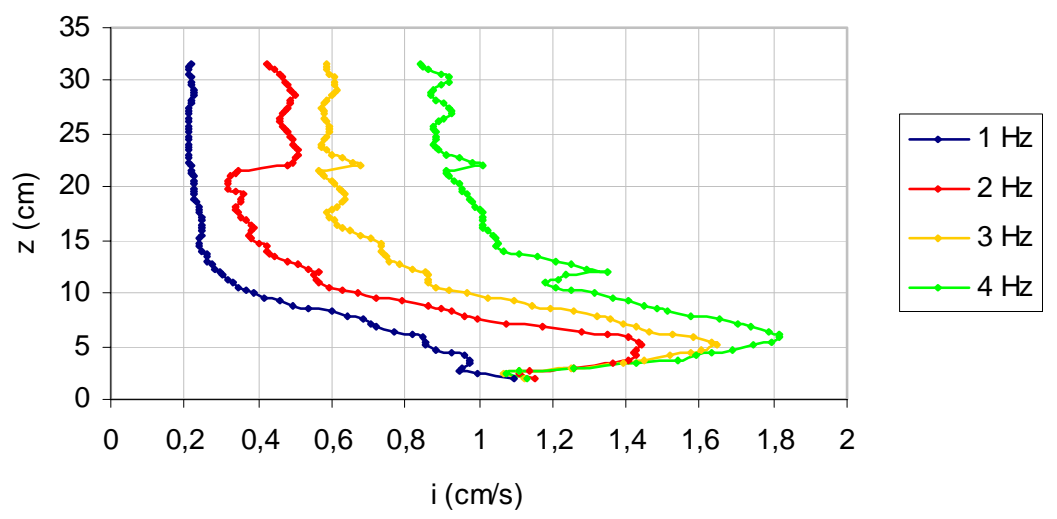

FIGURA 41 - Decaimento espacial da turbulência na região do Plano 1.

Entre barras

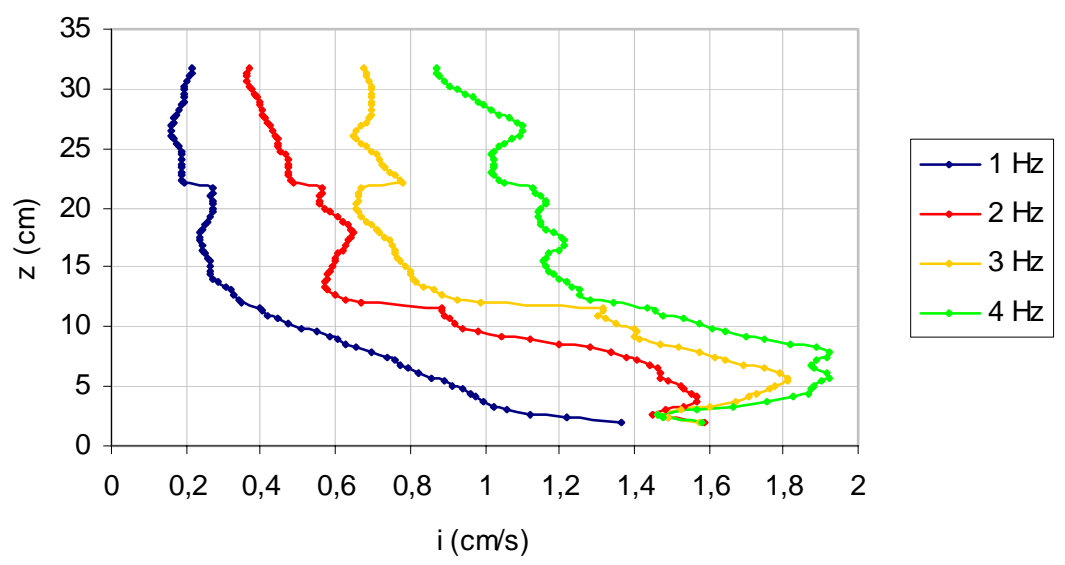

FIGURA 42 - Decaimento espacial da turbulência na região do Plano 2. 
Analisando os dois gráficos acima, podem ser observadas algumas características da turbulência gerada nos experimentos deste trabalho. A intensidade turbulenta e seu decaimento espacial foram semelhantes para os dois planos estudados (Plano 1 e Plano 2). Existe uma região de geração de turbulência junto à grade oscilante. Esta região é visível para $2 \mathrm{~Hz}, 3 \mathrm{~Hz}$ e $4 \mathrm{~Hz}$, o que não acontece para a frequiência de $1 \mathrm{~Hz}$. A geração ocorre até uma distância $\mathrm{z}=5-7 \mathrm{~cm}$ (em relação ao centro de oscilação da grade), quando é ultrapassado o pico da intensidade turbulenta. A partir daí, há decaimento e os mecanismos preponderantes são a difusão e a dissipação da energia cinética turbulenta.

As descontinuidades que ocorreram nos gráficos para as distâncias $\mathrm{z}=12 \mathrm{~cm} \mathrm{e} \mathrm{z}=$ 22 cm são conseqüências da ordem de obtenção de imagens para diferentes situações de posição e frequiência dos experimentos.

Tomando o Plano 1 como exemplo, primeiramente foram capturadas as imagens na POS 1, para todas as 4 frequiências. Procedeu-se da mesma forma para POS 2 e POS 3. A união das curvas das 3 posições e de mesma frequiência, causou saltos vistos nos gráficos. Conclui-se, com isto, que as imagens referentes a uma determinada freqüência devem ser obtidas para todas as posições da câmera. Só então a freqüência deve ser alterada para aquisição de novas imagens.

Para melhor definição das curvas experimentais de decaimento espacial da turbulência e melhor comparação com seu equacionamento proposto na literatura, é necessário maior número de imagens do escoamento. Tempo superior ao de $10 \mathrm{~min}$, empregado neste trabalho e no de DE SILVA \& FERNANDO (1994), é recomendado antes de cada experimento, para que haja melhor estabelecimento da turbulência no interior do tanque. 


\section{CONCLUSÕES}

- Construiu-se um equipamento adequado para a análise de escoamentos gerados por grades oscilantes. A solução inovadora para o sistema de oscilação da grade, com peças de teflon fazendo o isolamento do volume de controle do tanque, mostrou-se eficiente para longos períodos diários de funcionamento do equipamento.

- O programa computacional desenvolvido para este trabalho mostrou-se indispensável para o cálculo dos campos de velocidade turbulenta, a partir dos campos instantâneos de velocidade gerados pelo software Visiflow.

- Os gráficos criados a partir dos campos de intensidade turbulenta possibilitaram observação do decaimento espacial e da região de produção de turbulência. Os campos médios de velocidade mostraram-se muito inferiores aos campos instantâneos, indicando existência de baixo escoamento médio do fluido. Condições de isotropia e homogeneidade espacial da turbulência são mais aproximadas à medida que se afasta da grade. A intensidade turbulenta produzida está diretamente relacionada à frequiência de oscilação.

- O número de imagens para obtenção de média representativa da velocidade turbulenta neste equipamento parece ser dependente da frequência de oscilação da grade, algo que não é comentado na literatura.

- A obtenção de 200 campos instantâneos de velocidade para cada situação estudada não foi suficiente para produção de uma boa média. A memória insuficiente da câmera para armazenagem de fotos consecutivas do experimento (armazenava apenas 16 fotos, e não todas as 400) provavelmente afetou também de forma negativa esta média e precisa ser expandida. 


\section{SUGESTÕES PARA TRABALHOS FUTUROS}

Estas são sugestões para trabalhos que utilizem este equipamento em pesquisas com turbulência. Para novas medições de velocidade turbulenta com uso de técnica DPIV, podem ser feitas algumas alterações na metodologia, tais como: aquisição de maior número de imagens para obtenção das médias das velocidades, estabelecimento do movimento turbulento no tanque em tempo superior a 10 min e realização dos experimentos com a mesma frequência de oscilação em seqüência, para diferentes posições da câmera;

O equipamento construído possibilita:

- experimentos com diferentes grades e amplitudes de oscilação;

- instalação de um fundo falso no tanque, de altura variável, para avaliação de sua influência na turbulência gerada;

- estudos de turbulência gerada por um par de grades oscilantes, a partir da instalação de uma segunda grade no tanque. 


\section{ANEXO}

Campos instantâneos de velocidade, campos médios de velocidade, distribuição horizontal de $\mathbf{u}, \mathbf{w}$ e $\mathbf{i}$, gráficos de $\mathbf{w}$ / $\mathbf{u}$ e de tensões de Reynolds, para diferentes situações de posição da câmera e frequência de oscilação da grade. 


\section{Campos instantâneos de velocidade}

Apresenta-se nas FIGURAS 43-64 um campo pertencente a cada sequiência de 200 campos instantâneos de velocidade, para cada uma das 22 situações de freqüência de posição da câmera e frequiência da grade, que não foram ilustradas no Capítulo 5.

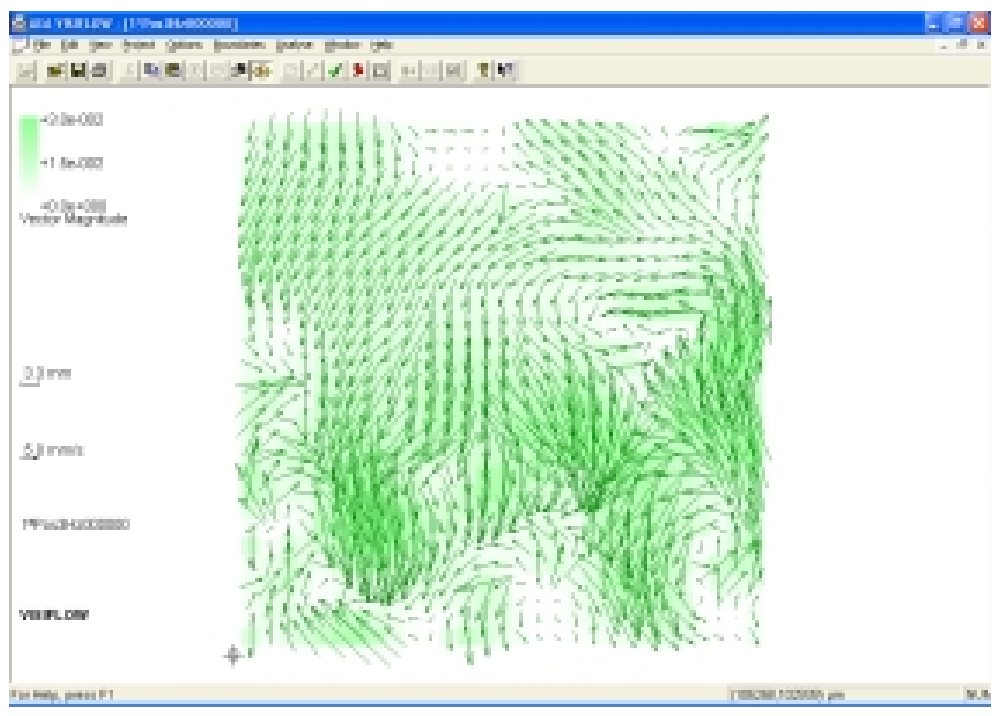

FIGURA 43 - Campo instantâneo de velocidade, para Pos 1 e frequiência $3 \mathrm{~Hz}$

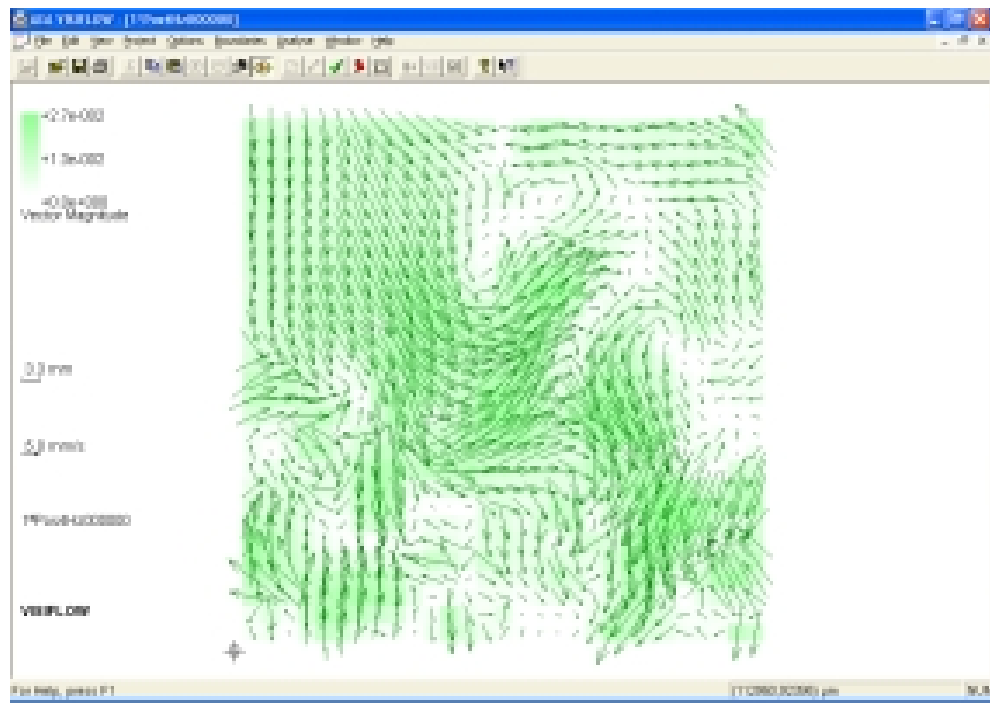

FIGURA 44 - Campo instantâneo de velocidade, para Pos 1 e freqüência 4 Hz 


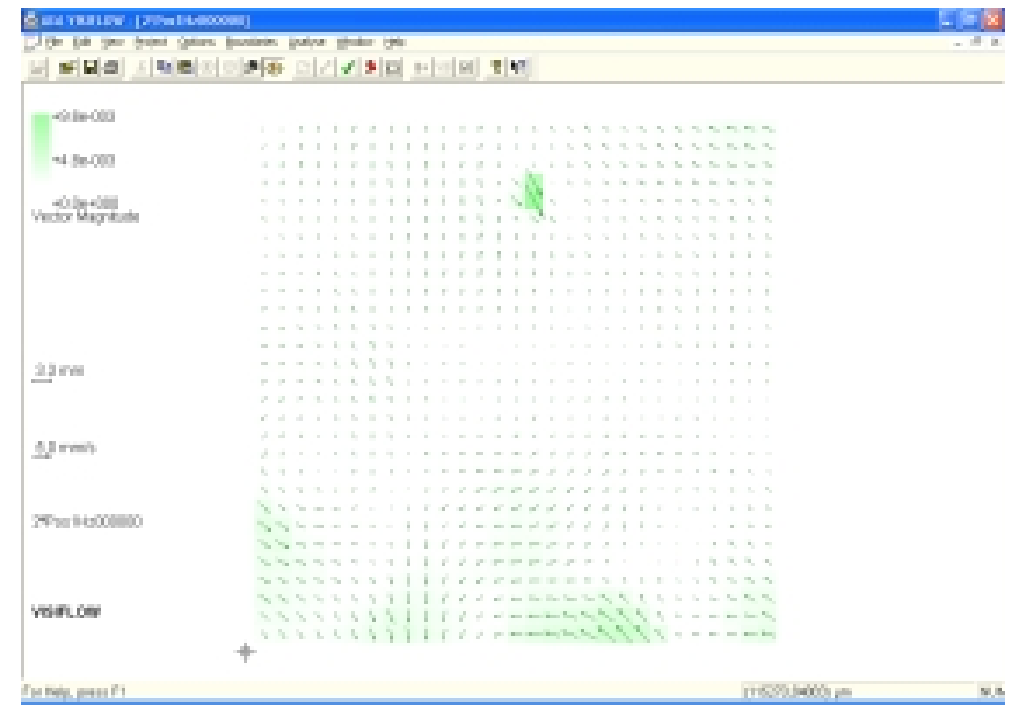

FIGURA 45 - Campo instantâneo de velocidade, para Pos 2 e freqüência $1 \mathrm{~Hz}$.

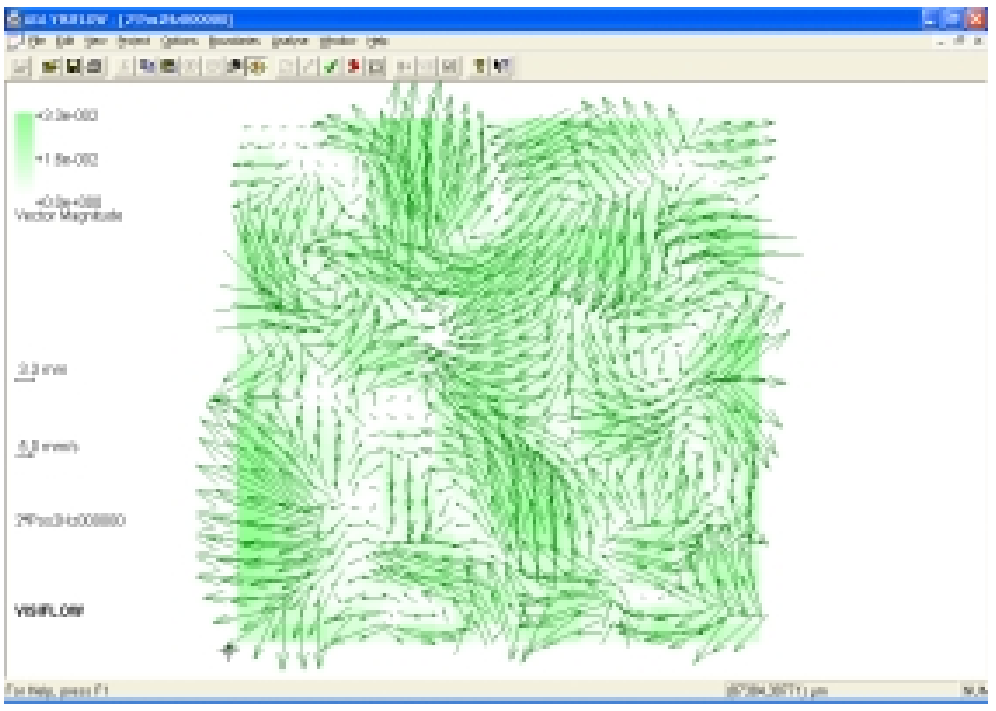

FIGURA 46 - Campo instantâneo de velocidade, para Pos 2 e frequiência 2 Hz. 


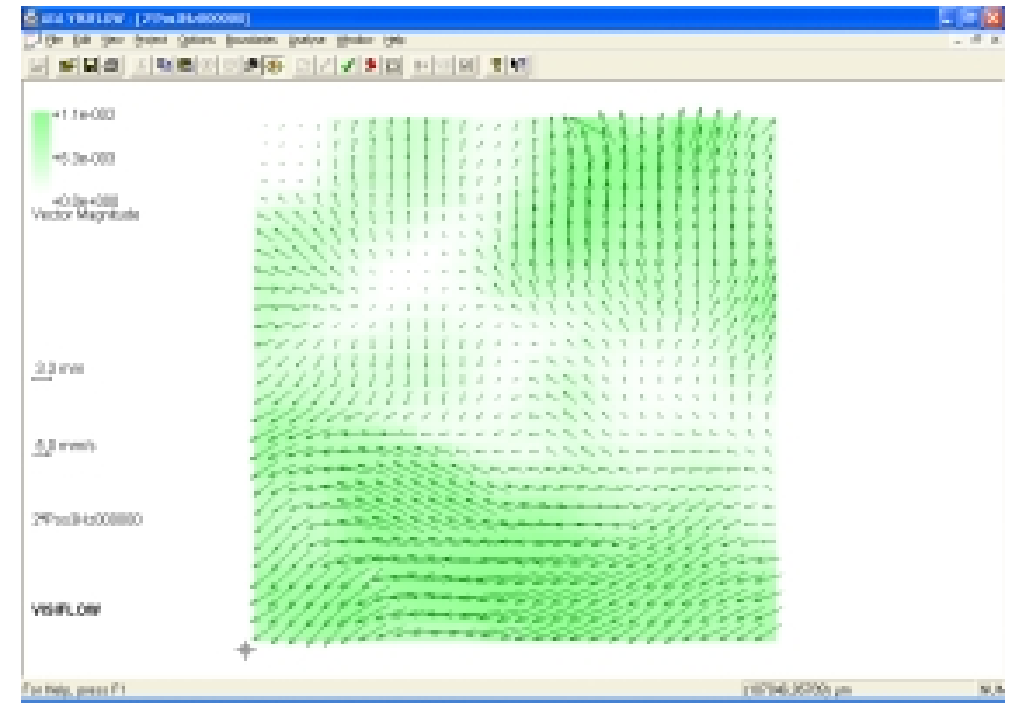

FIGURA 47 - Campo instantâneo de velocidade, para Pos 2 e frequiência 3 Hz.

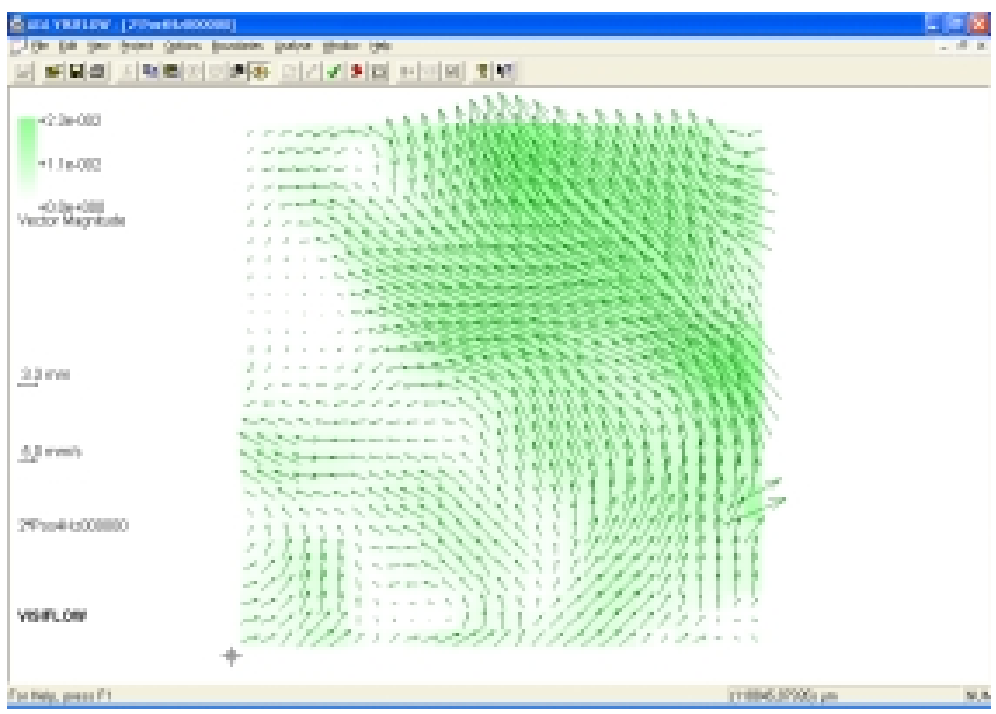

FIGURA 48 - Campo instantâneo de velocidade, para Pos 2 e frequiência 4 Hz. 


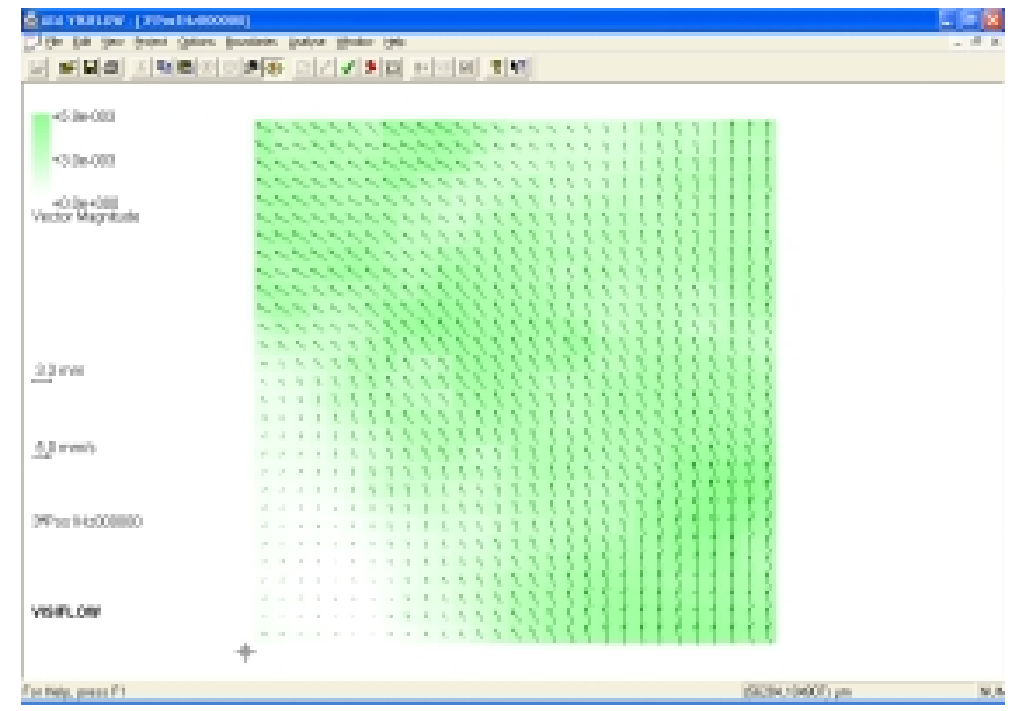

FIGURA 49 - Campo instantâneo de velocidade, para Pos 3 e frequiência $1 \mathrm{~Hz}$.

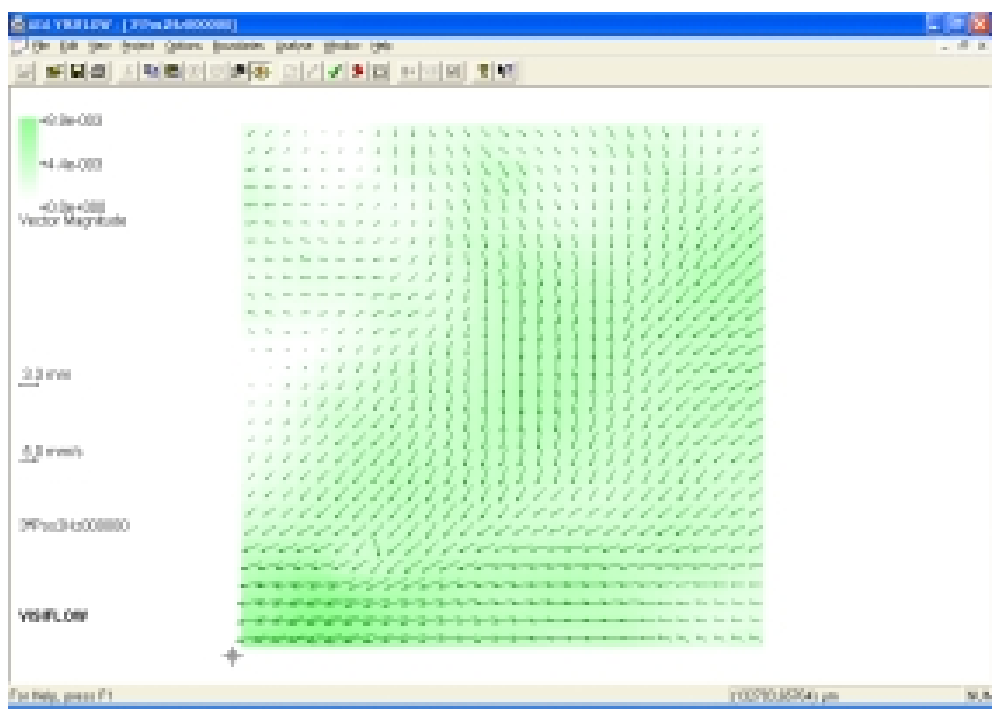

FIGURA 50 - Campo instantâneo de velocidade, para Pos 3 e frequiência 2 Hz. 


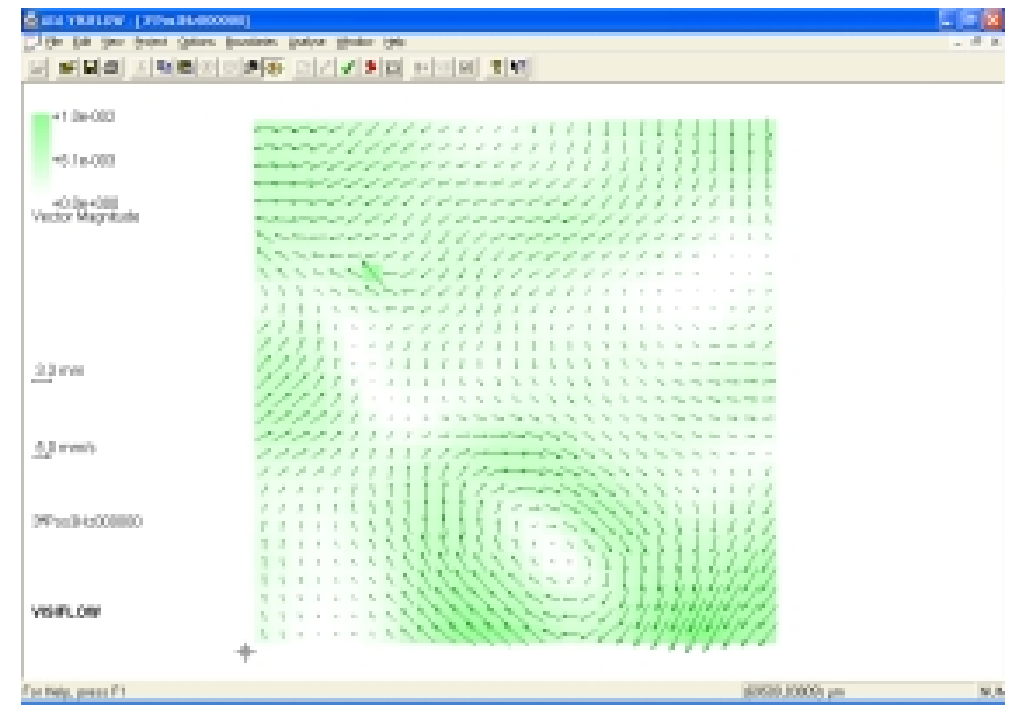

FIGURA 51 - Campo instantâneo de velocidade, para Pos 3 e frequiência 3 Hz.

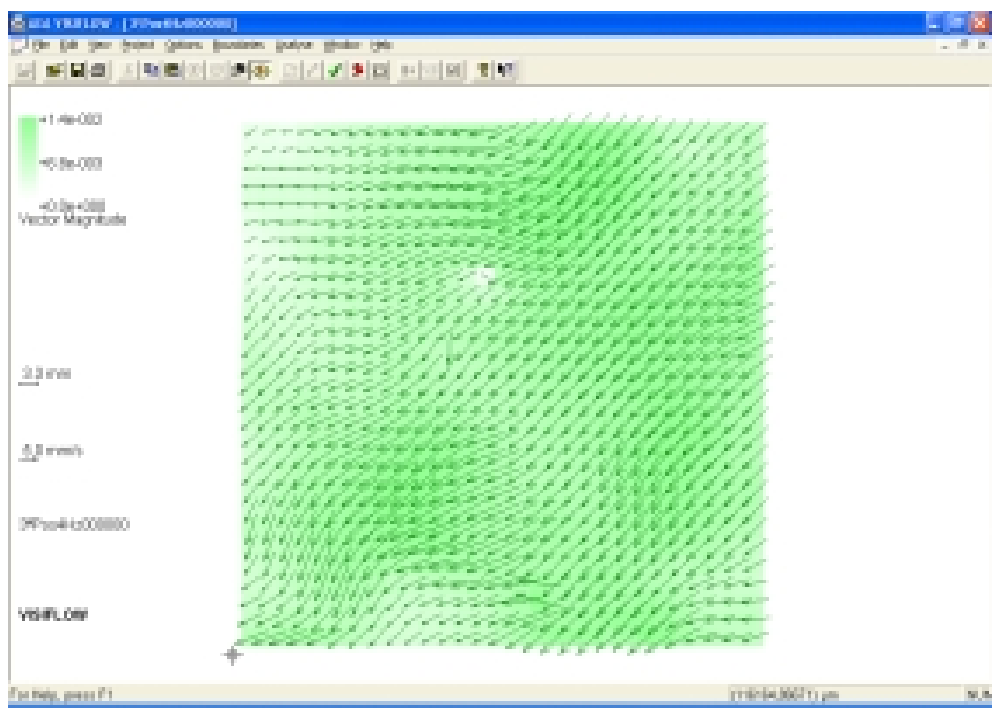

FIGURA 52 - Campo instantâneo de velocidade, para Pos 3 e freqüência 4 Hz. 


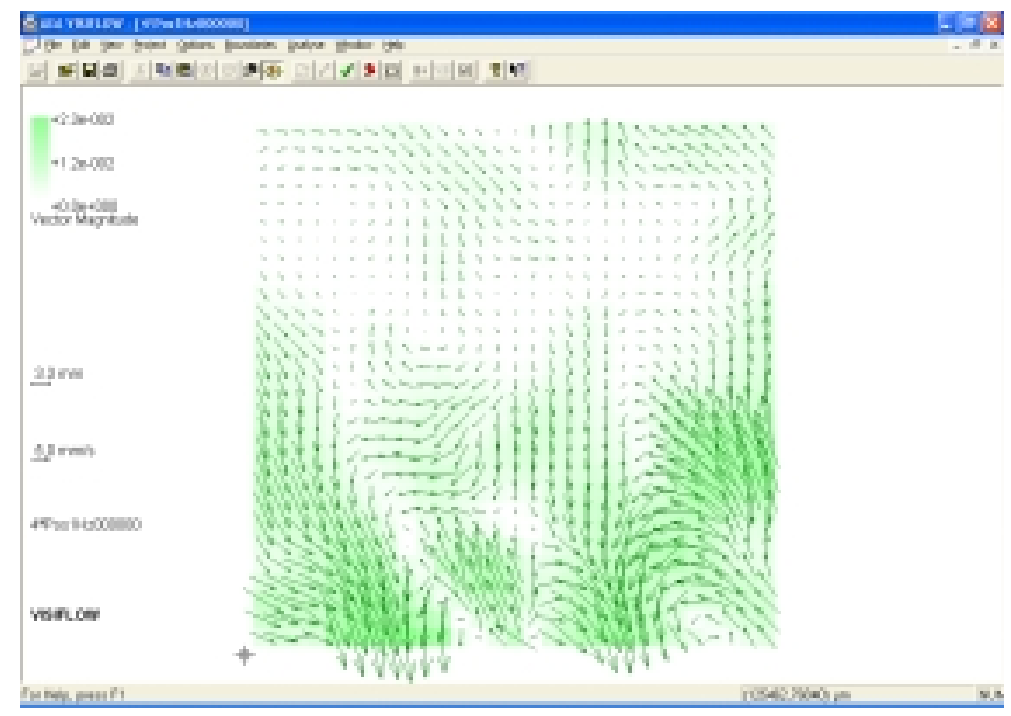

FIGURA 53 - Campo instantâneo de velocidade, para Pos 4 e frequiência $1 \mathrm{~Hz}$.

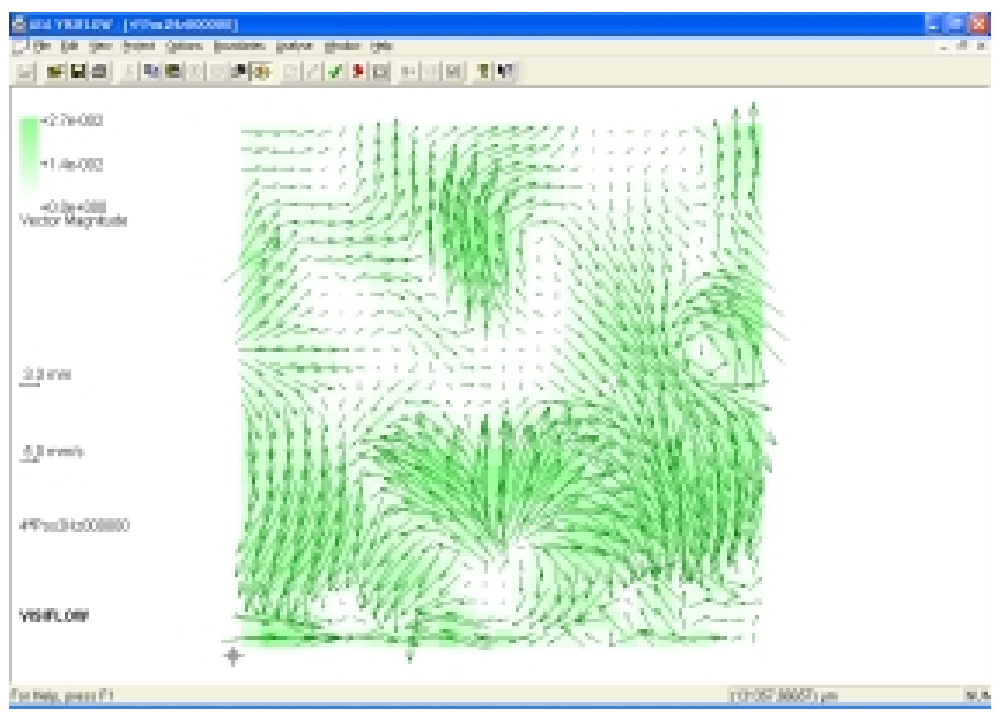

FIGURA 54 - Campo instantâneo de velocidade, para Pos 4 e freqüência 2 Hz. 


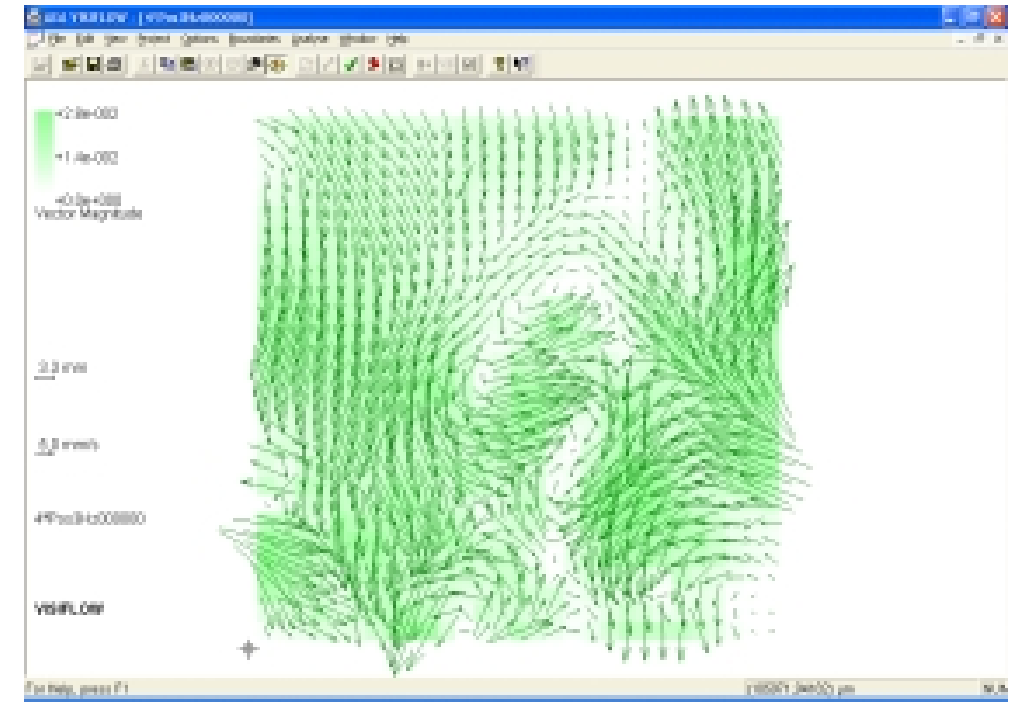

FIGURA 55 - Campo instantâneo de velocidade, para Pos 4 e freqüência 3 Hz.

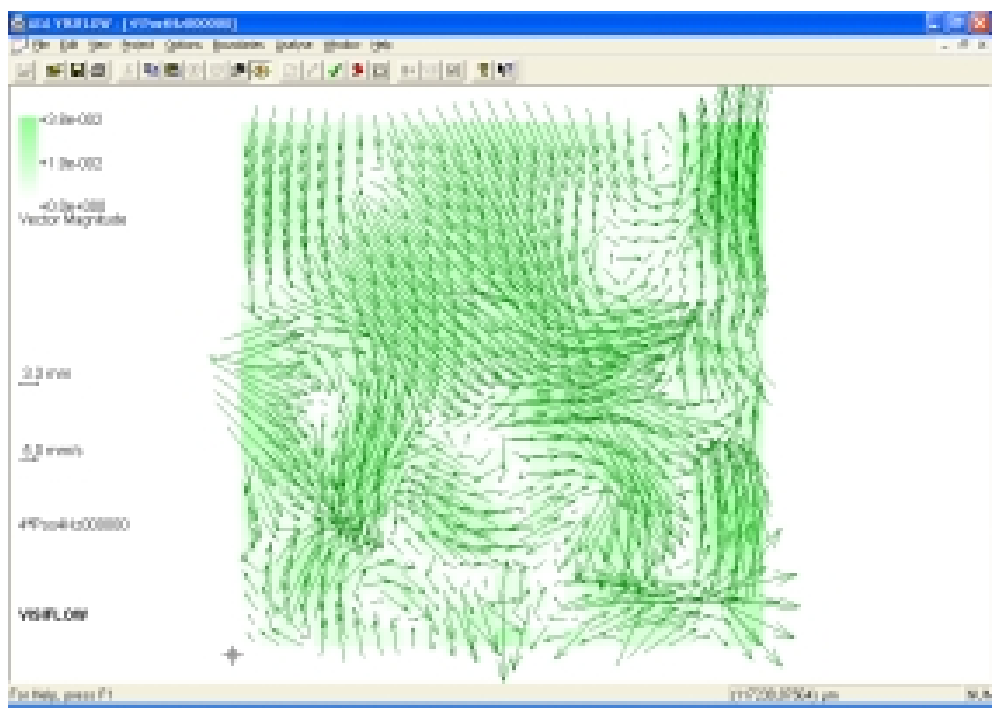

FIGURA 56 - Campo instantâneo de velocidade, para Pos 4 e freqüência 4 Hz. 


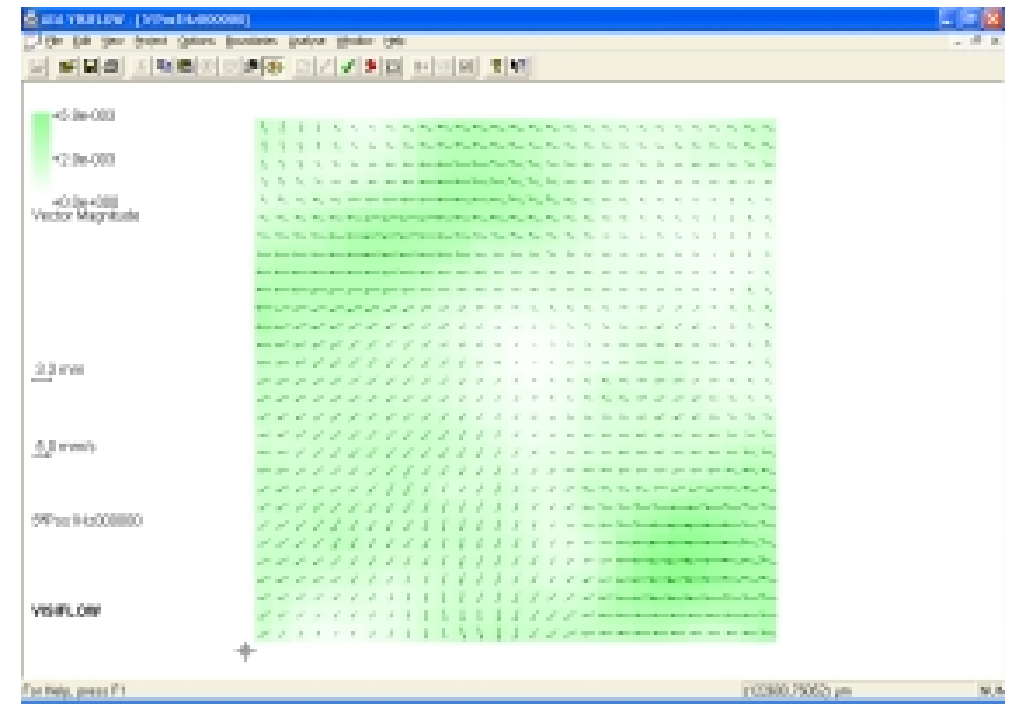

FIGURA 57 - Campo instantâneo de velocidade, para Pos 5 e frequiência $1 \mathrm{~Hz}$.

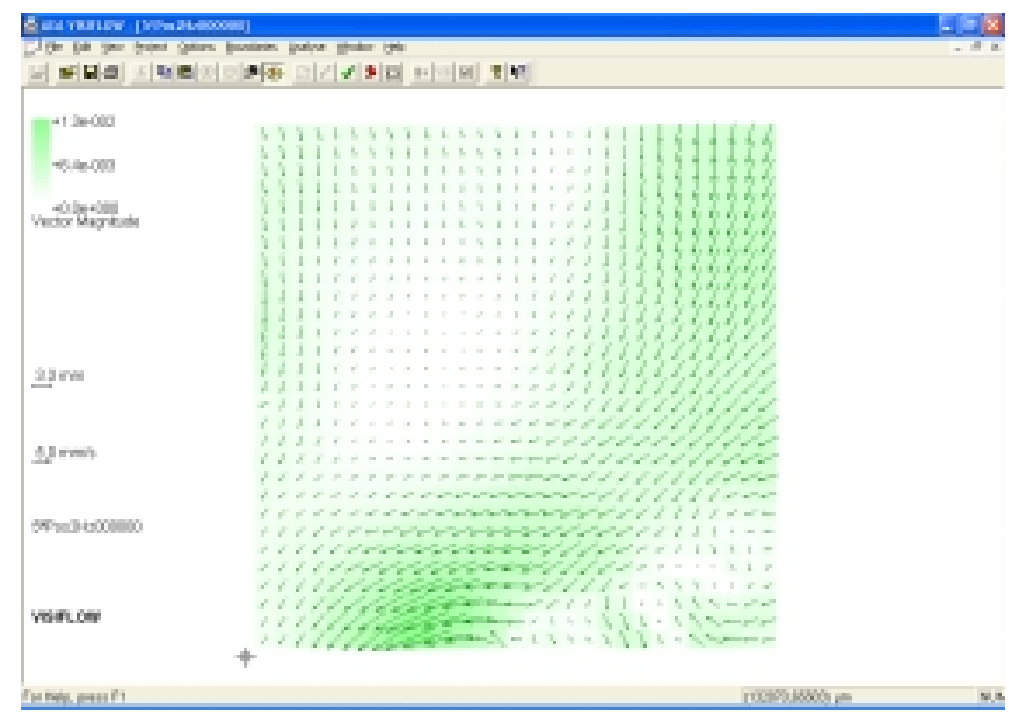

FIGURA 58 - Campo instantâneo de velocidade, para Pos 5 e freqüência 2 Hz. 


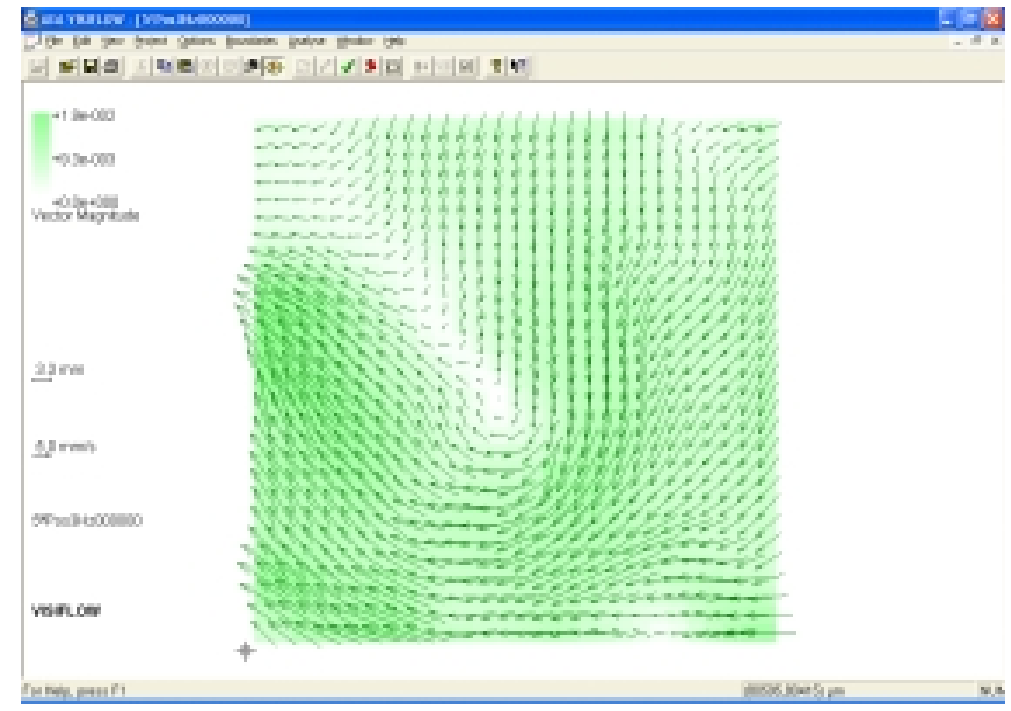

FIGURA 59 - Campo instantâneo de velocidade, para Pos 5 e frequiência 3 Hz.

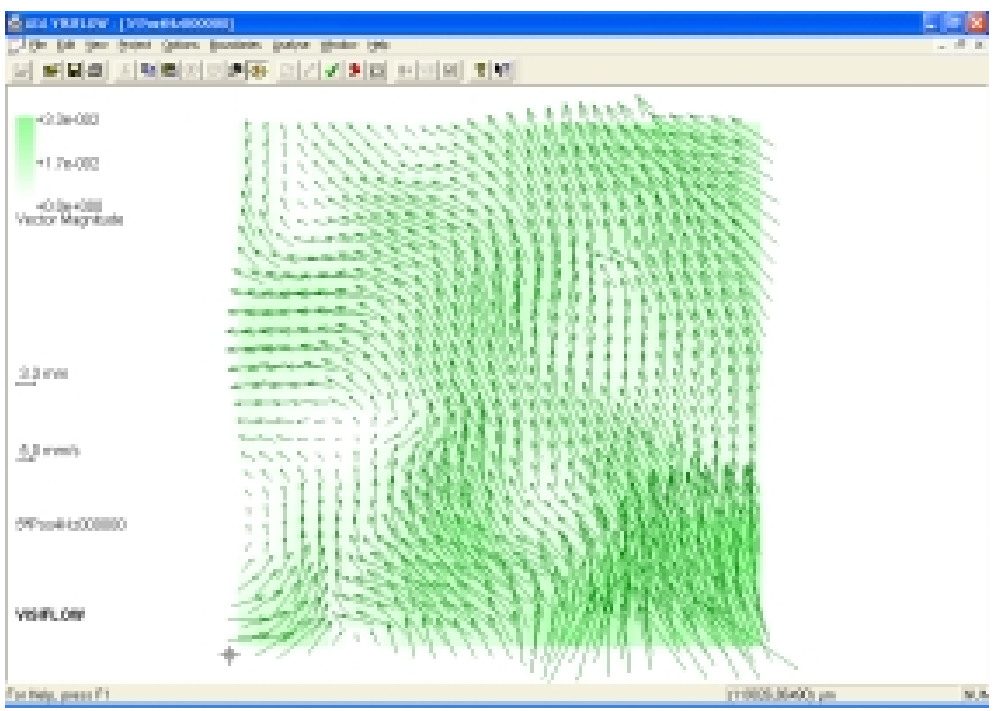

FIGURA 60 - Campo instantâneo de velocidade, para Pos 5 e freqüência 4 Hz. 


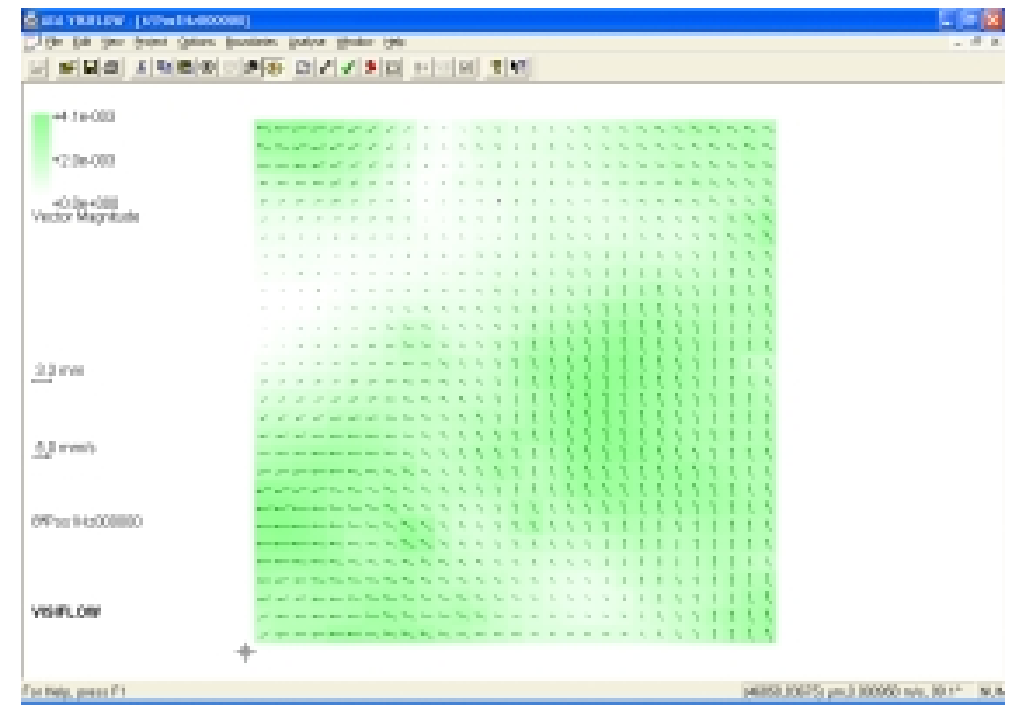

FIGURA 61 - Campo instantâneo de velocidade, para Pos 6 e frequiência $1 \mathrm{~Hz}$.

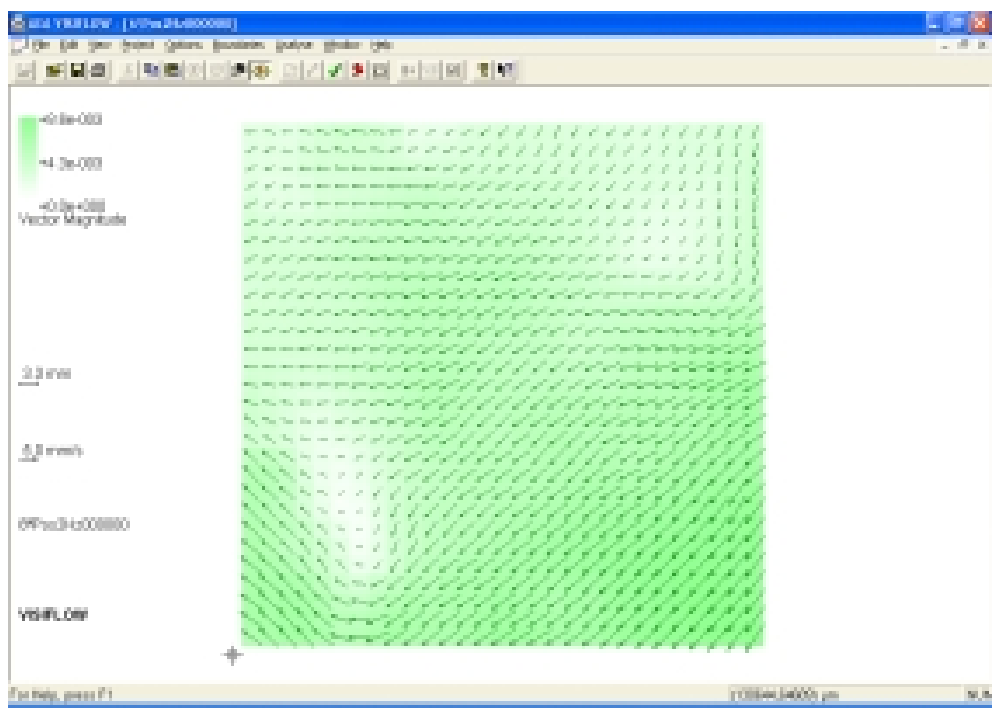

FIGURA 62 - Campo instantâneo de velocidade, para Pos 6 e freqüência 2 Hz. 


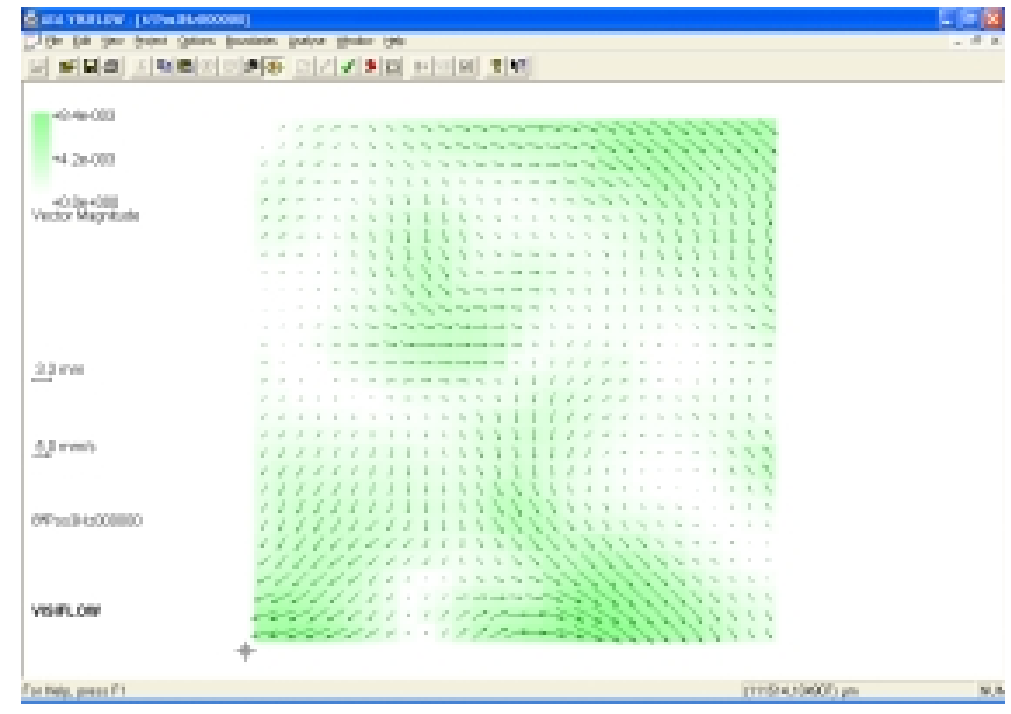

FIGURA 63 - Campo instantâneo de velocidade, para Pos 6 e frequiência 3 Hz.

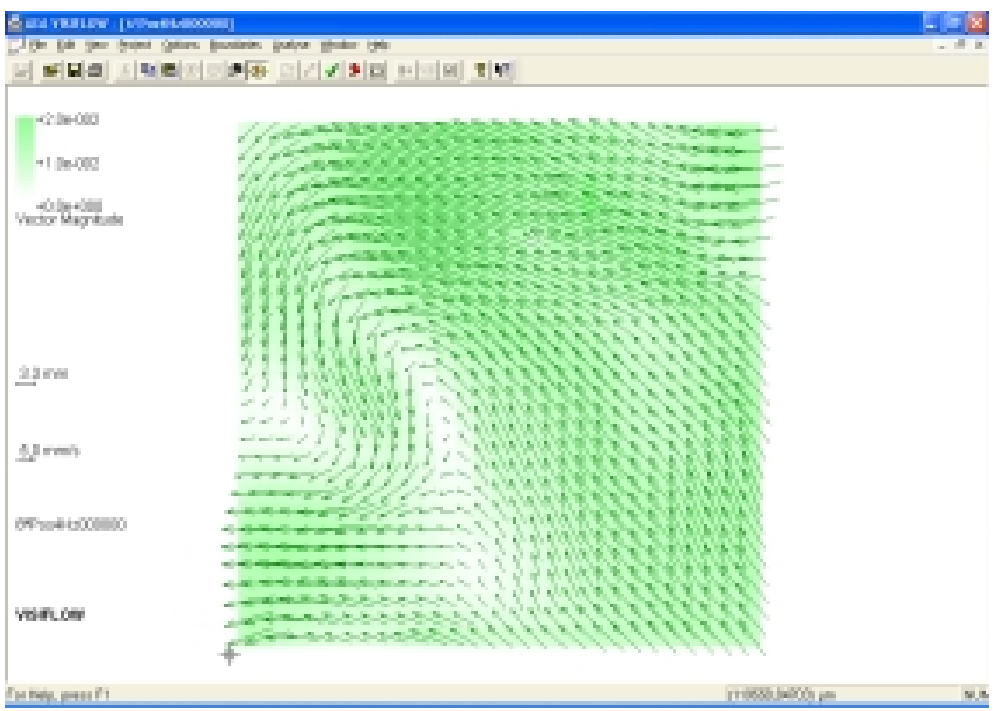

FIGURA 64 - Campo instantâneo de velocidade, para Pos 6 e freqüência 4 Hz. 


\section{Campos médios de velocidade}

Apresenta-se nas FIGURAS 65-86 os campos médios de velocidade, obtidos a partir de cada freqüência de 200 campos instantâneos, para cada uma das 22 situações de frequiência de posição da câmera e freqüência da grade, que não foram ilustradas no Capítulo 5.

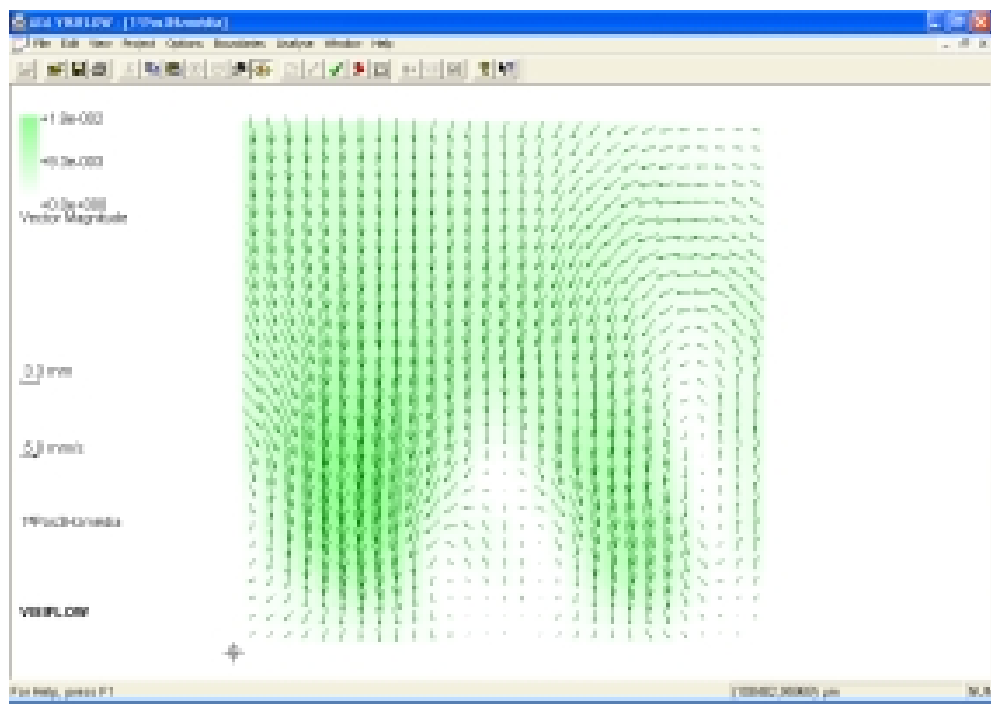

FIGURA 65 - Campo médio de velocidade para Pos 1 e freqüência $3 \mathrm{~Hz}$.

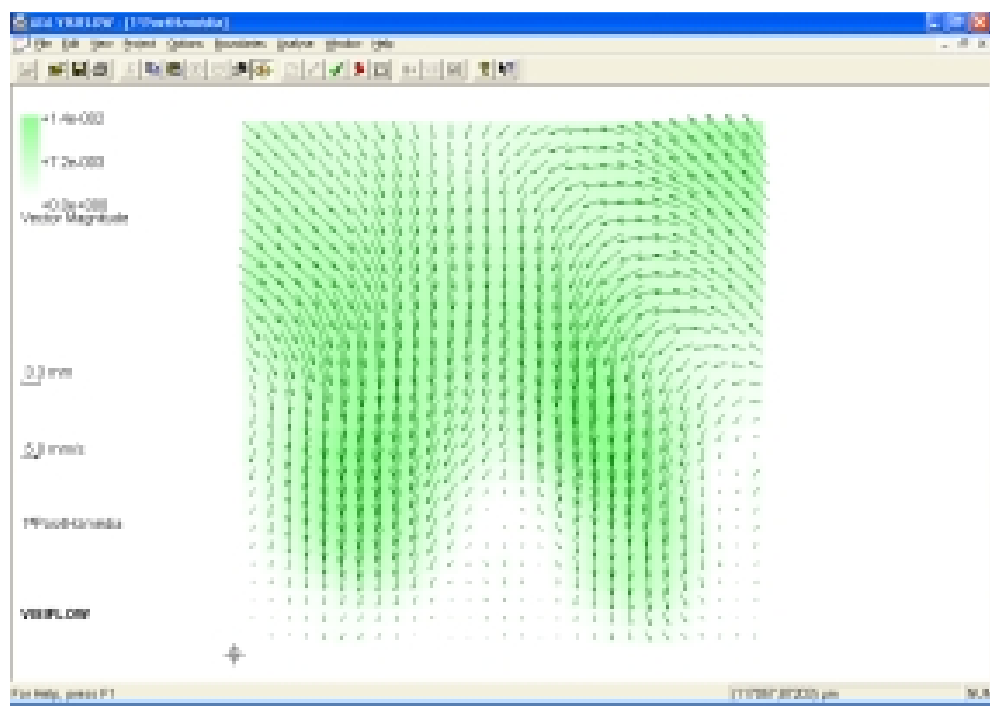

FIGURA 66 - Campo médio de velocidade para Pos 1 e freqüência 4 Hz. 


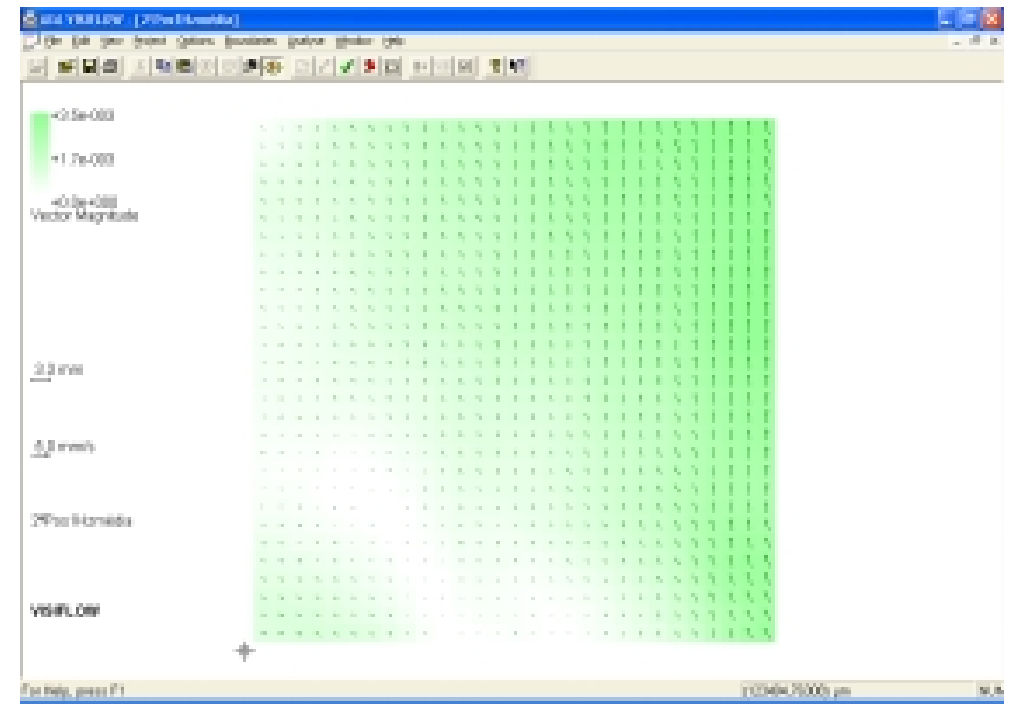

FIGURA 67 - Campo médio de velocidade para Pos 2 e freqüência $1 \mathrm{~Hz}$.

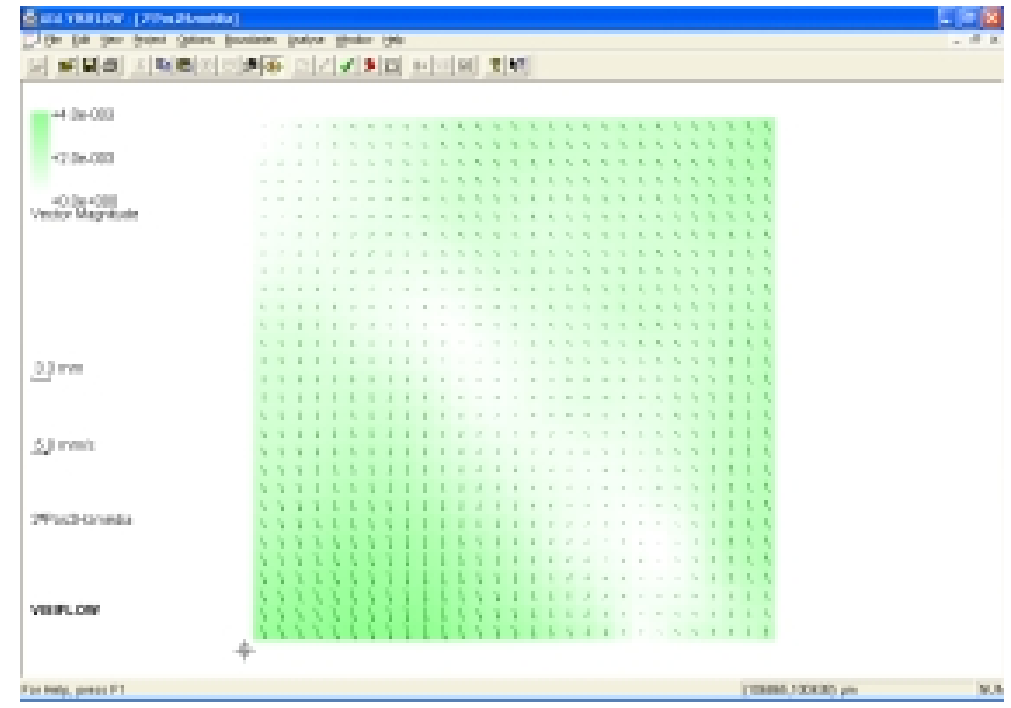

FIGURA 68 - Campo médio de velocidade para Pos 2 e freqüência $2 \mathrm{~Hz}$. 


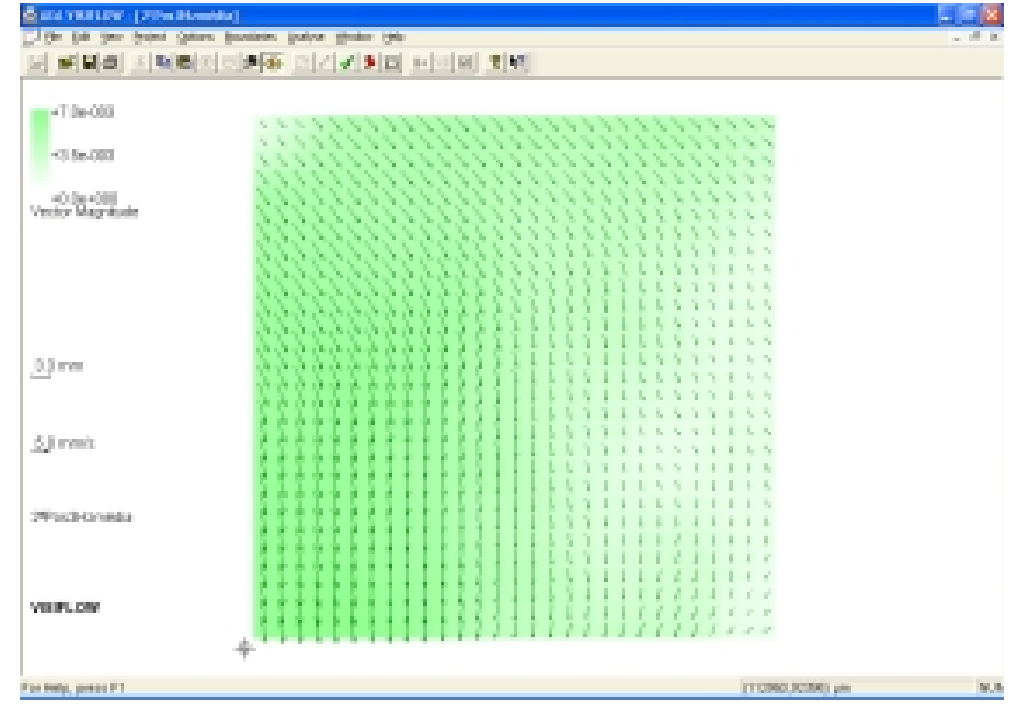

FIGURA 69 - Campo médio de velocidade para Pos 2 e freqüência $3 \mathrm{~Hz}$.

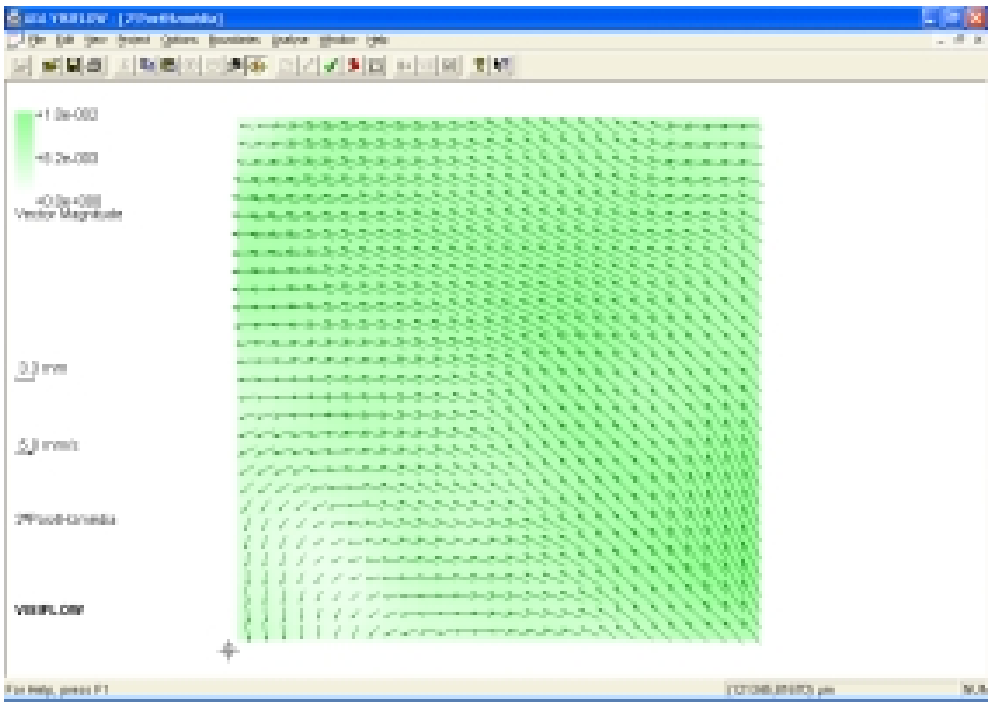

FIGURA 70 - Campo médio de velocidade para Pos 2 e frequiência 4 Hz. 


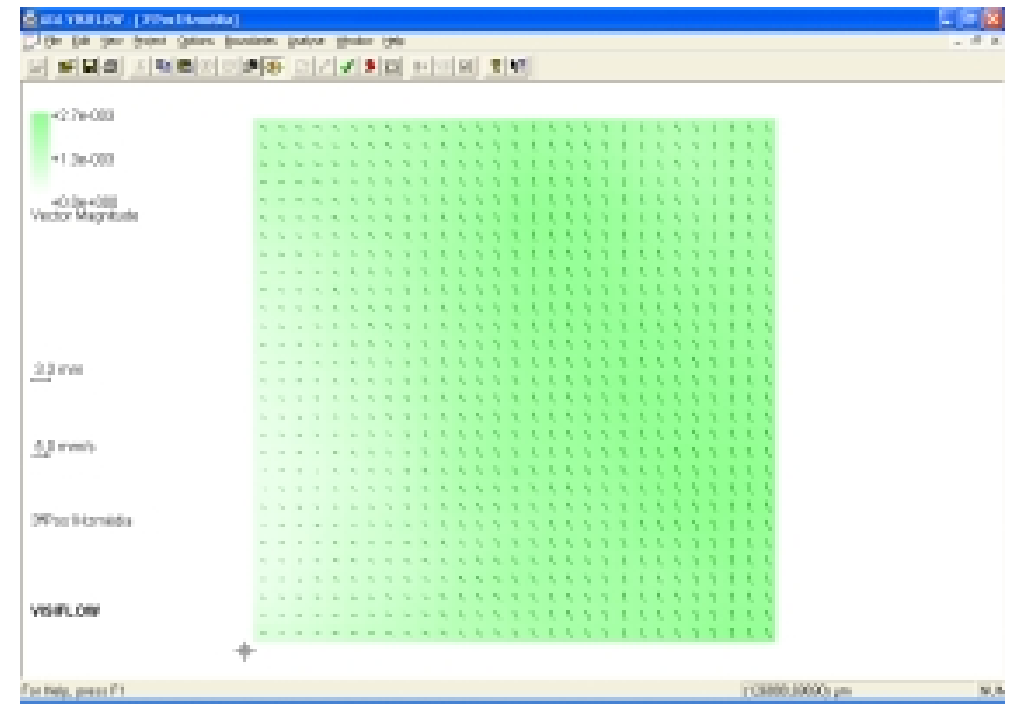

FIGURA 71 - Campo médio de velocidade para Pos 3 e freqüência $1 \mathrm{~Hz}$.

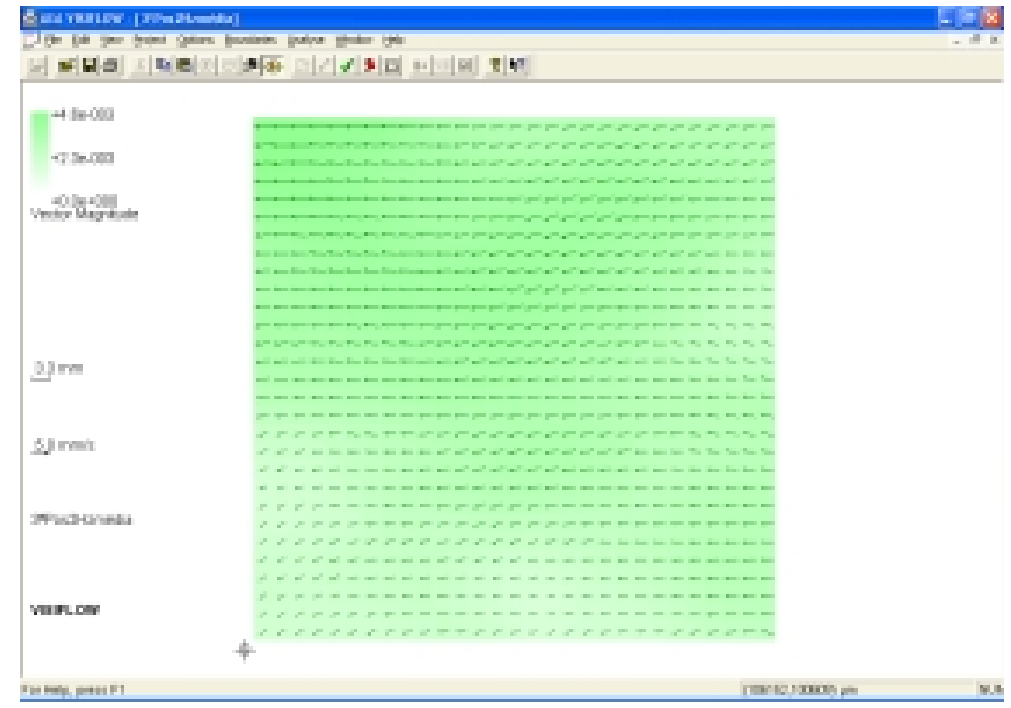

FIGURA 72 - Campo médio de velocidade para Pos 3 e frequiência $2 \mathrm{~Hz}$. 


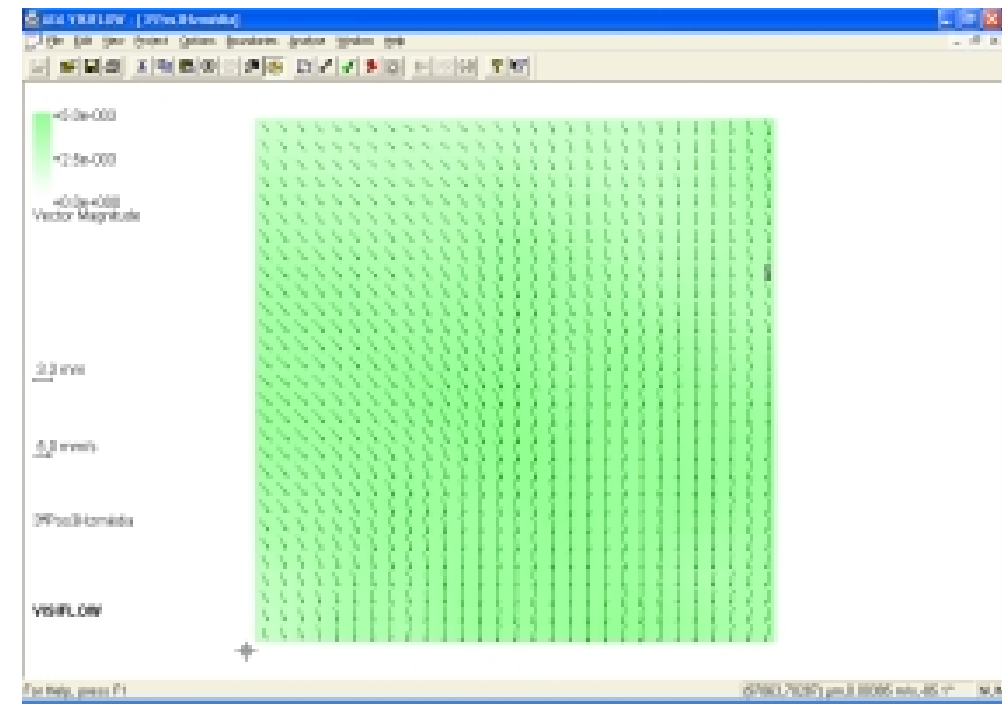

FIGURA 73 - Campo médio de velocidade para Pos 3 e freqüência $3 \mathrm{~Hz}$.

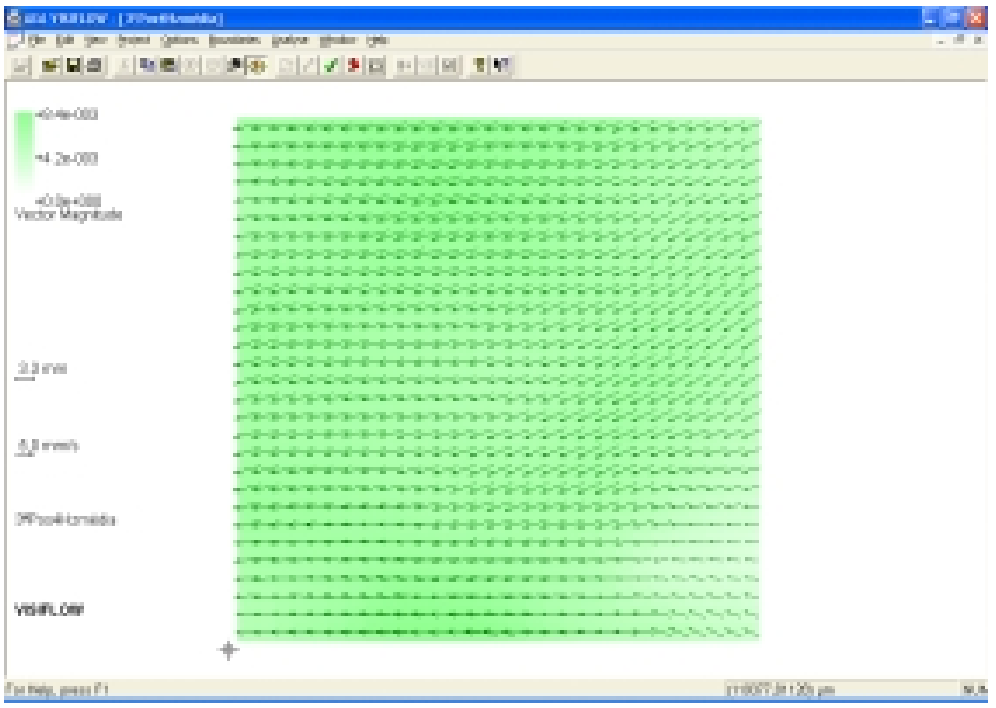

FIGURA 74 - Campo médio de velocidade para Pos 3 e frequiência 4 Hz. 


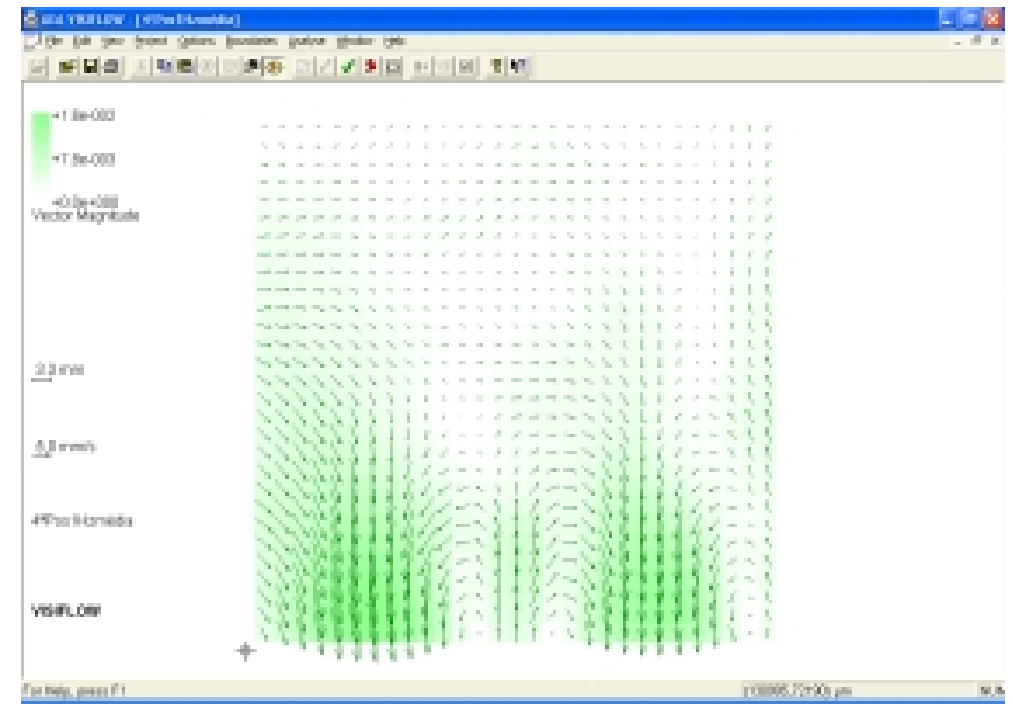

FIGURA 75 - Campo médio de velocidade para Pos 4 e freqüência $1 \mathrm{~Hz}$.

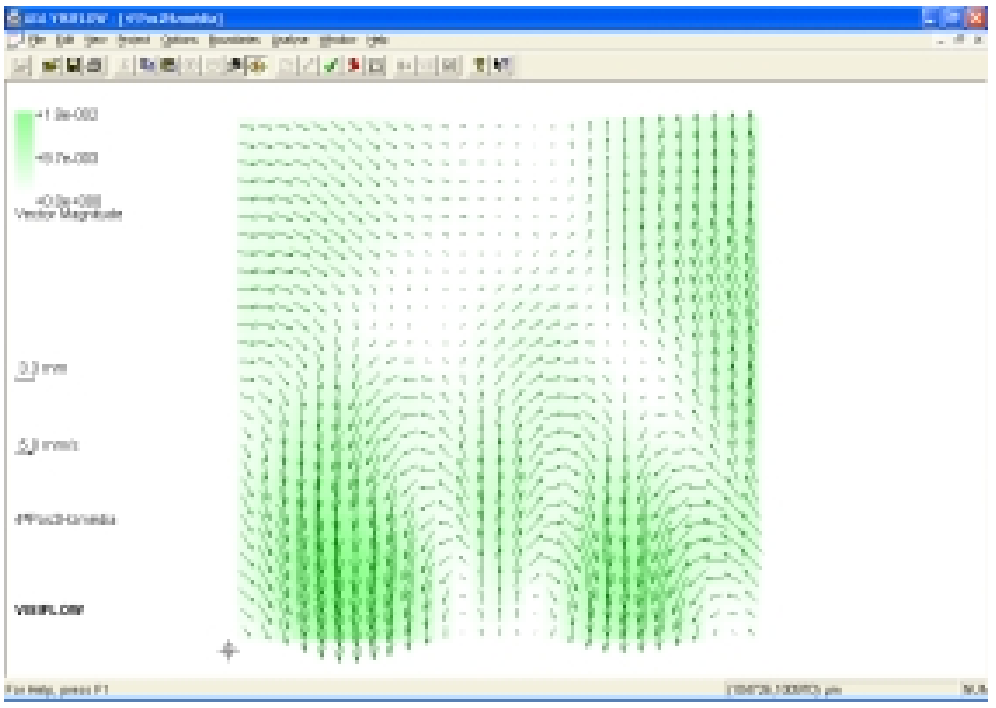

FIGURA 76 - Campo médio de velocidade para Pos 4 e frequiência $2 \mathrm{~Hz}$. 


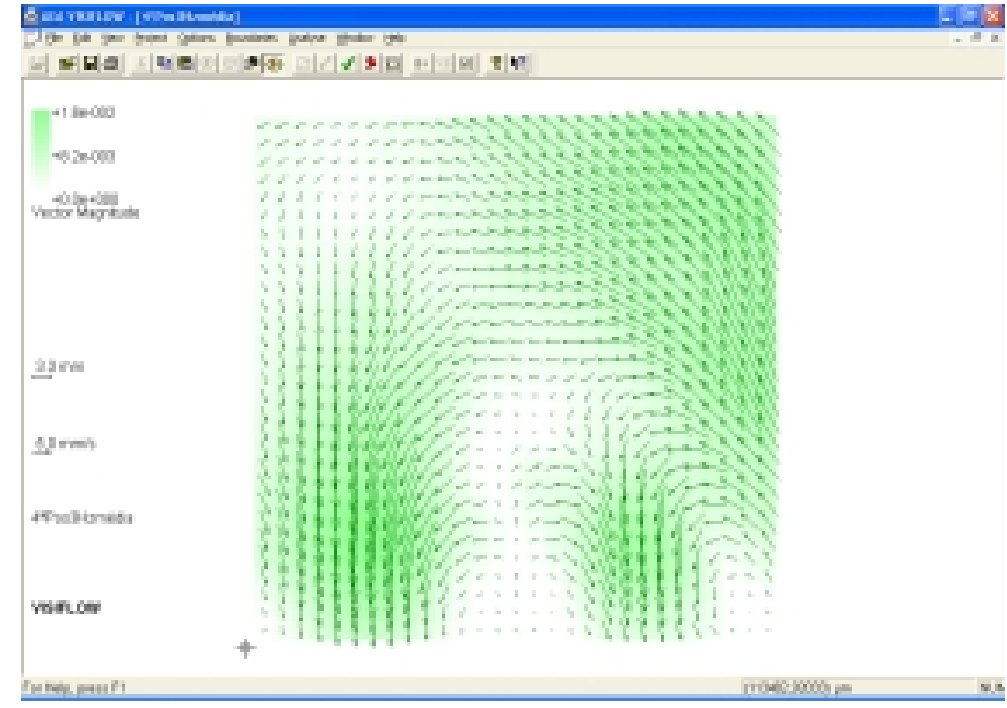

FIGURA 77 - Campo médio de velocidade para Pos 4 e freqüência $3 \mathrm{~Hz}$

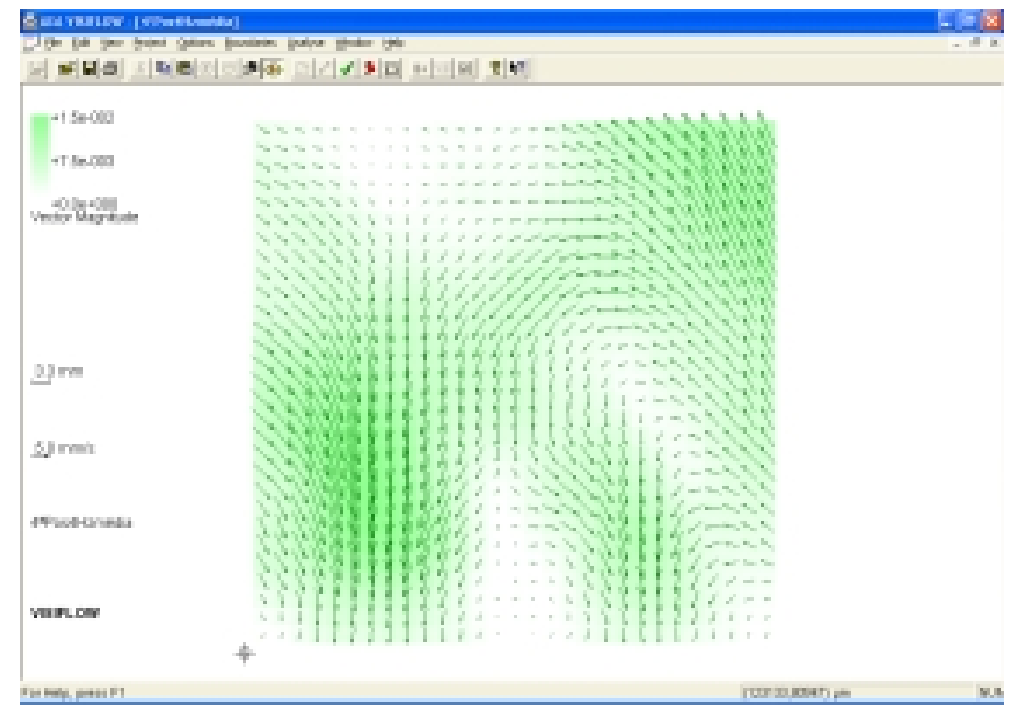

FIGURA 78 - Campo médio de velocidade para Pos 4 e frequiência 4 Hz. 


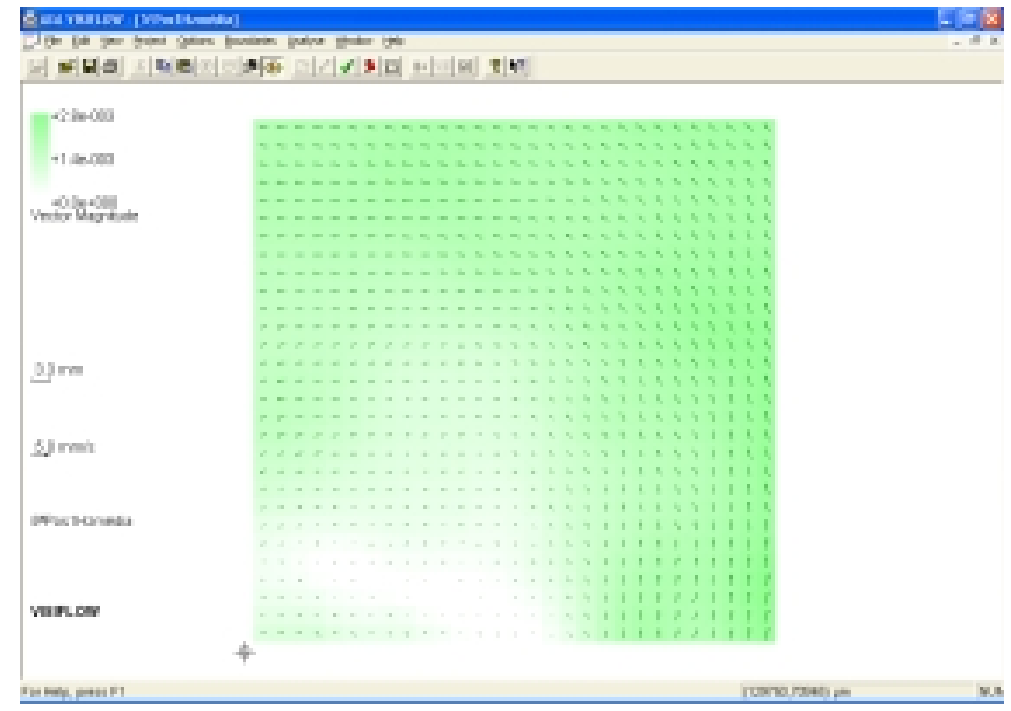

FIGURA 79 - Campo médio de velocidade para Pos 5 e frequiência $1 \mathrm{~Hz}$.

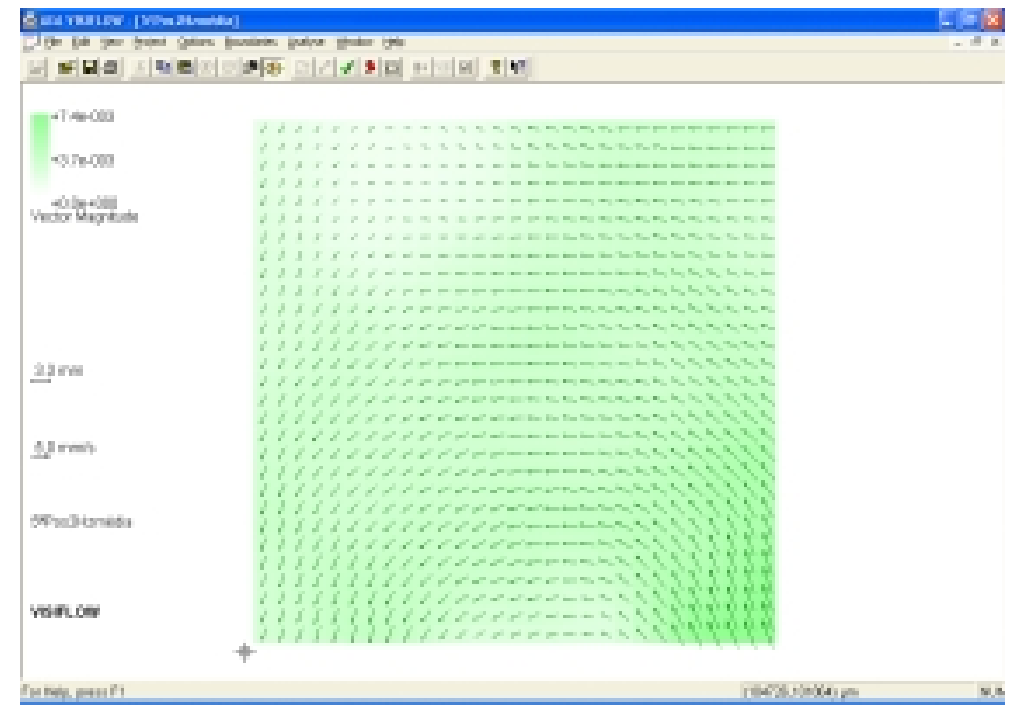

FIGURA 80 - Campo médio de velocidade para Pos 5 e freqüência $2 \mathrm{~Hz}$. 


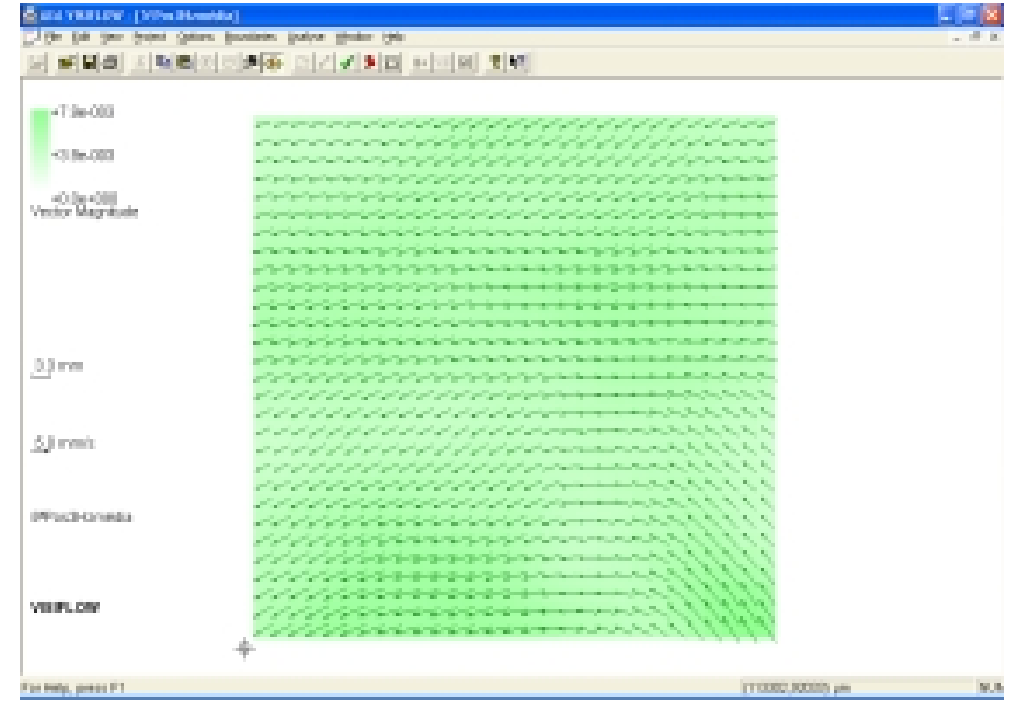

FIGURA 81 - Campo médio de velocidade para Pos 5 e freqüência $3 \mathrm{~Hz}$.

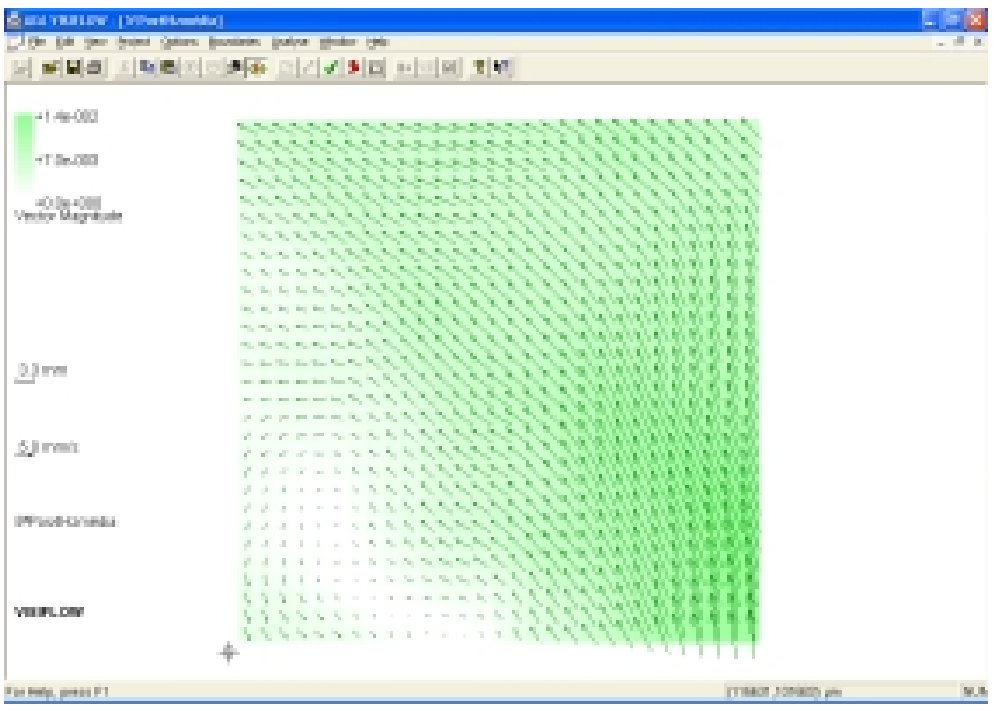

FIGURA 82 - Campo médio de velocidade para Pos 5 e frequiência 4 Hz. 


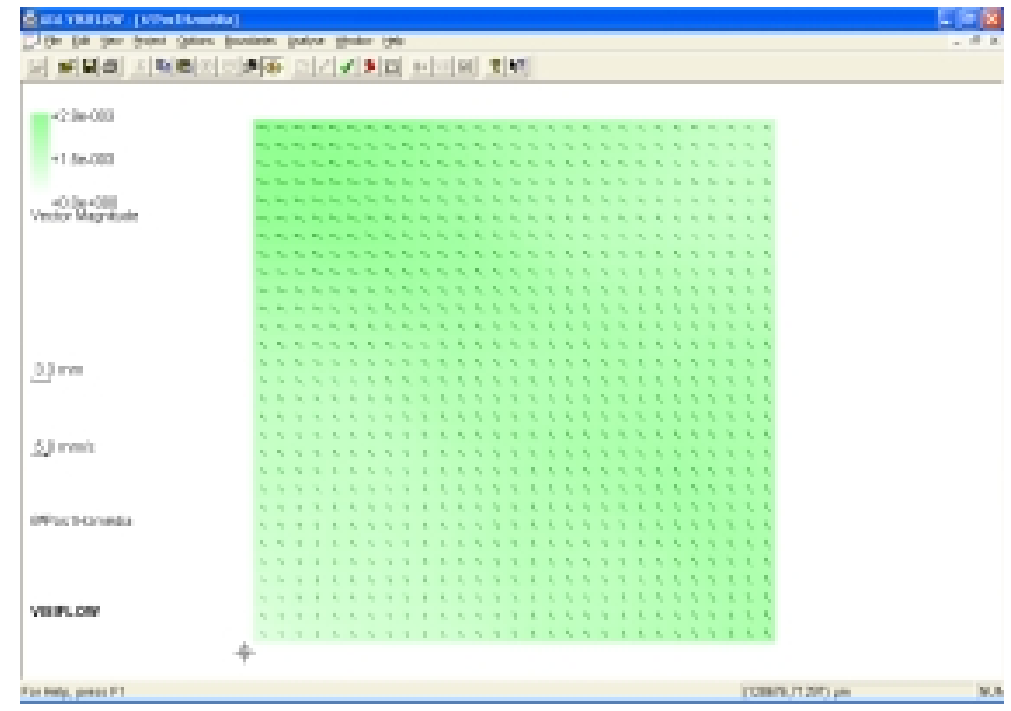

FIGURA 83 - Campo médio de velocidade para Pos 6 e freqüência $1 \mathrm{~Hz}$.

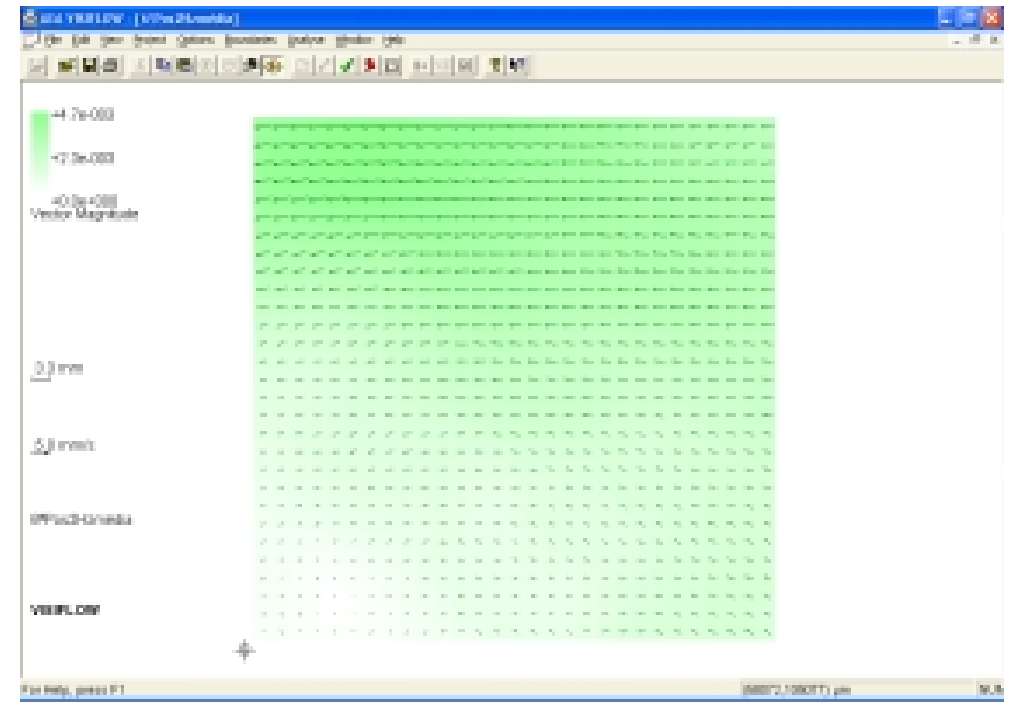

FIGURA 84 - Campo médio de velocidade para Pos 6 e frequiência $2 \mathrm{~Hz}$. 


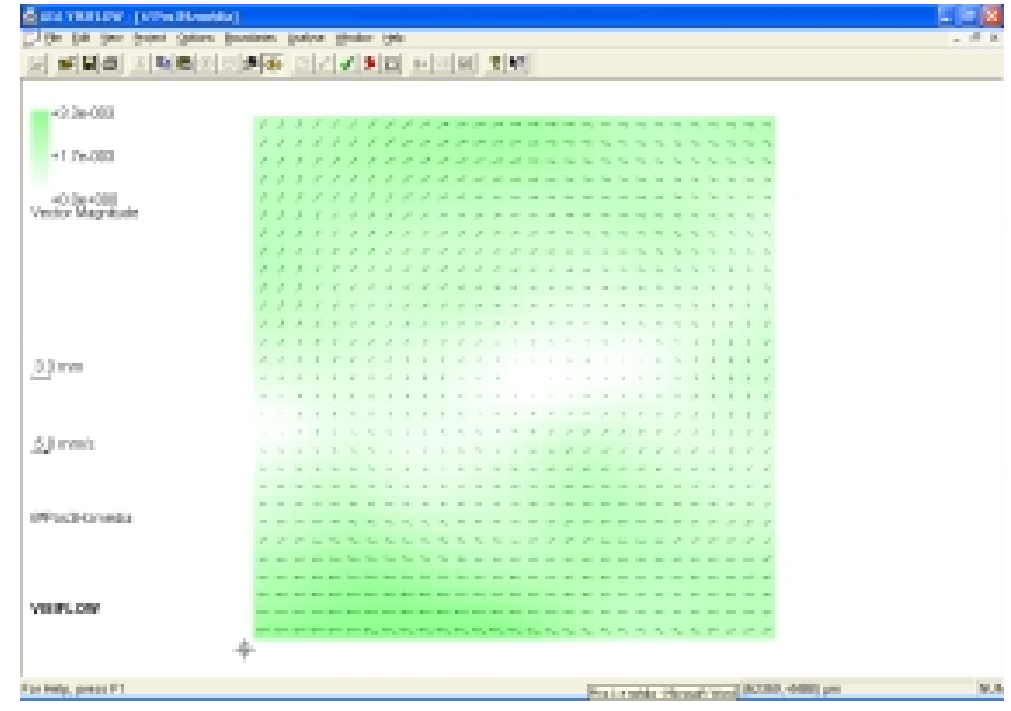

FIGURA 85 - Campo médio de velocidade para Pos 6 e freqüência $3 \mathrm{~Hz}$.

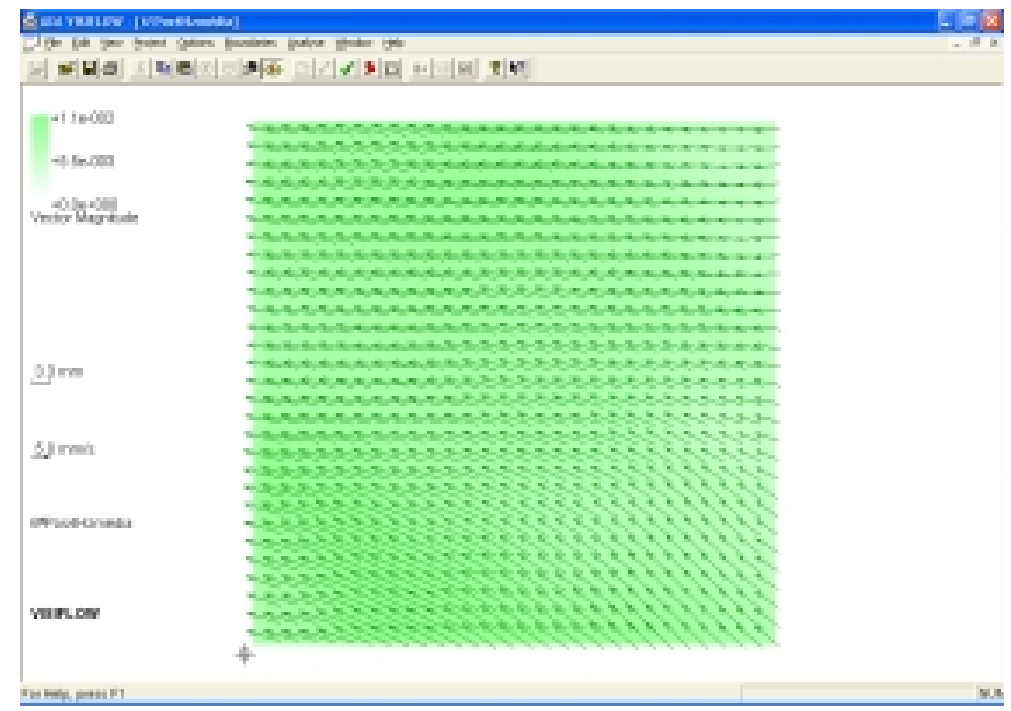

FIGURA 86 - Campo médio de velocidade para Pos 6 e frequiência $4 \mathrm{~Hz}$. 


\section{Distribuição horizontal de u, w e i}

Apresenta-se nas FIGURAS 87-92 a distribuição horizontal de $\mathbf{u}, \mathbf{w}$ e i, para o Plano 1 (sobre a barra) e frequiências de $3 \mathrm{~Hz}$ e $4 \mathrm{~Hz}$, e para o Plano 2 (entre barras) e freqüências de $1,2,3$ e $4 \mathrm{~Hz}$.

Sobre a barra - $3 \mathrm{~Hz}$
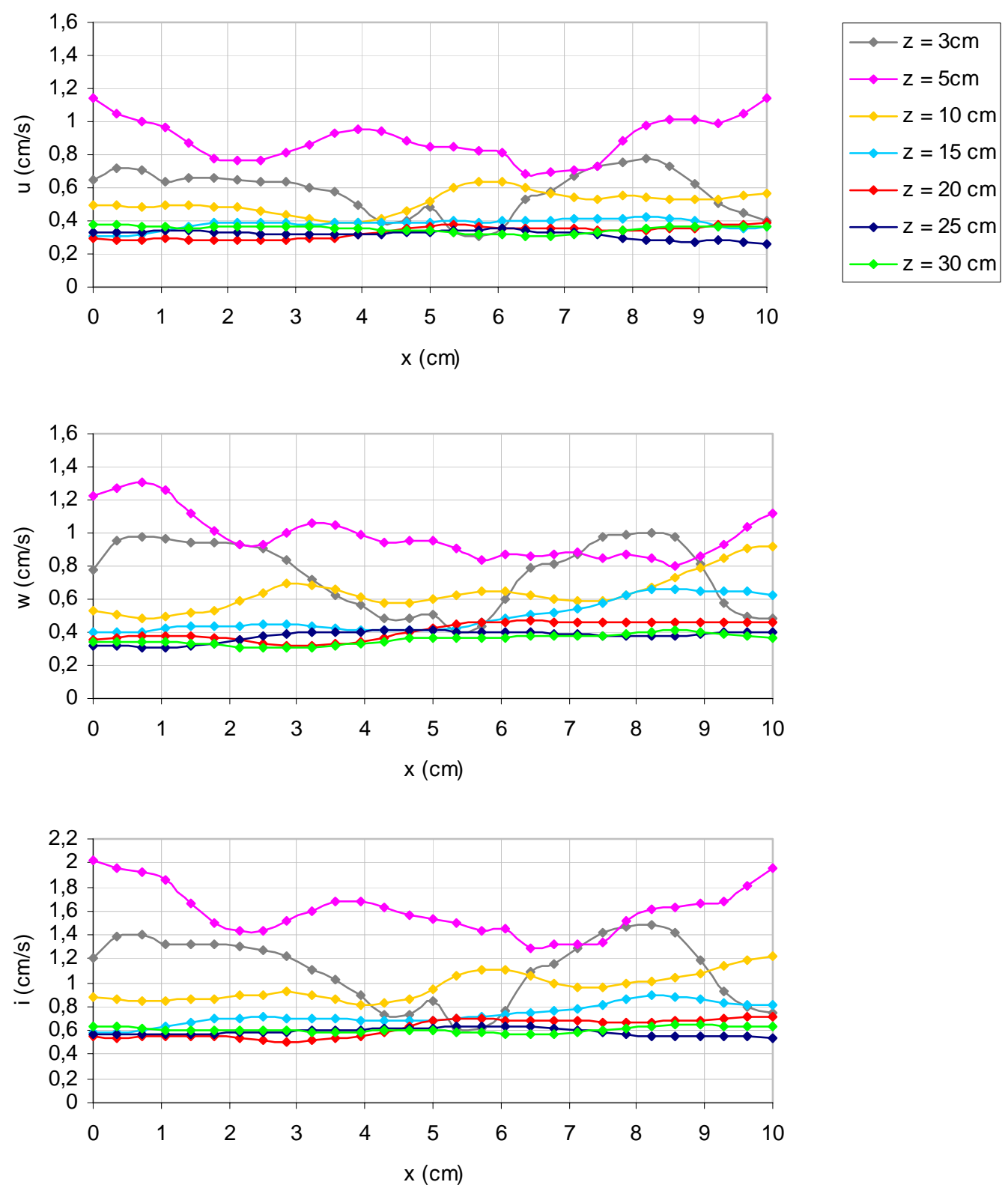

FIGURA 87 - Distribuição horizontal de u, w e i, para o Plano 1 e freqüência 3 Hz. 
Sobre a barra - $4 \mathrm{~Hz}$
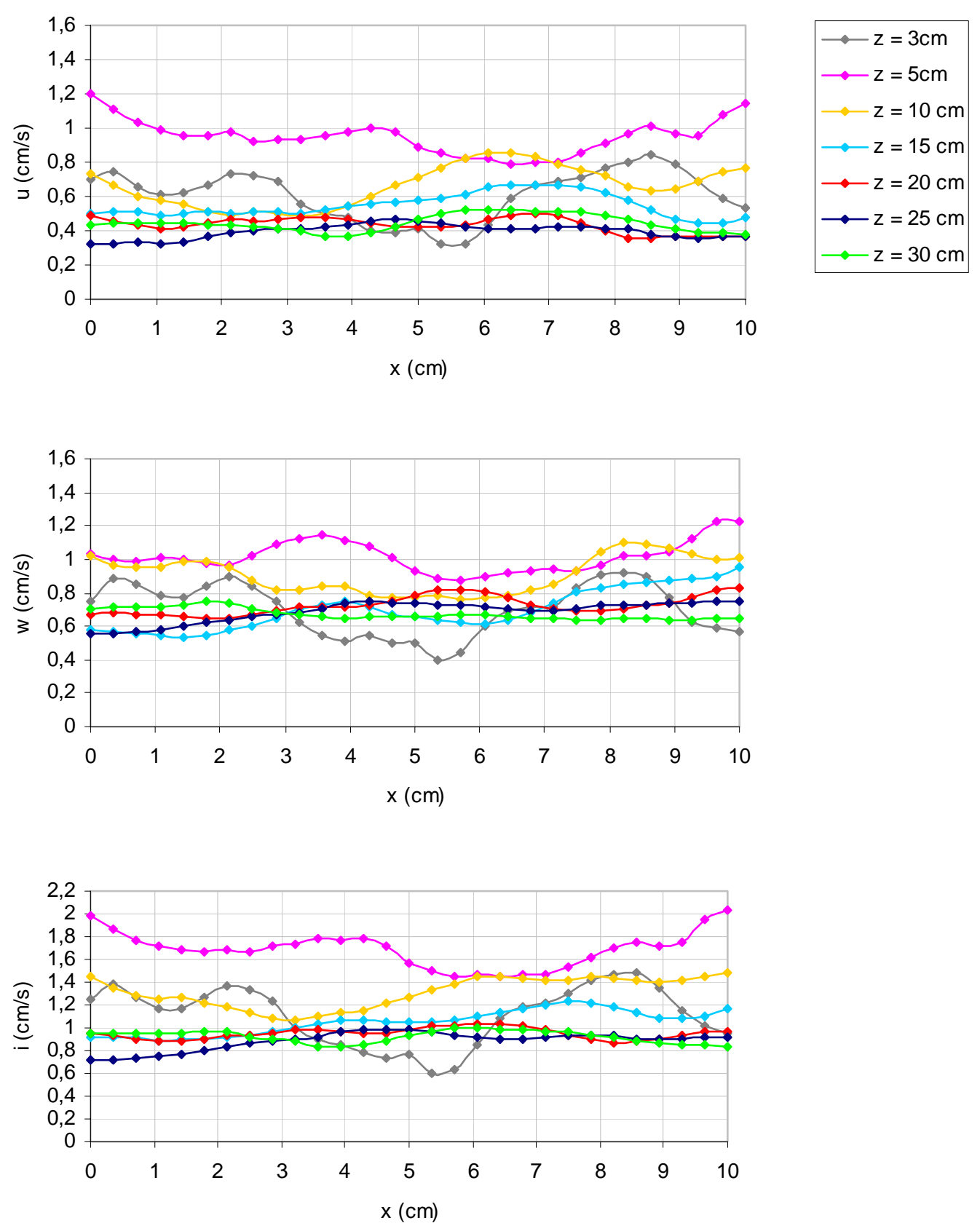

FIGURA 88 - Distribuição horizontal de u, w e i, para o Plano 1 e frequiência 4 Hz. 
Entre barras - $1 \mathrm{~Hz}$
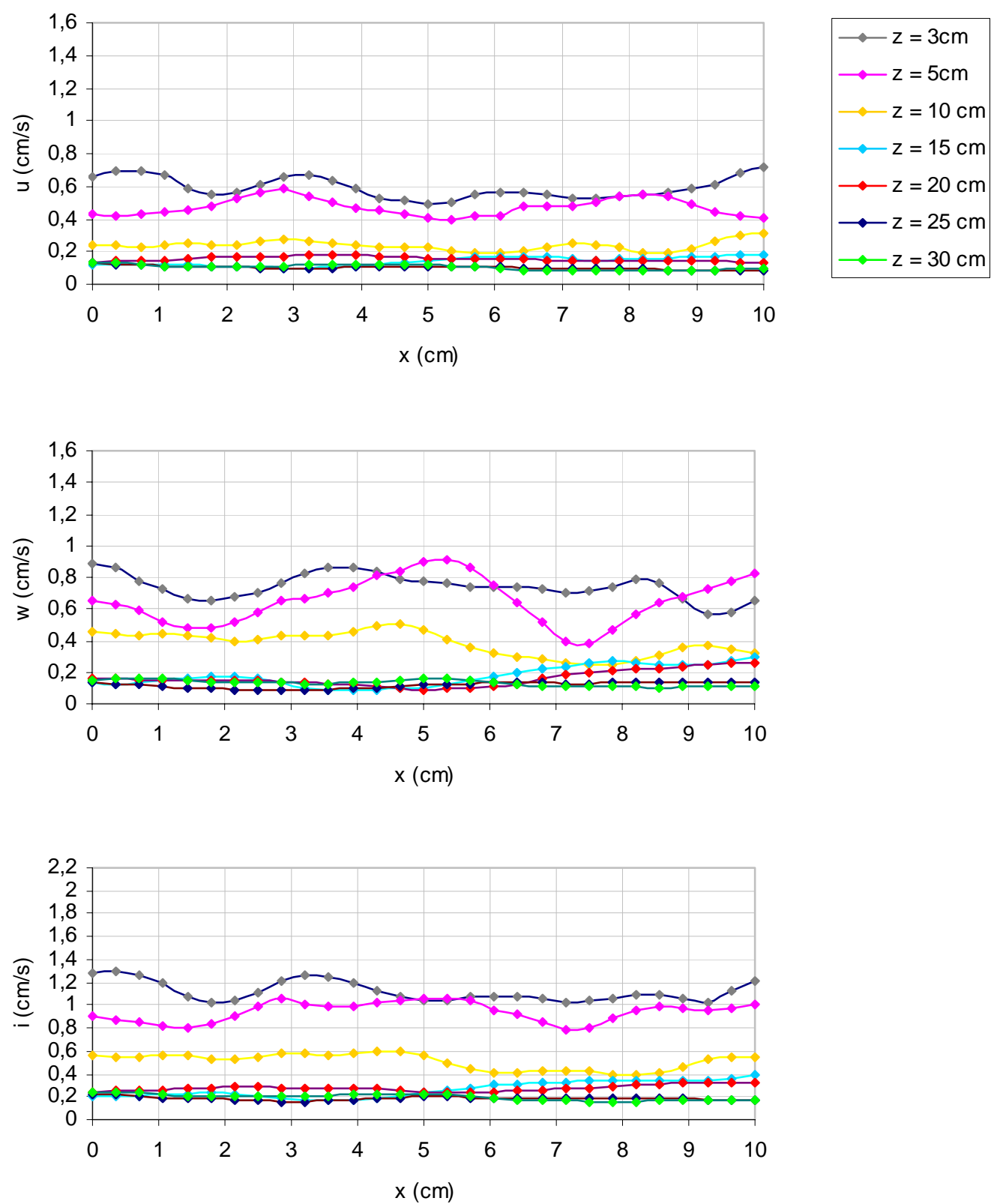

FIGURA 89 - Distribuição horizontal de u, w e i, para o Plano 2 e freqüência $1 \mathrm{~Hz}$. 
Entre barras $-2 \mathrm{~Hz}$
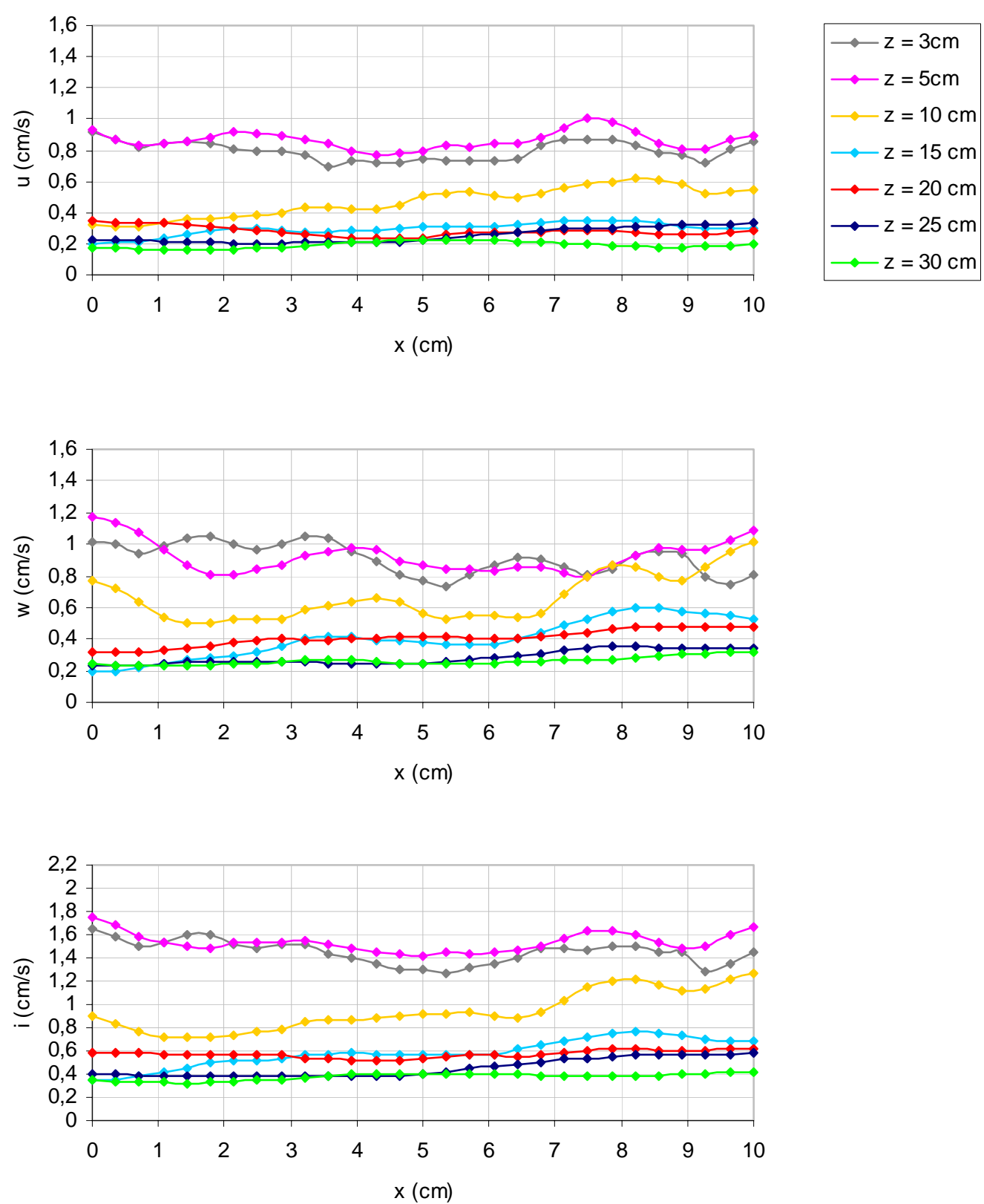

FIGURA 90 - Distribuição horizontal de u, w e i, para o Plano 2 e freqüência 2 Hz. 
Entre barras - $3 \mathrm{~Hz}$
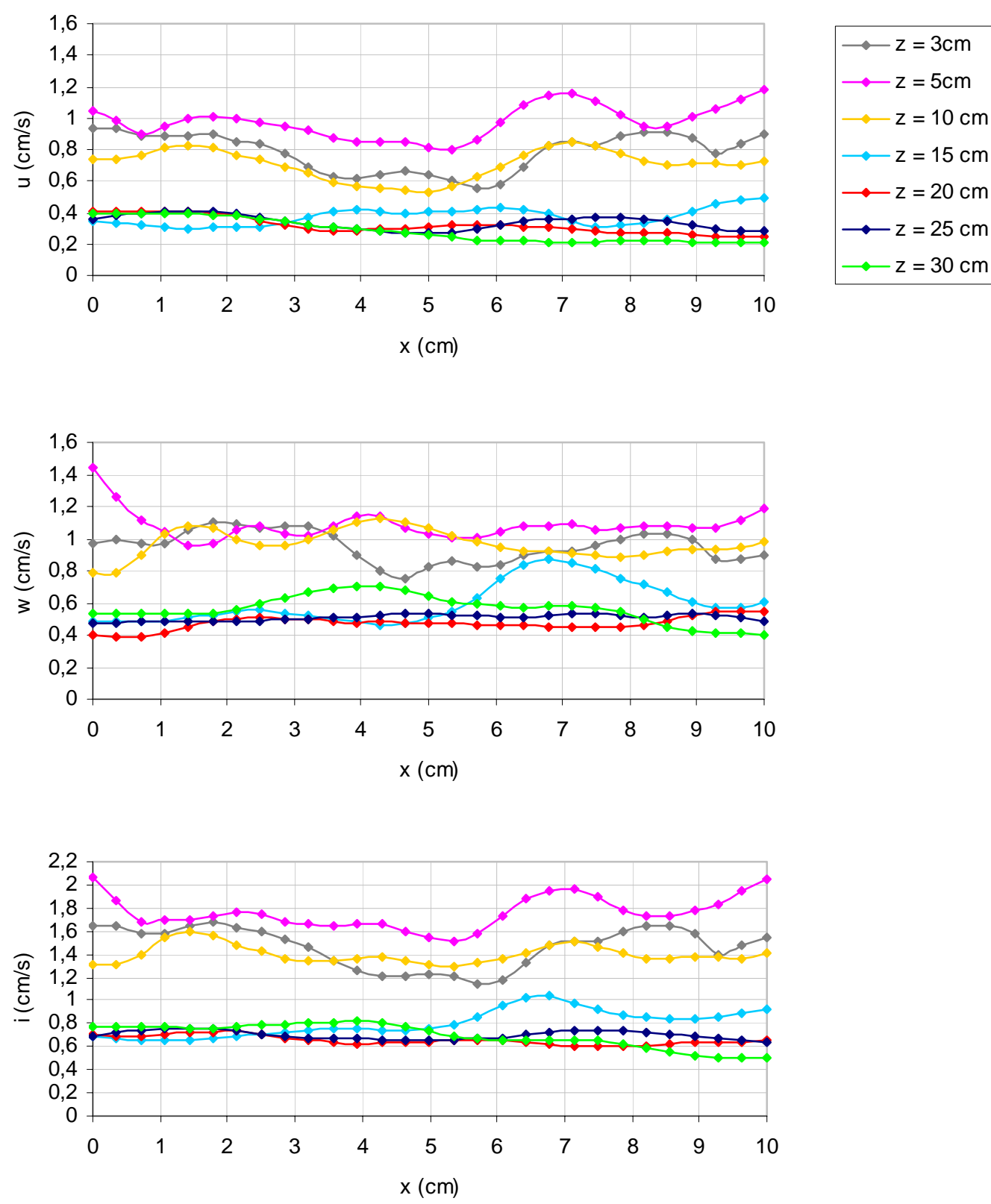

FIGURA 91 - Distribuição horizontal de u, w e i, para o Plano 2 e freqüência 3 Hz. 
Entre barras - $4 \mathrm{~Hz}$

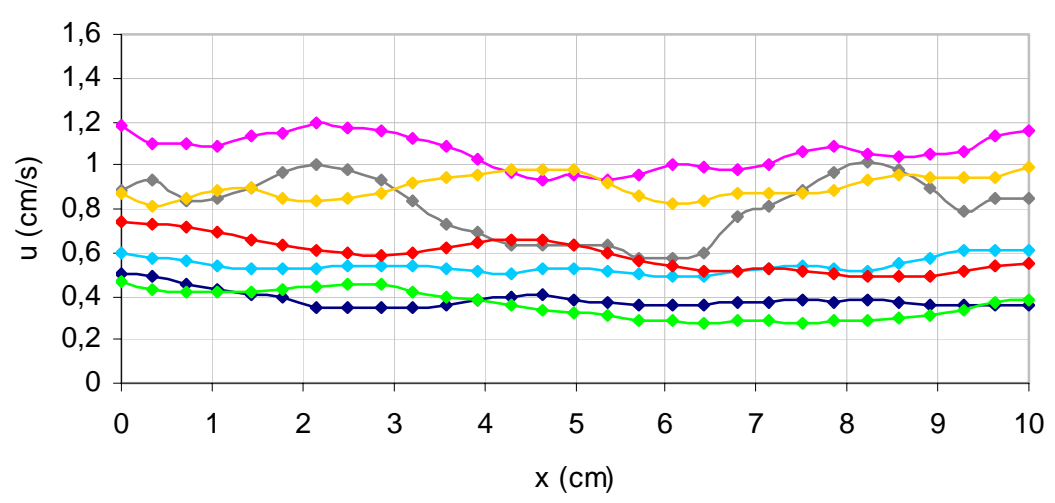

$$
\begin{aligned}
& \longrightarrow z=3 \mathrm{~cm} \\
& \longrightarrow z=5 \mathrm{~cm} \\
& \because z=10 \mathrm{~cm} \\
& \longrightarrow z=15 \mathrm{~cm} \\
& \longrightarrow z=20 \mathrm{~cm} \\
& \longrightarrow z=25 \mathrm{~cm} \\
& \longrightarrow z=30 \mathrm{~cm}
\end{aligned}
$$
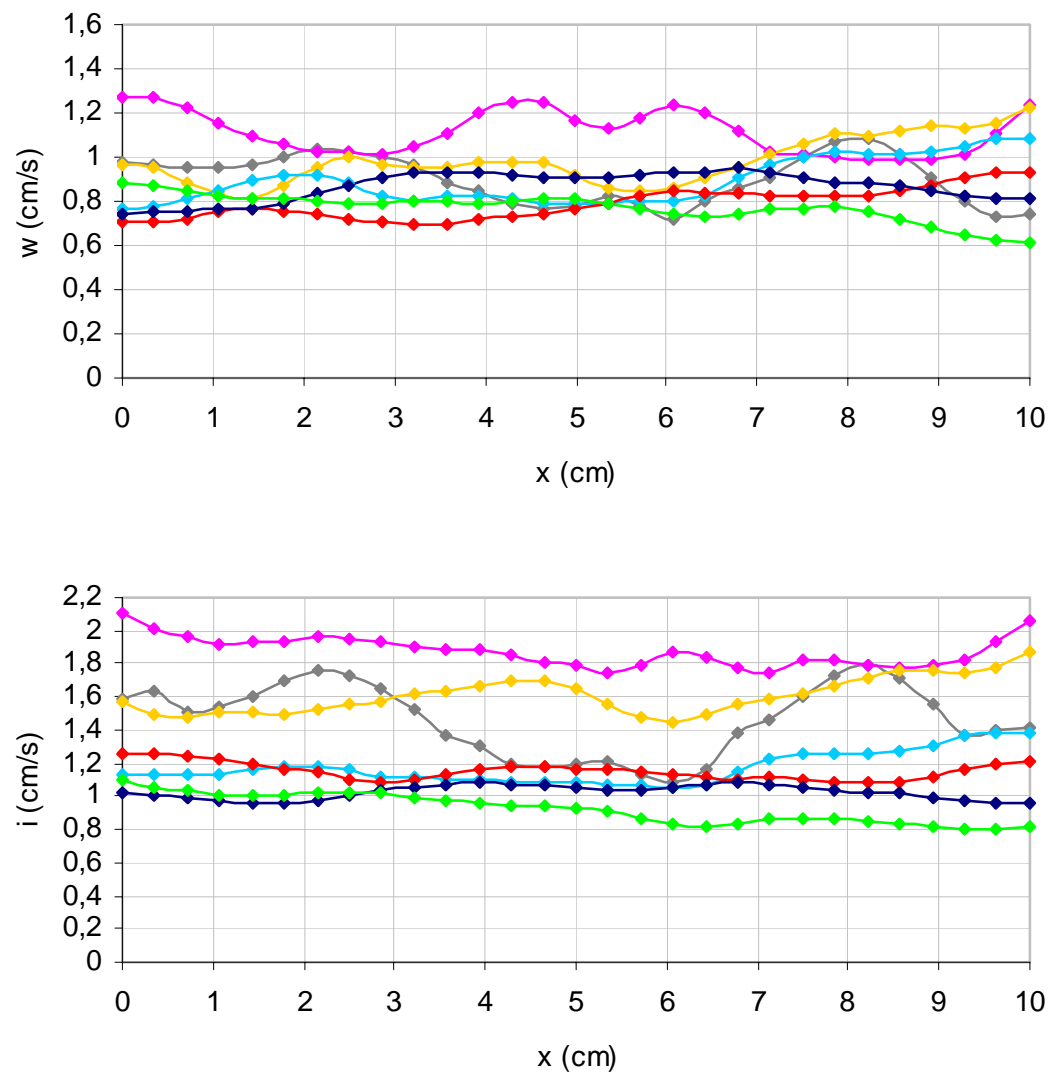

FIGURA 92 - Distribuição horizontal de u, w e i, para o Plano 2 e freqüência 4 Hz. 
Propriedade da turbulência isotrópica: $\mathrm{w} / \mathrm{u}=1$

As FIGURAS 93 e 94 apresentam a relação w / u para o Plano 1 e freqüências de 3 $\mathrm{Hz}$ e $4 \mathrm{~Hz}$, e a mesma relação para o Plano 2 e frequiências de 1, 2, 3 e 4 Hz de oscilação da grade.

Sobre a barra $-3 \mathrm{~Hz}$

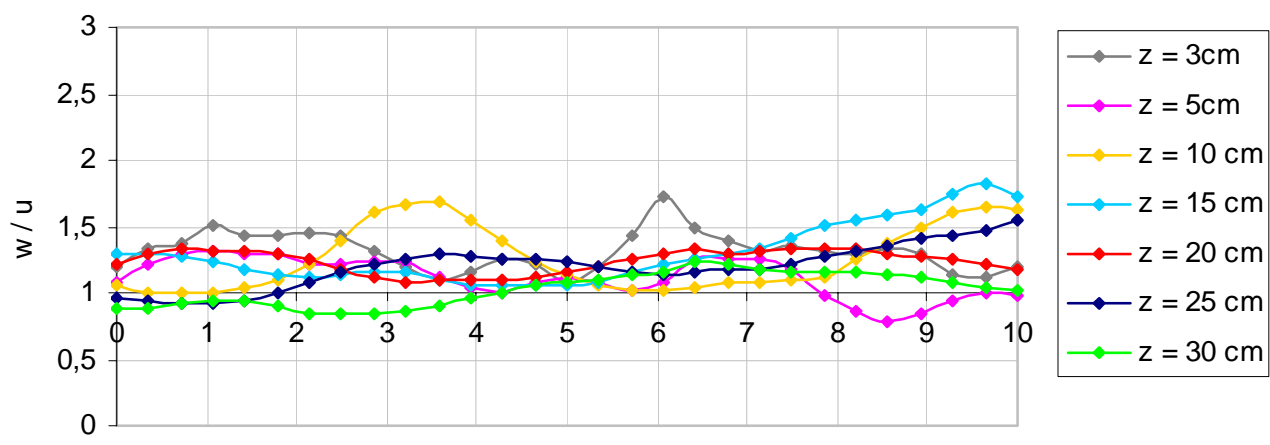

Sobre a barra $-4 \mathrm{~Hz}$

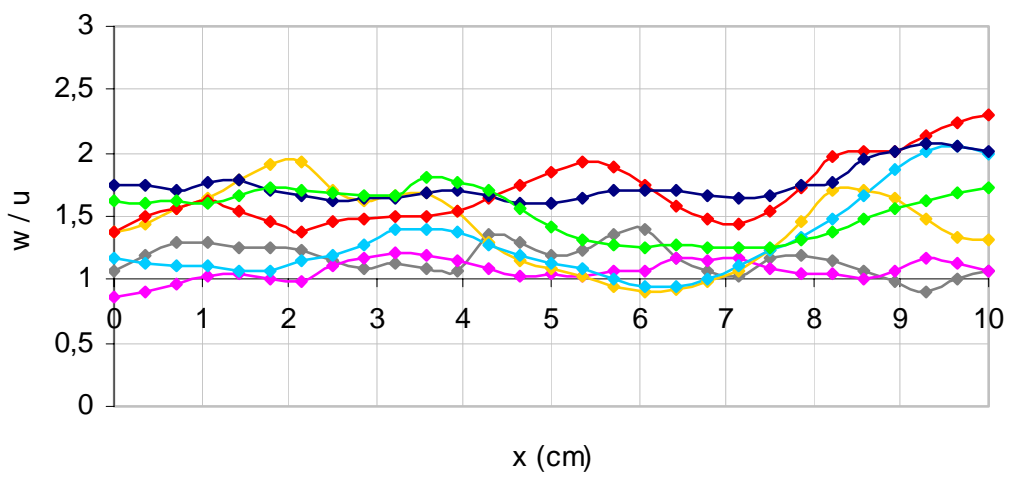

FIGURA 93 - Relação w / u para o Plano 1 e freqüências de 3 Hz e 4 Hz. 
Entre barras - $1 \mathrm{~Hz}$

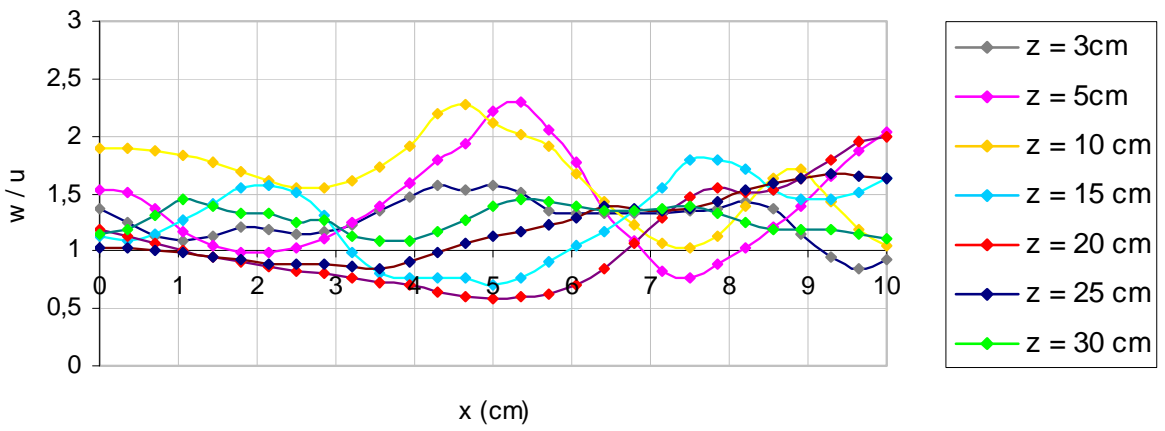

Entre barras - $2 \mathrm{~Hz}$

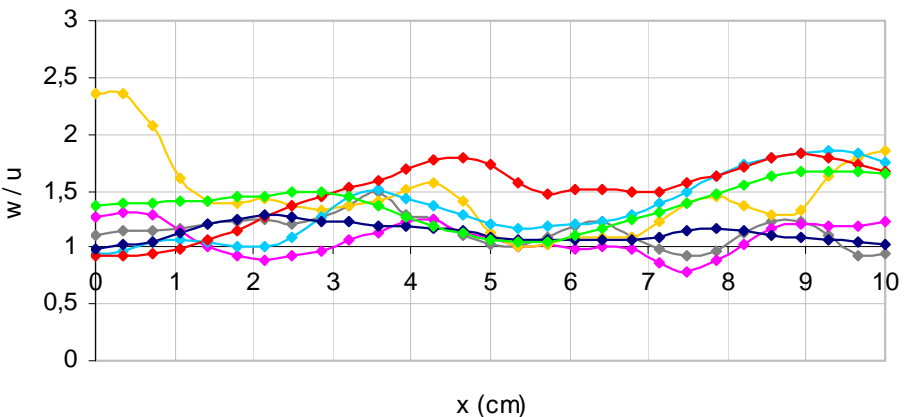

Entre barras - $3 \mathrm{~Hz}$

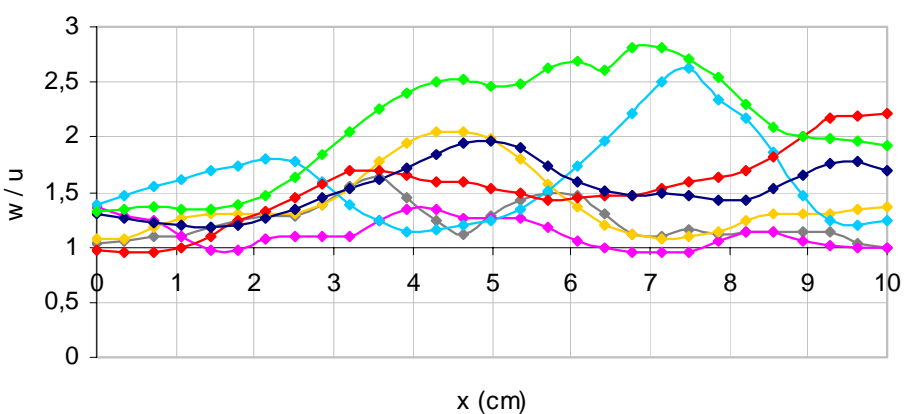

Entre barras - $4 \mathrm{~Hz}$

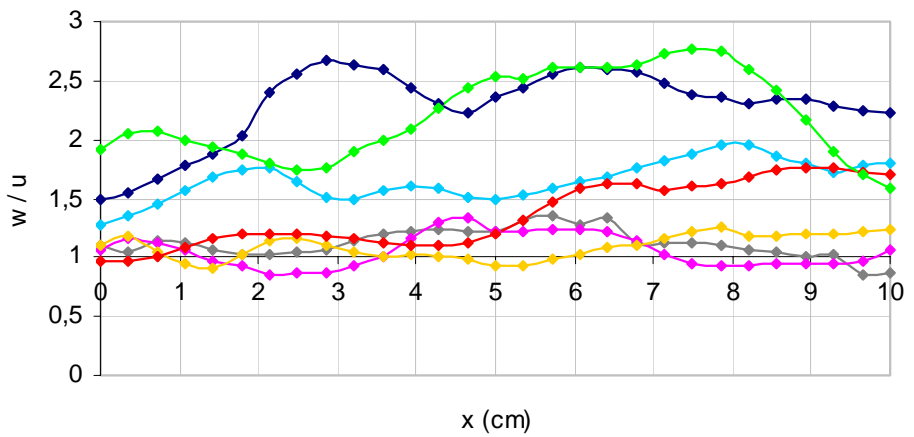

FIGURA 94 - Relação w / u para o Plano 2 e frequiências de 1, 2, 3 e 4 Hz. 


\section{Tensões de Reynolds}

As FIGURAS 95 e 96 mostram as tensões de Reynolds para o Plano 1 e frequiências de $3 \mathrm{~Hz}$ e $4 \mathrm{~Hz}$, e as tensões de Reynolds para o Plano 2 e freqüências de 1, 2, 3 e $4 \mathrm{~Hz}$.

\section{Sobre a barra - $3 \mathrm{~Hz}$}
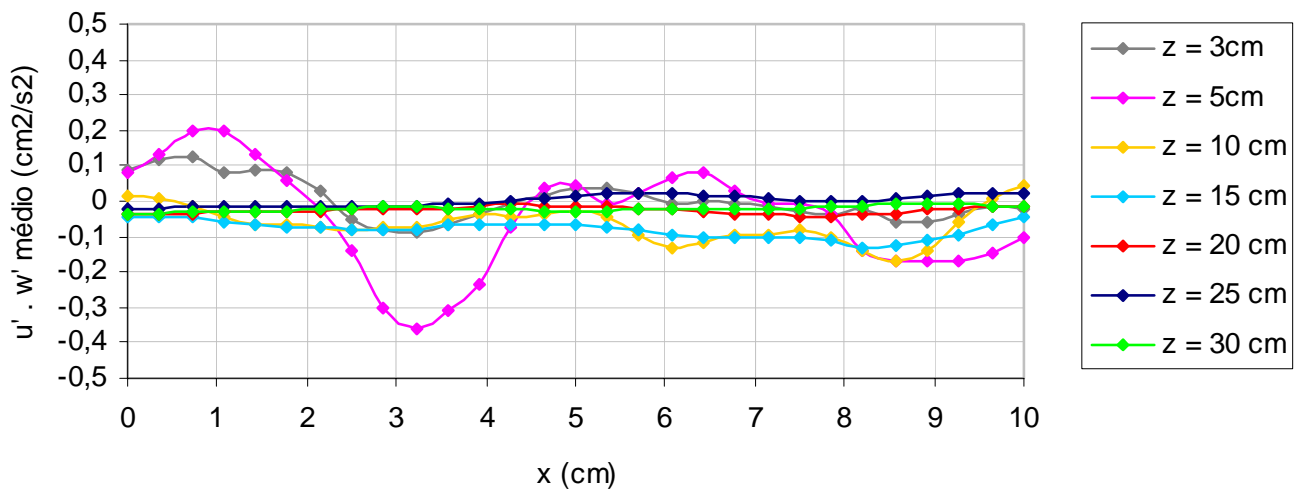

Sobre a barra - $4 \mathrm{~Hz}$

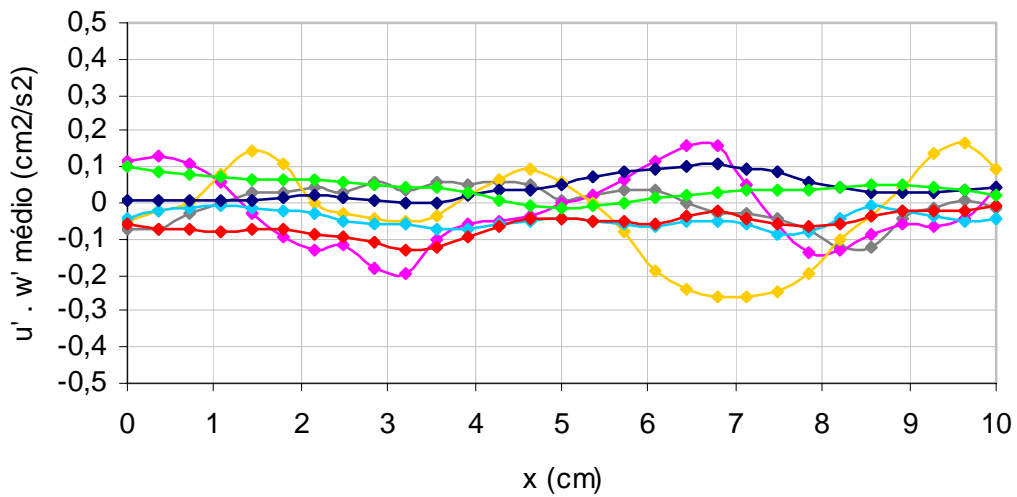

FIGURA 95 - Tensões de Reynolds para o Plano 1 e frequiências 3 Hz e 4 Hz. 
Entre barras - $1 \mathrm{~Hz}$

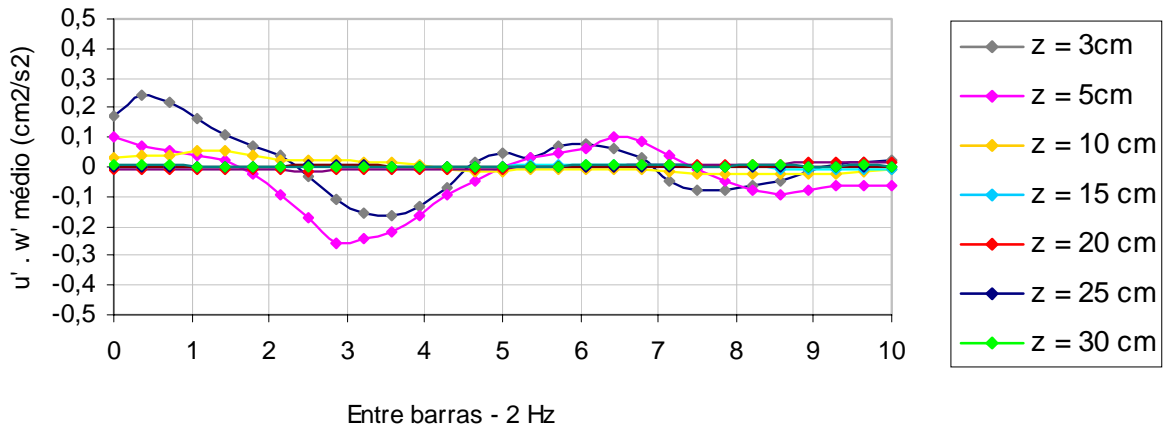

Entre barras - $2 \mathrm{~Hz}$

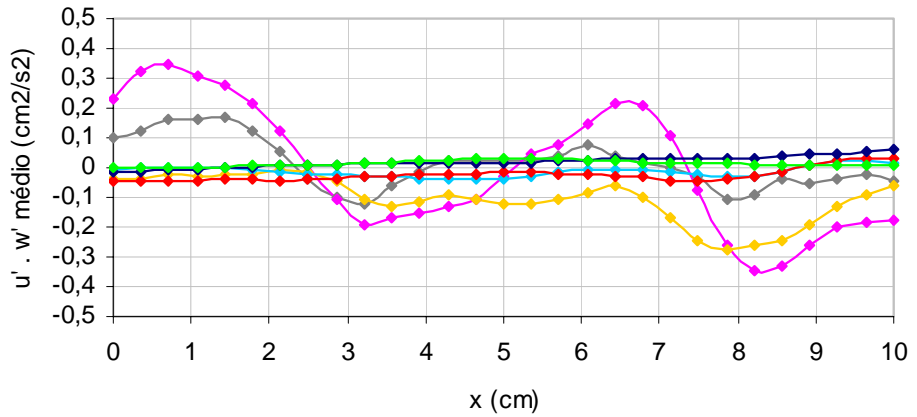

Entre barras - $3 \mathrm{~Hz}$

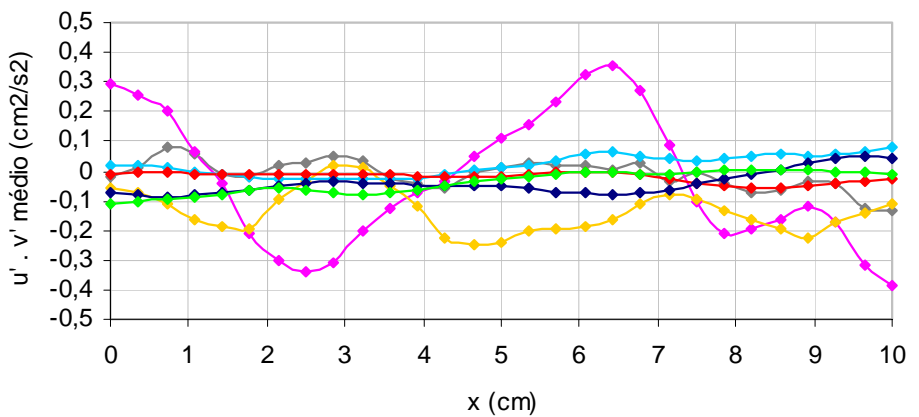

Entre barras - $4 \mathrm{~Hz}$

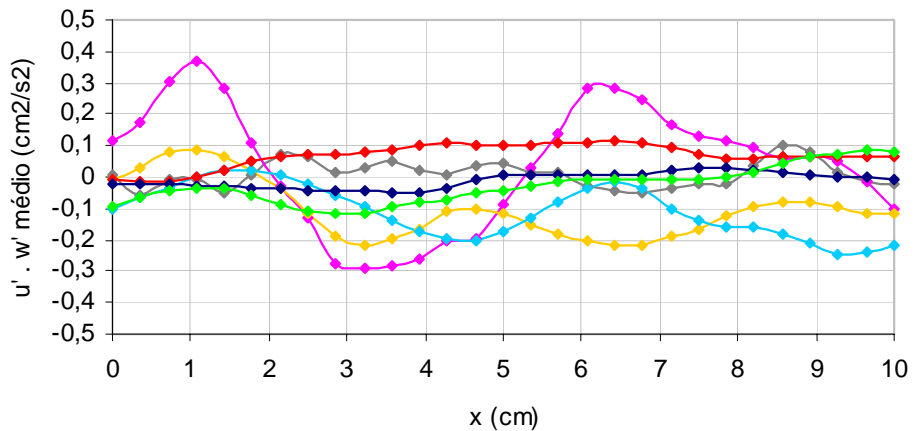

FIGURA 96 - Tensões de Reynolds para o Plano 2 e freqüências de 1, 2, 3 e 4 Hz. 


\section{REFERÊNCIAS BIBLIOGRÁFICAS}

ATKINSON, J. F.; WOLCOTT, S. B. (1990). Interfacial Mixing Driven by Mean Shear and Oscillating Grid. Journal of Hydraulic Engineering, v. 116, n. 3, p. 397-413, Mar.

BAINES, W. D.; PETERSON, E. G. (1951). An investigation of flow through screens, Transactions American Society of Mechanical Engineers, v.73, p.467.

BARRY, M. E.; IVEY, G. N., WINTERS, K. B., IMBERGER, J. (2001). Measurements of diapycnal diffusivities in stratified fluids. Journal of Fluid Mechanics, v.442, p.267-291, Sept.

BATCHELOR, G. K.; TOWNSEND, A. A. (1947). Decay of vorticity in isotropic turbulence, Proceedings Royal Society A, v.190, p.534.

BATCHELOR, G. K.; TOWNSEND, A. A. (1948). Decay of isotropic turbulence in the initial period, Proceedings Royal Society A, v. 193, p. 539.

BOUVARD, M.; DUMAS, H. (1967). Application de la methode de fil chaud a la mesure de la turbulence dans l'eau. La Houille Blanche, n.3, p.257-270.

BRUMLEY, B. H.; JIRKA, G. H. (1987). Near-Surface Turbulence in a Grid-Stirred Tank, Journal of Fluid Mechanics, v.183, p.236-263.

BRUNK, B.; WEBER-SHIRK, M., JENSEN, A.; JIRKA, G.; LION, L. W. (1996). Modeling natural hydrodynamics systems with a differential-turbulence column. Journal of Hydraulic Engineering, v.122, n.7, July.

BRUNK, B. K.; KOCH, D. L.; LION, L. W. (1998). Observations of coagulation in isotropic turbulence. Journal of Fluid Mechanics, v. 371, p.81-107, Sep.

BUDWIG, R.; TAVOULARIS, S.; CORRSIN, S. (1985). Temperature fluctuations and heat flux in grid-generated isotropic turbulence with streamwise and transverse meantemperature gradients. Journal of Fluid Mechanics, v.153, p.441-460.

CASSON, L. W.; LAWLER, D. F.; BOGARD, D. G. (1994). Spectral analysis of fluid flow in oscillating grid reactor. Journal of Engineering Mechanics, v.120, n.2, Feb.

CHENG, N. S.; LAW, A. W.K. (2001). Measurements of Turbulence Generated by Oscillating Grid. Journal of Hydraulic Engineering, v. 127, n. 3, p. 201-208, Mar.

COMTE-BELLOT, G.; CORRSIN, S. (1966). The use of a contraction to improve the isotropy of grid-generated turbulence. Journal of Fluid Mechanics, v.25, n.4, p.657682.

CORRSIN, S. (1942). Decay of turbulence behind three similar grids, Aerospace Engineering. California. Tese - California Institute of Technology.

CORRSIN, S. (1963). Turbulence: experimental methods. Handbuch der Physik, v.8, Strömungsmechanik II, p. 524-587. 
DAVIES, J. T. (1972). Turbulence Phenomena. New York, Academic Press. Cap.1, p. 1-77: Velocities and Stresses in Turbulent Flows.

DE SILVA, I. P. D.; FERNANDO, H. J. S. (1992). Some aspects of mixing in a stratified turbulent patch. Journal of Fluid Mechanics, v.240, p.601-625.

DE SILVA, I. P. D.; FERNANDO, H. J. S. (1994). Oscillating grids as a source of nearly isotropic turbulence. Physics of Fluids, v.6, n.7, p.2455-2464.

DE SILVA, I. P. D.; FERNANDO, H. J. S. (1998). Experiments on collapsing turbulent regions in stratified fluids. Journal of Fluid Mechanics, v.358, p.29-60.

DOEBELIN, E. O. (1990). Measurements systems- application and design. 4.ed. New York, McGraw-Hill. (Measuring devices, pt.2).

DRYDEN, H. L.; KUETHE, A. M. (1930). Natl. Advisory Comm. Aeronaut. Tech. Repts., n.342

DRYDEN, H. L.; SCHUBAUER, G. B.; MOCK, W. C.; SKRAMSTAD, H. K. (1937). Measurements of the intensity and scale of wind tunnel turbulence and their relation to the critical Reynolds number of spheres. NACA Rep., n.581.

E, X.; HOPFINGER, E. J. (1986). On mixing across an interface in stably stratified fluid. Journal of Fluid Mechanics, v.166, p.227-244.

FERREIRA, A. B. H. (1999). Novo Aurélio. 3.ed. São Paulo, Nova Fronteira, p.2018.

GRANT, H. L.; NISBET, I. C. T. (1957). The inhomogeneity of grid turbulence. Journal of Fluid Mechanics, v.2, p.263.

HIBBS, D. E.; GULLIVER, J. S. (1999). Dissolution rate coefficients for surface slicks on rivers. Water Research, v.133, n.8, p.1811-1816.

HINZE, J. O. (1959). Turbulence: An Introduction to Its Mechanism and Theory. New York, McGraw-Hill.

HOPFINGER, E. J.; TOLY, J. A. (1976). Spatially decaying turbulence and its relation to mixing across density interfaces. Journal of Fluid Mechanics, v.78, part 1, p.155-175.

HOUAISS, A.; VILLAR, M. S. (2001). Dicionário Houaiss da Língua Portuguesa, Rio de Janeiro, Objetiva Ltda., p.2787.

HUNT, J. C. R.; SANDHAM, N. D.; VASSILICOS, J. C., LAUNDER, B. E.; MONKEWITZ, P. A.; HEWITT, G. F. (2001). Developments in turbulence research: a review based on the 1999 Programme of the Isaac Newton Institute, Cambridge. Journal of Fluid Mechanics, v.436, p.353-391.

ITSWEIRE, E. C.; HELLAND, K. N.; VAN ATTA, C. W. (1986). The evolution of gridgenerated turbulence in a stably stratified fluid, Journal of Fluid Mechanics, v.162, p.299-338. 
KIT, E. L. G.; STRANG, E. J.; FERNANDO, H. J. S. (1997). Measurements of turbulence near shear-free density interfaces. Journal of Fluid Mechanic, v.334, p.293-314.

LIEM, L. E.; SMITH, D. W.; STANLEY, S. J. (1999). Turbulent velocity in floculation by means of grids. Journal of environmental Engineering, v.125, n.3, p.224-233.

LYN, D. A. (1997). A PIV study of an oscillating-grid flow. Experimental and numerical flow visualization and laser anemometry, v.13, Fluids Engineering Division (Publication), ASME, New York.

McDOUGAL, T. J. (1979). Measurements of turbulence in a zero-mean-shear mixed layer. Journal of Fluid Mechanics, Cambridge, U.K., v.94, p.409-431.

MATSUNAGA, N.; SUGIHARA, Y.; KOMATSU, T. (1991). A numerical simulation of oscillating-grid turbulence by using the $k$ - $\varepsilon$ model, In: LEE, J. H. W.; CHEUNG, Y. K., eds. Environmental Hydraulics, The Netherlands, A.A.Balkema. v.1, p.427-432.

MOHAMED, M. S., LA RUE, J. C. (1990). The decay power law in grid-generated turbulence. Journal of Fluid Mechanics, v.219, p.195-214.

NOKES, R. I. (1988). On the entrainment rate across a density interface. Journal of Fluid Mechanics, v.188, p.185-204.

O PERIGO vem do Ártico (2001). Época, Rio de Janeiro, ed. Globo, ano III, n.143, fevereiro.

ROMA, W. N. L. (1988). Medida dos parâmetros de turbulência superficial e sua interrelação com o coeficiente de reaeração. São Paulo. 74p. Tese (Livre-doscência) Escola de Engenharia de São Carlos, Universidade de São Paulo.

ROUSE, H. (1939). Experiments on the mechanics of sediment suspension. In: INTERNATIONAL CONGRESS OF APPLIED MECHANICS, 5., Cambridge. Proceedings.p.550-554.

SCHULZ, H. E. (2001). Alternativas em Turbulência. São Carlos, EESC-USP

SHY, S. S.; TANG, C. Y.; FANN, S. Y. (1997). A nearly isotropic turbulence generated by a pair of vibrating grids. Experimental Thermal and Fluid Science, v.14, p.251-262.

SIMONS, L. F. G.; SALTER, C. (1934). Experimental investigation and analysis of the velocity variations in turbulent flow, Proceedings of the Royal Society A, v.145, 212.

SRDIC, A.; FERNANDO, H. J. S.; MONTENEGRO, L. (1996). Generation of nearly isotropic turbulence using two oscillating grids. Experiments in Fluids, v.20, p.395-397.

TAYLOR, G. I. (1935b). Statistical Theory of Turbulence. Proceedings of the Royal Society of London A, v.151.

TAYLOR, G. I.; KARMAN, T. V. (1937). Journal Aeronautial Society, v.41, p.1109. 
THOMPSON, S. M.; TURNER, J. S. (1975). Mixing across an interface due to turbulence generated by an oscillating grid. Journal of Fluid Mechanics, v.67, n.2, p.349-368.

TOWNSEND, A. A. (1976). Homogeneous Turbulent Flows. In: THE STRUCTURE of turbulent shear flow. Cambridge, Cambridge University Press. Cap.3, p. 45-103.

TSUJI, H.; HAMA, F. R. (1953). Experiment on the decay of turbulence behind two grids. Journal of Aerosol Science, v. 20, p.848.

TURNER, J. S. (1968). The influence of molecular diffusivity on turbulent entrainment across a density interface. Journal of Fluid Mechanics, n. 23, p. 639.

VOROPAYEV, S. I.; FERNANDO, H. J. S. (1996). Propagation of grid turbulence in homogeneous fluids. Physics of Fluids, v.8 n.9, Sept.

WYATT, L. A. (1955). Energy and spectra in decaying homogeneous turbulence. Manchester. Tese (Doutorado) - University of Manchester. 


\section{APÊNDICE}

Planilha gerada pelo software Visiflow, referente a um campo instantâneo de velocidade para a POS 1 e freqüência de $1 \mathrm{~Hz}$. As primeiras duas colunas se referem às coordenadas do vetor velocidade nos eixos x e z, respectivamente. A terceira coluna referese à magnitude do vetor e a quarta ao ângulo de inclinação do vetor, em radianos, em relação ao eixo x. Através desta tabela pode se ter uma idéia da dificuldade em se trabalhar apenas com o Visiflow para a obtenção dos campos de velocidade turbulenta a partir dos 4800 campos instantâneos nele gerados.

\section{Campo instantâneo de velocidade gerado pelo programa Visiflow para a POS 1}

\section{e freqüência de $1 \mathrm{~Hz}$.}

$\begin{array}{ll}\text { VISIFLOW ASCII Velocity data file: } & \\ \text { Start of header data; } & \\ \text { Number of vectors }= & 841 \\ \text { Randomly positioned data }= & 0 \\ \text { Number of columns }= & 29 \\ \text { Number of rows }= & 29 \\ \text { Vector grid separation }= & 3347 \\ \text { Area left corner }= & 0.000000 \\ \text { Area right corner }= & 100.418 .500 .800 \\ \text { Area bottom corner }= & 0.000000 \\ \text { Area top corner }= & 100.418 .500 .800 \\ \text { Number of peaks }= & 1 \\ \text { Number of microns/xpixel }= & 209.205 .210 \\ \text { Number of microns/ypixel }= & 209.205 .210 \\ \text { Macro factor }= & 1.000 .000 \\ \text { Time separation }= & 33.898 .000 .000 \\ \text { Flow variable }= & \text { none }\end{array}$

$\begin{array}{rlrr}3347 & 3347 & 0.007336 & 2.792 .517 \\ 6694 & 3347 & 0.010298 & 2.632 .451 \\ 10041 & 3347 & 0.010677 & 2.522 .907 \\ 13388 & 3347 & 0.008723 & 2.241 .674 \\ 16735 & 3347 & 0.003619 & -3.092 .898 \\ 20082 & 3347 & 0.002567 & -2.252 .182 \\ 23429 & 3347 & 0.002876 & -1.166 .982 \\ 26776 & 3347 & 0.003938 & -1.084 .768 \\ 30123 & 3347 & 0.013390 & -0.984905 \\ 33470 & 3347 & 0.012540 & -1.380 .968 \\ 36817 & 3347 & 0.008993 & -1.968 .251 \\ 40164 & 3347 & 0.008910 & -1.692 .015 \\ 43511 & 3347 & 0.004715 & -1.824 .241\end{array}$




\begin{tabular}{|c|c|c|c|}
\hline 46858 & 3347 & 0.007182 & 2.272 .496 \\
\hline 50205 & 3347 & 0.014795 & 2.132.399 \\
\hline 53552 & 3347 & 0.004836 & 2.104 .339 \\
\hline 56899 & 3347 & 0.003133 & 2.138 .079 \\
\hline 60246 & 3347 & 0.002368 & 2.231 .584 \\
\hline 63593 & 3347 & 0.003439 & 2.342 .851 \\
\hline 66940 & 3347 & 0.004371 & 2.246 .616 \\
\hline 70287 & 3347 & 0.007032 & 1.999 .128 \\
\hline 73634 & 3347 & 0.011774 & 1.541 .145 \\
\hline 76981 & 3347 & 0.015403 & 1.375 .892 \\
\hline 80328 & 3347 & 0.013664 & 1.269 .405 \\
\hline 83675 & 3347 & 0.006507 & 1.345 .723 \\
\hline 87022 & 3347 & 0.003700 & 1.353 .729 \\
\hline 90369 & 3347 & 0.001481 & 1.537 .108 \\
\hline 93716 & 3347 & 0.000457 & 1.753 .695 \\
\hline 97063 & 3347 & 0.000284 & 1.412 .881 \\
\hline 3347 & 6694 & 0.014885 & 2.789 .827 \\
\hline 6694 & 6694 & 0.020505 & 2.709 .568 \\
\hline 10041 & 6694 & 0.016118 & 2.595 .171 \\
\hline 13388 & 6694 & 0.009471 & 2.100 .606 \\
\hline 16735 & 6694 & 0.001799 & -2.450 .105 \\
\hline 20082 & 6694 & 0.004481 & -1.078 .696 \\
\hline 23429 & 6694 & 0.007482 & -0.586254 \\
\hline 26776 & 6694 & 0.012514 & -0.180667 \\
\hline 30123 & 6694 & 0.011101 & -0.357625 \\
\hline 33470 & 6694 & 0.007194 & -1.202 .183 \\
\hline 36817 & 6694 & 0.006081 & -1.751 .328 \\
\hline 40164 & 6694 & 0.004166 & -1.680 .637 \\
\hline 43511 & 6694 & 0.001076 & 2.946 .129 \\
\hline 46858 & 6694 & 0.004508 & 2.132 .603 \\
\hline 50205 & 6694 & 0.010691 & 2.058 .557 \\
\hline 53552 & 6694 & 0.002572 & 1.890 .944 \\
\hline 56899 & 6694 & 0.002969 & 2.016 .153 \\
\hline 60246 & 6694 & 0.004752 & 2.145 .917 \\
\hline 63593 & 6694 & 0.006460 & 2.207 .282 \\
\hline 66940 & 6694 & 0.006623 & 1.963 .814 \\
\hline 70287 & 6694 & 0.008245 & 1.859 .972 \\
\hline 73634 & 6694 & 0.011007 & 1.480 .088 \\
\hline 76981 & 6694 & 0.016900 & 1.189 .687 \\
\hline 80328 & 6694 & 0.015187 & 1.195 .331 \\
\hline 83675 & 6694 & 0.009427 & 1.359 .338 \\
\hline 87022 & 6694 & 0.006516 & 1.625 .716 \\
\hline 90369 & 6694 & 0.004872 & 1.836 .603 \\
\hline 93716 & 6694 & 0.003131 & 1.952 .205 \\
\hline 97063 & 6694 & 0.001702 & 2.049 .778 \\
\hline 3347 & 10041 & 0.023266 & 2.698 .983 \\
\hline 6694 & 10041 & 0.013186 & 2.764 .901 \\
\hline 10041 & 10041 & 0.010783 & 2.548 .518 \\
\hline 13388 & 10041 & 0.003763 & 2.558 .347 \\
\hline 16735 & 10041 & 0.002065 & 0.397151 \\
\hline 20082 & 10041 & 0.003493 & -0.277126 \\
\hline 23429 & 10041 & 0.007231 & -0.363598 \\
\hline 26776 & 10041 & 0.010543 & -0.279329 \\
\hline
\end{tabular}




\begin{tabular}{|c|c|c|c|}
\hline 30123 & 10041 & 0.009297 & -0.466984 \\
\hline 33470 & 10041 & 0.007135 & -1.193 .864 \\
\hline 36817 & 10041 & 0.005804 & -1.244 .368 \\
\hline 40164 & 10041 & 0.003279 & -0.958145 \\
\hline 43511 & 10041 & 0.001906 & 0.239728 \\
\hline 46858 & 10041 & 0.001937 & 0.650904 \\
\hline 50205 & 10041 & 0.003277 & 1.098 .942 \\
\hline 53552 & 10041 & 0.002633 & 1.457 .244 \\
\hline 56899 & 10041 & 0.003831 & 1.910 .925 \\
\hline 60246 & 10041 & 0.006220 & 2.013 .528 \\
\hline 63593 & 10041 & 0.007706 & 2.043 .665 \\
\hline 66940 & 10041 & 0.007445 & 1.815 .957 \\
\hline 70287 & 10041 & 0.007158 & 1.727 .510 \\
\hline 73634 & 10041 & 0.011073 & 1.262 .579 \\
\hline 76981 & 10041 & 0.009376 & 1.131 .595 \\
\hline 80328 & 10041 & 0.009130 & 1.069 .177 \\
\hline 83675 & 10041 & 0.011759 & 1.550 .089 \\
\hline 87022 & 10041 & 0.012929 & 1.803 .867 \\
\hline 90369 & 10041 & 0.010233 & 1.928 .295 \\
\hline 93716 & 10041 & 0.007437 & 1.982 .655 \\
\hline 97063 & 10041 & 0.004943 & 2.008 .493 \\
\hline 3347 & 13388 & 0.022029 & 2.855.799 \\
\hline 6694 & 13388 & 0.012923 & 2.546 .950 \\
\hline 10041 & 13388 & 0.009469 & 2.550 .949 \\
\hline 13388 & 13388 & 0.003279 & 2.183 .260 \\
\hline 16735 & 13388 & 0.003330 & 0.954763 \\
\hline 20082 & 13388 & 0.002494 & -0.143363 \\
\hline 23429 & 13388 & 0.006148 & -0.778177 \\
\hline 26776 & 13388 & 0.006562 & -0.827627 \\
\hline 30123 & 13388 & 0.006144 & -0.850630 \\
\hline 33470 & 13388 & 0.004583 & -0.782713 \\
\hline 36817 & 13388 & 0.004532 & -0.691952 \\
\hline 40164 & 13388 & 0.005097 & -0.407996 \\
\hline 43511 & 13388 & 0.004852 & -0.087129 \\
\hline 46858 & 13388 & 0.004421 & 0.335277 \\
\hline 50205 & 13388 & 0.006847 & 0.471171 \\
\hline 53552 & 13388 & 0.004740 & 1.531 .751 \\
\hline 56899 & 13388 & 0.005804 & 1.782 .787 \\
\hline 60246 & 13388 & 0.009034 & 1.865 .991 \\
\hline 63593 & 13388 & 0.009367 & 1.766 .735 \\
\hline 66940 & 13388 & 0.008179 & 1.747 .341 \\
\hline 70287 & 13388 & 0.004515 & 1.621 .681 \\
\hline 73634 & 13388 & 0.004571 & 1.443 .437 \\
\hline 76981 & 13388 & 0.006211 & 1.359 .404 \\
\hline 80328 & 13388 & 0.008210 & 1.334 .210 \\
\hline 83675 & 13388 & 0.014379 & 1.739 .535 \\
\hline 87022 & 13388 & 0.022564 & 1.913 .617 \\
\hline 90369 & 13388 & 0.020143 & 1.921 .121 \\
\hline 93716 & 13388 & 0.009983 & 1.990 .700 \\
\hline 97063 & 13388 & 0.008248 & 2.019.907 \\
\hline 3347 & 16735 & 0.014438 & 2.146.969 \\
\hline 6694 & 16735 & 0.011515 & 1.895 .261 \\
\hline 10041 & 16735 & 0.009205 & 1.918 .279 \\
\hline
\end{tabular}




\begin{tabular}{|c|c|c|c|}
\hline 13388 & 16735 & 0.005548 & 1.945 .452 \\
\hline 16735 & 16735 & 0.001565 & 1.247 .016 \\
\hline 20082 & 16735 & 0.003511 & -1.316 .253 \\
\hline 23429 & 16735 & 0.005381 & -1.156 .353 \\
\hline 26776 & 16735 & 0.006208 & -1.062 .110 \\
\hline 30123 & 16735 & 0.005864 & -1.047 .838 \\
\hline 33470 & 16735 & 0.005077 & -0.979774 \\
\hline 36817 & 16735 & 0.005092 & -0.719109 \\
\hline 40164 & 16735 & 0.006168 & -0.307342 \\
\hline 43511 & 16735 & 0.005896 & 0.190955 \\
\hline 46858 & 16735 & 0.007145 & 0.984147 \\
\hline 50205 & 16735 & 0.009951 & 1.305 .489 \\
\hline 53552 & 16735 & 0.009426 & 1.410 .695 \\
\hline 56899 & 16735 & 0.006979 & 1.481 .052 \\
\hline 60246 & 16735 & 0.008397 & 1.663 .136 \\
\hline 63593 & 16735 & 0.008025 & 1.529 .450 \\
\hline 66940 & 16735 & 0.006626 & 1.472 .833 \\
\hline 70287 & 16735 & 0.002867 & 1.444 .564 \\
\hline 73634 & 16735 & 0.002795 & 1.811 .746 \\
\hline 76981 & 16735 & 0.006354 & 1.941 .484 \\
\hline 80328 & 16735 & 0.008677 & 1.811 .373 \\
\hline 83675 & 16735 & 0.014187 & 1.857 .348 \\
\hline 87022 & 16735 & 0.018504 & 1.898 .119 \\
\hline 90369 & 16735 & 0.018198 & 1.915 .081 \\
\hline 93716 & 16735 & 0.015776 & 1.909 .737 \\
\hline 97063 & 16735 & 0.014506 & 2.126.908 \\
\hline 3347 & 20082 & 0.016579 & 1.663 .537 \\
\hline 6694 & 20082 & 0.015693 & 1.644 .358 \\
\hline 10041 & 20082 & 0.009416 & 1.968 .089 \\
\hline 13388 & 20082 & 0.006021 & 2.383 .257 \\
\hline 16735 & 20082 & 0.004110 & -2.337 .121 \\
\hline 20082 & 20082 & 0.004983 & -1.679 .948 \\
\hline 23429 & 20082 & 0.005735 & -1.426 .822 \\
\hline 26776 & 20082 & 0.005781 & -1.262 .921 \\
\hline 30123 & 20082 & 0.005107 & -1.059 .392 \\
\hline 33470 & 20082 & 0.004187 & -0.844713 \\
\hline 36817 & 20082 & 0.003849 & -0.342287 \\
\hline 40164 & 20082 & 0.005333 & 0.236839 \\
\hline 43511 & 20082 & 0.007931 & 0.862006 \\
\hline 46858 & 20082 & 0.013621 & 1.296 .231 \\
\hline 50205 & 20082 & 0.015787 & 1.290 .226 \\
\hline 53552 & 20082 & 0.014294 & 1.336 .095 \\
\hline 56899 & 20082 & 0.010049 & 1.350 .397 \\
\hline 60246 & 20082 & 0.009200 & 1.331 .481 \\
\hline 63593 & 20082 & 0.008582 & 1.158 .232 \\
\hline 66940 & 20082 & 0.007691 & 0.912276 \\
\hline 70287 & 20082 & 0.001868 & 0.218931 \\
\hline 73634 & 20082 & 0.000244 & -0.300302 \\
\hline 76981 & 20082 & 0.003148 & 1.452 .473 \\
\hline 80328 & 20082 & 0.010699 & 1.835 .382 \\
\hline 83675 & 20082 & 0.016090 & 1.936 .298 \\
\hline 87022 & 20082 & 0.019370 & 1.892 .131 \\
\hline 90369 & 20082 & 0.019936 & 1.865 .376 \\
\hline
\end{tabular}




\begin{tabular}{|c|c|c|c|}
\hline 93716 & 20082 & 0.019530 & 1.869 .350 \\
\hline 97063 & 20082 & 0.019732 & 1.890 .637 \\
\hline 3347 & 23429 & 0.016660 & 1.456 .378 \\
\hline 6694 & 23429 & 0.012751 & 1.493 .211 \\
\hline 10041 & 23429 & 0.006909 & 1.960 .471 \\
\hline 13388 & 23429 & 0.003815 & -2.803 .142 \\
\hline 16735 & 23429 & 0.005687 & -2.230 .403 \\
\hline 20082 & 23429 & 0.006728 & -1.758 .924 \\
\hline 23429 & 23429 & 0.006733 & -1.473 .836 \\
\hline 26776 & 23429 & 0.006306 & -1.274 .790 \\
\hline 30123 & 23429 & 0.005390 & -0.957704 \\
\hline 33470 & 23429 & 0.004374 & -0.773111 \\
\hline 36817 & 23429 & 0.002609 & -0.074274 \\
\hline 40164 & 23429 & 0.005527 & 1.035 .117 \\
\hline 43511 & 23429 & 0.012527 & 1.350 .742 \\
\hline 46858 & 23429 & 0.018681 & 1.487 .462 \\
\hline 50205 & 23429 & 0.022871 & 1.382 .847 \\
\hline 53552 & 23429 & 0.020781 & 1.424 .311 \\
\hline 56899 & 23429 & 0.013191 & 1.550 .470 \\
\hline 60246 & 23429 & 0.011681 & 1.485 .015 \\
\hline 63593 & 23429 & 0.012325 & 1.095 .993 \\
\hline 66940 & 23429 & 0.010292 & 0.683756 \\
\hline 70287 & 23429 & 0.011383 & 0.103046 \\
\hline 73634 & 23429 & 0.007426 & 0.189416 \\
\hline 76981 & 23429 & 0.004784 & 1.284 .270 \\
\hline 80328 & 23429 & 0.012598 & 1.948 .972 \\
\hline 83675 & 23429 & 0.016350 & 1.884 .127 \\
\hline 87022 & 23429 & 0.018500 & 1.712 .983 \\
\hline 90369 & 23429 & 0.019040 & 1.685 .729 \\
\hline 93716 & 23429 & 0.018596 & 1.731 .277 \\
\hline 97063 & 23429 & 0.017045 & 1.731 .581 \\
\hline 3347 & 26776 & 0.014882 & 1.068 .724 \\
\hline 6694 & 26776 & 0.010478 & 0.727533 \\
\hline 10041 & 26776 & 0.003401 & 1.895 .441 \\
\hline 13388 & 26776 & 0.002873 & -2.475 .765 \\
\hline 16735 & 26776 & 0.005686 & -2.001 .242 \\
\hline 20082 & 26776 & 0.007986 & -1.600 .381 \\
\hline 23429 & 26776 & 0.007939 & -1.497 .015 \\
\hline 26776 & 26776 & 0.006510 & -1.396 .125 \\
\hline 30123 & 26776 & 0.004630 & -1.166 .310 \\
\hline 33470 & 26776 & 0.002976 & -1.099 .051 \\
\hline 36817 & 26776 & 0.000762 & 0.959937 \\
\hline 40164 & 26776 & 0.005933 & 1.656 .356 \\
\hline 43511 & 26776 & 0.015187 & 1.742 .001 \\
\hline 46858 & 26776 & 0.018281 & 1.664 .405 \\
\hline 50205 & 26776 & 0.022063 & 1.539 .944 \\
\hline 53552 & 26776 & 0.021466 & 1.612 .789 \\
\hline 56899 & 26776 & 0.018443 & 1.835 .633 \\
\hline 60246 & 26776 & 0.015154 & 1.780 .507 \\
\hline 63593 & 26776 & 0.009871 & 1.229 .807 \\
\hline 66940 & 26776 & 0.006440 & 0.578101 \\
\hline 70287 & 26776 & 0.010235 & -0.197975 \\
\hline 73634 & 26776 & 0.007177 & -0.067446 \\
\hline
\end{tabular}




$\begin{array}{rrrr}76981 & 26776 & 0.004443 & 0.773248 \\ 80328 & 26776 & 0.008747 & 1.413 .271 \\ 83675 & 26776 & 0.014172 & 1.481 .532 \\ 87022 & 26776 & 0.018269 & 1.444 .643 \\ 90369 & 26776 & 0.018087 & 1.391 .799 \\ 93716 & 26776 & 0.013668 & 1.246 .440 \\ 97063 & 26776 & 0.010627 & 1.173 .906 \\ 3347 & 30123 & 0.016304 & 0.840097 \\ 6694 & 30123 & 0.011548 & 0.867171 \\ 10041 & 30123 & 0.003174 & 1.205 .407 \\ 13388 & 30123 & 0.001578 & -1.669 .050 \\ 16735 & 30123 & 0.004447 & -1.650 .472 \\ 20082 & 30123 & 0.007853 & -1.567 .164 \\ 23429 & 30123 & 0.008215 & -1.571 .794 \\ 26776 & 30123 & 0.006603 & -1.618 .613 \\ 30123 & 30123 & 0.003500 & -1.835 .678 \\ 33470 & 30123 & 0.002435 & -2.268 .364 \\ 36817 & 30123 & 0.003397 & 2.916 .772 \\ 40164 & 30123 & 0.006612 & 2.260 .333 \\ 43511 & 30123 & 0.014570 & 2.099 .816 \\ 46858 & 30123 & 0.017009 & 1.940 .069 \\ 50205 & 30123 & 0.017066 & 1.778 .349 \\ 53552 & 30123 & 0.018006 & 1.881 .250 \\ 56899 & 30123 & 0.015717 & 1.695 .007 \\ 60246 & 30123 & 0.012281 & 1.685 .189 \\ 63593 & 30123 & 0.004163 & 1.714 .253 \\ 66940 & 30123 & 0.001637 & 0.101006 \\ 70287 & 30123 & 0.005413 & -0.273585 \\ 73634 & 30123 & 0.006056 & -0.182224 \\ 76981 & 30123 & 0.004031 & 0.461912 \\ 80328 & 30123 & 0.008214 & 1.082 .848 \\ 83675 & 30123 & 0.012451 & 1.149 .011 \\ 87022 & 30123 & 0.016549 & 1.065 .715 \\ 90369 & 30123 & 0.014867 & 1.016 .108 \\ 93716 & 30123 & 0.009487 & 0.751675 \\ 97063 & 30123 & 0.009544 & -0.414349 \\ 3347 & 33470 & 0.012491 & 1.042 .834 \\ 6694 & 33470 & 0.008726 & 1.082 .331 \\ 10041 & 33470 & 0.002709 & 1.436 .248 \\ 13388 & 33470 & 0.000870 & -0.904238 \\ 16735 & 33470 & 0.004355 & -1.428 .886 \\ 20082 & 33470 & 0.006345 & -1.505 .783 \\ 23429 & 33470 & 0.007438 & -1.632 .111 \\ 26776 & 33470 & 0.005894 & -1.841 .190 \\ 30123 & 33470 & 0.003588 & -2.541 .517 \\ 33470 & 33470 & 0.004126 & 3.126 .153 \\ 36817 & 33470 & 0.005847 & 2.918 .434 \\ 40164 & 33470 & 0.003322 & 3.016 .427 \\ 43511 & 33470 & 0.012811 & 2.103 .193 \\ 46858 & 33470 & 0.015293 & 1.953 .539 \\ 50205 & 33470 & 0.010678 & 1.551 .370 \\ 53552 & 33470 & 0.011511 & 1.311 .757 \\ 56899 & 33470 & 0.013893 & 1.166 .692\end{array}$




\begin{tabular}{|c|c|c|c|}
\hline 60246 & 33470 & 0.012467 & 0.930777 \\
\hline 63593 & 33470 & 0.005457 & 0.697524 \\
\hline 66940 & 33470 & 0.004206 & -0.225284 \\
\hline 70287 & 33470 & 0.005407 & -0.613804 \\
\hline 73634 & 33470 & 0.004581 & -0.763127 \\
\hline 76981 & 33470 & 0.004232 & -0.050321 \\
\hline 80328 & 33470 & 0.006481 & 0.585352 \\
\hline 83675 & 33470 & 0.012377 & 0.918521 \\
\hline 87022 & 33470 & 0.014122 & 1.010 .499 \\
\hline 90369 & 33470 & 0.012722 & 1.089 .410 \\
\hline 93716 & 33470 & 0.009065 & 0.863561 \\
\hline 97063 & 33470 & 0.004962 & 1.623 .982 \\
\hline 3347 & 36817 & 0.012293 & 2.105 .151 \\
\hline 6694 & 36817 & 0.006097 & 1.902 .849 \\
\hline 10041 & 36817 & 0.002220 & 1.415 .329 \\
\hline 13388 & 36817 & 0.001539 & -0.555110 \\
\hline 16735 & 36817 & 0.004468 & -1.135 .594 \\
\hline 20082 & 36817 & 0.006097 & -1.321 .830 \\
\hline 23429 & 36817 & 0.006946 & -1.563 .484 \\
\hline 26776 & 36817 & 0.005033 & -2.031 .136 \\
\hline 30123 & 36817 & 0.004315 & -2.810 .917 \\
\hline 33470 & 36817 & 0.006315 & 2.811 .370 \\
\hline 36817 & 36817 & 0.008322 & 2.569 .346 \\
\hline 40164 & 36817 & 0.010300 & 2.360 .030 \\
\hline 43511 & 36817 & 0.013745 & 2.132.351 \\
\hline 46858 & 36817 & 0.015571 & 1.914 .887 \\
\hline 50205 & 36817 & 0.010633 & 1.534 .848 \\
\hline 53552 & 36817 & 0.011332 & 1.221 .392 \\
\hline 56899 & 36817 & 0.014892 & 0.899509 \\
\hline 60246 & 36817 & 0.015475 & 0.581096 \\
\hline 63593 & 36817 & 0.014377 & 0.256930 \\
\hline 66940 & 36817 & 0.007306 & -0.392041 \\
\hline 70287 & 36817 & 0.006650 & -0.684040 \\
\hline 73634 & 36817 & 0.005195 & -0.819531 \\
\hline 76981 & 36817 & 0.004164 & -0.335517 \\
\hline 80328 & 36817 & 0.004705 & 0.302254 \\
\hline 83675 & 36817 & 0.007994 & 0.804477 \\
\hline 87022 & 36817 & 0.010168 & 1.129 .407 \\
\hline 90369 & 36817 & 0.011643 & 1.813 .246 \\
\hline 93716 & 36817 & 0.010222 & 1.348 .542 \\
\hline 97063 & 36817 & 0.010891 & 1.339 .443 \\
\hline 3347 & 40164 & 0.009907 & 2.081 .145 \\
\hline 6694 & 40164 & 0.004487 & 1.717 .163 \\
\hline 10041 & 40164 & 0.001863 & 0.404702 \\
\hline 13388 & 40164 & 0.003836 & -0.539246 \\
\hline 16735 & 40164 & 0.006390 & -0.711858 \\
\hline 20082 & 40164 & 0.006575 & -1.042 .559 \\
\hline 23429 & 40164 & 0.006556 & -1.490 .348 \\
\hline 26776 & 40164 & 0.005298 & -1.944 .233 \\
\hline 30123 & 40164 & 0.004543 & -2.802 .764 \\
\hline 33470 & 40164 & 0.006274 & 2.793 .647 \\
\hline 36817 & 40164 & 0.008331 & 2.504 .397 \\
\hline 40164 & 40164 & 0.010533 & 2.306 .032 \\
\hline
\end{tabular}




\begin{tabular}{|c|c|c|c|}
\hline 43511 & 40164 & 0.013357 & 2.200 .187 \\
\hline 46858 & 40164 & 0.010841 & 1.816 .175 \\
\hline 50205 & 40164 & 0.009197 & 1.579 .703 \\
\hline 53552 & 40164 & 0.008938 & 1.341 .744 \\
\hline 56899 & 40164 & 0.010326 & 0.901210 \\
\hline 60246 & 40164 & 0.011130 & 0.532393 \\
\hline 63593 & 40164 & 0.010712 & 0.156065 \\
\hline 66940 & 40164 & 0.006290 & -0.531241 \\
\hline 70287 & 40164 & 0.007241 & -0.699464 \\
\hline 73634 & 40164 & 0.006351 & -0.737915 \\
\hline 76981 & 40164 & 0.003576 & -0.621412 \\
\hline 80328 & 40164 & 0.002683 & 0.129251 \\
\hline 83675 & 40164 & 0.005452 & 0.785791 \\
\hline 87022 & 40164 & 0.010930 & 0.957630 \\
\hline 90369 & 40164 & 0.017337 & 0.985845 \\
\hline 93716 & 40164 & 0.019817 & 1.097 .116 \\
\hline 97063 & 40164 & 0.023469 & 1.173 .639 \\
\hline 3347 & 43511 & 0.003783 & 0.802628 \\
\hline 6694 & 43511 & 0.003684 & 0.256389 \\
\hline 10041 & 43511 & 0.005707 & -0.353534 \\
\hline 13388 & 43511 & 0.006789 & -0.488682 \\
\hline 16735 & 43511 & 0.005674 & -0.654271 \\
\hline 20082 & 43511 & 0.005695 & -0.927993 \\
\hline 23429 & 43511 & 0.006101 & -1.392 .840 \\
\hline 26776 & 43511 & 0.004854 & -1.803 .502 \\
\hline 30123 & 43511 & 0.003953 & -2.614 .455 \\
\hline 33470 & 43511 & 0.004230 & 3.100 .755 \\
\hline 36817 & 43511 & 0.005861 & 2.403 .236 \\
\hline 40164 & 43511 & 0.007166 & 2.117 .085 \\
\hline 43511 & 43511 & 0.008420 & 1.874 .272 \\
\hline 46858 & 43511 & 0.009544 & 1.784 .947 \\
\hline 50205 & 43511 & 0.008867 & 1.720 .386 \\
\hline 53552 & 43511 & 0.008102 & 1.798 .580 \\
\hline 56899 & 43511 & 0.003349 & 2.061 .131 \\
\hline 60246 & 43511 & 0.000779 & 1.455 .888 \\
\hline 63593 & 43511 & 0.003320 & -0.531275 \\
\hline 66940 & 43511 & 0.006158 & -0.815803 \\
\hline 70287 & 43511 & 0.007189 & -0.816157 \\
\hline 73634 & 43511 & 0.006564 & -0.730362 \\
\hline 76981 & 43511 & 0.004689 & -0.512091 \\
\hline 80328 & 43511 & 0.002353 & 0.210980 \\
\hline 83675 & 43511 & 0.003926 & 0.898136 \\
\hline 87022 & 43511 & 0.009058 & 1.029 .839 \\
\hline 90369 & 43511 & 0.016071 & 1.056 .770 \\
\hline 93716 & 43511 & 0.019780 & 1.206 .293 \\
\hline 97063 & 43511 & 0.025720 & 1.446 .884 \\
\hline 3347 & 46858 & 0.003884 & -0.157510 \\
\hline 6694 & 46858 & 0.004271 & -0.289415 \\
\hline 10041 & 46858 & 0.005975 & -0.582198 \\
\hline 13388 & 46858 & 0.006560 & -0.649668 \\
\hline 16735 & 46858 & 0.006076 & -0.783981 \\
\hline 20082 & 46858 & 0.005895 & -0.955711 \\
\hline 23429 & 46858 & 0.005501 & -1.333 .484 \\
\hline
\end{tabular}




\begin{tabular}{|c|c|c|c|}
\hline 26776 & 46858 & 0.004875 & -1.540 .788 \\
\hline 30123 & 46858 & 0.003577 & -1.943 .587 \\
\hline 33470 & 46858 & 0.002739 & -1.798 .260 \\
\hline 36817 & 46858 & 0.000847 & -2.202 .804 \\
\hline 40164 & 46858 & 0.002408 & 1.714 .566 \\
\hline 43511 & 46858 & 0.005914 & 1.533 .910 \\
\hline 46858 & 46858 & 0.006688 & 1.518 .299 \\
\hline 50205 & 46858 & 0.006155 & 1.465 .799 \\
\hline 53552 & 46858 & 0.003636 & 1.582 .752 \\
\hline 56899 & 46858 & 0.001512 & 1.879 .623 \\
\hline 60246 & 46858 & 0.001384 & -1.856 .124 \\
\hline 63593 & 46858 & 0.005200 & -1.319 .462 \\
\hline 66940 & 46858 & 0.006264 & -1.179 .568 \\
\hline 70287 & 46858 & 0.006543 & -1.040 .086 \\
\hline 73634 & 46858 & 0.005602 & -0.762393 \\
\hline 76981 & 46858 & 0.004034 & -0.468550 \\
\hline 80328 & 46858 & 0.002344 & 0.658351 \\
\hline 83675 & 46858 & 0.002518 & 1.299 .048 \\
\hline 87022 & 46858 & 0.006150 & 1.421 .114 \\
\hline 90369 & 46858 & 0.011732 & 1.374 .010 \\
\hline 93716 & 46858 & 0.019244 & 1.283 .193 \\
\hline 97063 & 46858 & 0.023783 & 1.297 .282 \\
\hline 3347 & 50205 & 0.006039 & -0.653155 \\
\hline 6694 & 50205 & 0.005899 & -0.908134 \\
\hline 10041 & 50205 & 0.005454 & -0.941056 \\
\hline 13388 & 50205 & 0.005339 & -0.951433 \\
\hline 16735 & 50205 & 0.004920 & -0.910143 \\
\hline 20082 & 50205 & 0.005394 & -1.086 .916 \\
\hline 23429 & 50205 & 0.006475 & -1.310 .366 \\
\hline 26776 & 50205 & 0.006120 & -1.359 .703 \\
\hline 30123 & 50205 & 0.005585 & -1.360 .147 \\
\hline 33470 & 50205 & 0.004718 & -1.320 .689 \\
\hline 36817 & 50205 & 0.003108 & -1.100 .730 \\
\hline 40164 & 50205 & 0.001831 & 0.027869 \\
\hline 43511 & 50205 & 0.004638 & 0.698577 \\
\hline 46858 & 50205 & 0.005710 & 0.653130 \\
\hline 50205 & 50205 & 0.006284 & 0.433047 \\
\hline 53552 & 50205 & 0.006030 & 0.449543 \\
\hline 56899 & 50205 & 0.003648 & 0.660210 \\
\hline 60246 & 50205 & 0.002890 & -1.186 .793 \\
\hline 63593 & 50205 & 0.006737 & -1.387 .019 \\
\hline 66940 & 50205 & 0.007115 & -1.377 .913 \\
\hline 70287 & 50205 & 0.006396 & -1.356 .028 \\
\hline 73634 & 50205 & 0.003922 & -1.133 .815 \\
\hline 76981 & 50205 & 0.002179 & -0.602970 \\
\hline 80328 & 50205 & 0.000912 & 0.761872 \\
\hline 83675 & 50205 & 0.003453 & 2.179 .175 \\
\hline 87022 & 50205 & 0.006938 & 1.873 .752 \\
\hline 90369 & 50205 & 0.012636 & 1.609 .909 \\
\hline 93716 & 50205 & 0.019960 & 1.396 .229 \\
\hline 97063 & 50205 & 0.022484 & 1.359 .214 \\
\hline 3347 & 53552 & 0.006366 & -0.763147 \\
\hline 6694 & 53552 & 0.006886 & -1.012 .310 \\
\hline
\end{tabular}




\begin{tabular}{|c|c|c|c|}
\hline 10041 & 53552 & 0.006048 & -1.061 .355 \\
\hline 13388 & 53552 & 0.005267 & -1.163 .529 \\
\hline 16735 & 53552 & 0.006053 & -1.194 .412 \\
\hline 20082 & 53552 & 0.007116 & -1.315 .690 \\
\hline 23429 & 53552 & 0.007414 & -1.352 .522 \\
\hline 26776 & 53552 & 0.007510 & -1.349 .990 \\
\hline 30123 & 53552 & 0.007825 & -1.264 .406 \\
\hline 33470 & 53552 & 0.006867 & -1.195 .017 \\
\hline 36817 & 53552 & 0.005719 & -1.013 .893 \\
\hline 40164 & 53552 & 0.004074 & -0.583428 \\
\hline 43511 & 53552 & 0.004410 & 0.015393 \\
\hline 46858 & 53552 & 0.005241 & 0.134010 \\
\hline 50205 & 53552 & 0.006503 & 0.127352 \\
\hline 53552 & 53552 & 0.007396 & 0.146292 \\
\hline 56899 & 53552 & 0.006577 & -0.012230 \\
\hline 60246 & 53552 & 0.005965 & -0.511447 \\
\hline 63593 & 53552 & 0.007152 & -1.197 .131 \\
\hline 66940 & 53552 & 0.006289 & -1.335 .286 \\
\hline 70287 & 53552 & 0.005550 & -1.518 .423 \\
\hline 73634 & 53552 & 0.003404 & -1.625 .131 \\
\hline 76981 & 53552 & 0.001199 & -1.936 .062 \\
\hline 80328 & 53552 & 0.002292 & 2.822 .674 \\
\hline 83675 & 53552 & 0.006987 & 2.723.982 \\
\hline 87022 & 53552 & 0.009099 & 2.389.372 \\
\hline 90369 & 53552 & 0.013421 & 1.966 .800 \\
\hline 93716 & 53552 & 0.015191 & 1.703 .632 \\
\hline 97063 & 53552 & 0.017670 & 1.577 .477 \\
\hline 3347 & 56899 & 0.006984 & -0.895670 \\
\hline 6694 & 56899 & 0.006846 & -1.024 .204 \\
\hline 10041 & 56899 & 0.006505 & -1.107 .725 \\
\hline 13388 & 56899 & 0.006450 & -1.212 .085 \\
\hline 16735 & 56899 & 0.006609 & -1.274 .146 \\
\hline 20082 & 56899 & 0.007122 & -1.342 .807 \\
\hline 23429 & 56899 & 0.007438 & -1.369 .161 \\
\hline 26776 & 56899 & 0.007772 & -1.363 .559 \\
\hline 30123 & 56899 & 0.008012 & -1.269 .147 \\
\hline 33470 & 56899 & 0.007607 & -1.180 .299 \\
\hline 36817 & 56899 & 0.006607 & -0.984147 \\
\hline 40164 & 56899 & 0.005666 & -0.797188 \\
\hline 43511 & 56899 & 0.004506 & -0.507556 \\
\hline 46858 & 56899 & 0.004823 & -0.367184 \\
\hline 50205 & 56899 & 0.005895 & -0.225085 \\
\hline 53552 & 56899 & 0.007482 & -0.050795 \\
\hline 56899 & 56899 & 0.009179 & 0.021771 \\
\hline 60246 & 56899 & 0.008525 & -0.170454 \\
\hline 63593 & 56899 & 0.006658 & -0.923058 \\
\hline 66940 & 56899 & 0.005362 & -1.381 .378 \\
\hline 70287 & 56899 & 0.004363 & -1.870 .544 \\
\hline 73634 & 56899 & 0.003734 & -2.269 .380 \\
\hline 76981 & 56899 & 0.003690 & -2.878 .542 \\
\hline 80328 & 56899 & 0.005524 & 2.818 .800 \\
\hline 83675 & 56899 & 0.007925 & 2.726 .054 \\
\hline 87022 & 56899 & 0.009369 & 2.517 .185 \\
\hline
\end{tabular}




\begin{tabular}{rrrr}
90369 & 56899 & 0.011276 & 2.213 .597 \\
93716 & 56899 & 0.013408 & 1.868 .564 \\
97063 & 56899 & 0.013421 & 1.797 .586 \\
3347 & 60246 & 0.006671 & -1.015 .202 \\
6694 & 60246 & 0.006495 & -1.074 .583 \\
10041 & 60246 & 0.006247 & -1.149 .163 \\
13388 & 60246 & 0.006428 & -1.215 .019 \\
16735 & 60246 & 0.006604 & -1.279 .434 \\
20082 & 60246 & 0.006655 & -1.355 .343 \\
23429 & 60246 & 0.006868 & -1.382 .354 \\
26776 & 60246 & 0.007250 & -1.389 .978 \\
30123 & 60246 & 0.007132 & -1.357 .541 \\
33470 & 60246 & 0.006794 & -1.268 .245 \\
36817 & 60246 & 0.006589 & -1.074 .742 \\
40164 & 60246 & 0.005877 & -0.968007 \\
43511 & 60246 & 0.004834 & -0.858245 \\
46858 & 60246 & 0.004997 & -0.815914 \\
50205 & 60246 & 0.005023 & -0.711992 \\
53552 & 60246 & 0.005497 & -0.420791 \\
56899 & 60246 & 0.006988 & -0.182064 \\
60246 & 60246 & 0.006651 & -0.274018 \\
63593 & 60246 & 0.004609 & -0.928437 \\
66940 & 60246 & 0.003597 & -1.514 .807 \\
70287 & 60246 & 0.003686 & -2.279 .978 \\
73634 & 60246 & 0.004208 & -2.796 .254 \\
76981 & 60246 & 0.005070 & 3.027 .272 \\
80328 & 60246 & 0.006072 & 2.707 .195 \\
83675 & 60246 & 0.007550 & 2.653 .302 \\
87022 & 60246 & 0.008470 & 2.542 .112 \\
90369 & 60246 & 0.008929 & 2.425 .902 \\
93716 & 60246 & 0.007842 & 2.394 .527 \\
97063 & 60246 & 0.005379 & 2.499 .041 \\
3347 & 63593 & 0.005548 & -1.077 .810 \\
6694 & 63593 & 0.005482 & -1.162 .633 \\
10041 & 63593 & 0.005829 & -1.195 .521 \\
13388 & 63593 & 0.006308 & -1.220 .399 \\
16735 & 63593 & 0.006598 & -1.271 .528 \\
20082 & 63593 & 0.006689 & -1.340 .591 \\
23429 & 63593 & 0.006778 & -1.356 .340 \\
26776 & 63593 & 0.006777 & -1.373 .602 \\
30123 & 63593 & 0.006749 & -1.374 .240 \\
33470 & 63593 & 0.006564 & -1.351 .925 \\
36817 & 63593 & 0.005917 & -1.289 .562 \\
40164 & 63593 & 0.005427 & -1.216 .486 \\
43511 & 63593 & 0.005107 & -1.162 .835 \\
46858 & 63593 & 0.004861 & -1.139 .656 \\
50205 & 63593 & 0.004478 & -1.077 .657 \\
568999 & 63593 & 0.003983 & -0.883548 \\
60246 & 63593 & 0.003375 & -0.513235 \\
63593 & 63593 & 0.003130 & -0.554516 \\
66940 & 63593 & 0.002134 & -0.964583 \\
70287 & 63593 & 0.002171 & -2.308 .799 \\
\hline 503 & 0.003490 & -2.803 .518
\end{tabular}




$\begin{array}{rrrr}73634 & 63593 & 0.005026 & -3.114 .067 \\ 76981 & 63593 & 0.006118 & 2.831 .396 \\ 80328 & 63593 & 0.007086 & 2.583 .318 \\ 83675 & 63593 & 0.007628 & 2.402 .510 \\ 87022 & 63593 & 0.007094 & 2.318 .156 \\ 90369 & 63593 & 0.005222 & 2.500 .579 \\ 93716 & 63593 & 0.004345 & 2.653 .560 \\ 97063 & 63593 & 0.004178 & 2.898 .167 \\ 3347 & 66940 & 0.004367 & -1.134 .888 \\ 6694 & 66940 & 0.004721 & -1.233 .089 \\ 10041 & 66940 & 0.005186 & -1.243 .259 \\ 13388 & 66940 & 0.005841 & -1.238 .486 \\ 16735 & 66940 & 0.006236 & -1.260 .344 \\ 20082 & 66940 & 0.006401 & -1.303 .612 \\ 23429 & 66940 & 0.006514 & -1.317 .444 \\ 26776 & 66940 & 0.006531 & -1.334 .204 \\ 30123 & 66940 & 0.006332 & -1.391 .575 \\ 33470 & 66940 & 0.006090 & -1.358 .321 \\ 36817 & 66940 & 0.005766 & -1.330 .162 \\ 40164 & 66940 & 0.005413 & -1.285 .042 \\ 43511 & 66940 & 0.005127 & -1.257 .212 \\ 46858 & 66940 & 0.004865 & -1.260 .259 \\ 50205 & 66940 & 0.004327 & -1.245 .559 \\ 53552 & 66940 & 0.003642 & -1.133 .542 \\ 56899 & 66940 & 0.002811 & -0.884181 \\ 60246 & 66940 & 0.002530 & -0.818042 \\ 63593 & 66940 & 0.001691 & -1.163 .718 \\ 66940 & 66940 & 0.001685 & -2.452 .819 \\ 70287 & 66940 & 0.003852 & -3.113 .653 \\ 73634 & 66940 & 0.006311 & 2.953 .870 \\ 76981 & 66940 & 0.007535 & 2.750 .646 \\ 80328 & 66940 & 0.008027 & 2.541 .446 \\ 83675 & 66940 & 0.007313 & 2.342 .951 \\ 87022 & 66940 & 0.003774 & 2.169 .140 \\ 90369 & 66940 & 0.002936 & 2.316 .846 \\ 93716 & 66940 & 0.003590 & 2.784 .538 \\ 97063 & 66940 & 0.003506 & 3.049 .970 \\ 3347 & 70287 & 0.002856 & -1.236 .016 \\ 6694 & 70287 & 0.003367 & -1.260 .375 \\ 10041 & 70287 & 0.004322 & -1.289 .505 \\ 13388 & 70287 & 0.004764 & -1.256 .970 \\ 16735 & 70287 & 0.005167 & -1.236 .854 \\ 20082 & 70287 & 0.005627 & -1.235 .107 \\ 23429 & 70287 & 0.005917 & -1.294 .894 \\ 26776 & 70287 & 0.005880 & -1.308 .232 \\ 30123 & 70287 & 0.005704 & -1.364 .977 \\ 33470 & 70287 & 0.005645 & -1.313 .604 \\ 40164 & 70287 & 0.005491 & -1.303 .431 \\ 43511 & 70287 & 0.005068 & -1.300 .947 \\ 46858 & 70287 & 0.004728 & -1.301 .014 \\ 50205 & 70287 & 0.004231 & -1.344 .948 \\ 53552 & 70287 & 0.003661 & -1.294 .312\end{array}$




\begin{tabular}{|c|c|c|c|}
\hline 56899 & 70287 & 0.002937 & -1.186 .337 \\
\hline 60246 & 70287 & 0.002418 & -0.996819 \\
\hline 63593 & 70287 & 0.000963 & -0.870939 \\
\hline 66940 & 70287 & 0.001121 & 2.569 .826 \\
\hline 70287 & 70287 & 0.004411 & 2.625 .355 \\
\hline 73634 & 70287 & 0.006918 & 2.654 .014 \\
\hline 76981 & 70287 & 0.008410 & 2.593 .303 \\
\hline 80328 & 70287 & 0.008720 & 2.507 .440 \\
\hline 83675 & 70287 & 0.006760 & 2.344 .009 \\
\hline 87022 & 70287 & 0.004303 & 2.254 .747 \\
\hline 90369 & 70287 & 0.002608 & 2.464 .494 \\
\hline 93716 & 70287 & 0.002887 & 2.776 .732 \\
\hline 97063 & 70287 & 0.004937 & 2.704 .576 \\
\hline 3347 & 73634 & 0.002606 & -1.355 .582 \\
\hline 6694 & 73634 & 0.002845 & -1.334 .462 \\
\hline 10041 & 73634 & 0.003351 & -1.294 .194 \\
\hline 13388 & 73634 & 0.003800 & -1.272 .164 \\
\hline 16735 & 73634 & 0.004355 & -1.257 .482 \\
\hline 20082 & 73634 & 0.004695 & -1.243 .277 \\
\hline 23429 & 73634 & 0.004924 & -1.219 .116 \\
\hline 26776 & 73634 & 0.004558 & -1.292 .740 \\
\hline 30123 & 73634 & 0.004524 & -1.276 .997 \\
\hline 33470 & 73634 & 0.005200 & -1.276 .847 \\
\hline 36817 & 73634 & 0.005148 & -1.283 .129 \\
\hline 40164 & 73634 & 0.004908 & -1.300 .232 \\
\hline 43511 & 73634 & 0.004713 & -1.326 .227 \\
\hline 46858 & 73634 & 0.004539 & -1.359 .744 \\
\hline 50205 & 73634 & 0.004170 & -1.414 .476 \\
\hline 53552 & 73634 & 0.003611 & -1.416 .055 \\
\hline 56899 & 73634 & 0.002811 & -1.328 .961 \\
\hline 60246 & 73634 & 0.002173 & -1.047 .338 \\
\hline 63593 & 73634 & 0.000999 & 0.463876 \\
\hline 66940 & 73634 & 0.003013 & 1.677 .167 \\
\hline 70287 & 73634 & 0.006334 & 2.099 .425 \\
\hline 73634 & 73634 & 0.007620 & 2.322.064 \\
\hline 76981 & 73634 & 0.008270 & 2.437 .176 \\
\hline 80328 & 73634 & 0.008123 & 2.442 .908 \\
\hline 83675 & 73634 & 0.005982 & 2.298.979 \\
\hline 87022 & 73634 & 0.003755 & 2.239 .744 \\
\hline 90369 & 73634 & 0.001456 & 2.654 .080 \\
\hline 93716 & 73634 & 0.001707 & 2.851 .216 \\
\hline 97063 & 73634 & 0.004289 & 2.621 .746 \\
\hline 3347 & 76981 & 0.002150 & -1.415 .170 \\
\hline 6694 & 76981 & 0.002296 & -1.397 .852 \\
\hline 10041 & 76981 & 0.002500 & -1.314 .522 \\
\hline 13388 & 76981 & 0.002854 & -1.275 .751 \\
\hline 16735 & 76981 & 0.003463 & -1.270 .560 \\
\hline 20082 & 76981 & 0.003973 & -1.230 .833 \\
\hline 23429 & 76981 & 0.003602 & -1.160 .944 \\
\hline 26776 & 76981 & 0.004230 & -1.224 .082 \\
\hline 30123 & 76981 & 0.004409 & -1.179 .057 \\
\hline 33470 & 76981 & 0.004471 & -1.218 .280 \\
\hline 36817 & 76981 & 0.004425 & -1.250 .852 \\
\hline
\end{tabular}




$\begin{array}{rrrr}40164 & 76981 & 0.004419 & -1.280 .411 \\ 43511 & 76981 & 0.004453 & -1.316 .069 \\ 46858 & 76981 & 0.004173 & -1.366 .376 \\ 50205 & 76981 & 0.003603 & -1.427 .210 \\ 53552 & 76981 & 0.003062 & -1.493 .253 \\ 56899 & 76981 & 0.002586 & -1.430 .268 \\ 60246 & 76981 & 0.002019 & -1.219 .105 \\ 63593 & 76981 & 0.001211 & 0.982790 \\ 66940 & 76981 & 0.004643 & 1.534 .886 \\ 70287 & 76981 & 0.010887 & 1.693 .691 \\ 73634 & 76981 & 0.006157 & 2.231 .555 \\ 76981 & 76981 & 0.006754 & 2.358 .132 \\ 80328 & 76981 & 0.006499 & 2.283 .602 \\ 83675 & 76981 & 0.005214 & 2.228 .646 \\ 87022 & 76981 & 0.003271 & 2.192 .464 \\ 90369 & 76981 & 0.001380 & 2.345 .043 \\ 93716 & 76981 & 0.001365 & 2.315 .356 \\ 97063 & 76981 & 0.002820 & 2.237 .659 \\ 3347 & 80328 & 0.002433 & -1.584 .070 \\ 6694 & 80328 & 0.002222 & -1.492 .785 \\ 10041 & 80328 & 0.002191 & -1.332 .482 \\ 13388 & 80328 & 0.002480 & -1.257 .181 \\ 16735 & 80328 & 0.003114 & -1.233 .045 \\ 20082 & 80328 & 0.003816 & -1.204 .613 \\ 23429 & 80328 & 0.003992 & -1.154 .999 \\ 26776 & 80328 & 0.003690 & -1.173 .368 \\ 30123 & 80328 & 0.003539 & -1.165 .433 \\ 33470 & 80328 & 0.003832 & -1.242 .638 \\ 36817 & 80328 & 0.004072 & -1.194 .830 \\ 40164 & 80328 & 0.004070 & -1.235 .082 \\ 43511 & 80328 & 0.004070 & -1.287 .078 \\ 46858 & 80328 & 0.003739 & -1.343 .398 \\ 50205 & 80328 & 0.003259 & -1.437 .895 \\ 53552 & 80328 & 0.002954 & -1.457 .830 \\ 56899 & 80328 & 0.002665 & -1.520 .425 \\ 60246 & 80328 & 0.001881 & -1.578 .048 \\ 63593 & 80328 & 0.000062 & 1.601 .425 \\ 66940 & 80328 & 0.003347 & 1.592 .222 \\ 70287 & 80328 & 0.004870 & 1.714 .876 \\ 73634 & 80328 & 0.005293 & 1.968 .658 \\ 76981 & 80328 & 0.005541 & 2.146 .674 \\ 80328 & 80328 & 0.005569 & 2.199 .299 \\ 83675 & 80328 & 0.004696 & 2.192 .753 \\ 87022 & 80328 & 0.003735 & 2.105 .584 \\ 90369 & 80328 & 0.002758 & 1.862 .289 \\ 93716 & 80328 & 0.002345 & 1.840 .902 \\ 97063 & 80328 & 0.002280 & 1.795 .777 \\ 3347 & 83675 & 0.002201 & -1.634 .264 \\ 10041 & 83694 & 0.002015 & -1.555 .820 \\ 13388 & 83675 & 0.002167 & -1.228 .517 \\ 16735 & 83675 & 0.002875 & -1.125 .564 \\ 20082 & 83675 & 0.003090 & -1.220 .689\end{array}$




\begin{tabular}{|c|c|c|c|}
\hline 23429 & 83675 & 0.003735 & -1.138 .512 \\
\hline 26776 & 83675 & 0.003913 & -1.135 .788 \\
\hline 30123 & 83675 & 0.003958 & -1.132 .748 \\
\hline 33470 & 83675 & 0.003763 & -1.178 .504 \\
\hline 36817 & 83675 & 0.003783 & -1.191 .211 \\
\hline 40164 & 83675 & 0.003707 & -1.212 .416 \\
\hline 43511 & 83675 & 0.003716 & -1.250 .613 \\
\hline 46858 & 83675 & 0.003593 & -1.276 .935 \\
\hline 50205 & 83675 & 0.003413 & -1.361 .872 \\
\hline 53552 & 83675 & 0.003129 & -1.469 .353 \\
\hline 56899 & 83675 & 0.002945 & -1.571 .067 \\
\hline 60246 & 83675 & 0.002155 & -1.714 .748 \\
\hline 63593 & 83675 & 0.000635 & -2.947 .029 \\
\hline 66940 & 83675 & 0.002630 & 1.776 .944 \\
\hline 70287 & 83675 & 0.003718 & 1.780 .504 \\
\hline 73634 & 83675 & 0.004629 & 1.944 .159 \\
\hline 76981 & 83675 & 0.004710 & 1.983 .886 \\
\hline 80328 & 83675 & 0.004327 & 2.004 .117 \\
\hline 83675 & 83675 & 0.003755 & 1.975 .344 \\
\hline 87022 & 83675 & 0.002579 & 1.790 .849 \\
\hline 90369 & 83675 & 0.002263 & 1.426 .125 \\
\hline 93716 & 83675 & 0.002607 & 1.415 .828 \\
\hline 97063 & 83675 & 0.002319 & 1.123 .560 \\
\hline 3347 & 87022 & 0.001570 & -1.696 .323 \\
\hline 6694 & 87022 & 0.001551 & -1.609 .640 \\
\hline 10041 & 87022 & 0.001599 & -1.425 .122 \\
\hline 13388 & 87022 & 0.001893 & -1.332 .297 \\
\hline 16735 & 87022 & 0.002134 & -1.248 .688 \\
\hline 20082 & 87022 & 0.002379 & -1.160 .553 \\
\hline 23429 & 87022 & 0.002926 & -1.133 .746 \\
\hline 26776 & 87022 & 0.003359 & -1.133 .975 \\
\hline 30123 & 87022 & 0.003532 & -1.144 .923 \\
\hline 33470 & 87022 & 0.003393 & -1.184 .774 \\
\hline 36817 & 87022 & 0.003728 & -1.221 .005 \\
\hline 40164 & 87022 & 0.003405 & -1.256 .581 \\
\hline 43511 & 87022 & 0.003079 & -1.336 .718 \\
\hline 46858 & 87022 & 0.003447 & -1.304 .708 \\
\hline 50205 & 87022 & 0.003498 & -1.388 .036 \\
\hline 53552 & 87022 & 0.003510 & -1.508 .613 \\
\hline 56899 & 87022 & 0.003348 & -1.604 .367 \\
\hline 60246 & 87022 & 0.002501 & -1.784 .326 \\
\hline 63593 & 87022 & 0.001283 & -2.700 .570 \\
\hline 66940 & 87022 & 0.002442 & 2.177 .931 \\
\hline 70287 & 87022 & 0.003633 & 1.905 .421 \\
\hline 73634 & 87022 & 0.004395 & 1.700 .439 \\
\hline 76981 & 87022 & 0.004374 & 1.678 .153 \\
\hline 80328 & 87022 & 0.003730 & 1.650 .995 \\
\hline 83675 & 87022 & 0.002761 & 1.587 .817 \\
\hline 87022 & 87022 & 0.002335 & 1.388 .336 \\
\hline 90369 & 87022 & 0.002157 & 1.117 .561 \\
\hline 93716 & 87022 & 0.002361 & 0.868891 \\
\hline 97063 & 87022 & 0.002701 & 0.604399 \\
\hline 3347 & 90369 & 0.001392 & -1.762 .080 \\
\hline
\end{tabular}




$\begin{array}{rrrr}6694 & 90369 & 0.001312 & -1.686 .786 \\ 10041 & 90369 & 0.001378 & -1.547 .607 \\ 13388 & 90369 & 0.001697 & -1.374 .373 \\ 16735 & 90369 & 0.001818 & -1.240 .927 \\ 20082 & 90369 & 0.002016 & -1.155 .697 \\ 23429 & 90369 & 0.002453 & -1.152 .949 \\ 26776 & 90369 & 0.003145 & -1.116 .811 \\ 30123 & 90369 & 0.003415 & -1.130 .369 \\ 33470 & 90369 & 0.003445 & -1.173 .903 \\ 36817 & 90369 & 0.003255 & -1.270 .396 \\ 40164 & 90369 & 0.003227 & -1.321 .913 \\ 43511 & 90369 & 0.003171 & -1.343 .058 \\ 46858 & 90369 & 0.003374 & -1.365 .839 \\ 50205 & 90369 & 0.003361 & -1.446 .546 \\ 53552 & 90369 & 0.003383 & -1.547 .414 \\ 56899 & 90369 & 0.003146 & -1.636 .457 \\ 60246 & 90369 & 0.002410 & -1.797 .862 \\ 63593 & 90369 & 0.001321 & -2.528 .750 \\ 66940 & 90369 & 0.001767 & 2.363 .904 \\ 70287 & 90369 & 0.002598 & 1.987 .645 \\ 73634 & 90369 & 0.003232 & 1.711 .783 \\ 76981 & 90369 & 0.003820 & 1.475 .784 \\ 80328 & 90369 & 0.003413 & 1.343 .536 \\ 83675 & 90369 & 0.002217 & 0.973250 \\ 87022 & 90369 & 0.001750 & 0.731365 \\ 90369 & 90369 & 0.002159 & 0.367112 \\ 93716 & 90369 & 0.003325 & 0.170002 \\ 97063 & 90369 & 0.003655 & 0.163970 \\ 3347 & 93716 & 0.001252 & -1.875 .576 \\ 6694 & 93716 & 0.001163 & -1.716 .027 \\ 10041 & 93716 & 0.001212 & -1.573 .971 \\ 13388 & 93716 & 0.001342 & -1.388 .788 \\ 16735 & 93716 & 0.001501 & -1.189 .407 \\ 20082 & 93716 & 0.001752 & -1.165 .228 \\ 23429 & 93716 & 0.002048 & -1.129 .990 \\ 26776 & 93716 & 0.002410 & -1.128 .055 \\ 30123 & 93716 & 0.003023 & -1.133 .444 \\ 33470 & 93716 & 0.003018 & -1.225 .877 \\ 36817 & 93716 & 0.003235 & -1.241 .157 \\ 40164 & 93716 & 0.003374 & -1.282 .339 \\ 43511 & 93716 & 0.003365 & -1.315 .980 \\ 46858 & 93716 & 0.003270 & -1.394 .456 \\ 50205 & 93716 & 0.003005 & -1.545 .929 \\ 53552 & 93716 & 0.002826 & -1.641 .928 \\ 56899 & 93716 & 0.002421 & -1.710 .039 \\ 60246 & 93716 & 0.002075 & -1.787 .198 \\ 63593 & 93716 & 0.001446 & -2.015 .219 \\ 66940 & 93716 & 0.000679 & -2.937 .917 \\ 70287 & 93716 & 0.001253 & 1.963 .481 \\ 73634 & 93716 & 0.002270 & 1.574 .023 \\ 76981 & 93716 & 0.003178 & 1.303 .425 \\ 80328 & 93716 & 0.002917 & 1.091 .193 \\ 83675 & 93716 & 0.002251 & 0.479034\end{array}$




$\begin{array}{rrrr}87022 & 93716 & 0.002399 & 0.138249 \\ 90369 & 93716 & 0.002978 & 0.004328 \\ 93716 & 93716 & 0.003502 & -0.002738 \\ 97063 & 93716 & 0.003756 & 0.010246 \\ 3347 & 97063 & 0.001230 & -1.825 .130 \\ 6694 & 97063 & 0.001095 & -1.692 .554 \\ 10041 & 97063 & 0.001217 & -1.527 .369 \\ 13388 & 97063 & 0.001266 & -1.344 .574 \\ 16735 & 97063 & 0.001493 & -1.232 .143 \\ 20082 & 97063 & 0.001665 & -1.175 .590 \\ 23429 & 97063 & 0.001916 & -1.136 .005 \\ 26776 & 97063 & 0.002165 & -1.142 .314 \\ 30123 & 97063 & 0.002491 & -1.183 .423 \\ 33470 & 97063 & 0.002745 & -1.248 .126 \\ 36817 & 97063 & 0.002883 & -1.318 .909 \\ 40164 & 97063 & 0.003085 & -1.351 .244 \\ 43511 & 97063 & 0.003494 & -1.331 .721 \\ 46858 & 97063 & 0.003207 & -1.399 .767 \\ 50205 & 97063 & 0.002695 & -1.581 .049 \\ 53552 & 97063 & 0.002709 & -1.636 .592 \\ 56899 & 97063 & 0.002947 & -1.624 .018 \\ 60246 & 97063 & 0.002622 & -1.637 .460 \\ 63593 & 97063 & 0.001908 & -1.629 .361 \\ 66940 & 97063 & 0.000459 & -2.452 .728 \\ 70287 & 97063 & 0.000610 & 1.814 .796 \\ 73634 & 97063 & 0.001475 & 1.273 .120 \\ 76981 & 97063 & 0.002353 & 0.973411 \\ 80328 & 97063 & 0.002444 & 0.751489 \\ 83675 & 97063 & 0.002351 & 0.347046 \\ 87022 & 97063 & 0.002526 & 0.004718 \\ 90369 & 97063 & 0.002888 & -0.245352 \\ 93716 & 97063 & 0.003168 & -0.237786 \\ 97063 & 97063 & 0.003597 & -0.092456\end{array}$

